\section{ADVANCED STEEL CONSTRUCTION}

\section{An International Journal}

Volume 8 Number 2

June 2012

CONTENTS

Technical Papers

Approximate Analytical Method of Multi-Storey or High-Rise Steel Three-Dimensional Parking Structures Yongjun He and Xuhong Zhou

Fire Dynamic Simulation on Thermal Actions in Localized Fires in Large Enclosure Chao Zhang and Guoqiang Li

Research on Static Property of Suspen-Dome Structure under Heap Load Jiamin Guo, Shilin Dong and Xingfei Yuan

Uniform Corrosion Wastage Effects on the Load-Carrying Capacity of Damaged Steel Beams Yasser Sharif

Higher-Order Non-Linear Analysis of Steel Structures, Part I : Elastic Second-Order Formulation C.K. Iu and M.A. Bradford

Higher-Order Non-Linear Analysis of Steel Structures, Part II: Refined Plastic Hinge Formulation C.K. Iu and M.A. Bradford

Test Study on Basic Static Characteristics of Cable Supported Barrel Vault Structure Wentao Qiao, Zhihua Chen and Mingshan Zhao

Copyright $\odot 2012$ by

The Hong Kong Institute of Steel Construction

Website: http://www.hkisc.org

ISSN 1816-112X

Science Citation Index Expanded, Materials Science Citation Index and ISI Alerting

Cover:

THE COAL STORAGE DOMES AT THE ENEL TORREVALDALIGA NORTH THERMOELECTRIC POWER PLANT, ITALI

Credits:

Photo O: Alfredo D'Amato - Agenzia 7 Minutes

Structural system: MERO Italiana, Verona

Dome Design: Ing. Gilbert Pirozzi, Mero, Verona

Construction Management and Technical Support: ENEL Energy and Innovation Office,

Ing. Giovanni Belloni, Ing. Marco Ulisse, Ing. Ubaldo Savina, Ing. Sergio Castromnoco.

Scientific Consultant: Prof. Federico M. Mazzolani, University of Naples

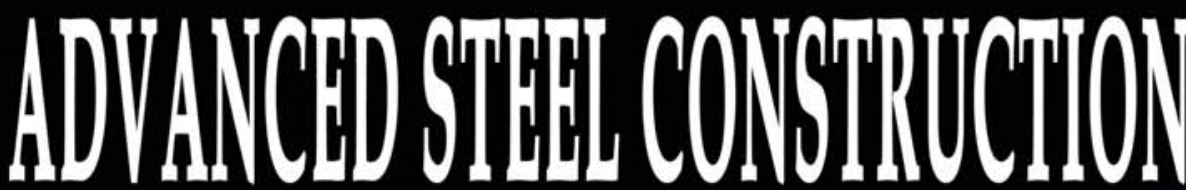

an International Jounal ISSN 1816-112X

Volume 8 Number 2

June 2012

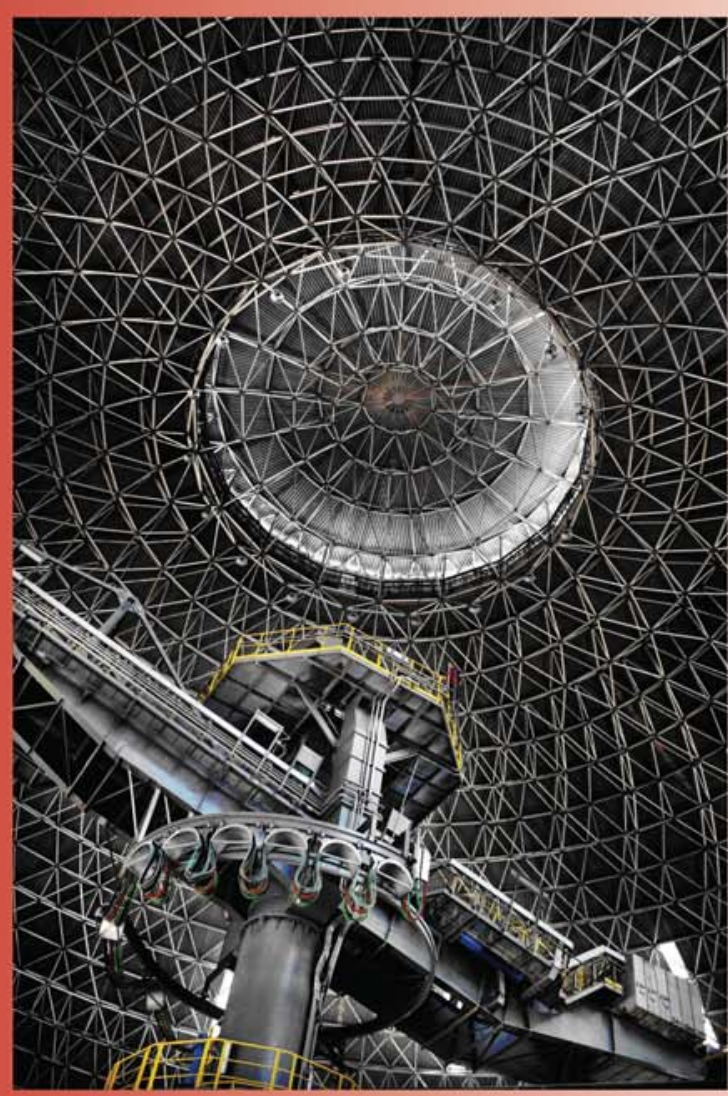

Editors-in-Chief

S.L. Chan, The Hong Kong Polytechnic University, Hong Kong

W.F. Chen, University of Hawaii at Manoa, USA

R. Zandonini, Trento University, Italy 


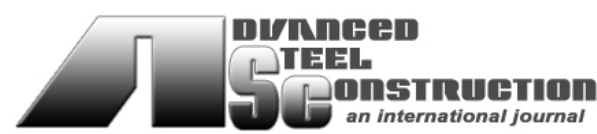

ISSN 1816-112X

Science Citation Index Expanded, Materials Science Citation Index and ISI Alerting

EDITORS-IN-CHIEF
Asian Pacific, African
and organizing Editor
S.L. Chan
The Hong Kong Polyt. Univ.,
Hong Kong
American Editor
W.F. Chen
Univ. of Hawaii at Manoa, USA
European Editor
R. Zandonini
Trento Univ., Italy
INTERNATIONAL
EDITORIAL BOARD

F.G. Albermani

The Univ. of Queensland, Australia

I. Burgess

Univ. of Sheffield, UK

F.S.K. Bijlaard

Delft Univ. of Technology, The Netherlands

R. Bjorhovde

The Bjorhovde Group, USA

M.A. Bradford

The Univ. of New South Wales, Australia

D. Camotim

Technical Univ. of Lisbon, Portugal

C.M. Chan

Hong Kong Univ. of Science \& Technology, Hong Kong

T.H.T. Chan

Queensland Univ. of Technology, Australia

S.P. Chiew

Nanyang Technological Univ., Singapore

W.K. Chow

The Hong Kong Polyt. Univ., Hong Kong

K.F. Chung

The Hong Kong Polyt. Univ., Hong Kong

G.G. Deierlein

Stanford Univ., California, USA

L. Dezi

Univ. of Ancona, Italy

\section{Advanced Steel \\ Construction an international journal}

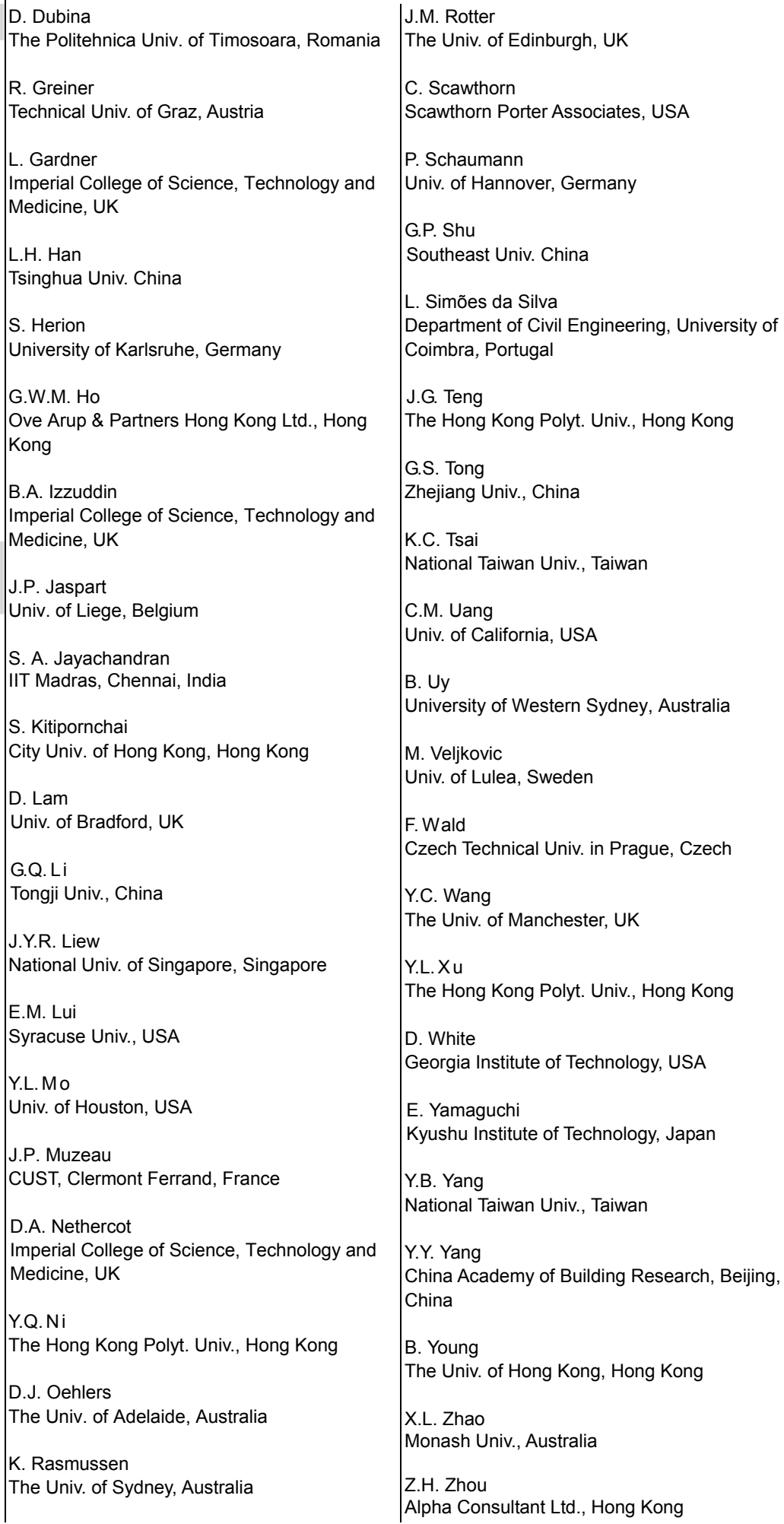




\begin{tabular}{ll}
\hline \hline & General Information \\
& Advanced Steel Construction, an international journal \\
\hline \hline Aims and scope
\end{tabular}

\section{Aims and scope}

The International Journal of Advanced Steel Construction provides a platform for the publication and rapid dissemination of ori ginal and up-to-date research and tec hnological developments in steel c onstruction, design and anal ysis. Scope of research $p$ apers published in this journal includes but is not limite $d$ to theor etical and expe rimental research on elements, assemblages, sy stems, material, design philosophy and codification, standards, fabrication, projects of innov ative nature an d computer tech niques. The journal is specifically $t$ ailored to channel the e xchange of tec hnological know-ho $w$ bet ween $r$ esearchers an d practitioners. Contributions from all aspects related to the recent developments of advanced steel construction are welcome.

\section{Instructions to authors}

Submission of the manuscript. Authors may submit double-spaced manuscripts preferably in MS Word by emailing to one of the chief editors as follows for arrangement of review. Alternatively papers can be submitted on a diskette to one of the chief editors.

Asian Pacific, African and organizing editor: Professor S.L. Chan, Email: ceslchan@polyu.edu.hk

American editor :

European editor:

Professor S.L. Chan, Email: ceslchan@polyu.edu

Professor R. Zandonini, Email: riccardo_zandonini@ing.unitn.it

All manuscripts submitted to the journal are recommended to accompany with a li st of four potential reviewers suggested by the author(s). This list should include the complete name, add ress, telephone and fax num bers, em ail address, and at least five keywords that identify the expertise of each reviewer. This scheme will improve the process of review.

Style of manuscript

General. Author(s) should provide full postal and email addresses and fax number for correspondence. The manuscript including abstract, keywords, references, figures and tables should be in English with pages numbered and typed with double line spacing on single side of A4 or letter-sized paper. The front page of the article should contain:

a) a short title (reflecting the content of the paper);

b) all the name(s) and postal and email addresses of author(s) specifying the author to whom correspondence and proofs should be sent;

c) an abstract of $100-200$ words; and

d) 5 to 8 keywords.

The paper must contain an introduction and a conclusion. The length of paper should not exceed 25 journal pages (approximately 15,000 words equivalents).

Tables and figures. Tables and figures including photographs should be typed, numbered consecutively in Arabic numerals and with short titles. They should be referred in the text as Figure 1, Table 2, etc. Originally drawn figures and photographs should be provided in a form suitable for photographic reproduction and reduction in the journal.

Mathematical expressions and units. The Systeme Internationale (SI) should be followed whenever possible. The numbers identifying the displayed mathematical expression should be referred to in the text as Eq. (1), Eq. (2).

References. References to published literature should be referred in the text, in the order of citation with Arabic numerals, by the last name(s) of the author(s) (e.g. Zandonini and Zanon [3]) or if more than three authors (e.g. Zandonini et al. [4]). References should be in English $w$ ith occasional allow ance of 1-2 e xceptional referenc es in local lang uages and $r$ eflect the curren $t$ state-of-technology. Journal titles should be abbreviated in the style of the Word List of Scientific Periodicals. References should be cited in the following style $[1,2,3]$.

Journal: [1] Chen, W.F. and Kishi, N., "Semi- rigid Steel Beam-to-column Connections, Data Base and Modellin g", Journal of Structural Engineering, ASCE, 1989, Vol. 115, No. 1, pp. 105-119.

Book: [2] Chan, S.L. and Chui, P.P.T., "Non-linear Static and Cyclic Analysis of Semi-rigid Steel Frames", Elsevier Science, 2000 .

Proceedings: [3] Zandonini, R. a nd Zanon, P., "Experimental Analy sis of S teel Beams with Semi -rigid Joint s", Proceedings of International Conference on Advances in Steel Structures, Hong Kong, 1996, Vol. 1, pp. 356-364.

Proofs. Proof will be sent to the c orresponding author to correct an y typesetting errors. Alternations to the original manuscript at this stage will not be accepted. Proofs should be returned within 48 hours of receipt by Express Mail, Fax or Email.

Copyright. Submission of an article to "Advanced Steel Construction" implies that it presents the original and unpublished work, and not under consideration for publication nor published elsewhere. On acceptance of a manuscript submitted, the copyright thereof is transferred to the publisher $b y$ the Transfer of $C$ opyright Agreement and upon the acceptance of publication for the $p$ apers, the corresponding author must sign the form for Transfer of Copyright.

Permission. Quoting from this journal is granted provided that the customary acknowledgement is given to the source.

Page charge and Reprints. There will be no page charges if the length of paper is within the limit of 25 journal pages. A total of 30 free offprints will be supplied free of charge to the corresponding author. Purchasing orders for additional offprints can be made on order forms which will be sent to the authors. These instructions can be obtained at the Hong Kong Institute of Steel Construction, Journal website: http://www.hkisc.org

The International Journal of Advanced Steel Construction is published quarterly by non-profit making learnt society, The Hong Kong Institute of Steel Construction, c/o Department of Civil \& Structural Engineering, The Hong Kong Polytechnic University, Hung Hom, Kowloon, Hong Kong.

Disclaimer. No responsibility is assumed for a ny injury and / or damage to per sons or property as a matter of products liability, negligence or otherwise, or from any use or operation of any methods, products, instructions or ideas contained in the material herein.

Subscription inquiries and change of address. Address all subscription inquiries and correspondence to Member Records, IJASC. Notify an address change as soon as possible. All communications should include both old and new addresses with zip codes and be accompanied by a mailing label from a recent issue. Allow six weeks for all changes to become effective.

The Hong Kong Institute of Steel Construction

HKISC

c/o Department of Civil and Structural Engineering,

The Hong Kong Polytechnic University,

Hunghom, Kowloon, Hong Kong, China.

Tel: 852- 27666047 Fax: 852- 23346389

Email: ces/chan@polyu.edu.hk Website: http://www.hkisc.org/

ISSN 1816-112X

Science Citation Index Expanded, Materials Science Citation Index and ISI Alerting

Copyright $\odot 2012$ by:

The Hong Kong Institute of Steel Construction. 


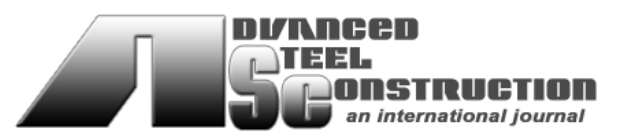

ISSN 1816-112X

Science Citation Index Expanded, Materials Science Citation Index and ISI Alerting

\section{EDITORS-IN-CHIEF}

\section{Asian Pacific, African} and organizing Editor

S.L. Chan

The Hong Kong Polyt. Univ., Hong Kong

Email: ces/chan@polyu.edu.hk

\section{American Editor \\ W.F. Chen}

Univ. of Hawaii at Manoa, USA

Email:waifah@hawaii.edu

\section{European Editor}

R. Zandonini

Trento Univ., Italy

Email: riccardo.zandonini@ing.unitn.it

\section{Advanced Steel Construction an international journal}

VOLUME 8 NUMBER 2

JUNE 2012

Technical Papers

Approximate Analytical Method of Multi-Storey or High-Rise Steel Three-Dimensional Parking Structures

Yongjun He and Xuhong Zhou

Fire Dynamic Simulation on Thermal Actions in Localized fires in Large Enclosure

Chao Zhang and Guoqiang $\mathrm{Li}$

Research on Static Property of Suspen-Dome Structure under

Heap Load

Jiamin Guo, Shilin Dong and Xingfei Yuan

Uniform Corrosion Wastage Effects on the Load-Carrying

Capacity of Damaged Steel Beams

Yasser Sharifi

Higher-Order Non-Linear Analysis of Steel Structures, Part I : Elastic Second-Order Formulation

C.K. Iu and M.A. Bradford

Higher-Order Non-Linear Analysis of Steel Structures, Part II: Refined Plastic Hinge Formulation

C.K. Iu and M.A. Bradford

Test Study on Basic Static Characteristics of Cable Supported Barrel Vault Structure

Wentao Qiao, Zhihua Chen and Mingshan Zhao 


\title{
APPROXIMATE ANALYTICAL METHOD OF MULTI-STOREY OR HIGH-RISE STEEL THREE-DIMENSIONAL PARKING STRUCTURES
}

\author{
Yongjun $\mathrm{He}^{1, *}$ and Xuhong Zhou ${ }^{1,2}$ \\ ${ }^{1}$ Professor, College of Civil Engineering, Hunan University, Changsha, 410082, PR China \\ ${ }_{2}^{2}$ Professor, Lanzhou University, Lanzhou, 730000, PR China \\ *(Corresponding author: E-mail: hyj0087@163.com)
}

Received: 11 April 2011; Revised: 14 July 2011; Accepted: 21 July 2011

\begin{abstract}
The configuration of a kind of multi-storey or high-rise steel three-dimensional parking structure is introduced in this paper. The approximate analytical method is studied in detail. The whole structure is regarded as a vertical cantilever. The equivalent bending stiffness and shear stiffness of the structure, including the shear stiffness of the lateral bracing system and that of the beam-column system, are derived. The lateral displacement formula of the structure under horizontal load is subsequently developed. Then the calculation formulae of internal forces of various structural components are derived. Numerical example shows that the error of the results by the presented formulas does not exceed $7.2 \%$ in comparison with those by finite element method. Therefore, the method and its related formulae are feasible for preliminary design of this kind of steel three-dimensional parking structure since it is accurate and brief.
\end{abstract}

Keywords: Steel three-dimensional parking structure, Configuration, Approximate analytical method, Equivalent stiffness, Calculation formulas

\section{INTRODUCTION}

With the development of urban economy and automobile industry, the amount of private cars is rapidly increasing. However, the parking lots cannot keep pace with the growing number of the private cars; the difficulty of parking and the caused transportation congestion are obviously not in harmony with the development of modern society, it has become a major restraining factor in urban development (Chen et al. [1] and Mei et al. [2]). The development of the mechanical three-dimensional (3D) garages is undoubtedly the effective way to solve this problem. The 3D parking structures has been studied and applied in practice earlier in some developed countries (JRA [3], Kim [4], Kwar and Song [5-6]).

The structural configuration of a kind of multi-storey or high-rise steel 3D parking structure is introduced in this paper. And it is regarded as a cantilever fixed to the ground to simplify the calculation; the equivalent shear stiffness and bending stiffness of the structure are derived based on continuum analogy method (Zhou and Dong [7]), including the shear stiffness of the lateral bracing system and that of the frame. The lateral displacement formula of the structure under horizontal load is subsequently developed. Then the calculation formulae of internal forces of the structural components are derived. A numerical example is given for illustration, and the results by the presented formulae are compared with those by finite element method. 


\section{THE CONFIGURATION OF THE 3D PARKING STRUCTURE}

As we all know, the internal space and structural layout of various high-rise buildings vary with their functions. As to the 3D parking structures, a hoisting shaft in it is needed to ensure that car can be lifted to the level of a parking space. And the car needs to be horizontally shifted to the corresponding parking space within the $3 \mathrm{D}$ garage in the process of parking, so the separating walls can not be set between the parking space and the hoisting shaft. The planar layout of garage needs not only to meet the technical requirements of parking, but also to consider the rationality of the structure. Whether the layout of steel 3D parking structure is reasonable or not may greatly affect the economic performance and the convenience of use. The system displayed in Figure 1 is a typical parking structure with high efficiency (He et al. [8-9]). There are two parking spaces on the two sides of the hoisting shaft, as shown in Figure 1(a). In the parking process, the car is lifted to the height of a parking space by the vertical elevator through the hoisting shaft, and then transferred to the parking board in the parking space by the horizontal transition device. The planar dimensions depend on the sizes of cars. When a car is put on the parking board, the safety distance between car and parking board should also be considered. Synthesizing architectural modulus, the length and width of a parking space can be taken as $6 \mathrm{~m}$ and $2.4 \mathrm{~m}$, respectively. And the width of hoisting shaft can generally be taken as $3.0 \mathrm{~m}$ to guarantee that the cars can be carried up and down. The multi-storey or high-rise steel 3D parking structure generally consists of the ground, typical, and top stories. The ground storey with height of $h_{1}$ is the place for entering and leaving of the vehicles. The typical stories with height $h_{2}$ of each storey are used for parking. And according to the actually required capacity of parking, the number of typical stories can be increased or reduced. The top storey with height of $h_{3}$ is for installing of equipment. Obviously, when the required number of the parking spaces is $2 N$, the corresponding number of typical stories must be no less than $N$. Therefore the minimum total number of stories is $N+2$, and the corresponding total height is $h_{1}+h_{2} \times N+h_{3}$. There are four lifting chains attached to the columns of the hoisting shaft to lift cars. To improve the lateral stiffness, bracings should be set in the transverse and longitudinal side frames as shown in Figures 1(b) and (d). However, to ensure the horizontal shift of the car between the parking spaces and hoisting shaft, bracing can not be set in the middle transverse frames as shown in Figure 1(c). The simplified analytical method of this kind of structure is studied in this paper.

\section{INTERNAL FORCE AND DISPLACEMENT ANALYSES}

To confine our research, some basic assumptions are made as follows.

(1) The contraflexure points of the frame beams are located on their mid-spans. (Generally, the inflection point of a beam in a frame with lateral displacement is close to its mid-span point (Shen [10]).) (2) The braces are connected with the frame by pin connection and the bracing system mainly bears horizontal shear force in the structure (Zheng and Zhao [11]). (3) The bending and shearing actions of the two orthogonal frames are independent. (4) The beams are rigidly connected with the columns; and the shearing resistance effect of the beam-column system is taken into account. (5) The steel is considered as homogeneous linearly elastic material. (6) The lateral displacements of all the nodes at the same level are identical. 


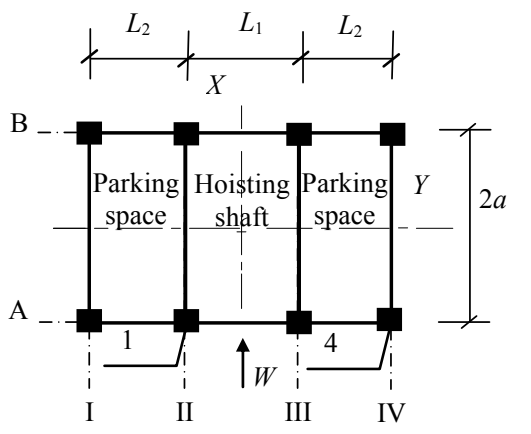

(a)

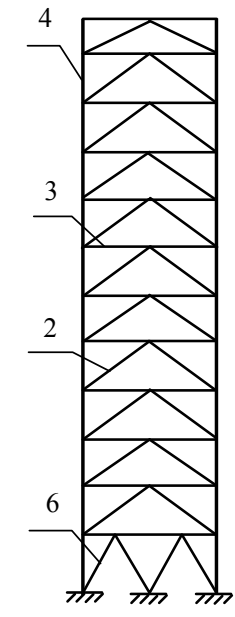

(b)

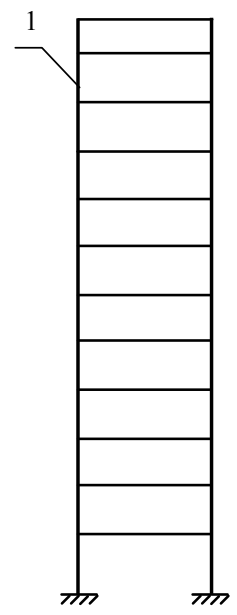

(c)

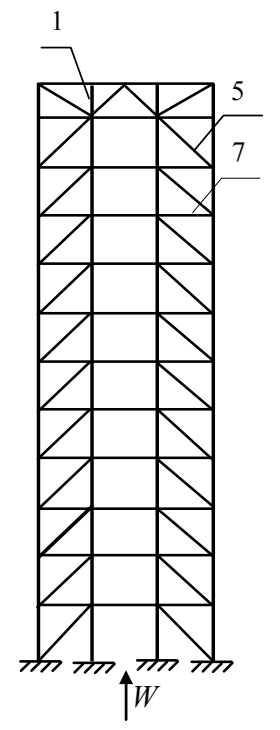

(d)

1: Column of hoisting shaft;

3: Lateral beam of the structure;

5: The diagonal brace in the front and back facades;

7: Front/rear beam of the typical stories;

$W$ : The direction of exit and entrance of the parking structure for cars

Figure 1. Schematic of the Multi-storey or High-rise Steel 3D Parking Structure:

(a) Planar layout; (b) Frame in axis I or IV; (c) Frame in axes II or III; (d) Frame in axes A or B

\subsection{The Equivalent Shear Stiffness}

Obviously, the shear stiffness of the braced frame structure is provided by both the frame and the bracing system. And according to the basic assumptions (2) and (4), the inter-storey shear deformation of the $i$-th storey of the structure is shown in Figure 2.

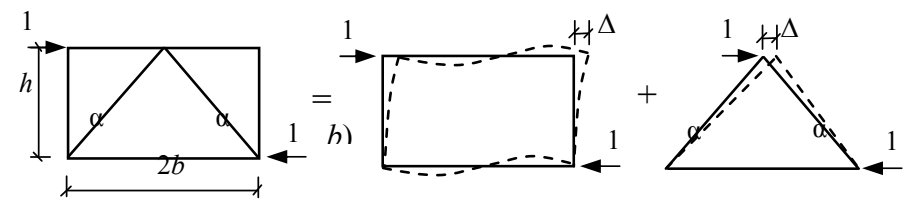

Figure 2. Schematic of Inter-storey Shear Deformation of the Structure

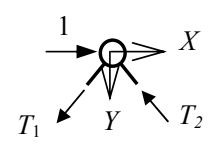

Figure 3. Free-body Diagram of a Node of K-shaped Brace

\subsubsection{The equivalent shear stiffness of the bracing system}

According to basic assumption (2), free-body diagram of a node of $\mathrm{K}$-shaped brace under horizontal unit force can be shown as Figure 3. Then the equilibrium equation due to unit horizontal force in X-direction can be obtained as

$T_{1} \cos \alpha+T_{2} \cos \alpha=1$

And that in Y-direction is

$T_{1} \sin \alpha=T_{2} \sin \alpha$ 
Based on the above equations, the internal force of the brace can be obtained as $T_{1}=T_{2}=T=1 /(2 \cos \alpha)$. Thus, the horizontal displacement of the brace node under the unit force can be calculated as

$\Delta=2 T^{2} L_{C} /\left(E A_{1}\right)$

where, $L_{C}=h / \sin \alpha$ is the length of the diagonal brace. Since the shear angle is $\gamma=\Delta / h$, the shear stiffness $C_{d}$ of a K-shaped brace can then be obtained as follows,

$C_{d}=1 / \gamma=2 E A_{1} \cos ^{2} \alpha \sin \alpha$

in which, $A_{1}$ is the cross-sectional area of a member of the $\mathrm{K}$-shaped brace, and $E$ is the elastic modulus of steel.

The total shear stiffness of the bracing system equals to the sum of those of all K-shaped braces in the same direction of a storey, namely $C_{b}=\sum C_{d i}$. Generally, two single-diagonal bracing members can be considered as a K-shaped brace.

\subsubsection{The equivalent shear stiffness of the beam-column system}

In calculation of the $i^{\text {th }}$ storey shear stiffness of the beam-column system, it is assumed that the beams connected with the far ends of the columns in the $i-1^{\text {th }}$ and $i+1^{\text {th }}$ stories of the frame is infinitely rigid. Based on this and assumption (1), the lateral deformation of the column $a b$ of the frame can be shown as Figure 4(b). In the figure, points 1, 2, 3, and 4 stand for the inflection points of beams am, $a f, b k$, and $b g$, respectively, which also are the midpoints of the beams. The relationship of the column $a b$ with other components is displayed in Figure 4(c) when the end rotation restraint of the column is freed and replaced by the end bending moments. The $M_{a b}$ and $M_{b a}$ indicate the end bending moments of the column at ends $a$ and $b$, respectively. Thus, the angular rotation of both ends can be calculated as follows (Schafer and Bajpai [12], Vasilopoulos and Beskos [13]).

$\theta_{a b}=\Delta / h-\alpha_{a b} M_{a b}+\beta M_{b a}$

$\theta_{b a}=\Delta / h+\beta M_{a b}-\alpha_{b a} M_{b a}$

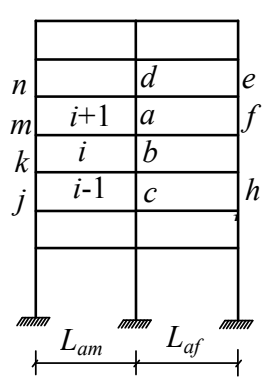

(a)

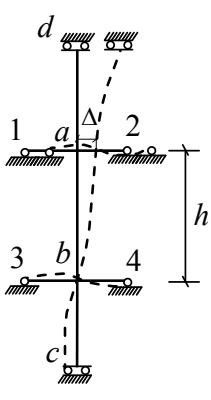

(b)

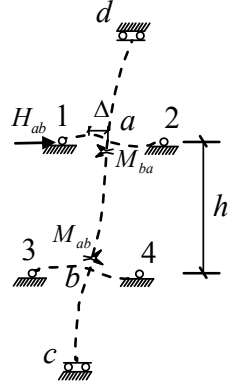

(c)
Figure 4. Lateral Deformation of Column of the Beam-column System

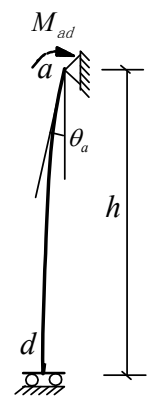

(a) Column

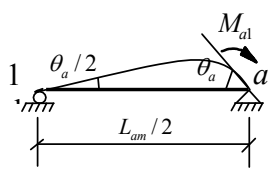

(b) Beam
Figure 5. Calculation Models of Components 
in which, $\Delta / h$ is the shear angle due to the storey drift $\Delta ; \alpha_{a b}$ is the angular rotation of end $a$ when the column is subjected to unit bending moment at end $a ; \alpha_{b a}$ is that of end $b$ when it is subjected to a unit bending moment at end $b$; while $\beta$ is the angular rotation of end $b$ when the column is subjected to a unit bending moment at end $a$ or that of end $a$ when it is subjected to unit bending moment at end $b$; for the steel components with uniform section (Bao [14]),

$\alpha_{a b}=\alpha_{b a}=1 /\left(3 K_{a b}\right), \quad \beta=1 /\left(6 K_{a b}\right)$

where $K_{a b}=E I_{a b} / h_{a b}, I_{a b}$ and $h_{a b}$ are the cross sectional moment of inertia and the length of column $a b$, respectively.

As shown in Figure 4(c), there must appear an angular rotation $\Phi_{a}=M_{a b} / \sum S_{a i}$ on node $a$ for the action of end bending moment $M_{a b}$. Here $\sum S_{a i}=S_{a 1}+S_{a 2}+S_{a d}$ is the sum of bending stiffness of all the components connected to node $a$. The models to calculate the bending stiffness of various components connected to node $a$ are displayed in Figure 5. For the column ad as shown in Figure $5(\mathrm{a})$

$\theta_{a}=\int_{0}^{h} M_{a d} /\left(E I_{a d}\right) d x=M_{a d} \times h /\left(E I_{a d}\right)$

And $M_{a d}$ represents the bending stiffness of column $a d$ when $\theta_{a}=1$. Thus

$S_{a d}=K_{a d}=E I_{a d} / h_{a d}$

where $I_{a d}$ and $h_{a d}$ are the cross sectional moment of inertia and the length of component $a d$, respectively.

For a beam as shown in Figure 5(b),

$M_{a 1}=4 E I_{a m} /\left(L_{a m} / 2\right) \times \theta_{a}+2 E I_{a m} /\left(L_{a m} / 2\right) \times\left(-\theta_{a} / 2\right)$

Obviously, $M_{a 1}$ represents the bending stiffness of beam am when $\theta_{a}=1$. Thus

$S_{a 1}=6 K_{a m}=6 E I_{a m} / L_{a m}$

where $I_{a m}$ and $L_{a m}$ are the cross sectional moment of inertia and the length of beam am, respectively. Analogously,

$S_{a 2}=6 K_{a f}=6 E I_{a f} / L_{a f}$

in which, $I_{a f}$ and $L_{a f}$ are the cross sectional moment of inertia and the length of beam af, respectively.

Similarly, the angular rotation of node $b$ under the action of $M_{b a}$ can be derived as 
$\Phi_{b}=M_{b a} / \sum S_{b i}$, where $\sum S_{b i}=S_{b 4}+S_{b 3}+S_{b c}, S_{b c}=K_{b c}=E I_{b c} / h, S_{b 3}=6 K_{b k}=6 E I_{b k} / L_{b k}$, and $S_{b 4}=6 K_{b g}=6 E I_{b g} / L_{b g}$. (The meanings of various parameters are the same as those stated above.) Considering $\theta_{a b}=\Phi_{a}, \theta_{b a}=\Phi_{b}$, and substituting $\alpha_{a b}, \alpha_{b a}$, and $\beta$ into Eqs. 5 and 6 , the following equations can then be obtained.

$$
\begin{aligned}
& M_{a b} / \sum S_{a i}=\Delta / h-M_{a b} /\left(3 K_{a b}\right)+M_{b a} /\left(6 K_{a b}\right) \\
& M_{b a} / \sum S_{b i}=\Delta / h+M_{a b} /\left(6 K_{a b}\right)-M_{b a} /\left(3 K_{a b}\right)
\end{aligned}
$$

Let $f_{a}=2+6 K_{a b} / \sum S_{a i}, f_{b}=2+6 K_{a b} / \sum S_{b i}$, and solve Eqs. 13 as well as $14, M_{a b}$ and $M_{b a}$ can be obtained as follows,

$$
\begin{aligned}
& M_{a b}=\left((\Delta / h) \times 6 K_{a b} \times\left(f_{a}+1\right)\right) /\left(f_{a} \times f_{b}-1\right) \\
& M_{b a}=\left((\Delta / h) \times 6 K_{a b} \times\left(f_{b}+1\right)\right) /\left(f_{a} \times f_{b}-1\right)
\end{aligned}
$$

Suppose that the distances between the contraflexure point of the column and ends $a$ as well as $b$ are $i_{0} h$ and $\left(1-i_{0}\right) h$, respectively. Then

$$
\begin{aligned}
& M_{a b}=H_{a b} \times i_{0} \times h \\
& M_{b a}=H_{a b} \times\left(1-i_{0}\right) \times h
\end{aligned}
$$

where $H_{a b}$ is the horizontal load applied to the end of column as shown in Figure 4(c). Substituting them into Eqs. 15 and 16, coefficient $i_{0}$ can be obtained as

$$
i_{0}=\left(f_{a}+1\right) /\left(f_{a}+f_{b}+2\right)
$$

Thus,

$$
H_{a b}=\frac{M_{a b}}{i_{0} h}=\frac{f_{\mathrm{a}}+1}{i_{0}\left(f_{a} f_{b}-1\right)} \times \frac{6 K_{a b} \Delta}{h^{2}}
$$

Based on the definition of shear stiffness, $H_{a b}$ equals to the shear stiffness of the column $C_{a b}$ when $\Delta / h=1$. Then

$$
C_{a b}=6 K_{a b}\left(f_{a}+1\right) /\left(i_{0}\left(f_{a} f_{b}-1\right) h\right)
$$

Analogously, other columns have the similar expression. The inter-storey shear stiffness of the beam-column system equals to the sum of those of all the columns in a same storey, namely $C_{f}=\sum C_{i}$. Considering the shear stiffness of the bracing system, the total shear stiffness of the $k$-th storey of the structure can be obtained as

$C_{k}=C_{b}+C_{f}$ 
For simplicity, the shear stiffness of the equivalent cantilever mast is calculated by weighted average along the height of the structure. Namely,

X direction: $\quad C_{x}=\sum_{\mathrm{i}=1}^{N} C_{x i} \times h_{i} / H$

Y direction: $\quad C_{y}=\sum_{i=1}^{N} C_{y i} \times h_{i} / H$

in which, $C_{x i}, C_{y i}$ are the equivalent shear stiffness of the $i$-th storey of the structure along the $\mathrm{X}$ and $\mathrm{Y}$ directions, respectively; $H$ is the total height of the structure, and $h_{i}$ is the storey height of the $i$-th storey.

\subsection{Lateral Displacement Analysis of the Parking Structure}

The high-rise parking structure described may be simplified as a vertical cantilever. Regarding it as a cantilever to simplify the calculation, the equivalent bending stiffness of the structure can be derived as follows based on continuum analogy method.

X-axis: $\quad E I_{x}=E\left(4 A_{2}\left[\left(\frac{L_{1}}{2}\right)^{2}+\left(\frac{L_{2}}{2}\right)^{2}\right]+4 I_{x s}+4 I_{x c}\right)$

Y-axis: $\quad E I_{y}=E\left(8 A_{2} a^{2}+8 I_{y c}\right)$

where, $E$ is the elastic modulus of the steel, $A_{2}$ is the cross-sectional area of the column; $L_{1}, L_{2}$ are the spans of the mid-span and side-span along the Y-direction of the parking structure (see Figure 1), respectively; $I_{x s}$ and $I_{x c}$ are the cross sectional moment of inertia of the side column and mid column to the centroidal axis which is parallel to X-axis, respectively; $2 a$ is the span along $\mathrm{X}$-direction, $I_{y c}$ is the cross-sectional moment of inertia of the column to the centroidal axis which is parallel to Y-axis.

The second-order effect of the structure must be taken into consideration due to the large height-to-width ratio of the structure. For convenience in calculation and consistence with the linear elastic method in the specifications (GB50017-2003 [15]), the $P-\Delta$ effect of gravity is estimated by using the linear elastic stiffness of the structure. Namely, the lateral displacement of the structure can be calculated by adding an assumed horizontal force $H_{\mathrm{mi}}$ as follows to the top of each storey (GB50017-2003 [15]).

$H_{\mathrm{mi}}=\frac{\alpha Q_{i}}{250} \sqrt{0.2+1 / n}$

where, $Q_{i}$ is the total design gravity load on the $i$-th storey; $n$ is the total number of stories; and $\alpha$ is the influence coefficient of strength of the steel, for Q235, Q345, Q390 and Q420, $\alpha$ equals to $1.0,1.1,1.2$, and 1.25 , respectively; additionally, $\sqrt{0.2+1 / n} \leq 1$, namely, it is taken as 1.0 when $\sqrt{0.2+1 / n}>1$. 
The lateral displacement calculation model of the parking structure is shown in Figure 6. The equivalent concentrated force $H_{i}$ of each storey is the sum of the assumed horizontal force $H_{m i}$ and all the actually applied horizontal loads. After the equivalent parameters are obtained, the storey drift of the $i$-th storey can be derived as follows based on the method of structural mechanics.

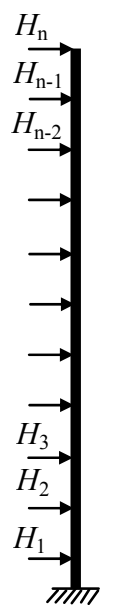

Figure 6. Lateral Displacement Calculation Model of the Parking Structure

$\Delta_{i}=\Delta_{v i}+\Delta_{M i}=h_{i} \sum_{j=i}^{n} H_{j} / C_{x}+h_{i}^{2}\left(M_{i}+\frac{2}{3} \sum_{j=i}^{n} H_{j}\right) /\left(2 E I_{y}\right)$

where, $\Delta_{\mathrm{vi}}=h_{i} \sum_{j=i}^{n} H_{j} / C_{x}$ and $\Delta_{M i}=h_{i}^{2}\left(M_{i}+\frac{2}{3} \sum_{j=i}^{n} H_{j}\right) /\left(2 E I_{y}\right)$ are the shear and bending relative displacements of the $i$-th storey, respectively; $h_{i}$ is the storey height; and $M_{i}$ is the total moment of various concentrated horizontal forces $H_{j}$ acting at the $i$-th storey and those above it relative to the top of the $i$-th storey.

\subsection{Internal Forces of Various Structural Components under Horizontal Loads}

While the storey drift $\Delta_{i}$ is obtained by Eq. 28, the axial deformation of the diagonal brace can be calculated as $\Delta_{C}=\Delta_{i} \cos \alpha$ according to Figure 2. Then the axial force of a lateral brace of the $i$-th storey can be gotten as

$T=\Delta_{C} E A_{1} / L_{C}=\Delta_{i} \sin \alpha \cos \alpha E A_{1} / h$

Substituting $\Delta_{i}$ into Eqs. 15 and 16, the bending moments of the upper and lower ends of the column of the $i$-th storey can be obtained as follows,

$$
\begin{aligned}
& M_{\text {iup }}=\left(\Delta_{i} / h\right) \times 6 K_{a b} \times\left(f_{a}+1\right) /\left(f_{a}+f_{b}+1\right) \\
& M_{\text {ilow }}=\left(\Delta_{i} / h\right) \times 6 K_{a b} \times\left(f_{b}+1\right) /\left(f_{a}+f_{b}+1\right)
\end{aligned}
$$

Substitute $\Delta_{i}$ into the shear stiffness of the column as shown in Eq. 21, the shear of the column of the $i$-th storey can be obtained as, 
$V_{i}=6 K_{a b} \Delta_{i}\left(f_{a}+1\right) /\left(i_{0}\left(f_{a} f_{b}-1\right) h^{2}\right)$

After the bending moments of various columns are obtained, the moments at the ends of various beams can be calculated based on the moment equilibrium condition of nodes.

For the beam connected with side column as shown in Figure 7(a), one has

$$
M_{i b m}=M_{i u p}+M_{i+1 l o w}
$$

And for the beam connected with mid column as shown in Figure 7(b),

$$
\begin{aligned}
& M_{i b m l}=\left(M_{i+1 u p}+M_{i l o w}\right) \frac{S_{i l}}{S_{i l}+S_{i r}} \\
& M_{i b m r}=\left(M_{i+1 u p}+M_{i l o w}\right) \frac{S_{i r}}{S_{i l}+S_{i r}}
\end{aligned}
$$

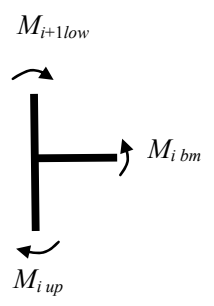

(a)

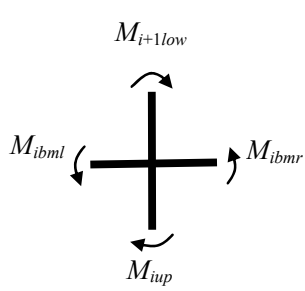

(b)

Figure 7. Bending Moment Diagram of Nodes

where, $S_{i l}$ and $S_{i r}$ are the bending stiffness of the left and right beams, respectively.

After the bending moments of the beams are obtained, the shears of the beams can be obtained according to the equilibrium condition of individual beam as shown in Figure 8. Namely,

$$
V_{i l}=V_{i r}=\left(M_{i l}+M_{i r}\right) / L
$$

where, $V_{i l}$ and $V_{i r}$ are the shear forces on the left and right ends of the beam $i$, respectively; while $M_{i l}$ and $M_{i r}$ are the corresponding end moments of the beam.

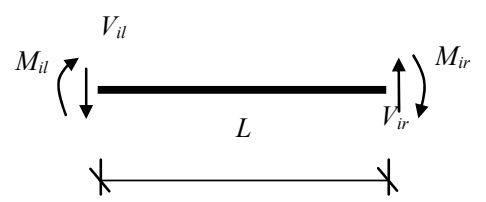

Figure 8. Free-body Diagram of Individual Beam

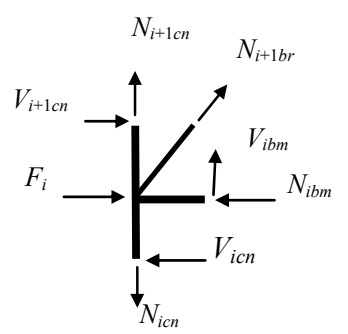

(b)

Figure 9. Free-body Diagram of Nodes

The axial forces of the beam and column under horizontal loads can be calculated based on the equilibrium condition of nodes. From Figure 9(a), one has

$$
N_{t p b m}=F_{t p}-V_{t p c n}, \quad N_{t p c n}=V_{t p b m}
$$

and from Figure 9(b), 
$N_{i b m}=V_{i+1 c n}-V_{i c n}+N_{i b r h}+F_{i}, \quad N_{i c n}=N_{i+1 c n}+N_{i b m}+N_{i b r v}$

in which, $N_{t p b m}$ and $V_{t p b m}$ are the axial and shear forces in the beam of the top storey, respectively; $N_{t p c n}$ and $V_{t p c n}$ are those of the column of the top storey; and $N_{i b r h}$ as well as $N_{i b r v}$ are the horizontal and vertical components of the axial internal force of the brace, respectively.

\subsection{Internal Forces Analyses of Parking Structures under the Vertical Loads}

When a vehicle is parked in the parking structure, it is generally put on the parking board. The parking board is connected with the structure only by the four adjacent columns, through which the vehicle load is transferred to the parking structure. Therefore, in analyses, the vertical load transferred by the parking board can be regarded as four equal concentrated forces applied at the tops of the adjacent columns of the parking space. The numerical analysis by finite element method shows that, the columns are the dominating load-carrying components under the vertical load, whereas, the internal forces of the other components are very small, which can be basically ignored. Therefore, in this case, the axial forces of various columns of the $i$-th storey of the parking structure can be calculated as

$$
N_{i c}=\sum_{j=i+1}^{n} \mathrm{G}_{j} / m_{i}
$$

where, $\sum_{j=i+1}^{n} \mathrm{G}_{j}$ is the total vertical load acting at various stories above the $i$-th one; $m_{i}$ is the number of columns of the $i$-th storey.

Additionally, the internal forces of the other components are assumed to be zero under the vertical loads.

\section{NUMERICAL EXAMPLES}

To confirm the validity of the derived formula, a numerical example is given in this section, compared with the results by ANSYS finite element analysis. The schematic diagram of the structure in the example is shown in Figure 1. The span along $X$ direction of the structure is $6.0 \mathrm{~m}$ and those of various bays along Y direction are all $3.0 \mathrm{~m}$. The storey heights of the bottom, standard, and the top stories are $2.7 \mathrm{~m}, 2.5 \mathrm{~m}$, and $1.5 \mathrm{~m}$, respectively. The components are assumed to be made of Q235 steel (Yield Strength $235 \mathrm{MPa}$ ). The beams and columns are made of $\mathrm{H}$-shaped sections H-250 $\times 150 \times 6 \times 8$ (in which, 250, 150, 6, and 8 are the height of the cross section, width of the flange, thickness of the web, and the thickness of the flange, respectively.) and H-300 $\times 200 \times 8 \times 10$, respectively. And the braces are circular steel tube $\Phi 80 \times 10$. The total number of stories is six. Two 1.5-ton cars are parked on each standard storey, and the horizontal load of $10 \mathrm{kN} / \mathrm{m}$ is applied to the structure along $\mathrm{X}$ direction. The results are displayed in Tables 1 and 2. 
Table 1. Result Comparison of Axial Internal Forces of the Columns of the Structure under the Vertical load

\begin{tabular}{cccc}
\hline $\begin{array}{c}\text { Storey } \\
\text { number }\end{array}$ & $\begin{array}{c}\text { By ANSYS software } \\
N / \mathrm{kN}\end{array}$ & $\begin{array}{c}\text { By the derived formula } \\
N_{1} / \mathrm{kN}\end{array}$ & $\left|\frac{N_{1}-N}{N}\right| \times 100 \%$ \\
\hline No.4 & 3.394 & 3.615 & $6.51 \%$ \\
No.3 & 6.954 & 7.350 & $5.69 \%$ \\
No.2 & 10.906 & 11.025 & $1.09 \%$ \\
No.1 & 15.258 & 14.70 & $3.66 \%$ \\
\hline
\end{tabular}

Table 2. Result Comparison of Internal Forces of Various Components of the Structure under the Horizontal Load

\begin{tabular}{|c|c|c|c|c|c|c|c|c|}
\hline \multirow{2}{*}{$\begin{array}{l}\text { Floor } \\
\text { number }\end{array}$} & \multicolumn{3}{|c|}{ Axial forces of components / $\mathrm{kN}$} & \multicolumn{2}{|c|}{ Shears of components $/ \mathrm{kN}$} & \multicolumn{3}{|c|}{ Moments of components $/ \mathrm{kNm}$} \\
\hline & Beam & Column & Brace & Beam & Column & Beam & $\begin{array}{l}\text { Upper end of } \\
\text { column }\end{array}$ & $\begin{array}{l}\text { Lower end } \\
\text { of column }\end{array}$ \\
\hline \multirow{2}{*}{ No.6 } & $7.05(6.65)$ & $0.14(0.13)$ & $5.62(5.39)$ & $0.14(0.13)$ & $0.44(0.42)$ & $0.41(0.39)$ & $0.41(0.39)$ & $0.25(0.24)$ \\
\hline & $5.67 \%$ & $7.14 \%$ & $4.09 \%$ & $7.14 \%$ & $4.54 \%$ & $4.88 \%$ & 4.8 & $4.00 \%$ \\
\hline \multirow{2}{*}{ No.5 } & $30.08(29.52)$ & $3.0(2.91)$ & $13.8(12.95)$ & $0.35(0.33)$ & $0.68(0.64)$ & $1.05(1.01)$ & $0.80(0.78)$ & $0.91(0.89)$ \\
\hline & $1.86 \%$ & $3.00 \%$ & $6.16 \%$ & $5.71 \%$ & $5.88 \%$ & $3.81 \%$ & $2.50 \%$ & $2.20 \%$ \\
\hline \multirow{2}{*}{ No.4 } & $43.03(42.6)$ & $12.56(12.31)$ & $20.7(19.56)$ & $0.69(0.65)$ & $0.93(0.87)$ & $2.07(2.06)$ & $1.16(1.08)$ & $1.16(1.15)$ \\
\hline & $1.00 \%$ & $1.99 \%$ & $5.50 \%$ & $5.80 \%$ & $6.45 \%$ & $0.48 \%$ & $6.89 \%$ & $0.86 \%$ \\
\hline \multirow{2}{*}{ No.3 } & $57.58(56.4)$ & $26.75(26.23)$ & $27.7(26.96)$ & $0.90(0.86)$ & $1.24(1.20)$ & $2.7(2.68)$ & $1.54(1.46)$ & $1.54(1.47)$ \\
\hline & $2.05 \%$ & $1.94 \%$ & $2.67 \%$ & $4.44 \%$ & $3.23 \%$ & $0.74 \%$ & $5.19 \%$ & $4.55 \%$ \\
\hline \multirow{2}{*}{ No.2 } & $76.80(74.8)$ & $45.62(44.41)$ & $34.6(32.34)$ & $1.15(1.12)$ & $1.53(1.42)$ & $3.44(3.25)$ & $1.89(1.85)$ & $1.93(1.91)$ \\
\hline & $2.60 \%$ & $2.65 \%$ & $6.53 \%$ & $2.61 \%$ & $7.19 \%$ & $5.52 \%$ & $2.12 \%$ & $1.04 \%$ \\
\hline \multirow{2}{*}{ No.1 } & $99.6(94.9)$ & $70.32(68.8)$ & $41.9(39.57)$ & $2.55(2.51)$ & $3.22(3.10)$ & $7.64(7.41)$ & $5.72(5.66)$ & $3.00(2.95)$ \\
\hline & $4.72 \%$ & $2.16 \%$ & $5.56 \%$ & $1.57 \%$ & $3.72 \%$ & $3.01 \%$ & $1.05 \%$ & $1.67 \%$ \\
\hline
\end{tabular}

Note: data in brackets refer to the results based on the derived formula, the others are the results by ANSYS software, and the percentages are the errors of the derived formula.

From the results in the tables it can be seen that, in comparison with the results by ANSYS software, the maximum error of the internal forces of various components of the structure under the vertical and horizontal loads are $6.51 \%$ and $7.19 \%$, respectively. This indicates that the formulae are highly accurate. Therefore, the method and its related formulas derived in this paper are feasible for preliminary design of this kind of steel 3D parking structure. And it is also convenient to be used.

\section{CONCLUSIONS}

The multi-storey or high-rise steel 3D parking structures are introduced in this paper and its approximate analytical method is studied. It is regarded as a vertical cantilever fixed on the ground level. The equivalent bending and shear stiffness of the structure is derived, including the shear stiffness of the lateral bracing system and that of the beam-column system. The lateral displacement formula of the structure under the horizontal load is subsequently developed. Then the calculation formulae of internal forces of the structural components are derived. A numerical example is given for illustration, and it is indicated that the error of the results by the presented formulae do not exceed $7.2 \%$ in comparison with those by computer analysis. Therefore, the method and its related formulae are feasible for preliminary design of the steel parking structures due to its accuracy and briefness. 


\section{ACKNOWLEDGEMENT}

This work was financially supported by the National Natural Science Foundation of China (Grant No. 51178176) and the Fundamental Research Funds for the Central Universities of Hunan University, which are gratefully acknowledged.

\section{REFERENCES}

[1] Chen, J., Liu, D. and Chen, X.W., "Planning Method of Urban Parking Facilities Locating Model with Its Genetic Algorithm", China Journal of Highway and Transport, 2001, Vol. 14, No. 1, pp. 85-88 [in Chinese].

[2] Mei, Z.Y., Xiang, Y.Q. and Chen, J., "Optimization Model of Parking Guidance Coordinated with Traffic Flow Control Based on Fuzzy Algorithm”, China Journal of Highway and Transport, 2008, Vol. 21, No. 2, pp. 84-88.

[3] JRA, "Recommendations for the Design and Construction of Parking Structures", Japan Road Association, 1992.

[4] Kim, K.H., "Design of Parking Garage Structures", Architectural Culture, Seoul, 1995.

[5] Kwar, H.G. and Song, J.Y., "Live Load Design Moments for Parking Garage Slabs Considering Support Deflection Effect", Computers \& Structures, 2001, Vol. 79, No. 19, pp. 1735-1751.

[6] Kwar, H.G. and Song, J.Y., "Live Load Factors for Parking Garage Members", Structural Safety, 2000, Vol. 22, No. 3, pp. 251-279.

[7] Zhou, D. and Dong, S.L., "A Simplified Method for Analyzing High Rise Frame Tube Building Structures", Journal of Zhejiang University (Engineering Science), 1998, Vol. 32, No. 3, pp. 251-259 [in Chinese].

[8] He, Y.J., Yang, C.C. and Zhou, X.H., "Structural Forms, Application and Development of Three-dimensional Garages", Journal of Architecture and Civil Engineering, 2009, Vol. 26, No. 4, pp. 30-34 [in Chinese].

[9] He, Y.J., Zhou, X.H. and Hu, J.C., "Structural Configurations and Economic Performance Comparison of Multi-Storey and High-Rise Steel Three-Dimensional Garages", Advanced Materials Research, 2011, Vols. 163-167, pp. 16-19.

[10] Shen, P.S., "Design of Concrete Structures", Beijing, Higher Education Press, 2005 [in Chinese].

[11] Zheng, T.Y. and Zhao, H.L., "Practical Approach of Second Order Analysis for Space Mega Steel Frame Structures", Construction Structure, 2005, Vol. 35, No. 8, pp. 57-60 [in Chinese].

[12] Schafer, B.W. and Bajpai, P., "Stability Degradation and Redundancy in Damaged Structures”, Engineering Structures, 2005, Vol. 27, No. 11, pp. 1642-1651.

[13] Vasilopoulos, A.A. and Beskos, D.E., "Seismic Design of Plane Steel Frames Using Advanced Methods of Analysis", Soil Dynamics and Earthquake Engineering, 2006, Vol. 26, No. 12, pp. 1077-1100.

[14] Bao, S.H., "Structure Mechanics Course", Beijing, Higher Education Press, 2003 [in Chinese].

[15] Ministry of Construction of the People's Republic of China, "GB 50017-2003, Code for Design of Steel Structures of China”, Beijing, China Planning Press, 2003. 


\title{
FIRE DYNAMIC SIMULATION ON THERMAL ACTIONS IN LOCALIZED FIRES IN LARGE ENCLOSURE
}

\author{
Chao Zhang ${ }^{1, *}$ and Guo-qiang $\mathrm{Li}^{2}$ \\ ${ }^{1}$ College of Civil Engineering, Tongji University, 1239 Siping Road, Shanghai 200092, China \\ ${ }^{2}$ Sate Key Laboratory for Disaster Reduction in Civil Engineering, 1239 Siping Road, Shanghai, China \\ *(Corresponding author: E-mail: 08_chao_zhang@tongji.edu.cn)
}

Received: 11 April 2011; Revised: 14 July 2011; Accepted: 21 July 2011

\begin{abstract}
Large enclosures commonly exist in many buildings like atria, open car parks and airport terminals. There is an international trend to prompt performance-based method (PBM) for fire resistance design. By PBM, the temperatures of structures in design fires should be determined. Localized fires are always adopted as design fires in large spaces. Currently, no agreed calculation method is available for the calculation of the heat flux from a localized fire to a vertical column. This paper aims at providing a feasible way of calculating the thermal actions in localized fires. Particularly, gas temperatures in localized fires and heat transfer from localized fires to steel vertical columns have been numerically investigated. The popular CFD code FDS is adopted as the numerical tool. A design fire scenario and four real localized fire tests are simulated in FDS. The effects of input parameters, including grid size and number of solid angles, on the accuracies of the numerical results have been investigated. Numerical results are compared with correlations and test data, which shows good agreement.
\end{abstract}

Keywords: Fire Dynamic Simulation (FDS), Steel column, Localized fire, Heat transfer, Temperature calculation, Grid size

\section{INTRODUCTION}

A compartment fire will generally undergo six stages which include ignition, growth, flashover, full fire development or steady burning, decay and extinguishment. Flashover is the rapid transition between the primary fire which is essentially localized around the item first ignited, and the general conflagration within the compartment when all fuel surfaces are burning [1]. Depending on whether flashover will happen or not, the real fires are usually divided into pre- and post- flashover fires. For small and middle scaled compartments with sufficient fuel and ventilation, the potential fires will develop to flashover and be characterized as post-flashover fires. For large scale enclosures or where sprinklers work effectively, flashover is unlikely to occur and the fires are characterized as pre-flashover fires. Post-flashover fires provide the worst case scenarios which are usually considered in fire resistance design. However, localized heating of key elements of structure in pre-flashover fires must be also considered.

For post-flashover fires, the gas properties within the compartment are approximately uniform that temperature-time curves are usually adopted to represent the fire environments. Correspondingly, the temperature of exposed members can be easily determined by interpreting the homogenous gas temperature as the effective black body radiation temperature and as the same gas temperature for convection calculation. At present, various formulae are provided by fire codes in different countries for calculating the temperature of steel members in post-flashover fires [2-4]. However, for pre-flashover or localized fires, the distribution of gas temperature is spatially non-uniform. Although correlations had been derived for calculating the fire environment in localized fires (e.g. given by the Annex C in EC1 [5]), no agreed analytical method is available for calculating the temperature response of steel columns exposed to localized fires. In EC1 [5], correlations proposed by Hasemi are adopted to calculate the total heat fluxes from localized fires to horizontal members. Heat fluxes from fires (flames) to adjacent vertical walls have also been studied by many 
researchers, and calculation formulae are proposed in SFPE handbook [6]. To the authors' acknowledge, only Kamikawa et al. [7] had tested the thermal mechanism of steel columns exposed to localized fires.

Simulation method is a feasible way to predict the thermal action in localized fires. This paper is an extension of a previous work [8], concerning on using FDS [9] to simulate the heating mechanism of steel columns in localized fires. In [8], the surrounding fire test with heat release rate of $81 \mathrm{~kW}$ in [7] had been simulated by using FDS (where 'surrounding' is the location of the fire source to the column), and the numerical result agree well with the test data. To give general recommendations on using FDS for predicting the thermal actions in localized fires, the other 3 surrounding fire tests in [7] are simulated in this paper, and the results for gas temperatures in a design fire scenario predicted by FDS are compared with those predicted by correlations. Sensitivity studies have been conducted to investigate the effects of input parameters include grid size and number of solid angles, on the accuracies of the numerical results.

\section{CORRELATIONS FOR LOCALIZED FIRES}

\subsection{Plume Temperature}

A localized fire is loosely divided into the lower combustion (flame) and the upper non-combustion (plume) regions, as shown in Figure 1. In Figure 1, the ceiling jet, which refers to the relatively rapid gas flow in a shallow layer beneath the ceiling surface that is driven by the buoyancy of the hot combustion products from the plume, is also illustrated. Assuming the plume gases are ideal gases produced from a virtual point source which extend vertically due to buoyancy force, and assuming profiles of the distributions of the plume temperature and velocity, by solving the balance equations for mass, momentum and heat of plume gases, correlations for calculating the plume temperature had been derived by the classic plume theory [10]. The correlation derived from top-hat assumption [11] which assumes uniform distributions of plume temperature and velocity in horizontal plane is widely used in smoke control calculation, such as NFPA 92B, TM 119.

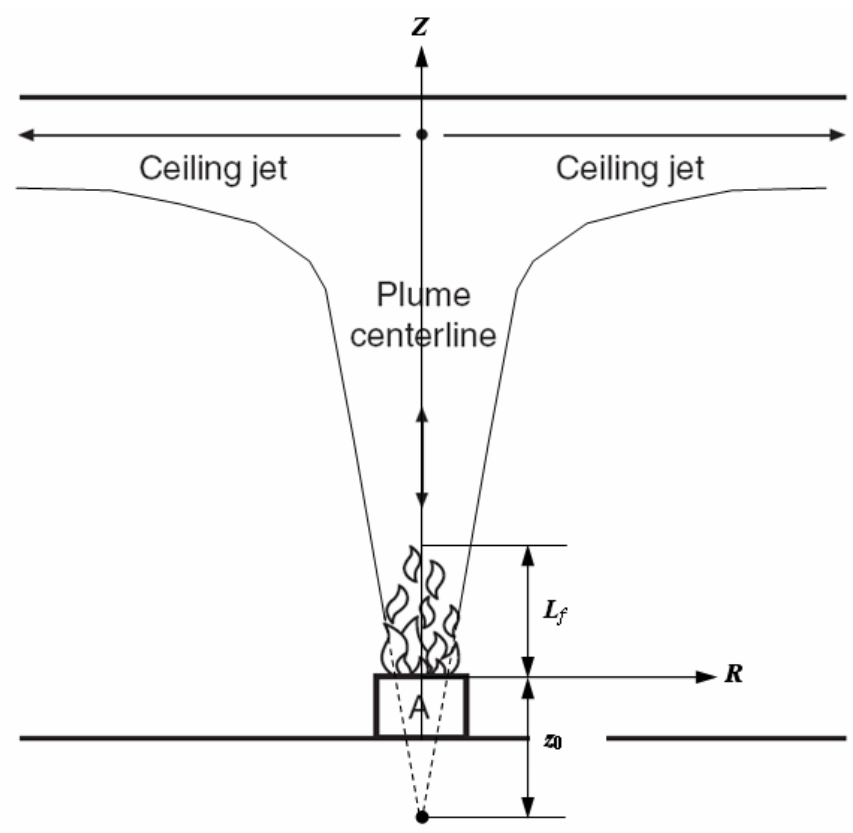

Figure 1. Illustration of the Localized Fire Model 
Assume profile of temperature rise is represented as Gaussian in shape, the plume temperature is calculated by [11]

$$
\Delta T=\Delta T_{0} \exp \left[-\left(\frac{R}{\sigma_{T}}\right)^{2}\right]
$$

with

$$
\sigma_{T}=1.20 b_{\Delta T}
$$

$$
b_{\Delta T}=0.12\left(\frac{T_{0}}{T_{\infty}}\right)^{1 / 2}\left(z-z_{0}\right)
$$

where $T_{0}$ is the plume centerline temperature calculated by

$$
\Delta T_{0}=9.1\left(\frac{T_{\infty}}{g c_{p}^{2} \rho_{\infty}^{2}}\right)^{1 / 3} \dot{Q}_{c}^{2 / 3}\left(z-z_{0}\right)^{-5 / 3}
$$

Taking the values of constant into Eq. 4, we get the correlation recommended in EC1 [5], thus

$$
T_{0}=20+0.25\left(1000 \dot{Q}_{c}\right)^{2 / 3}\left(z-z_{0}\right)^{-5 / 3}
$$

in which, $\dot{Q}_{c}=\left(1-\chi_{r}\right) \dot{Q}$ is the convective part of the heat release rate of the fire source; $\chi_{r}$ is the radiative fraction, and; $z_{0}$ is the height of the virtual source, calculated by

$$
z_{0}=-1.02 D+0.083 \dot{Q}^{2 / 5}
$$

here, $D=\sqrt{4 A / \pi}$ is the equivalent diameter of the fire, in which $A$ is the area of the fire source.

\subsection{Flame Temperature}

Eq. 4 is not valid for calculation in the flame region. The flame temperature can be calculated using the correlation given by Quintiere and Grove [12], thus

$$
\Delta T_{\text {flame }}=C_{T, f}\left(1-\chi_{r}\right) \frac{\Delta H_{c} / s_{a}}{c_{p}}
$$

where $C_{T, f}$ is a constant dependent on a fit to data, which is usually taken as $0.50[13] ; \Delta H_{c} / s_{a}$ is the heat released by consuming a unit mass of air, for most common fuel $\Delta H_{c} / s_{a}=3.03 \pm 0.02$ $\mathrm{kJ} / \mathrm{g}$ [1]; and $c_{p}$ is the specific heat of the gas, often taken as $1.00 \mathrm{~J} / \mathrm{gK}$ 。Correspondingly, Eq. (7) can be approximated by

$$
\Delta T_{\text {flame }}=1500\left(1-\chi_{r}\right)
$$

Eq. 7 or 8 assumes that all of the air entrainment into the flame zone is completely consumed. However, in practice, with height increase the amount of air entrainment will become more than that of air required for reaction and the exceeded air will cool the flame temperature. 
The flame and plume regions are usually divided by flame height. The correlation given by Heskestad for calculating the flame height is adopted by EC1 [5], which is given by

$$
L_{f}=-1.02 D+0.235 \dot{Q}^{2 / 5}
$$

\subsection{Ceiling Jet Temperature}

Correlations derived by Alpert [14] are widely used in designing smoke detectors and are recommended by PD 7974-2 [15] to determine the maximum temperature of the ceiling jets under an unconfined ceiling, which are given by

$$
\begin{aligned}
& \Delta T=16.9 \frac{\dot{Q}^{2 / 3}}{H^{5 / 3}} \quad(r / H \leq 0.18) \\
& \Delta T=5.38 \frac{\dot{Q}^{2 / 3} / H^{5 / 3}}{(r / H)^{2 / 3}} \quad(r / H>0.18)
\end{aligned}
$$

where $H$ is the height of the ceiling; and $r$ is the horizontal distance from the plume axis.

Alpert's correlations are derived for weak plume-driven ceiling jet flow, for strong plume-driven ceiling jet flow where the flame height of the fire plume is comparable to the height of the ceiling, correlation given by Heskestad and Hamada [16] is recommended for calculating the maximum temperature of the ceiling jet, thus

$$
\frac{\Delta T}{\Delta T_{p}}=1.92\left(\frac{r}{b}\right)^{-1}-\exp \left[1.61\left(1-\frac{r}{b}\right)\right] \quad\left(1 \leq \frac{r}{b} \leq 40\right)
$$

where $\Delta T_{p}$ is the excess temperature on the plume centerline at the level of the ceiling and $b$ is the characteristic plume radius given by

$$
b=0.045 \frac{T_{p}^{1 / 2} \dot{Q}_{c}^{2 / 5}}{\Delta T_{p}^{3 / 5}}
$$

\section{DESCRIPTION OF THE NUMERICAL TOOL}

The CFD code FDS [9] is adopted as the numerical tool. FDS is developed in particular for fire related simulations. In FDS, the fluid flow is modeled by solving the conservation equations for mass, mixture fraction, momentum and energy in a low Mach number form. The effect of the flow field turbulence is treated by means of the Smagorinsky form of Large-Eddy Simulation (LES), in which the large scale eddies are computed directly and sub-grid scale dissipative processes are modeled. An explicit, second-order accurate scheme is used for the time integration.

The combustion model in FDS is based on the assumption that the combustion is mixing-controlled. This implies that all species of interest can be described in terms of the mixture fraction $Z$, a conserved scalar variable. Heat from the reaction of fuel and oxygen is released along an infinitely thin sheet where $Z$ takes on its stoichiometric value as determined by the solution of the transport equation for $Z$. 
The radiative heat transfer is computed by solving the radiation transport equation (RTE) for a non-scattering grey gas using a Finite Volume Method (FVM) on the same grid as the flow solver. Solving the RTE over all wavelengths is computationally expensive; therefore, the radiation spectrum is divided into small bands. However, in most large-scale fires, soot is the most important combustion product controlling the thermal radiation. The gas can be described as a gray medium, such that the radiation spectrum of soot is continuous, reducing the number of spectral bands to a single band. The absorption coefficients are calculated using a narrow-band model called RadCal [17].To obtain the discretized form of the RTE, the unit sphere is divided into a finite number of the solid angles.

The governing equations are approximated on one or more rectilinear grids that obstructions with complex geometries are approximated with groups of prescribed rectangles in FDS. More and detail description of the mathematical models in FDS can be found in [9].

\section{DESIGN FIRE SCENARIO}

\subsection{Description}

Figure 2 shows the numerical model in FDS for the design fire scenario. The fire source is a $2.0 \mathrm{~m}$ square porous propane burner, which produces steady heat release rate of $1.6 \mathrm{MW}$ for 400 second. The area of the floor is $10 \mathrm{~m} \times 10 \mathrm{~m}=100 \mathrm{~m}^{2}$, and the height of the ceiling is $5 \mathrm{~m}$. The fire source is located at the centre of the floor. The design fire scenario can represent the small news agents or small shop fires in large enclosure [18].

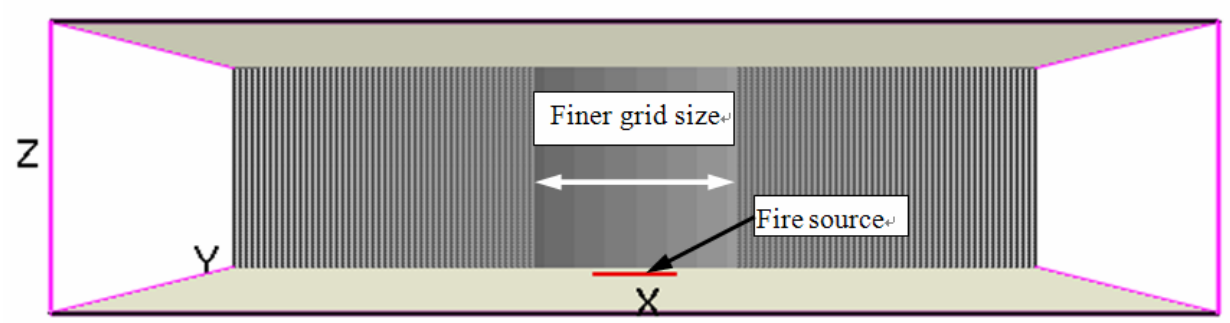

Figure 2. Numerical Model for the Design Fire Scenario

\subsection{Grid Sizes}

The grid sizes used is one of the most important numerical parameter in CFD dictating its numerical accuracy. The necessary spatial resolution for a proper LES simulation is customary defined in terms of the characteristic diameter of a plume, which is defined as [9],

$D^{*}=\left(\frac{\dot{Q}}{\rho_{\infty} c_{p} T_{\infty} \sqrt{g}}\right)^{2 / 5}$

The special resolution $R^{*}$ of a numerical grid is defined as,

$R^{*}=\frac{\delta x}{D^{*}}$ 
where $\delta x$ is the characteristic length of a cell for a given grid. The necessary resolution suggested in most studies is between 1/5 and 1/20 [9]. Ma and Quintiere [13] suggested resolution of 1/20 to successfully predict the flame height. Resolution between $1 / 10$ and $1 / 15$ were chosen by Gutierrez-Montes et al. [19] to successfully model atrium fires. Lin et al. [20] suggested $R^{*}=1 / 13$ is enough for CFD simulations to resolve the fire characteristics (flame height and thermal radiation).

For the design fire scenario, both coarse and fine grid sizes are used. For the coarse case, uniform grid size of $0.1 \mathrm{~m}\left(R^{*}=1 / 10\right)$ in XYZ directions are used, and the computation domain is consisted of 2,000,000 control volumes. For the fine case, near the fire source the grids at XY directions are stretched to provide smaller grid size of $R^{*}=1 / 20$.

\subsection{Results}

Figure 3 gives the 3D contour view of the distribution of gas temperatures in simulation. Figure 4 shows the distribution of gas temperatures at $X=0$. Figure 5 shows the comparison of the results for maximum plume center line temperatures predicted by correlations and FDS. Above the flame height calculated by Eq. 9, the gas temperatures predicted by FDS are higher than those by correlations; and below, the gas temperatures predicted by FDS are lower than those by correlations. The numerical results predicted by using fine grid sizes fit close to the results predicted by correlations. Figure 6 shows the comparison of the results for maximum ceiling jet temperatures predicted by correlations and FDS. The numerical results predicted by using fine grid size fit close to those predicted by Alpert's correlations.

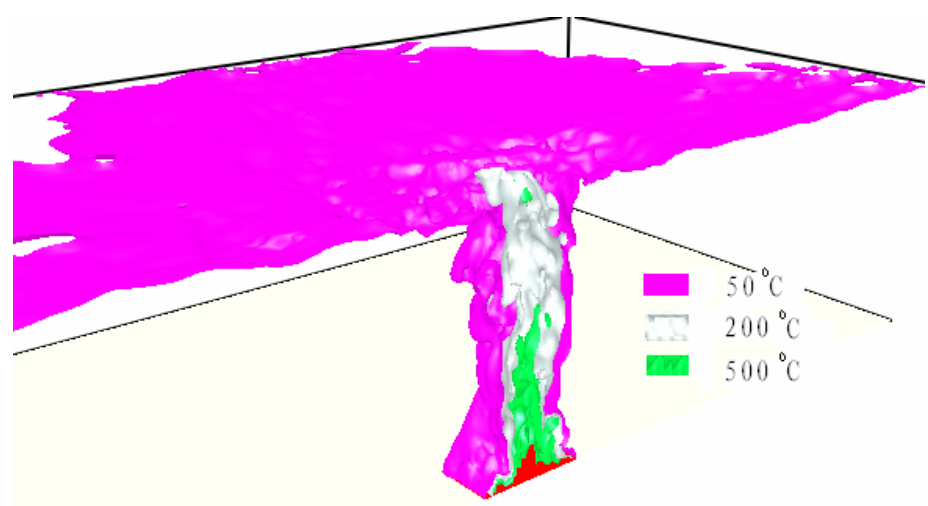

Figure 3. 3D Contour View of the Distribution of Gas Temperatures in the Design Fire Scenario

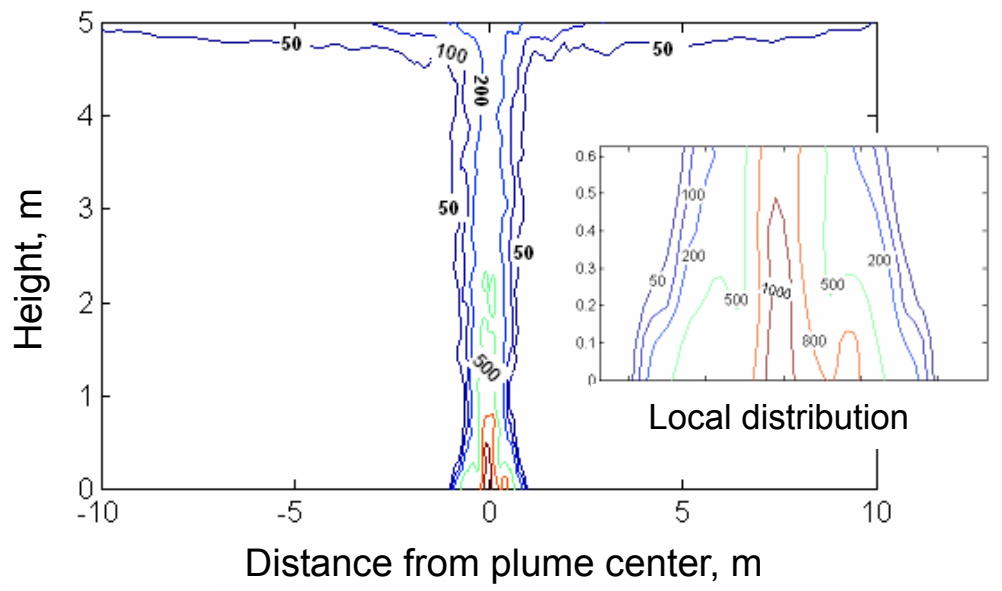

Figure 4. Numerical Results for the Distribution of Gas Temperatures in the Design Fire Scenario 


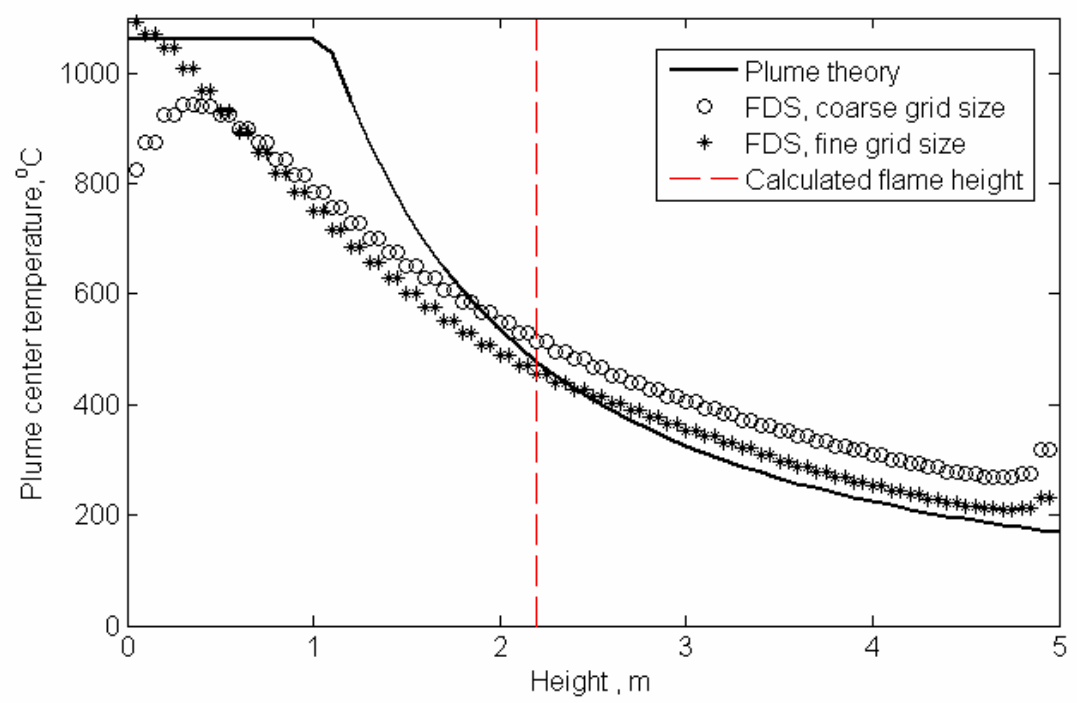

Figure 5. Results for Maximum Fire Plume Central Line Temperatures for the Design Fire Scenario

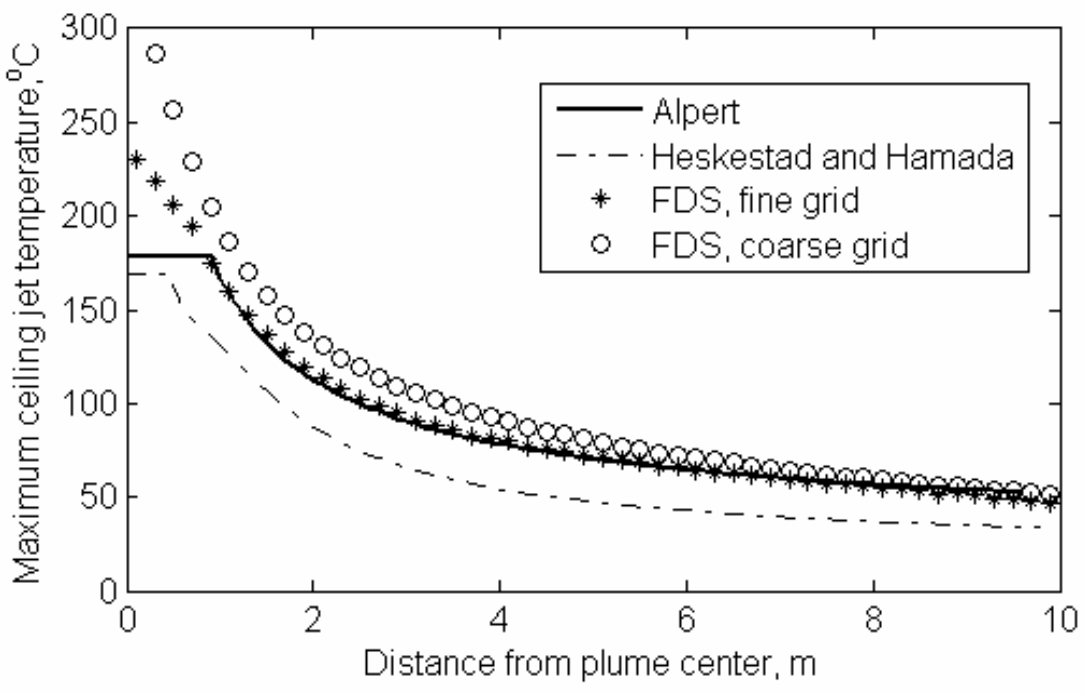

Figure 6. Results for Maximum Ceiling Jet Temperatures for the Design Fire Scenario

\section{SURROUNDING FIRE TETS}

\subsection{Description of the Experiment}

In Kamikawa et al.'s surrounding fire tests [7], a $2.50 \mathrm{~m}$ tall, $0.15 \mathrm{~m}$ square and $4.5 \mathrm{~mm}$ thick steel column were prepared as the specimen, as illustrated in Figure 7 . Eight $0.15 \mathrm{~m}$ square porous burners with propane as the fuel were placed around the $0.15 \mathrm{~m}$ square column to make a $0.45 \mathrm{~m}$ square burner-column complex. The total heat release rate (HRR) was controlled by fuel supply rate to range from 40.5 to $162 \mathrm{~kW}$. Heat fluxes to the column surfaces were measured by $15 \mathrm{~mm}$ diameter Schmidt-Boelter heat flux gauges and temperatures of the column surfaces were measured by K-type thermocouples. 


\subsection{FDS Model}

Figure 7 shows the geometry of the numerical model and calculation mesh used in FDS simulation. The computational domain has dimensions of $0.6 \mathrm{~m}(\mathrm{x}) \times 0.6 \mathrm{~m}(\mathrm{y}) \times 2.4 \mathrm{~m}(\mathrm{z})$. The grids in all directions are uniform. For the burner area, the heat release rate per unit area (HRRPUA) was specified to generate the same HRR as in the experiments. OPEN vents were used on the exterior mesh boundaries to represent opening conditions in the experiments [7]. Thermal properties of the steel were taken from [21]. The default emissivity of solid surfaces (0.9) was used.
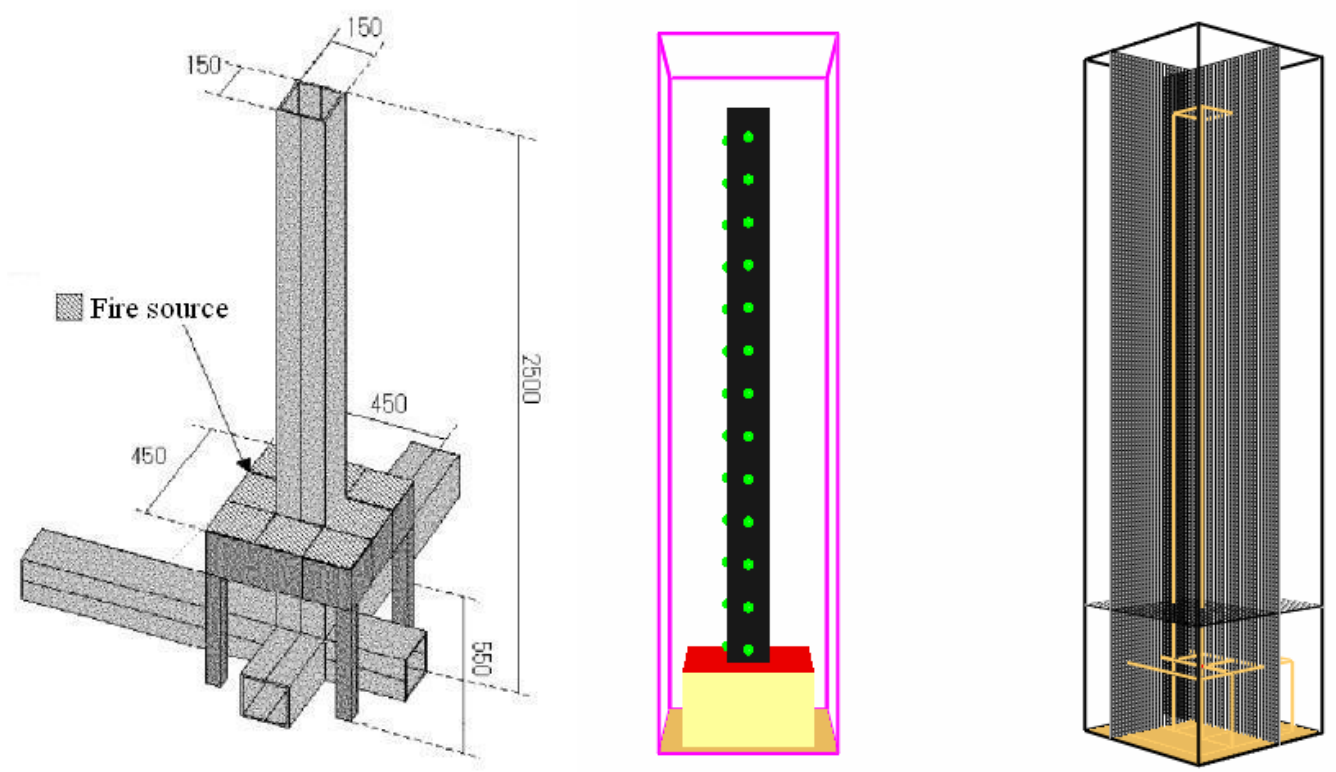

Figure 7. Experimental Setup in [7], the Corresponding Numerical Model and Calculation Mesh used in FDS Simulation

\subsection{Sensitivity Studies}

\subsubsection{Grid sizes}

Figure 8 shows the results of predicted heat fluxes using different resolution $R^{*}$, for $40.5 \mathrm{~kW}$ fire test. The height $z$ is the vertical distance from the measuring point to the burner surface. Resolutions ranged from 1/8.9 to $1 / 35.6$ are considered. It shows the predicted results using $R^{*}=1 / 8.9$ to $1 / 16.0$ are similar, also for $R^{*}=1 / 17.8$ to $1 / 28.6$. The predicted results using resolution of about $1 / 32.0$ fit very well with the test data.

Figure 9 shows the results of predicted heat fluxes using different resolution $R$, for $81 \mathrm{~kW}$ fire test. Resolutions ranged from 1/8.8 to $1 / 29.3$ are considered. It shows the predicted results using $R^{*}=1 / 11.7$ to $1 / 14.7$ are similar, also for $R^{*}=1 / 17.6$ to $1 / 21.1$, and $R^{*}=1 / 23.5$ to $1 / 29.3$. The predicted results using $R^{*}=1 / 23.5$ to $1 / 29.3$ fit very well with the test data.

Figure 10 shows the results of predicted heat fluxes using different resolution $R^{*}$, for $121.5 \mathrm{~kW}$ fire test. Resolutions ranged from $1 / 13.8$ to $1 / 31.1$ are considered. The predicted results using resolution of about $1 / 27.6$ fit well with the test data.

Figure 11 shows the results of predicted heat fluxes using different resolution $R^{*}$, for $162 \mathrm{~kW}$ fire test. Resolutions ranged from 1/19.4 to $1 / 34.8$ are considered. It shows the predicted results using $R^{*}=1 / 23.2$ to $1 / 34.8$ are similar. The predicted results using resolution using $R^{*}=1 / 23.2$ to $1 / 34.8$ fit well with the test data. 


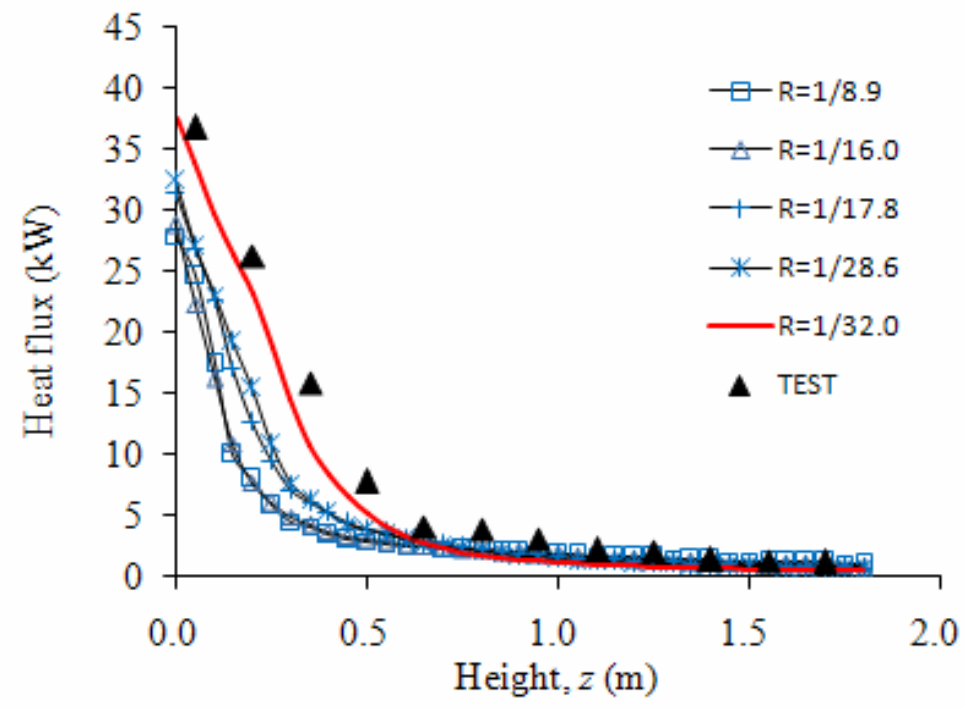

Figure 8. Results of Predicted Heat Fluxes Using Different R*, 40.5 kW

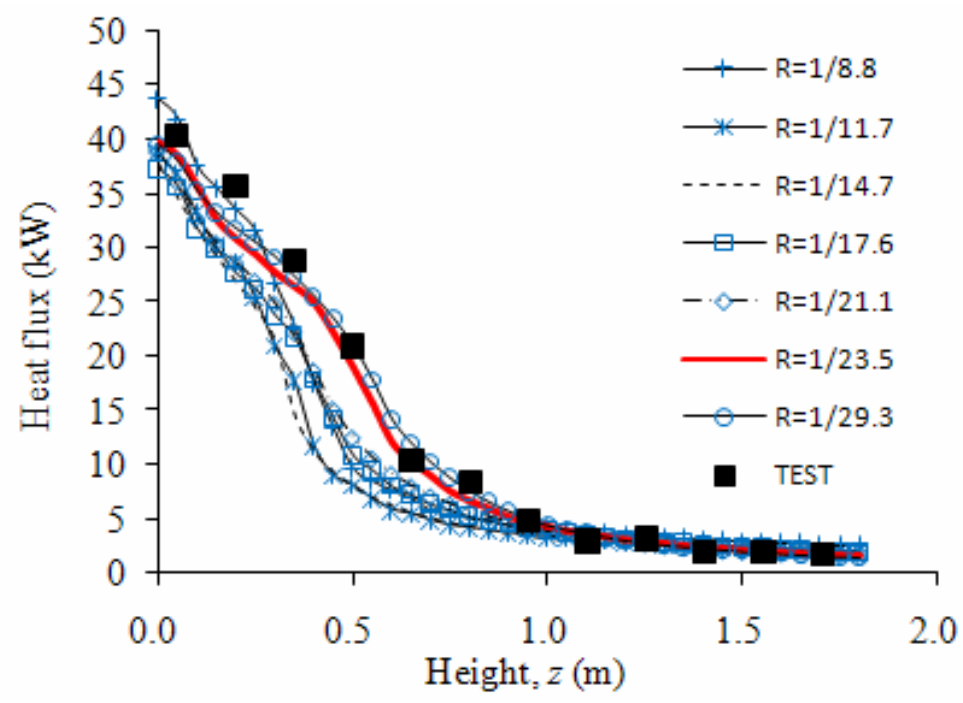

Figure 9. Results of Predicted Heat Fluxes Using Different R*, $81 \mathrm{~kW}$

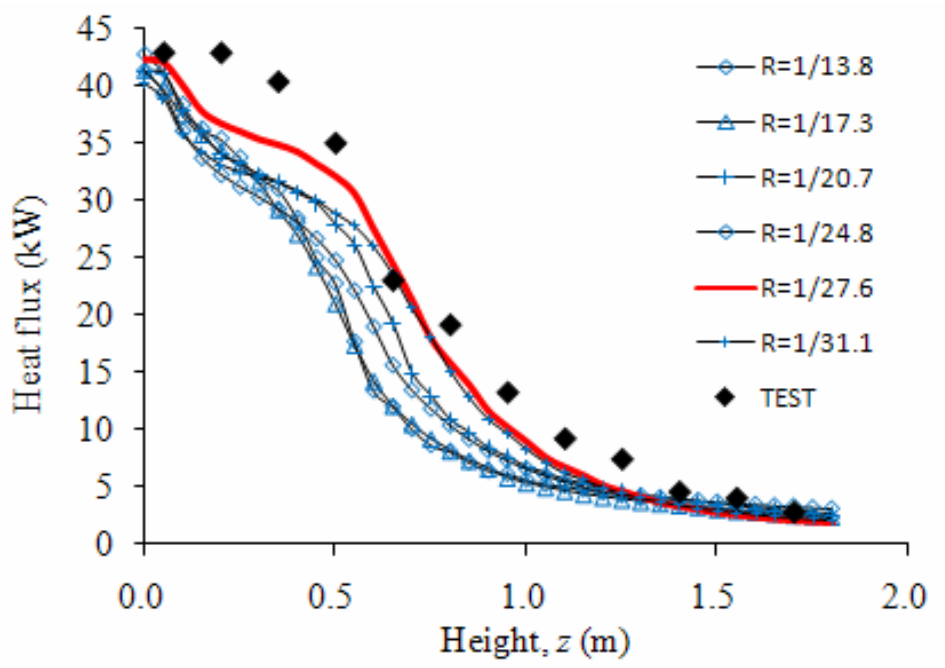

Figure 10. Results of Predicted Heat Fluxes Using Different R*, 121.5 kW 


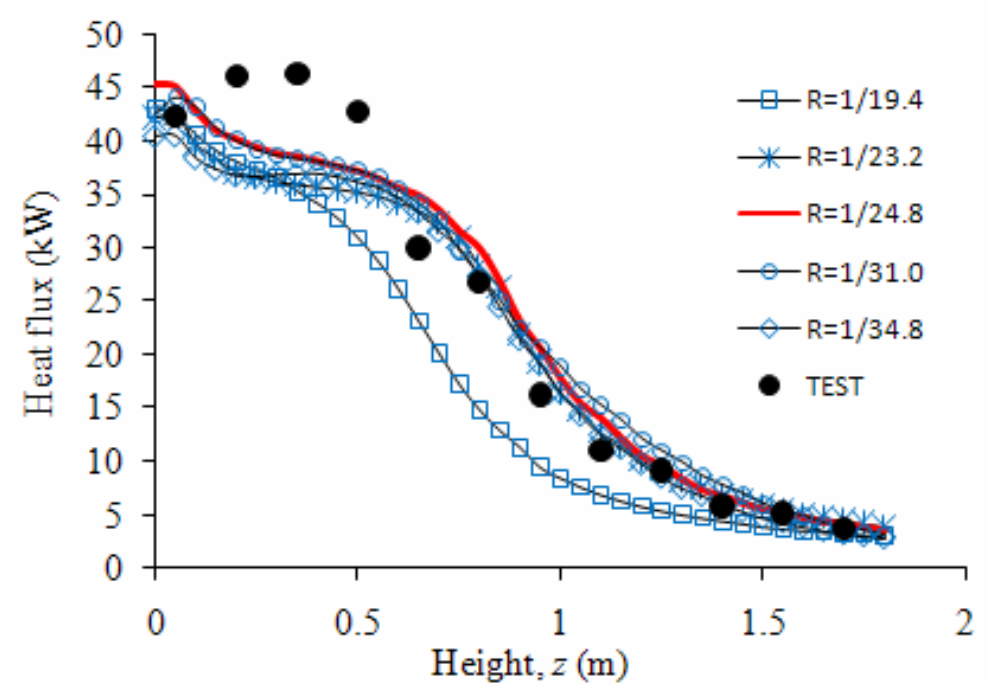

Figure 11. Results of Predicted Heat Fluxes Using Different R*, 162 kW

For all cases, using resolution of about $1 / 30$ can give good prediction of heat fluxes. Table 1 gives the grid sizes used in the following simulations.

Table 1. Simulation Inputs

\begin{tabular}{ccccccc}
\hline$H R R(\mathrm{~kW})$ & $D^{*}$ & Grid number & $\delta x$ & $R^{*}$ & $N S A$ & $\chi_{r}$ \\
\hline 40.5 & 0.2668 & $72 \times 72 \times 288$ & 0.0083 & $1 / 32.0$ & 300 & 0.35 \\
81 & 0.3521 & $40 \times 40 \times 160$ & 0.0150 & $1 / 23.5$ & 300 & 0.35 \\
121.5 & 0.4141 & $40 \times 40 \times 160$ & 0.0150 & $1 / 27.6$ & 300 & 0.35 \\
162 & 0.4646 & $32 \times 32 \times 128$ & 0.0188 & $1 / 24.8$ & 300 & 0.35 \\
\hline
\end{tabular}

\subsubsection{Number of solid angles}

Number of solid angles (NSA) is very significant for the accurate prediction of the radiative heat fluxes [22]. 104 solid angles is default in FDS. In Ref. [23], 304 solid angles were used for radiation solver to ensure accuracy of the FVM solution. Lin et al. [20] suggested 500 solid angles (when using gray model to solve RTEs ) are enough to predict the radiative heat fluxes emitted from the burners.

Figure 12 shows the distribution of predicted heat fluxes using different NSAs. It shows the numerical results are not sensitive to NSA, whilst using more solid angles needs more computing times. As a result, 300 solid angles is used in the simulations, as given in Table 1.

\subsection{Results and Discussions}

For HRRs of $40.5 \mathrm{~kW}$ and $81 \mathrm{~kW}$, the predicted heat fluxes agree very well with the test data. For HRRs of $121.5 \mathrm{~kW}$ and $162 \mathrm{~kW}$, overall the predicted heat fluxes agree very well with the test data, whereas at low elevation the predicted results divergence slightly to the test data.

Figures 12 and 13 show the comparisons between the predicted surface temperatures and the test data. For HRR of $81 \mathrm{~kW}$, the predicted surface temperatures agree very well with the test data. For HRR of $40.5 \mathrm{~kW}$, the predicted surface temperatures agree well with the test data. For HRRs of $121.5 \mathrm{~kW}$ and $162 \mathrm{~kW}$, overall the predicted temperatures agree very well with the test data, whereas at low elevation the predicted results divergence slightly to the test data. 


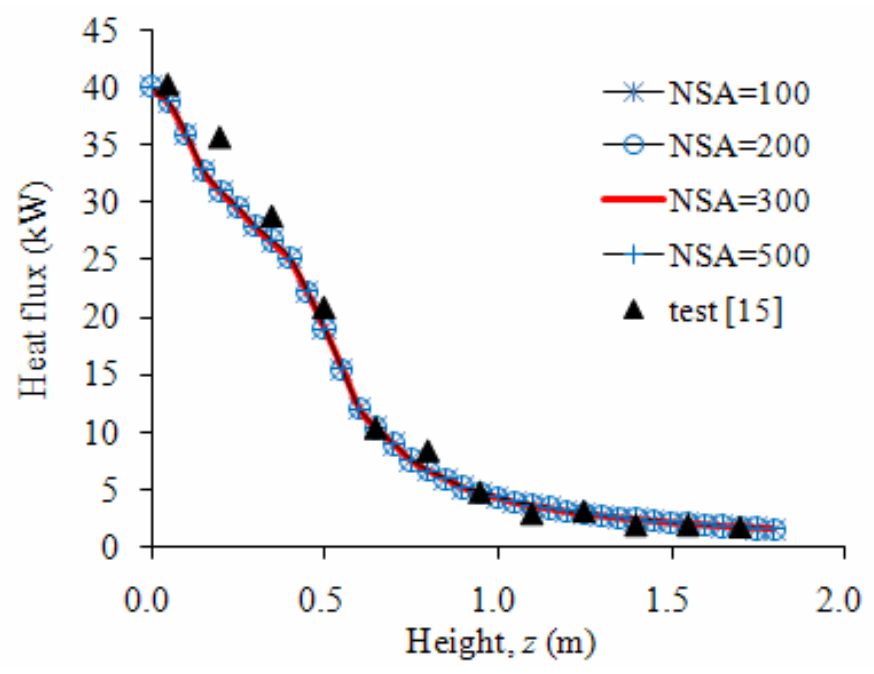

Figure 12. Distribution of Predicted Heat Fluxes Using Different NSAs

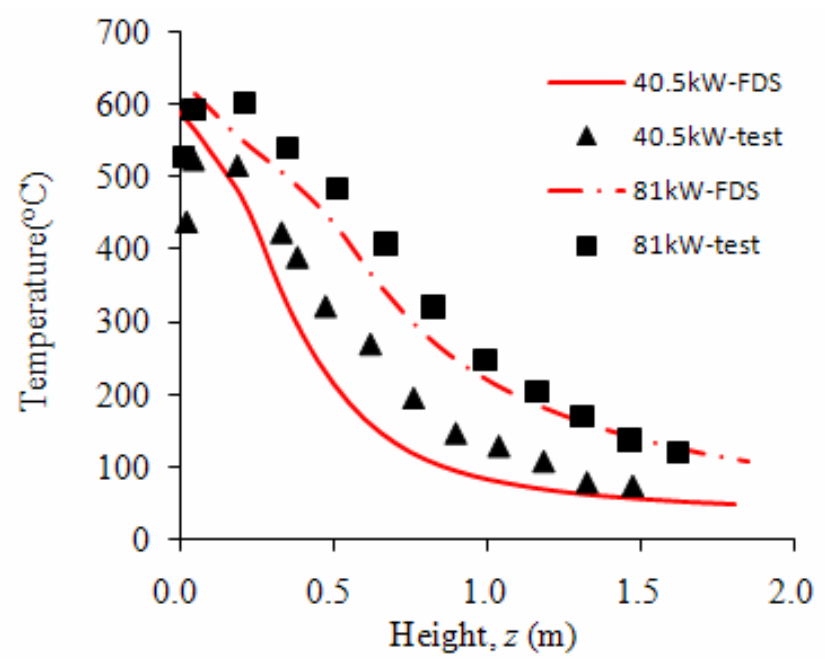

Figure 13. Comparisons of Predicted Surface Temperature with the Test Data for HRRs of $40.5 \mathrm{~kW}$ and $81 \mathrm{~kW}$

Those differences between the predicted and measured results could be mainly attributed to the accuracy of the sub-models in FDS. It is well known that the accuracy of combustion and radiation models has a paramount effect on the heat flux prediction. Although FDS provides a reliable flow solver, the mixture fraction combustion model could yield errors at large as 20 percent as suggested by the code developer [9] and the radiation model cannot solve accurately the radiation equation with grid sizes on the order of centimeter due to the fourth power dependence of radiation on temperature.

\section{CONCLUSIONS}

The application of using the popular CFD code FDS to predict the thermal actions in localized fires has been investigated. Based on the results of this study, the following conclusions can be drawn:

- The CFD code FDS can simulate the thermal actions in localized fires with acceptable accuracy. The predicted gas temperatures in the design fire scenario agree with those predicted by correlations; and the predicted heat fluxes and steel temperatures in the surrounding fire tests fit well with the test data. 
- The grid size used is the most important input parameter affecting the numerical results. Comparing with correlations, simulation using fine grid gives better prediction of gas temperatures than simulation using coarse grid. Resolution of 1/20 can give good prediction of gas temperatures in localized fires. For surrounding fire tests, sensitivity studies shows that resolutions of $1 / 32,1 / 23.5,1 / 27.6$ and $1 / 24.8$ give best prediction of the heat fluxes for HRRs of $40.5 \mathrm{~kW}, 81 \mathrm{~kW}, 121.5 \mathrm{~kW}$ and $162 \mathrm{~kW}$ respectively (whilst using resolution of about 1/30 give acceptable prediction of heat fluxes for all cases). Those resolutions are finer than the expected values from literature (1/20 [13], 1 /13 [20]). As a result, it is recommended that the user should take special care of the grid size and sensitivity studies should be always conducted when performing simulations.

- The number of solid angels has negligible effect on the numerical results.

\section{REFERENCES}

[1] Drysdale, D., “An Introduction to Fire Dynamics”, 2nd Edition, John Wiley and Sons, 1999.

[2] Li, G.Q. and Zhang, C., "Thermal Response to Fire of Uniformly Insulated Steel Members : Background and Verification of the Formulation Recommened by Chinese Code CECS200", Advanced Steel Construction, 2010, Vol. 6, pp. 788-802.

[3] Zhang, C., Li, G.Q. and Wang, Y.C., "Sensitivity Study on Using Different Formulae for Calculating the Temperature of Insulated Steel Members in Natural Fires”, Fire Technology, 20120, Vol. 48, pp.343-66.

[4] Li, G.Q. and Zhang, C., "Simple approach for calculating maximum temperature of insulated steel members in natural-fires", Journal of Constructional Steel Research, 2012, Vol.71, pp. 104-10.

[5] EN 1991-1-2, Eurocode 1: Actions on Structures - Part 1-2: General Rules - Actions on Structures Exposed to Fire, British Standard Institution, London, 2002.

[6] Brian, Y. Lattimer, "Heat Fluxes from Fires to Surfaces", SFPE Handbook 3rd Edition, Sec. 2-14, National Fire Protection Association, 2003.

[7] Kamikawa, D., Hasemi, Y., Wakamatu, T. and Kagiya, K., "Experimental Flame Heat Transfer and Surface Temperature Correlations for a Steel Column Adjacent to and Surrounded by a Pool Fire”, Proceedings of IFASS 2002, 2002.

[8] Li, G.Q. and Zhang, C., "Thermal Response of Steel Columns Exposed to Localized Fires Numerical Simulation and Comparison with Experimental Results”, Proceedings of the Sixth International Conference on Structures in Fire, MI, USA, 2010, pp. 35-42.

[9] McGrattan, K., McDermott, R., Hostikka, S. and Floyd, J., "Fire Dynamics Simulator (Version 5) User's Guide”, NIST Special Publication 1019-5, National Institute of Standards and Technology (NIST), Gaithersburg, Maryland; 2010.

[10] Quintiere, J.G., “Fundamentals of Fire Phenomena”, John Wiley \& Sons, Ltd., 2006.

[11] Heskestad, G., "Fire Plumes, Flame Height, and Air Entrainment”, SFPE Handbook 3rd Edition, Sec. 2-1, National Fire Protection Association, 2003.

[12] Quintiere, J.G. and Grove, B.S., “A Unified Analysis for Fire Plumes”, 27 ${ }^{\text {th }}$ Symposium (International) on Combustion”, The Combustion Institute, 1998, pp. 2757-66.

[13] Ma, T.G. and Quintiere, J.G., "Numerical Simulation of Axi-symmetric Fire Plumes: Accuracy and Limitations”, Fire Safety Journal, 2003, Vol. 38, pp. 467-92.

[14] Alpert, R., "Calculation of Response Time of Ceiling-mounted Fire Detectors". Fire Technology, 1972, Vol. 8, pp. 181-95.

[15] PD 7974-2, Application of Fire Safety Engineering Principles to the Design of Buildings Part 2: Spread of Smoke and Toxic Gases within and Beyond the Enclosure of Origin (Sub-system 2), British Standard Institution, London, 2002. 
[16] Heskestad, G. and Hamada, T., "Ceiling Jets of Strong Fire Plumes”, Fire Safety Journal, 1993, Vol. 21, pp. 69-82.

[17] Grosshandler, W.L., "RADCAL: A Narrow-band Model for Radiation Calculations in a Combustion Environment”, National Institute of Standard and Technology, NIST Technical Note 1402, 1993.

[18] Chow, W.K., Li, Y.Z., Cui, E. and Huo, R., "Natural Smoke Filling in Atrium with Liquid Pool Fires Up to 1.6MW”, Building and Environment, 2001, Vol. 36, pp. 121-27.

[19] Gutierrez-Montes, C., Sanmiguel-Rojas, E., Viedma, A. and Rein, G., "Experimental Data and Numerical Modeling of 1.3 and 2.3 MW Fires in a $20 \mathrm{~m}$ Cubic Atrium,” Building and Environment, 2009, Vol. 44, pp. 1827-39.

[20] Lin, C.H., Ferng, Y.M, and Hsu, W.S., "Investigating the Effect of Computational Grid Sizes on the Predicted Characteristics of Thermal Radiation for a Fire", Applied Thermal Engineering, 2009, Vol. 29, pp. 2243-50.

[21] Wakamatsu, T., Hasemi, Y. and Ptchelintsev, A.V., "Heating Mechanism of Building Components Exposed to a Localizedfire: CFD Prediction of the Heat Flux of a Steel Beam”, Fire Science and Technology, 2000, Vol. 20, pp. 1-12.

[22] Jensen, K.A., Ripoll, J-F., Wray, A.A., Joseph, D. and Mouna EI Hafi, “On Various Modeling approaches to Radiative Heat Transfer in Pool Fires”, Combustion and Flame, 2007, Vol. 148, pp. 263-79.

[23] Hostikka, S., McGrattan, K. and Hamins, A., "Numerical Mdeling of Pool Fires Using LES and Finite Volume Method for radiation. Fire Safety Science - Proceedings of the 7th International symposium, pp. 383-94. 


\title{
RESEARCH ON STATIC PROPERTY OF SUSPEN-DOME STRUCTURE UNDER HEAP LOAD
}

\author{
Jiamin Guo ${ }^{1, *}$, Shilin Dong ${ }^{2}$ and Xingfei Yuan ${ }^{2}$ \\ ${ }^{1}$ College of Ocean Environment and Engineering, Shanghai Maritime University, Shanghai 200135, China \\ ${ }^{2}$ Space Structures Research Center, Zhejiang University, Hangzhou 310027, China \\ *(Corresponding author: E-mail: guojiamin@zju.edu.cn)
}

Received: 24 April 2011; Revised: 2 August 2011; Accepted: 11 August 2011

\begin{abstract}
Suspen-dome includes single-layer latticed shell and the lower cable-struts system, its mechanical properties is better than single-layer latticed shell because of the lower cable-struts system. Heap load might appear during construction or active service, especially during construction. To ensure structure be safe during construction and active service, the structural static property under heap load is chief content in this paper. First, a 1:15 reduced scale suspen-dome model according to the actual structure with $122 \mathrm{~m}$ span is made, which includes single-layer latticed shell, lower cable-struts system and supporting system. Then the measured points for stress and displacement are arranged in model according to experimental contents and model characteristics. And, the structural overall stability under heap load and full-span load are studied and compared. Last, heap load, whose value is $80 \mathrm{Kg}$, are loaded on corresponding model node at 5 different times during experiment in order to study structural static properties under heap load. Results show that the theoretical and experimental data are basically in well agreement, internal forces and displacements is basically linear during loading process, and heap load is more important to structure than full-span load, so it is proposed that heap load should be considered during designing and some measures should be applied to avoid heap load come into being during construction and active service.
\end{abstract}

Keywords: Suspen-dome, Scale model, Similar ratio, Pre-stress, Cable-struts, Heap load

\section{INTRODUCTION}

With the increasing demand for spatial structures, some new types of spatial structures are constantly invented. Until recently, the number of spatial structure type has been thirty eight (Dong [1]). Suspen-dome, which was invented by Kawaguchi in Japan [2], is one of thirty eight types. Suspen-dome including single-layer latticed shell and the lower cable-struts system is a hybrid structure between single-layer latticed shell and cable domes (Geiger [3]). The structural overall stability and stiffness of suspen-dome are better than single-layer latticed shell, and construction difficulty and tension to outer supporting system are lower than cable domes. Until recently, some theoretical and experimental research on this structure have been done in China and other countries $[2,4-12]$. More than ten projects adopted suspen-dome have been designed and constructed based on research achievements. In China, suspen-dome is used as the roof structure in the Tianjin business center hall, in the badminton arena for 2008 Olympic games, in the Changzhou stadium and in the stadium of Jinan Olympic center and so on (Chen et al. [12]). At abroad, similar projects are Guangqiu dome and Juhui dome. Reference (Chen eet al. [8]) study structural static and dynamic properties of the roof structure in the Tianjin business center hall through experiment. Reference (Wang et al. [10]) study mechanical properties of Changzhou stadium by 1:10 scale model. Reference (Zhang et al. [11]) study Jinan Olympic stadium. Those experiments of suspen-dome are good for validating theoretical conclusions, and give us intuitive grasp of structural mechanical properties and construction. During practical construction and usage of spatial structure, heap load is likely to appear because of incorrect construction or active service, especially during construction. Until recently, however, there is less study on mechanical properties of suspen-dome under heap load. From published literatures, only Liu [13] studied the collapse of a hub joint steel shell and pointed out that heap load is main reason which causes structure to collapse. Because heap load possibly has adverse effect on structural mechanical properties. At the 
same time, to instruct practical construction and usage correctly, knowing more knowledge about mechanical properties of suspen-dome under heap load is chief content in the paper. First, a 1:15 reduced scale suspen-dome model according to the actual structure with 122 meters span is made and shown in Figure 1-2. The model structural span is 8 meters, and its rise is 0.8 meters, which includes single-layer latticed shell, lower cable-struts system and supporting system. Structural static property under heap load are studied through structural model. Experimental and theoretical results in the paper can be referred by similar practical structure.

\section{DESIGN AND CONSTRUCTION OF EXPERIMENTAL MODEL}

Suspen-dome model is composed of single-layer latticed shell, cable-struts system and supporting system. Cable-struts system includes radial cables, hoop cables and struts. Its composition can be seen in Figure 1. After considering some practical factors, for example, experimental equipments which can be utilized, the area of experimental field and the experimental cost and so on (Fu [14]), the practical structure with 122 meters span is scaled to the model with 8 meters span. Thus, its geometrical similar ratio is equal to about 1:15. The structure model is shown in Figure 2.
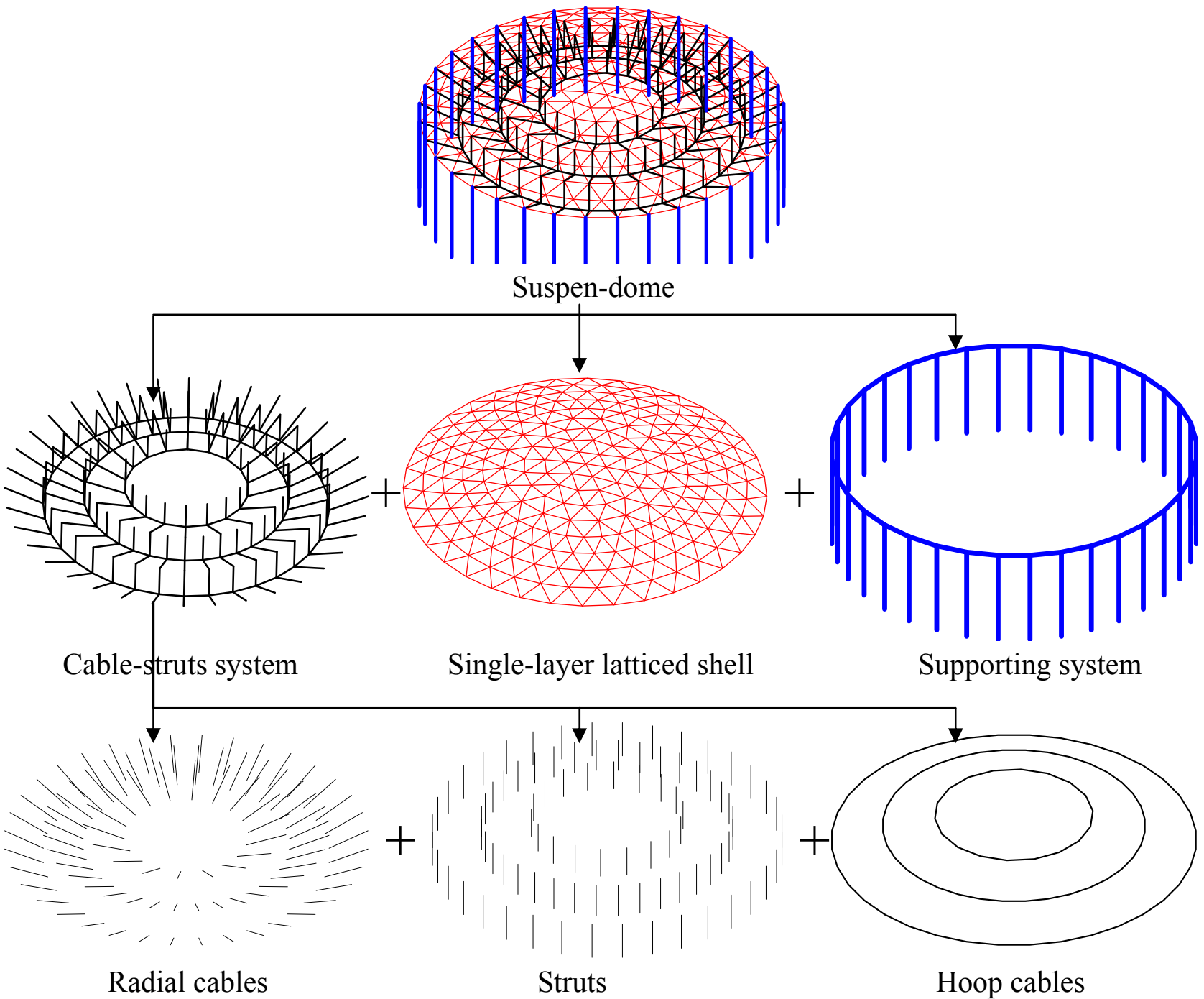

Figure 1. Composition of Suspen-dome 


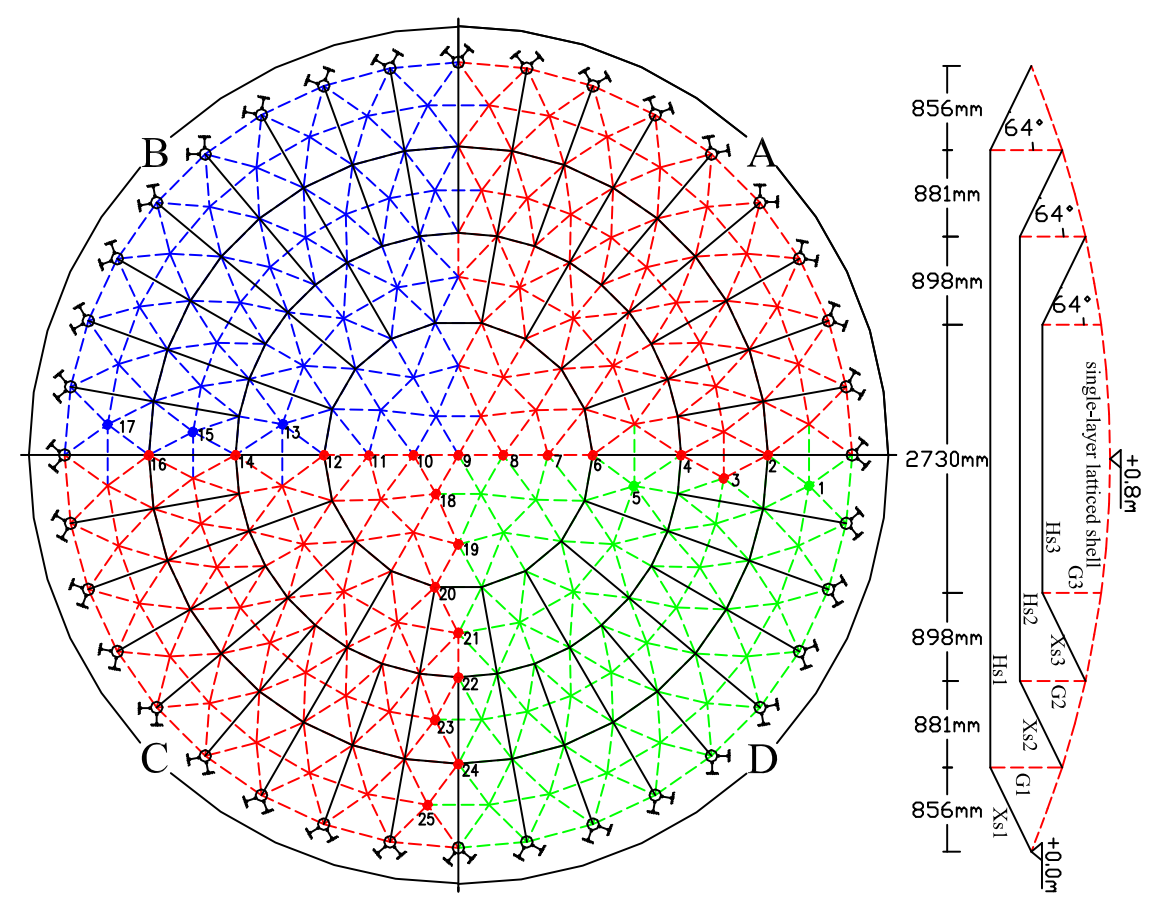

(a) Calculation Model of Suspen-dome

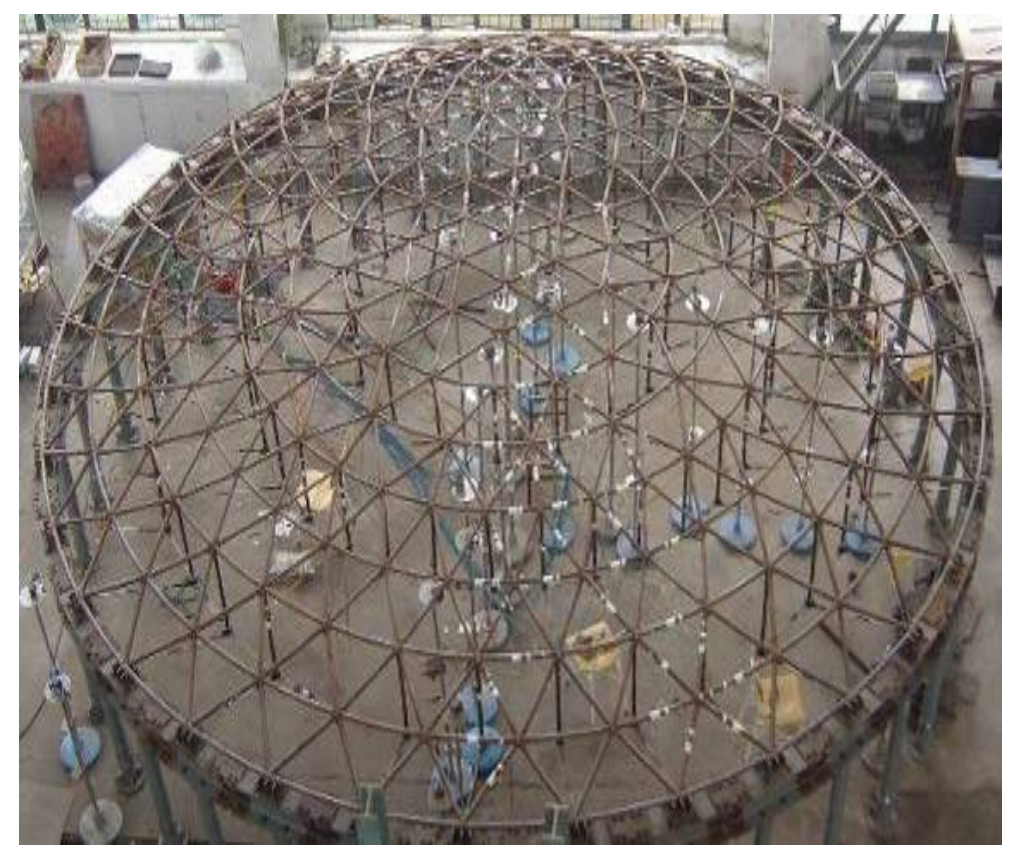

(b) Experimental Model of Suspen-dome

Figure 2. Model of Suspen-dome

\subsection{Design of Supporting System}

From Figure 1-2 we can see that suspen-dome is supported on supporting system. Diameter of supporting system is equal to diameter of upper single-layer latticed shell, whose value is 8 meters. Supporting system is composed of thirty six basic elements which are easy to manufacture, to move and to connect. Basic element, which includes ring beams and pillars, can be reused. Ring beam is welding I-beam, pillar is steel tube whose type is $\Phi 114 \times 6$. Ring beam is connected with plate, which lays on the top of pillar, by four $\Phi 16$ high-strength bolts. There is a circle plate, whose diameter and thickness is respectively $240 \mathrm{~mm}$ and $20 \mathrm{~mm}$, on the bottom of pillar. Because floor is 
at different levels, a tunable socket is utilized in pillars in order to avoid pillars suspend. In order to strength ring beam stiffness of supporting system, one welding I-beam connects with another by steel plate in top and seat flange and by steel plate in inner and outer web. Connection of basic elements is shown in Figure 3.

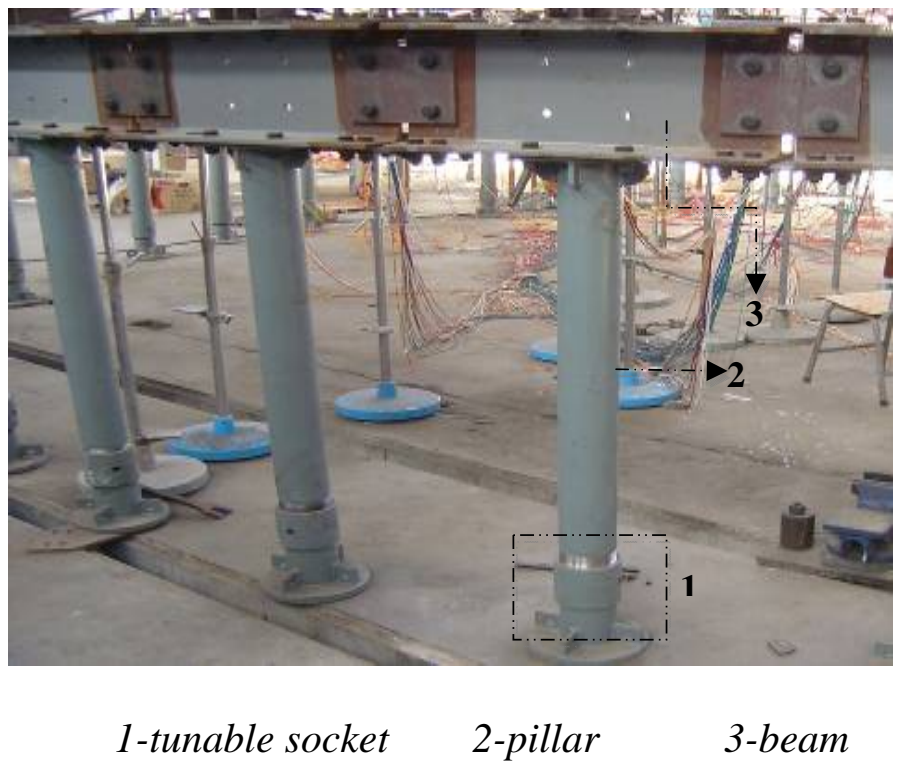

Figure 3. Connection of Basic Elements

\subsection{Design of Single-Layer Latticed Shell}

Geometrical similar ratio, which can be denoted as $c_{l}$, is $1: 15$, nodal coordinate and fabrication length of elements are calculated according to the above similar ratio and practical structural drawings. So model span is set as 8 meters and its rise is 0.8 meters. When the mid-span node in single-layer latticed shell is selected as reference origin of coordinates, the model nodal coordinates scaled by $c_{l}$ are shown in Figure 4. Elements in single-layer latticed shell are entirely objected to axial force[15], so the paper scales the model bar section according to axial stress consistent principle. Load similar ratio $\left(C_{q}\right)$ is determined by experimental loading equipments, loading way and loading value and so on. After considering above influence factors, the value of $c_{q}$ is set as 2 during design experiment model. The relation among geometrical similar ratio, load similar ratio and structural sectional similar ratio can be summarized as the following Eq. 1. Structural sectional similar ratio $\left(c_{A}\right)$ can be calculated by the following equation (1). When $c_{l}$ is $1: 15, c_{q}$ is equal to 2 , structural sectional similar ratio $\left(c_{A}\right)$ is 0.0086 .

$c_{A}=\left(c_{l}\right)^{2} \cdot c_{q}$

First, practical section area is theoretically scaled to model section by the structural sectional similar ratio described above. Then, production type of market supply, purchase cycle of production, manufacture craft and influence of element section area on structural mechanical property [15] are considered. Last, sectional area in single-layer latticed shell is shown in Figure 5, where 1 stands for $\Phi 30 \times 1.5$ and 2 stands for $\Phi 35 \times 1.5$. Model sectional types selected are shown in table 1 . 


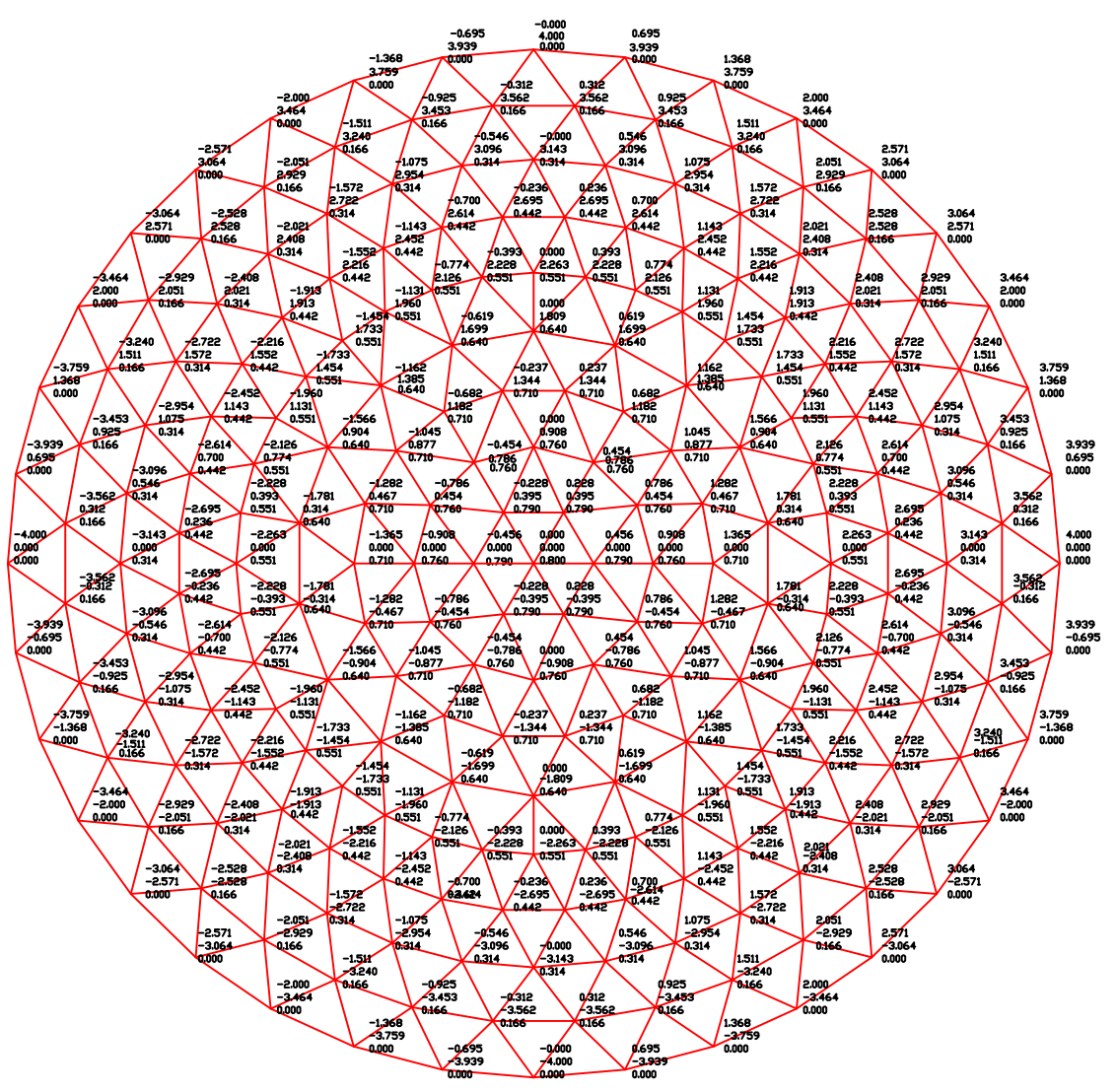

Figure 4. Nodal Coordinates of Single-layer Latticed Shell

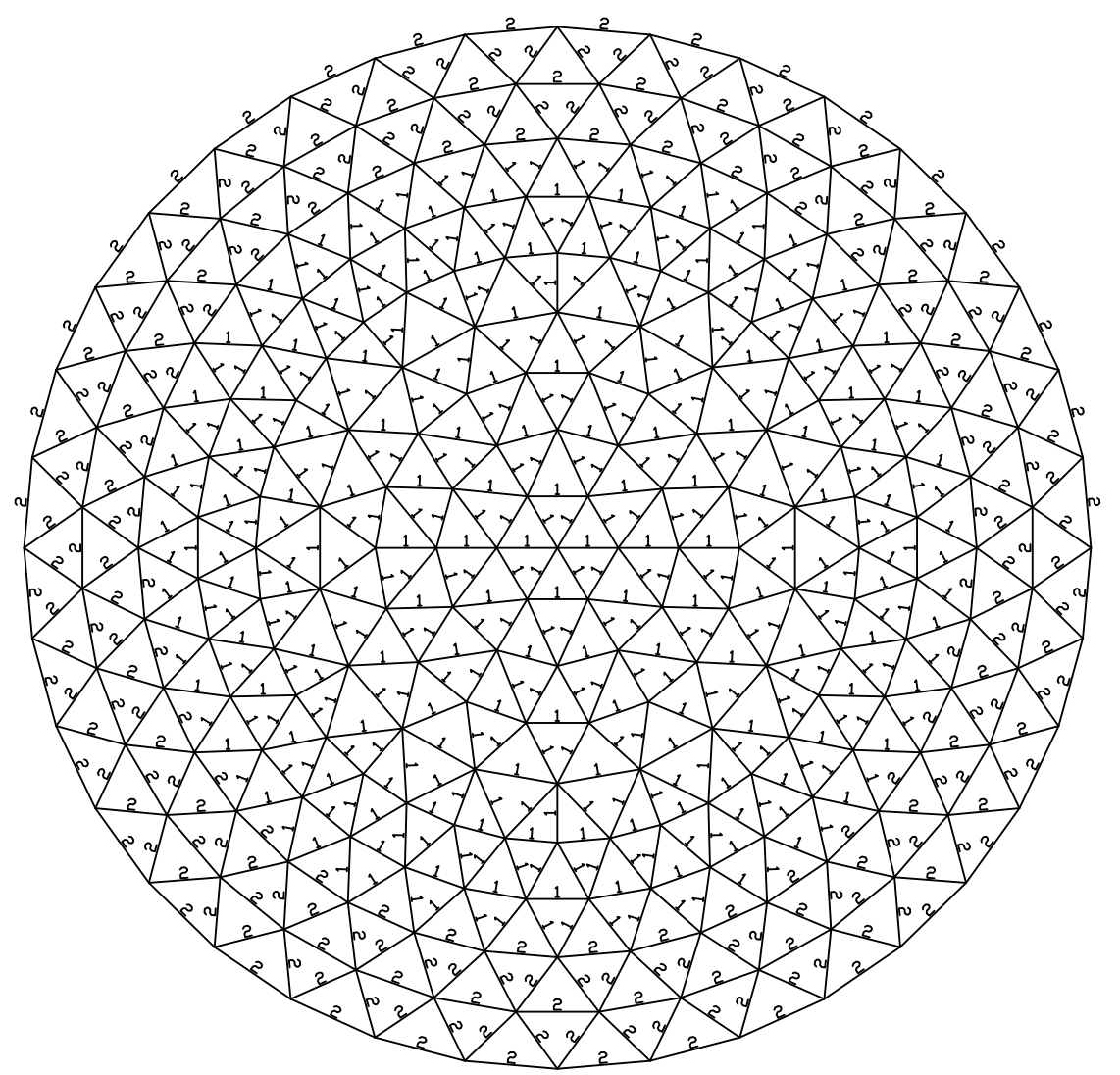

Figure 5. Distribution of Sectional Type in Single-layer Latticed Shell 
Table 1. Sectional Type of Practical Structure and Model Structure

\begin{tabular}{ccc||ccc}
\hline Member & Practical structure & Model structure & Member & Practical structure & Model structure \\
\hline Xs1 & $\Phi 85$ & $\Phi 8$ & 1 & $\Phi 377 \times 14$ & $\Phi 30 \times 1.5$ \\
Xs2 & $\Phi 55$ & $\Phi 5$ & & & \\
Xs3 & $\Phi 45$ & $\Phi 5$ & 2 & $\Phi 377 \times 16$ & $\Phi 35 \times 1.5$ \\
Hs1 & $2 \Phi 5 \times 199$ & $2 \Phi 8$ & G1 & $\Phi 299 \times 10$ & $\Phi 30 \times 1.5$ \\
Hs2 & $\Phi 5 \times 165$ & $\Phi 8$ & G2 & $\Phi 245 \times 6.5$ & $\Phi 30 \times 1.5$ \\
Hs3 & $\Phi 5 \times 55$ & $\Phi 6$ & G3 & $\Phi 219 \times 6$ & $\Phi 30 \times 1.5$ \\
\hline
\end{tabular}

\subsection{Design of Cable-Struts System}

Cable-struts system of structure model includes 90 radial cables, 90 struts and 12 hoop cables. Though hoop cable is theoretically continuous, for easy of manufacture and tension, each hoop cable is divided into four parts, total number of hoop cable is 12 parts. Struts, radial cables and hoop cables are shown in Figure 6. From Figure 6, we can see the length of each element can be controlled by a tunable socket. Hoop cables are made of $\Phi 8$ and $\Phi 6$ type wire rope, the effective sectional area and elasticity modulus of wire rope are respectively unknown to us, the product of effective sectional area and elasticity modulus, however, can be checked by electronic tensile tester, so the product of effective sectional area and elasticity modulus is used for sectional rigid during calculation. The sectional rigid of $\Phi 8$ and $\Phi 6$ type wire rope from checking are $2213095 \mathrm{~N}$ and $1311274 \mathrm{~N}$, respectively. Radial cables are made of stainless steel bars, struts are made of circle steel tube. Tunable socket in struts, radial cables and hoop cables can be turned to add pre-stress to overall structure. A standard measured part, on which strain gauges can be arranged, is installed in radial cables and hoop cables. The sectional type of cable-struts can also be seen in Table 1 .

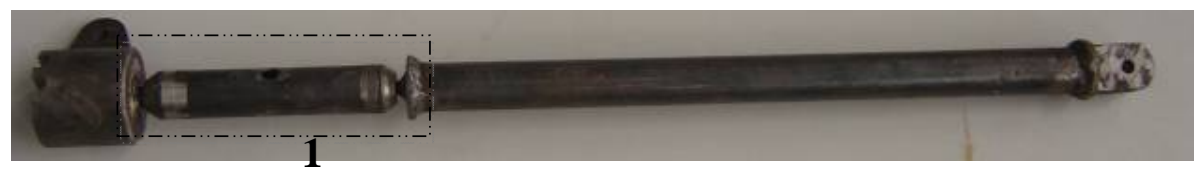

(a) Struts

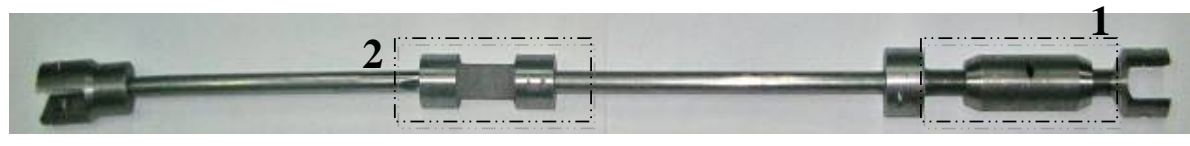

(b) Radial cables

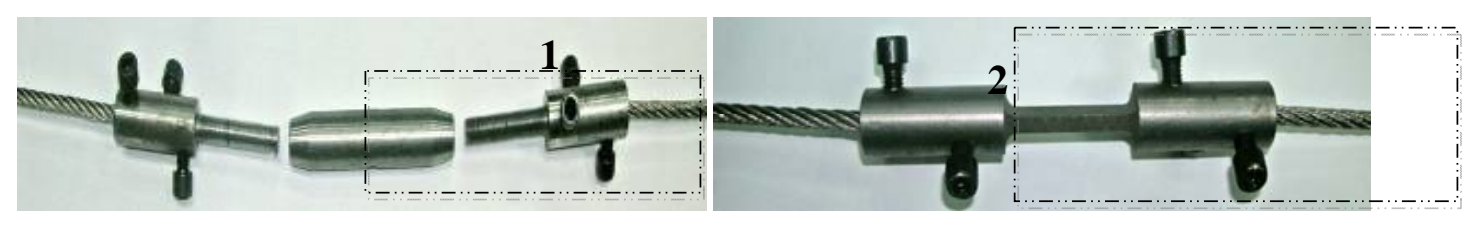

(c) Hoop cables

1-tunable socket

2-standard measured part

Figure 6. Cable-struts 


\subsection{Design of Nodes}

There are 3 types of nodes in model structure. They are upper single-layer latticed shell node, supporting node and cable-struts node. The principle instructing node design is easy to manufacture on the based that the structure is safe. Nodes in single-layer latticed shell adopts tubular joint with simple strength plate, which is simpler than practical node, node in mid-span of single-layer latticed shell is shown in Figure 7. Supporting node, which is shown in Figure 8, is also simpler than practical node. Supporting node connects with elements in single-layer latticed shell by welding. The lower cable-struts node, through which a continuous hoop cable goes, is shown in Figure 9. The node connected by radial cables, struts and hoop cables is shown in Figure 10.

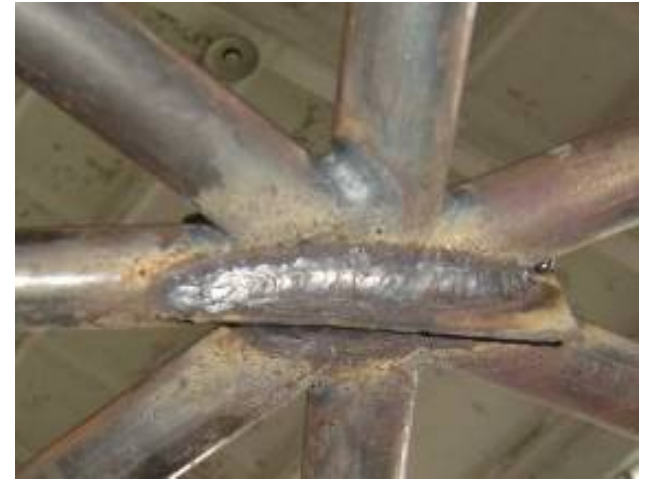

Figure 7. Node in Single-layer Latticed Shell

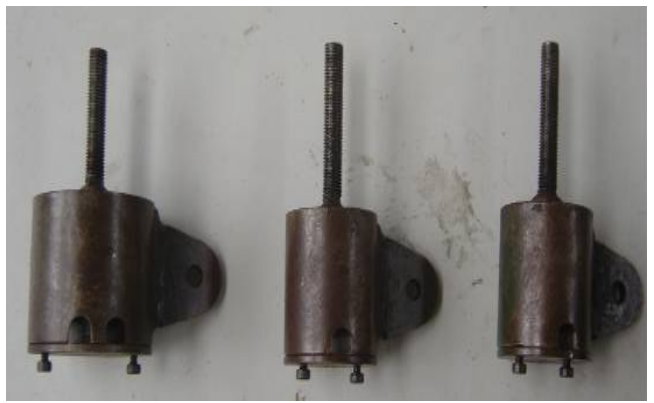

Figure 9. Node of Struts

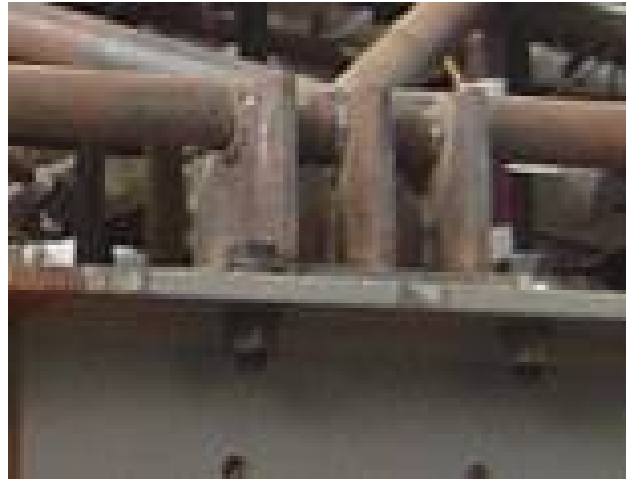

Figure 8. Supporting Node

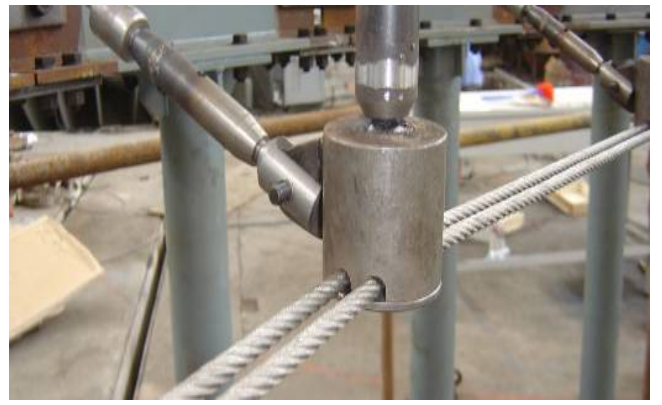

Figure 10. Node Connection

\section{ARRANGEMENT OF EXPERIMENTAL MEASURED POINTS}

During experiment, some element inner force and nodal displacement will be measured in order to estimate structural mechanical properties under heap load. Inner force of structural elements are measured by DH3815N type static resistance strain measurers, the type of strain gage used during experiment is $3 X 5 \mathrm{~mm}$. Structural nodal displacement are measured by dial indicator. To avoid eccentricity of element cause measure errors, two strain gages are arranged in middle of elements, and they are symmetry and parallel to element axial line, two strain gages are in series.

After considering some factors which include measurement content, measurement equipment and structural symmetry and so on, 90 strain points are selected in single-layer latticed shell. For easy of tension control, cables and struts laid in a quarter area of the lower cable-struts system are all arranged by measured points, one third of cables and struts laid in other 3 quarter area of bottom cable-struts system are arranged by measured points. The total number of measured points for strain selected in cable-struts system is 102, 12 measured points lay in hoop cables, 45 measured points lay in radial cables, 45 measured points lay in struts. The number of measured points for displacement is 25 , in which 17 dial indicators lay in the same line, other 8 dial indicators lay in 
another line, which is right to above line. All strain measured points are shown in Figure 11 and displacement measured points are shown in Figure 2.

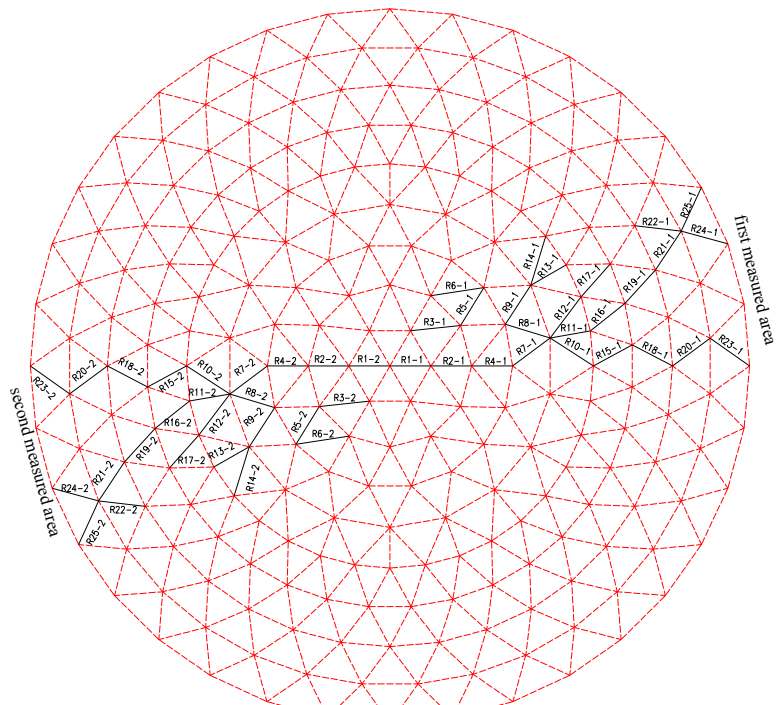

(a)Radial elements

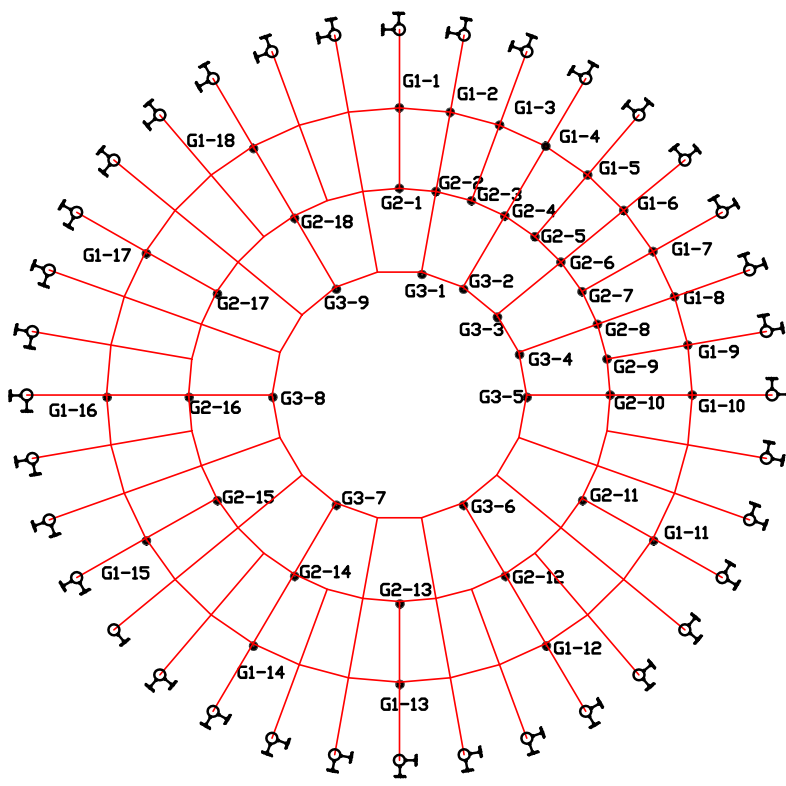

(c) Struts

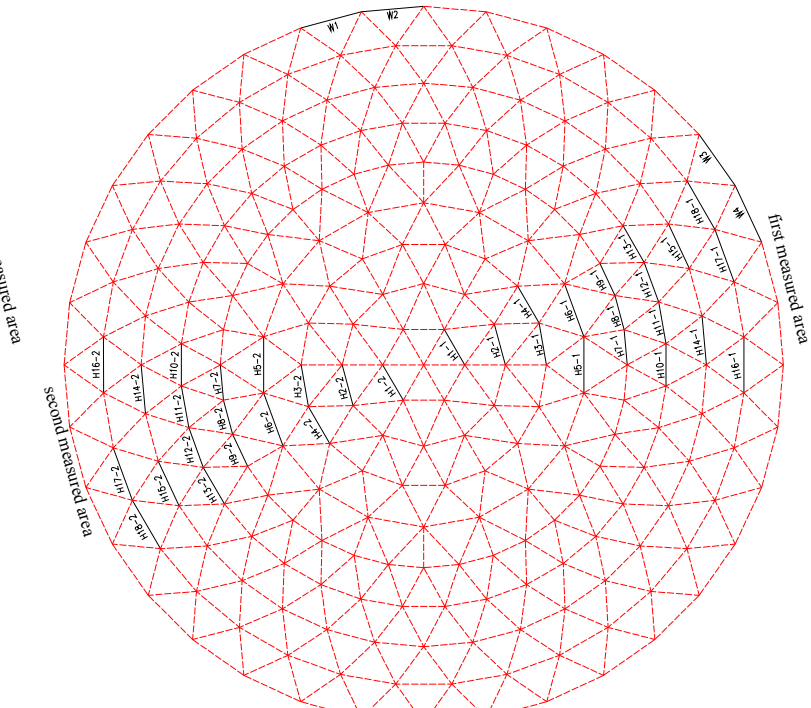

(b) Hoop elements

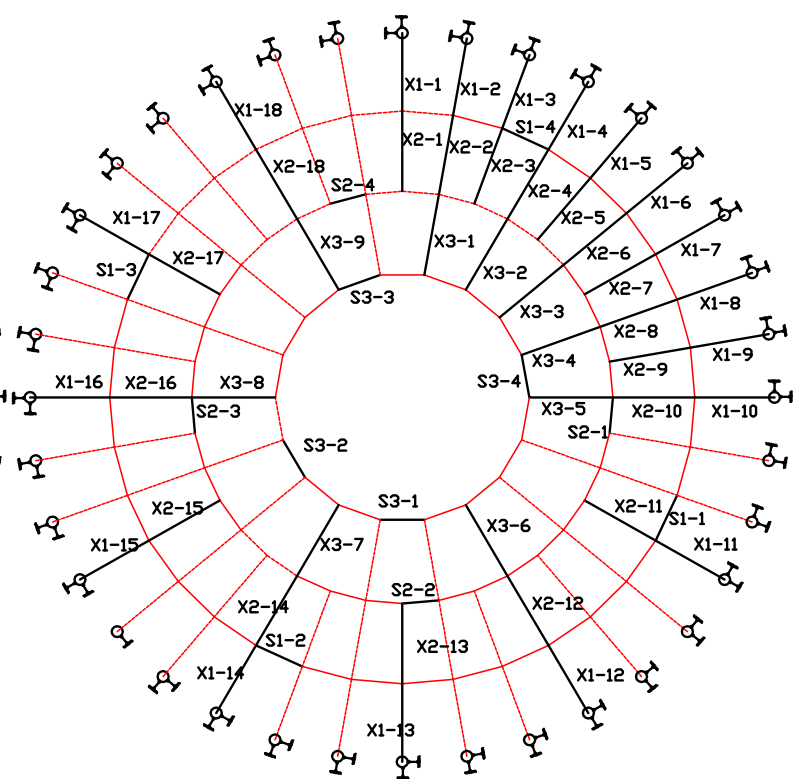

(d) Hoop cable elements and radial cable elements

Figure 11. Arrangement Plan for Stress Measured Points

\section{THEORETICAL AND EXPERIMENTAL RESEARCH ON MODEL STRUCTURE}

During practical construction and active service of spatial structure, heap load is likely to appear because of incorrect construction or usage, especially during construction. Structural static properties under heap load will be theoretically and experimentally studied in the following text. The total node number in single-layer latticed shell is 235, among which 199 nodes are not supporting node, among which 90 nodes lay on the top of struts. During experiment some sandbags are put on corresponding points to simulate load in structure. During loading sandbags, frame is constructed above suspen-dome model to ensure load safely and conveniently. Heap load is simulated by loading some sandbags on " $\mathrm{A}$ " area (which is just in 1st measured area), which is a quarter of single-layer latticed shell as shown in Figure 2. To be convenient, all sandbags which are 
loaded each point are $80 \mathrm{~kg}$. In the process of loading, $80 \mathrm{~kg}$ loads are loaded corresponding points at 5 different times, load magnitude is $20 \mathrm{~kg}, 20 \mathrm{~kg}, 20 \mathrm{~kg}, 10 \mathrm{~kg}, 10 \mathrm{~kg}$, respectively. Measured data can be read after ten to fifteen minutes from completing load each time in order to ensure structural response to outer loads complete. The pre-stress value in model structure is determined by practical structural pre-stress value according to axial stress consistent principle. The pre-stress value in hoop cables, which have been tensioned before loading, is shown in table 2 .

Table 2. Pre-stress Value of Hoop Cables before Loading

\begin{tabular}{c||c||c}
\hline $\mathrm{Hs} 1 / \mathrm{kN}$ & $\mathrm{Hs} 2 / \mathrm{kN}$ & $\mathrm{Hs} 3 / \mathrm{kN}$ \\
\hline 22.7 & 11.8 & 4.14 \\
\hline
\end{tabular}

To ensure model structure be safe during loading and to know the difference of mechanical properties between under full-span load (loading on A, B, C and D area, which is shown in Figure 2) and heap load, the overall stability of structure model under full-span load and heap load, whose basic magnitude in each corresponding node is $80 \mathrm{Kg}$, are first calculated by finite element software ANSYS[16]. The curves between nodal vertical displacement and loads, which can reflect structural overall stability, are drawn in Figure 12(a). When heap load reaches critical value, the stress distribution of single-layer latticed shell is given in Figure 12(b). Because the critical load value under heap load is smaller than full-span load, in order to compare conveniently, the stress distribution, which can be seen in Figure 12(c), under full-span load is given when full-span load factor reaches heap critical value.

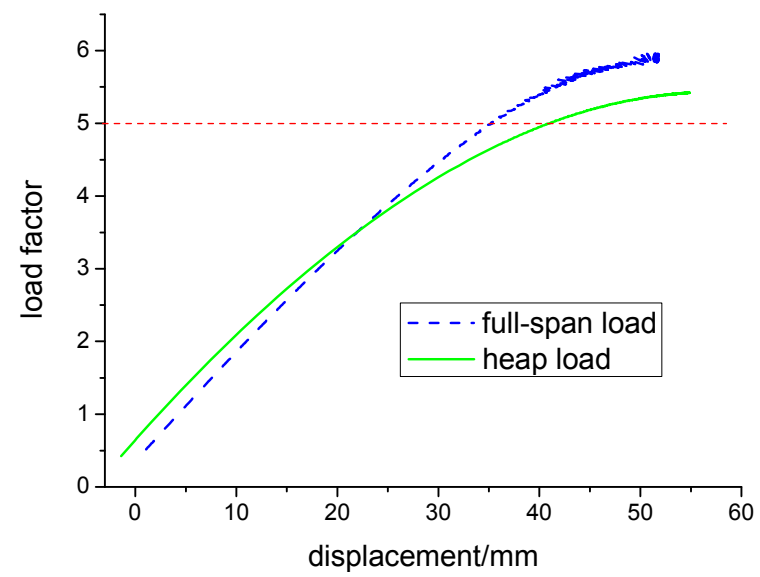

(a) Load-displacement curves

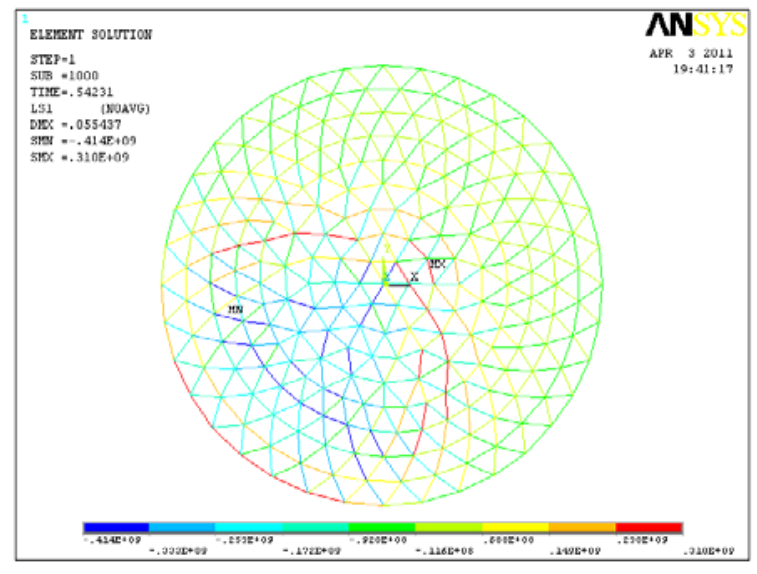

(b) Stress distribution under heap critical load

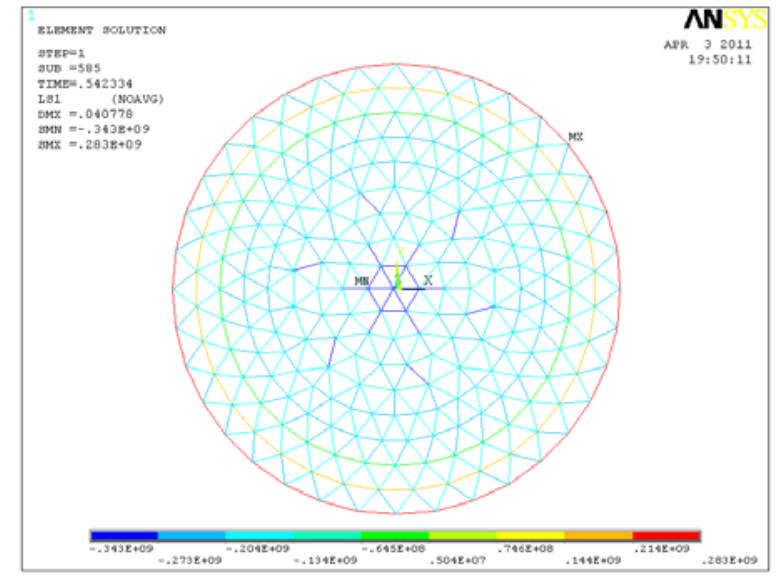

(c) Stress distribution under full-span load 
From Figure 12, we can see the overall stability factor are more than 5 under full-span load and heap load. So the structure is impossible to loss its overall stability during the imposing of heap load. We can also see that the overall stability factor and structural stiffness under full-span load is better than under heap load. From Figure 12(b)-(c), we can also see that the stress magnitude of single-layer latticed shell under critical heap load is more than corresponding full-span load. Calculation results show that the structural stability property under heap load is little worse than full-span load. From Figure 12(a), we can see that two curves do not intersect in origin of coordinates because of influence of pre-stress on structural displacement.

In order to know much more about mechanical properties under heap load, heap load are loaded in structure during experiment. Inner force of elements and nodal displacement are recorded in the process of loading. The process of loading is shown in Figure 13. Because measured data are so much that they can't be all listed in the paper, only some measured points are concerned, theoretical and experimental results during loading are listed in table 3 and table 4. Because sectional area of struts are big during design, strain measured in struts are small, they are almost less than $30 \mu \varepsilon$, but the errors from type static resistance strain measurers fall within $+/-3$, and there are also some errors between theoretical model and experimental model after the structure is tensioned, so there are much errors between theoretical model and experimental model in struts during loading. Here, those data of struts are not listed in the paper.

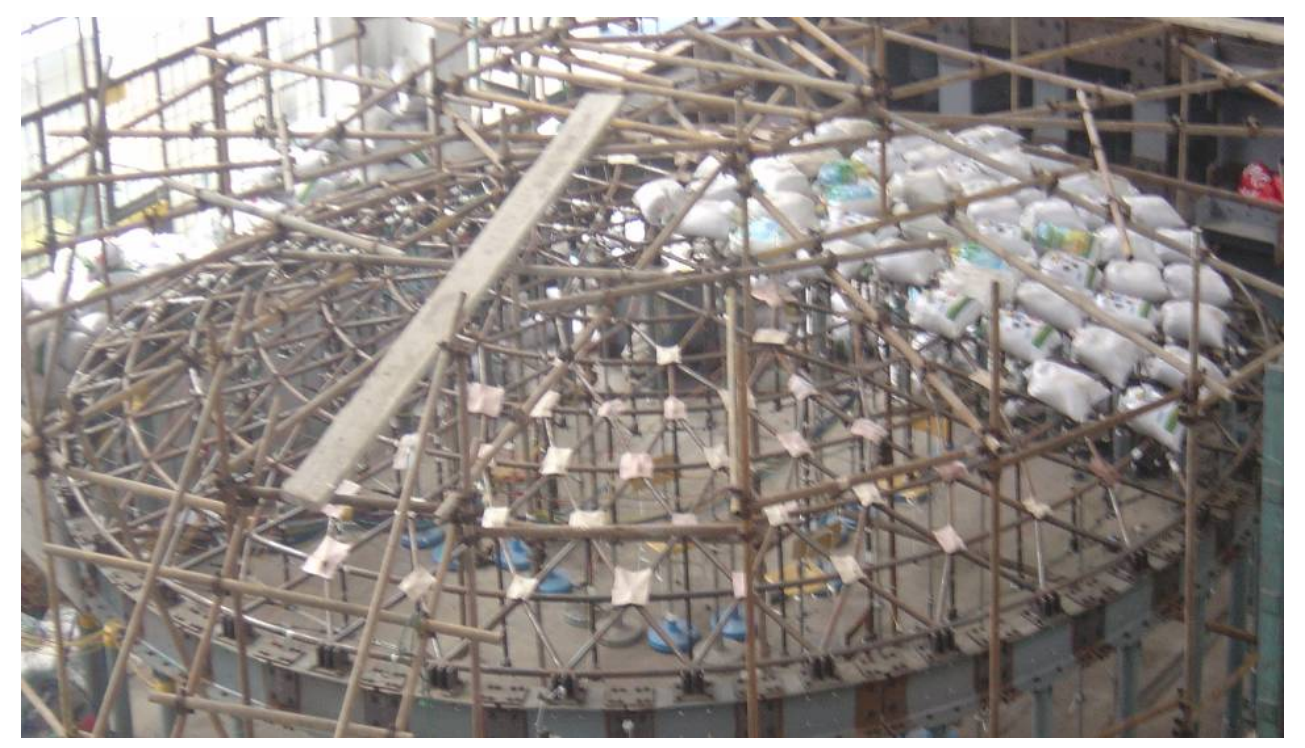

Figure 13. Loading of Heap Load

Table 3. Theoretical and Measured Axial Force of Partial Cable-struts during Loading (units: N)

\begin{tabular}{cccccccc}
\hline load & Inner force & \multicolumn{7}{c}{ Measured points number } \\
\cline { 3 - 8 } process & $/ \mathrm{N}$ & $\mathrm{X} 1-7$ & $\mathrm{X} 2-8$ & $\mathrm{X} 3-5$ & $\mathrm{~S} 1-2$ & $\mathrm{~S} 2-2$ & $\mathrm{~S} 3-2$ \\
\hline \multirow{3}{*}{ 1st } & Theoretical & 4359.5 & 2268.9 & 1541.8 & 22658.8 & 11767.4 & 4002.1 \\
& measured & 4301.3 & 2249.5 & 1549.1 & 21877.2 & 11601.9 & 3811.0 \\
& Relative error & -1.3 & -0.9 & 0.5 & -3.4 & -1.4 & -4.8 \\
\hline \hline \multirow{3}{*}{ 2nd } & Theoretical & 4403.9 & 2283.0 & 1539.4 & 22895.3 & 11840.4 & 3996.0 \\
& measured & 4326.0 & 2249.5 & 1549.1 & 22289.2 & 11733.8 & 3811.0 \\
& Relative error & -1.8 & -1.5 & 0.6 & -2.6 & -0.9 & -4.6 \\
\hline \hline \multirow{3}{*}{$3 \mathrm{rd}$} & Theoretical & 4448.9 & 2297.4 & 1536.8 & 23135.0 & 11915.0 & 3989.1 \\
& measured & 4412.5 & 2274.2 & 1557.4 & 22701.2 & 11915.0 & 3841.9 \\
& Relative error & -0.8 & -1.0 & 1.3 & -1.9 & 0.0 & -3.7 \\
\hline \hline
\end{tabular}




\begin{tabular}{|c|c|c|c|c|c|c|c|}
\hline \multirow{3}{*}{4 th } & Theoretical & 4494.6 & 2312.1 & 1533.6 & 23377.7 & 11991.7 & 3981.2 \\
\hline & measured & 4474.3 & 2315.4 & 1565.6 & 23113.2 & 12046.9 & 3903.7 \\
\hline & Relative error & -0.5 & 0.1 & 2.1 & -1.1 & 0.5 & -1.9 \\
\hline \multirow{3}{*}{5 th } & Theoretical & $4+4517.6$ & 2319.7 & 1532.0 & 23500.9 & 12030.7 & 3976.8 \\
\hline & measured & 4499.0 & 2331.9 & 1573.8 & 23278.0 & 12129.3 & 3924.3 \\
\hline & Relative error & -0.4 & 0.5 & 2.7 & -0.9 & 0.8 & -1.3 \\
\hline \multirow{2}{*}{$\begin{array}{c}\text { load } \\
\text { process }\end{array}$} & Inner force & \multicolumn{6}{|c|}{ Measured points number } \\
\hline & $/ \mathrm{N}$ & $\mathrm{X} 1-13$ & $\mathrm{X} 2-13$ & X3-9 & $\mathrm{S} 1-4$ & S2-3 & S3-3 \\
\hline \multirow{3}{*}{$1 \mathrm{st}$} & Theoretical & 4362.1 & 2264.6 & 1542.1 & 22658.8 & 11767.4 & 4002.1 \\
\hline & measured & 4214.8 & 2216.6 & 1549.1 & 22660.0 & 11387.7 & 3975.8 \\
\hline & Relative error & -3.4 & -2.1 & 0.5 & 0.0 & -3.2 & -0.7 \\
\hline \multirow{3}{*}{ 2nd } & Theoretical & 4409.4 & 2278.3 & 1539.3 & 22888.2 & 11840.7 & 3996.3 \\
\hline & measured & 4301.3 & 2224.8 & 1549.1 & 23072.0 & 11503.0 & 3975.8 \\
\hline & Relative error & -2.5 & -2.3 & 0.6 & 0.8 & -2.9 & -0.5 \\
\hline \multirow{3}{*}{$3 \mathrm{rd}$} & Theoretical & 44457.4 & 2292.3 & 1536.2 & 23120.6 & 11915.7 & 3989.5 \\
\hline & measured & 4375.4 & 2233.0 & 1557.4 & 23525.2 & 11684.3 & 4047.9 \\
\hline & Relative error & -1.8 & -2.6 & 1.4 & 1.7 & -1.9 & 1.5 \\
\hline \multirow{3}{*}{4 th } & Theoretical & 4505.8 & 2306.8 & 1532.6 & 23356.3 & 11992.7 & 3981.8 \\
\hline & measured & 4462.0 & 2274.2 & 1565.6 & 23937.2 & 11799.7 & 4078.8 \\
\hline & Relative error & -1.0 & -1.4 & 2.2 & 2.5 & -1.6 & 2.4 \\
\hline \multirow{3}{*}{5 th } & Theoretical & 4530.4 & 2314.2 & 1530.7 & 23475.3 & 12031.7 & 3977.6 \\
\hline & measured & 4499.0 & 2282.5 & 1606.8 & 24143.2 & 11915.0 & 4089.1 \\
\hline & Relative error & -0.7 & -1.4 & 5.0 & 2.8 & -1.0 & 2.8 \\
\hline
\end{tabular}

Table 4. Theoretical and Measured Displacement of Partial Node during Loading

\begin{tabular}{ccccccccc}
\hline load & displacement & \multicolumn{7}{c}{ dial indicators number } \\
\cline { 3 - 9 } process & $/ \mathrm{mm}$ & 1 & 2 & 3 & 5 & 6 & 8 & 9 \\
\hline \multirow{3}{*}{ 1st } & Theoretical & 0.04 & 0.07 & 0.09 & 0.10 & 0.10 & -0.22 & -0.72 \\
& measured & -0.04 & 0.07 & 0.11 & 0.24 & 0.25 & -0.35 & -0.94 \\
& Absolute error & 0.08 & 0.00 & -0.02 & -0.14 & -0.15 & 0.13 & 0.22 \\
\hline \multirow{3}{*}{ 2nd } & Theoretical & 0.08 & 0.14 & 0.18 & 0.21 & 0.20 & -0.43 & -1.45 \\
& measured & -0.04 & 0.10 & 0.18 & 0.47 & 0.50 & -0.68 & -1.88 \\
& Absolute error & 0.12 & 0.04 & 0.00 & -0.26 & -0.30 & 0.25 & 0.43 \\
\hline \multirow{3}{*}{ 3rd } & Theoretical & 0.13 & 0.22 & 0.27 & 0.32 & 0.31 & -0.63 & -2.19 \\
& measured & -0.02 & 0.15 & 0.26 & 0.62 & 0.78 & -0.96 & -2.87 \\
& Absolute error & 0.15 & 0.07 & 0.01 & -0.30 & -0.47 & 0.33 & 0.68 \\
\hline \multirow{3}{*}{ 4th } & Theoretical & 0.15 & 0.25 & 0.31 & 0.37 & 0.37 & -0.73 & -2.55 \\
& measured & -0.01 & 0.17 & 0.29 & 0.73 & 0.91 & -1.15 & -3.35 \\
& Absolute error & 0.16 & 0.08 & 0.02 & -0.36 & -0.54 & 0.42 & 0.80 \\
\hline \multirow{3}{*}{ 5th } & Theoretical & 0.17 & 0.29 & 0.36 & 0.41 & 0.38 & -0.68 & -2.50 \\
& measured & 0.00 & 0.20 & 0.31 & 0.94 & 1.03 & -1.17 & -3.66 \\
& Absolute error & 0.17 & 0.09 & 0.05 & -0.53 & -0.65 & 0.49 & 1.16 \\
\hline
\end{tabular}


The Table 3 and Table 4 show that the theoretical and experimental data are basically in well agreement. The most error appears in measured point whose number is X3-9, the error value is five percent after fifth loads is loaded. The errors in displacement lay between $-1 \mathrm{~mm}$ and $+1 \mathrm{~mm}$, the displacement values listed in the paper are all small, less than $10 \mathrm{~mm}$. In order to further analysis mechanical properties under heap load in detail, comparison between the theoretical and experimental data for some inner force, nodal displacement in single-layer latticed shell during loading are given in Figure 14. After all nodal loads are loaded on corresponding node, theoretical and experimental distribution of stress and displacement in single-layer latticed shell under heap load, theoretical stress distribution under full-span load and the comparison among them are given in Figure 15.

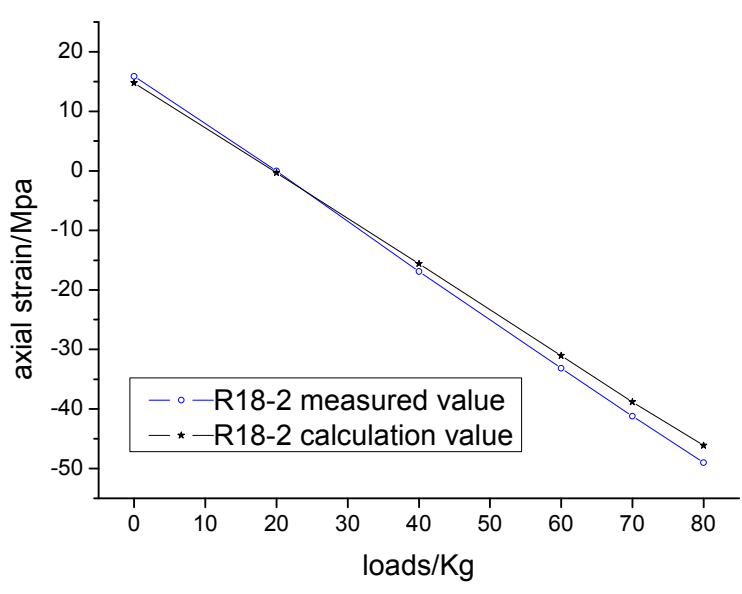

(a) R18-2

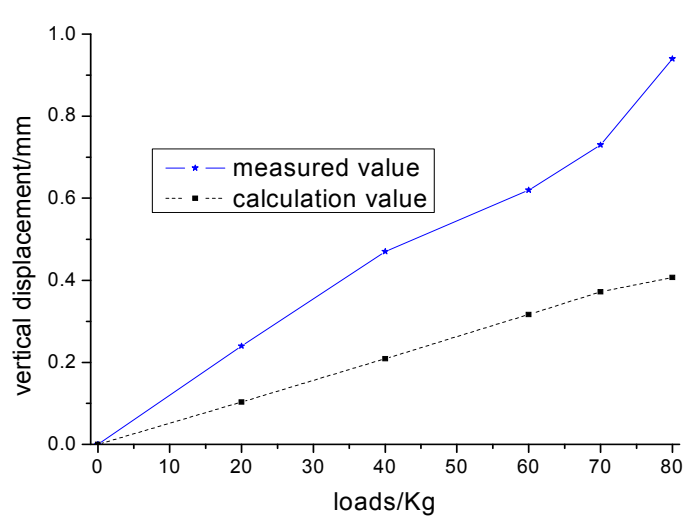

(c) 5th dial indicator

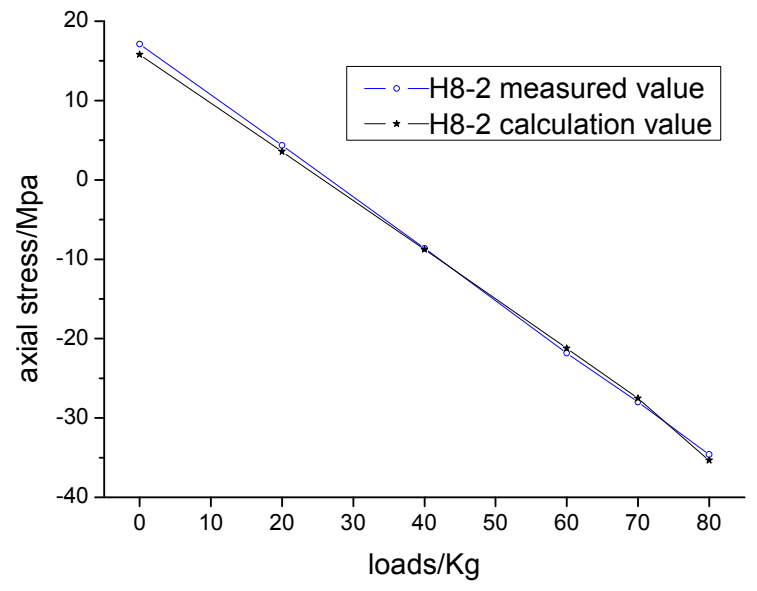

(b) $\mathrm{H} 8-2$

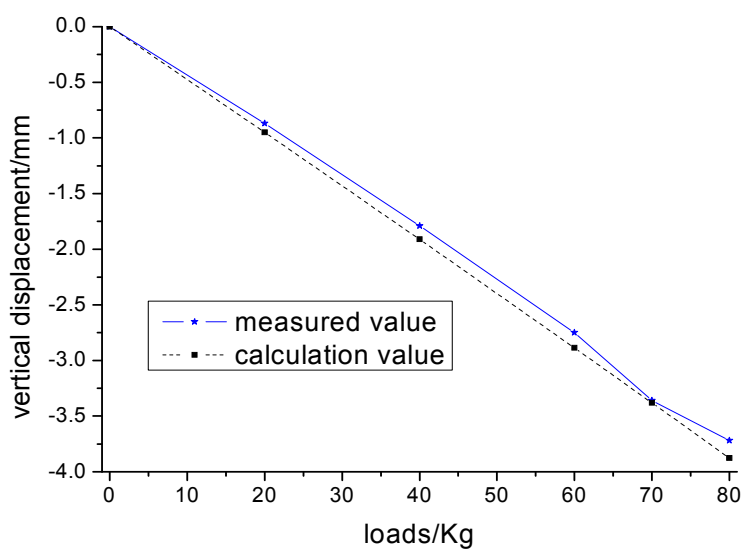

(d) 14th dial indicator

Figure 14. Comparison of Measured and Calculation Results during Loading

From Figure 14(a)-(b), we can see that the theoretical and experimental stress results are basically in well agreement. From Figure 14(c)-(d), we can see that the theoretical and experimental displacement in 14th dial indicator is basely available, while there is obvious difference between theory and experiment in 5th dial indicator. At the same time, we can also see that the theoretical and experimental value in 5th dial indicator are all little, its value is less than $1 \mathrm{~mm}$. That the displacement value is too little is main reason resulting in obvious difference between theory and experiment. 


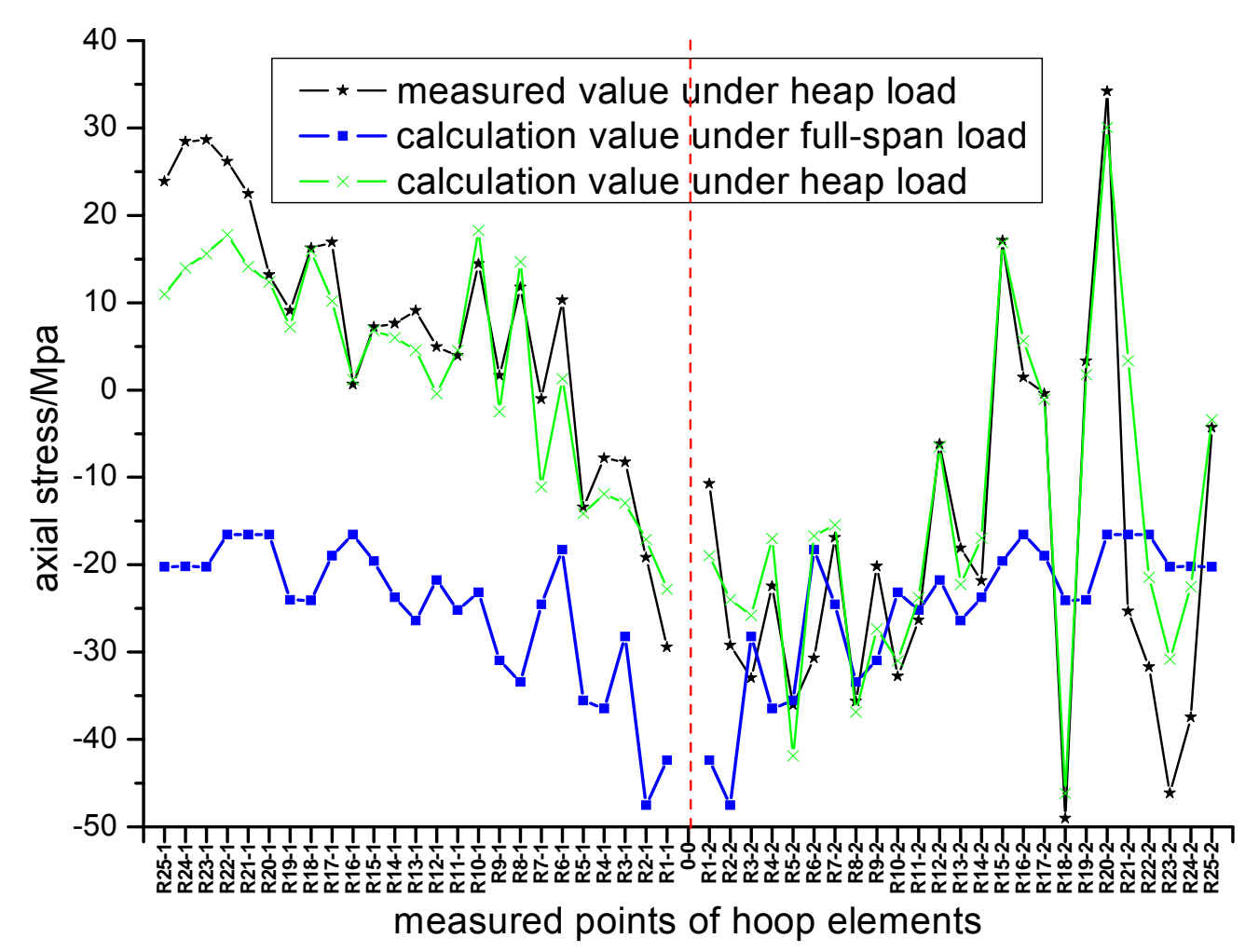

(a) Distribution of Radial Elements Stress after the Last Loading

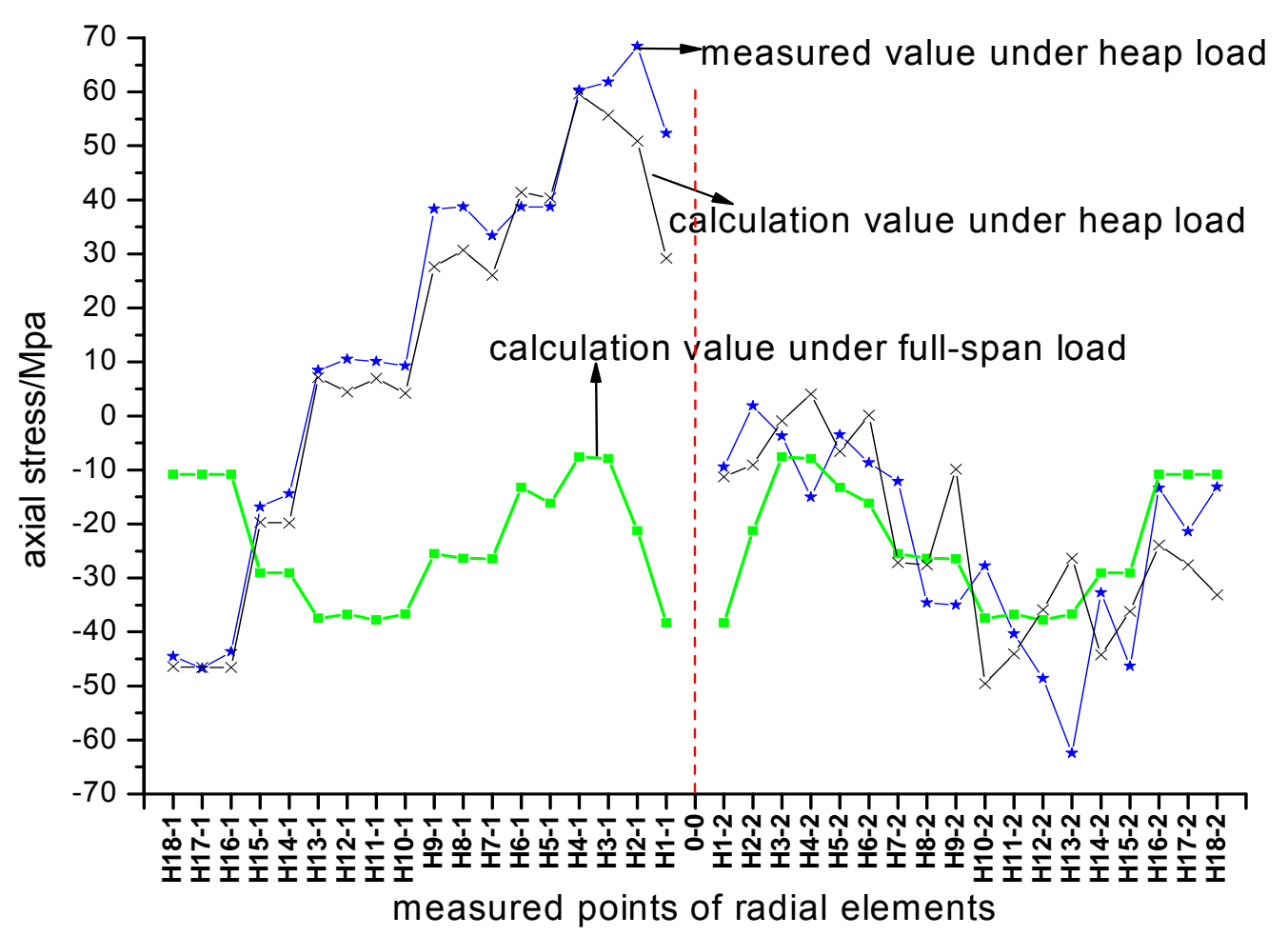

(b) Distribution of Hoop Elements Stress after the Last Loading 


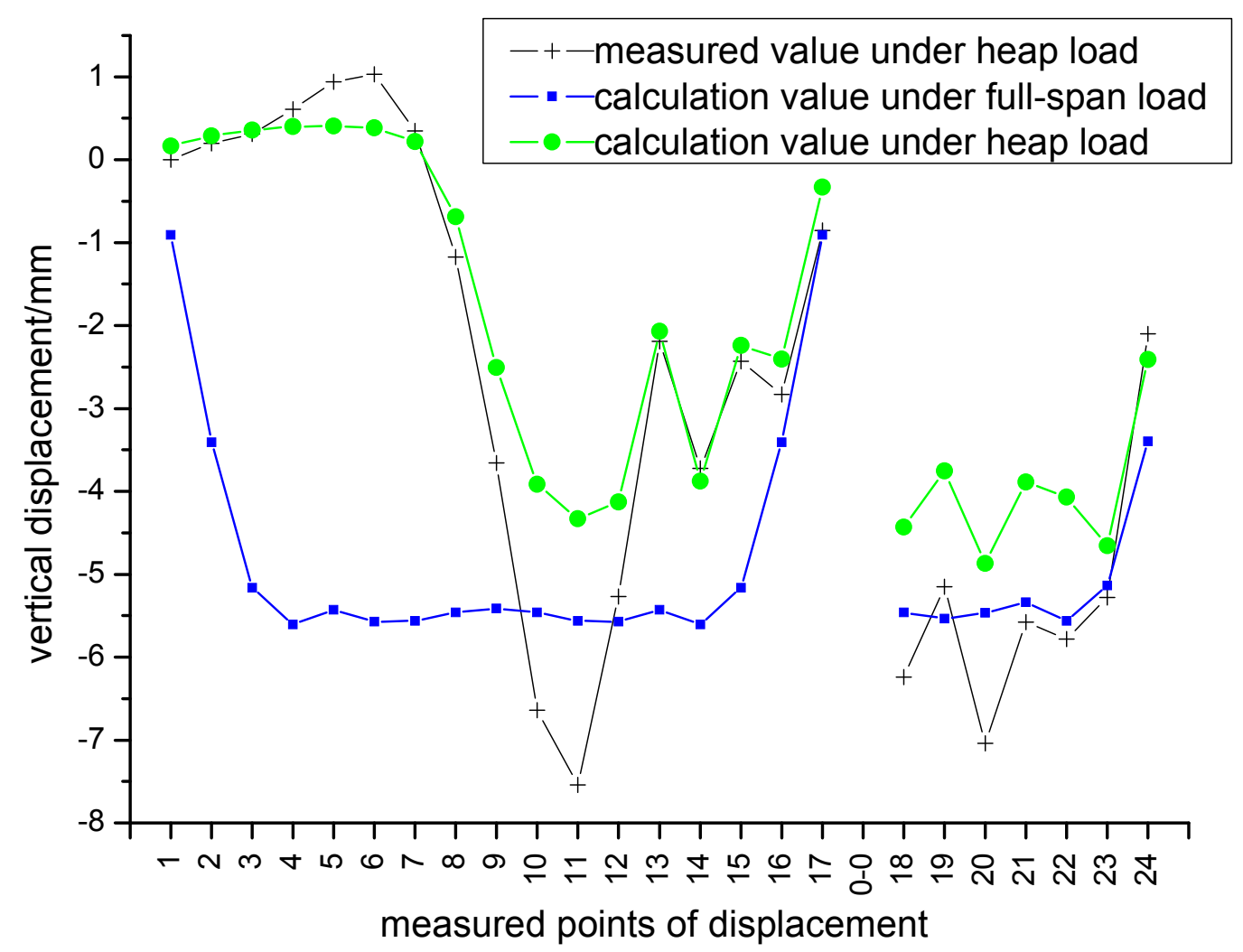

(c) Distribution of Nodal Displacement after Last Loading

Figure 15. Comparison of Distribution of Measured and Calculation Results

From Figure 15(a)-(b), we can see that the theoretical and experimental distribution under heap load are basically in well agreement. From Figure 15(a), we can see that the maximal and minimal stress of radial elements all appear in 2nd measured area, the maximal value is almost $40 \mathrm{Mpa}$, the minimal value is almost $-50 \mathrm{Mpa}$. The uniformity of stress distribution in 1st measured area is obviously better than 2nd measured area. At the same time, we can see that the distribution uniformity under heap load is obviously worse than full-span load, the maximal and minimal stress of radial elements all appear under heap load. Some radial elements are compressed, others are tensioned under heap load, but all radial elements are compressed under full-span load. From Figure 15(b), we can see that hoop elements in 2nd area are all compressed, while some elements are compressed others tensioned in 1st area under heap load. The maximal stress appears in 1st measured area, whose value is almost $70 \mathrm{Mpa}$. The minimal stress appears in 2nd measured area, whose value is almost $-65 \mathrm{Mpa}$. The stress distribution uniformity in 1 st area is obviously worse than in 2nd area. At the same time, from Figure 15(b), we can also see that the distribution uniformity under heap load is obviously worse than full-span load, the maximal and minimal stress of hoop elements all appear under heap load. Some hoop elements are compressed, others are tensioned under heap load, but all hoop elements are compressed under full-span load. From Figure 15(a)-(b), we can see that the maximal compress and tension all appear in hoop elements under heap load, whose values are less than sectional yield stress. 
From Figure 15(c), we can see that the maximal displacement under heap load increases $7 \mathrm{~mm}$ than the condition that the structural tension is completed but loading does not begin. Under heap load, nodes in $1^{\text {st }}$ area move downward greatly, In 2 nd area, nodal upward displacements are less. From Figure 15(c), we can also see that displacement uniformity in single-layer latticed shell under heap load is worse than full-span load. Some nodes move upward, others move downward under heap load, but all nodes move downward under full-span load.

Overall, the structural overall stability under heap load is little worse than full-span load. The stress distribution uniformity under heap load is obviously worse than full-span load, the maximal and minimal stress of elements all appear under heap load. Some elements are compressed, others are tensioned under heap load, but all elements are compressed under full-span load. The maximal compress and tension, whose values are less than sectional yield stress, all appear in hoop elements under heap load. Displacement uniformity in single-layer latticed shell under heap load is worse than full-span load. Some nodes move upward, others move downward under heap loads, but all nodes move downward under full-span loads.

\section{CONCLUSIONS AND SUGGESTIONS}

Based on the study, the results may be due to give some understanding on structural static property under heap load for suspen-dome and similar large span structure; conclusions and suggestions are as follows:

(1) The structural overall stability factor under full-span load is bigger than heap load.

(2) Theoretical and experimental data are basically in well agreement during experiment, it can be say that the design of experimental model, method and process of load, arrangement of measured points and process of measurement are satisfied with request .

(3) The stress distribution uniformity under heap load is obviously worse than full-span load, the maximal and minimal stress of elements all appear under heap load. Some elements are compressed, others are tensioned under heap load, but all elements are compressed under full-span load.

(4) The maximal compress and tension all appear in hoop elements under heap load, their values are less than sectional yield stress.

(5) Displacement distribution uniformity in single-layer latticed shell under heap load is worse than full-span load. Some nodes move upward, others move downward under heap load, but all nodes move downward under full-span load.

(6) Heap load is disadvantage to structural static properties, it is proposed that heap load should be considered during designing and some measures should be applied to avoid heap loads come into being during construction and active service.

\section{ACKNOWLEDGMENT}

These authors are highly grateful to the anonymous reviewers for their valuable suggestions. This work is supported by NSFC Grants (No. 51108259), Science \& Technology Program of Shanghai Maritime University (No.20120050), and Key disciplines Program of Shanghai Maritime University (No. 20100010). 


\section{REFERENCES}

[1] Dong, S.L., "The Development History, Innovation, Classification and Practical Application of Spatial Structures", Spatial Structures, 2009, Vol. 15, No. 3, pp. 22-43. ( in Chinese)

[2] Kawaguchi, M., Abe, M. and Tatemichi, I., "Design, Test, and Realization of "Suspend-Dome" System", Journal of IASS, 1999, Vol. 40, No. 131, pp. 179-192.

[3] Geiger, D.H., "The Design and Construction of Two Cable Domes for the Korean Olympics" $[\mathrm{C}] / /$ Proceedings of IASS-ASC E International Symposium on Shells, Membranes and Space Frames. Osaka : [s.n], 1986.

[4] Kitipornchai, S., Kang, W.J. and Lam, H.F., et al, "Factors Affecting the Design and Construction of Lamella Suspen-Dome Systems", Journal of Constructional Steel Research, 2005, Vol. 61, pp. 764-785.

[5] Gao, B.Q. and Weng, E.H., "Sensitivity Analyses of Cables to Suspen-Dome Structural System", Journal of Zhejiang University Science, 2004, Vol. 5, No. 9, pp. 1045-1052.

[6] Guo, J.M. and Dong, S.L., "Theoretical and Experimental Study on Tensioning of Suspend-Dome”, China Civil Engineering Journal, 2011, Vol. 44, No. 2, pp. 65-71. (in Chinese)

[7] Guo, J.M., Dong, S.L. and Yuan, X.F., "Morphological Analysis of Suspend-Dome Structures and Its Practical Analysis Method", China Civil Engineering Journal, 2009, Vol. 41, No. 12, pp. 1-7. (in Chinese)

[8] Chen, Z.H. and Qin, Y.L., et al, "An Experimental Study on Rigid Suspen-Dome Structures", China Civil Engineering Journal, 2006, Vol. 39, No. 9, pp. 47-53. (in Chinese)

[9] Zhang, A.L. and Liu, X.C., et al, "Static Experimental Study on the Model of the Suspen-Dome of the Badminton Gymnasium for 2008 Olympic Games", Journal of Building Structures, 2007, Vol. 28, No. 6, pp. 58-67. (in Chinese)

[10] Wang, Y.Q. and Guo, Z.X., et al, "Pre-stressed Cable Construction of Large-span Elliptic Suspen-dome in Changzhou Gymnasium”, Construction Technology, 2006, Vol. 37, No. 3, pp. 33-36. (in Chinese)

[11] Zhang, Z.H., Cao, Q.S. and Dong, S.L., et al, "Structural Design of a Practical Suspen-Dome”, Advanced Steel Construction, 2008, Vol. 4, No. 4, pp. 323-340.

[12] Chen, Z.H., Liu, H.B. and Wang,, X.D., et al, "Review and Forecast of Suspen-Dome Structures", Journal of Building Structures, 2010, Supplementary Issue 1, pp. 210-215. (in Chinese)

[13] Liu, F., Qian, J.H. and Song, T., et al, "Analysis of Reasons for the Collapse of a Hub Joint Steel Shell”, Spatial Structures, 2007, Vol. 13, No. 4, pp. 38-42. (in Chinese)

[14] Fu, H.Q, "Structure Experiment", Metallurgy Industry Press, Beijing, 1992. (in Chinese).

[15] JGJ 61-2003, "Technical Specification for Latticed Shells", China Architecture \& Building Press, Beijing, 2003. (in Chinese).

[16] ANSYS Users Manual Revision 6.1, ANSYS, INC., Inc,. Canonsburg, Pennsylvania, 2002. 


\title{
UNIFORM CORROSION WASTAGE EFFECTS ON THE LOAD-CARRYING CAPACITY OF DAMAGED STEEL BEAMS
}

\author{
Yasser Sharifi \\ Department of Civil Engineering \\ Vali-e-Asr University of Rafsanjan, Rafsanjan, Iran \\ (Corresponding author: E-mail: y.sharifi@vru.ac.ir or yasser_sharifi@yahoo.com)
}

Received: 28 April 2011; Revised: 11 July 2011; Accepted: 21 July 2011

\begin{abstract}
The aim of the present study is to investigate the effects of uniform corrosion on the load-carrying capacity of steel beam sections. In this paper, a credible corrosion model for damaged steel beams has been developed based on the real existing data. Thickness loss data were compiled from corrosion damaged samples beams which picked up from a petrochemical industry. The developed deteriorated model was employed to demonstrate the effects of uniform corrosion on the structural behavior of damaged steel beams due to uniform corrosion wastage. It was found from the obtained results that the lateral distorsional buckling is the critical failure mode at the preliminary age of corrosion wastage.
\end{abstract}

Keywords: Corrosion, Steel structures, Failure modes, Corrosion damaged models, Thickness loss data

\section{INTRODUCTION}

To produce steel, iron ores must be processed. During the process of metal extraction, it consumes a large amount of energy to separate the metal from the ore. Large amounts of energy are consumed in the manufacturing of metals. This energy is essentially stored in the metal. Because of the fact that all configurations in nature tend to spontaneously change to lower states of energy, refined metal will deteriorate or corrode (Fontana [1]).

Based on the environment, type of steel, type of structure, and other related parameters there are five main forms of corrosion which can affect a steel structure. The most prevalent form is a general loss of surface material; this condition will lead to the gradual thinning of members. Pitting corrosion also involves loss of material at the surface. However, it is restricted to a very small area. Galvanic corrosion occurs when two dissimilar metals are electrochemically coupled. Such situations may occur at bolted or welded connections. Galvanic corrosion can be local, leading to pit formation. Crevice corrosion occurs in small confined areas, such as beneath peeling paint or between faying surfaces (Fontana [1]; Kayser [2]).

Steel structures can be affected by corrosion in many ways. The main effects can be loss of material from the surface, which leads to thinner sections. Section loss due to uniform corrosion may take place over a large area of a structural member. The loss of material due to uniform corrosion results in the reduction of section properties of a member, such as cross sectional area, moment of inertia, section modulus, radius of gyration and etc., thus causing a reduction in the carrying capacity of the structure. At severe levels of corrosion, the ultimate capacity of a steel member may fall below the service loads. Also it should be pointed out that the mode of failure due to loss of material can be changed (Sharifi and Rahgozar [3-7]). Corrosion damage must be carefully appraised and evaluated. In some cases, immediate repair or closure is necessary while in other cases, the conditions created by corrosion can be tolerated (Kulicki et al. [8]). It has been pointed out by Czarnecki and Nowak [9] that corrosion can lead to cracking (fracture), yielding or bucking of members. This can result in stress concentration, changes in geometric parameters, and a build-up of the corrosion products. These parameters are critical for the member's ability to resist load effects. 
The effects of both uniform and pitting corrosion on load-carrying capacity and reliability of corrosion damaged steel box-girder bridges has been investigated by Sharifi and Paik [10,11] and Sharifi [12], respectively.

The effect of corrosion on structural strength is not yet clear. Further investigation is necessary to clarify how the corrosion affects strength of beams. When beam strength is considered, (1) collapse strength (no buckling), (2) lateral-distortional buckling strength, (3) local buckling strength, (4) shear strength of web plates and (5) web crippling strength under concentrated loading etc. are important factors (Nethercot [13]).

It is possible to establish a relationship between the remaining capacities of various failure modes (moment, shear, lateral torsional buckling, bearing ...) and the loss of thickness for a special member. This approach can form the basis to derive a relationship between the magnitude of corrosion defects and the corresponding remaining capacity. For a particular failure mode of a beam, if the percentage remaining capacity is plotted against the percentage loss of thickness, it will be obtained a curve that gives the relationship between them. In this paper steel I-beams with uniform corrosion are used to calculate their remaining capacity. The overall aim of this paper is to consider remaining capacity of corroded steel I-beams using thickness loss information provided by visual inspection or measurements. The results of this study can be used for a better prediction of the service life (remaining capacity) of deteriorating I-beams.

\section{SPECIMENS OF CORRODED STEEL BEAMS}

Three same steel I-beams were removed from the site where all specimens were in a severely corroded condition (nearly 40 years old). The thicknesses of these beams were measured by an instrument which was designed especially for this purpose. The instrument, which was used together with a depth gauge, is shown in Figure 1.

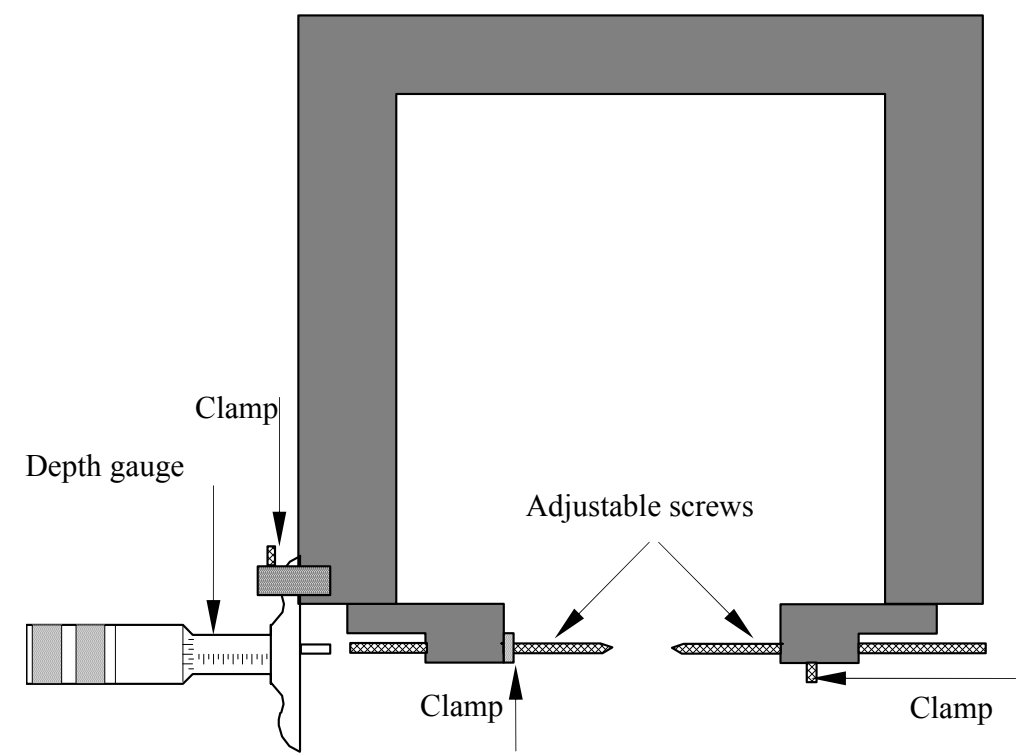

Figure 1. Instrument Used for Thickness Measurements of Sample Beams

As many readings as possible (up to 150 readings for each beam) were taken in order to increase the accuracy of the measurements. Average measurements of the thicknesses of each beam are shown in Table 1. The loss of thickness on average was more significant in the flanges than in the webs. 
Table 1. Average Measured Thicknesses of Corroded Beams ([Rahgozar [14])

\begin{tabular}{lllll}
\hline Element & New & Beam 1 & Beam 2 & Beam 3 \\
\hline Average thickness of top flange & 10.20 & 7.45 & 7.81 & 7.23 \\
\hline Average thickness of bottom flange & 10.20 & 5.62 & 5.85 & 4.84 \\
\hline Average thickness of top and bottom flanges & 10.20 & 6.54 & 6.83 & 6.04 \\
\hline $\begin{array}{l}\text { Average thickness loss of top and bottom } \\
\text { flanges }\end{array}$ & 0.00 & 3.66 & 3.37 & 4.16 \\
\hline $\begin{array}{l}\text { Percentage average thickness loss of top and } \\
\text { bottom flanges }\end{array}$ & 0.00 & $35.9 \%$ & $33.3 \%$ & \multirow{2}{*}{$40.8 \%$} \\
\hline Average thickness of upper part of web $\left(0.75 h_{w}\right)$ & 6.10 & 5.63 & 5.74 & 5.45 \\
\hline Average thickness of lower part of web $\left(0.25 h_{w}\right)$ & 6.10 & 3.16 & 4.32 & 3.18 \\
\hline Average thickness of web & 6.10 & 5.01 & 5.39 & 4.88 \\
\hline Average thickness loss of web $(\mathrm{mm})$ & 0.00 & 1.09 & 0.71 & 1.22 \\
\hline Percentage average thickness loss of web & 0.00 & $17.8 \%$ & $11.7 \%$ & $20.0 \%$ \\
\hline Note: $h=$ depth of web, all measurements are in millimeters & & &
\end{tabular}

\section{CORROSION MODEL DEVELOPMENT}

It has been pointed out by Kayser and Nowak [15] that severe corrosion may take place at the bottom one quarter of the web. Therefore the top surface of the bottom flange and the bottom part of the web are the regions where severe corrosion may take place, as shown in Figures 2. Corrosion also takes place in the top flange and the top part of the web but the loss is much less as compared to that of the web's bottom part.

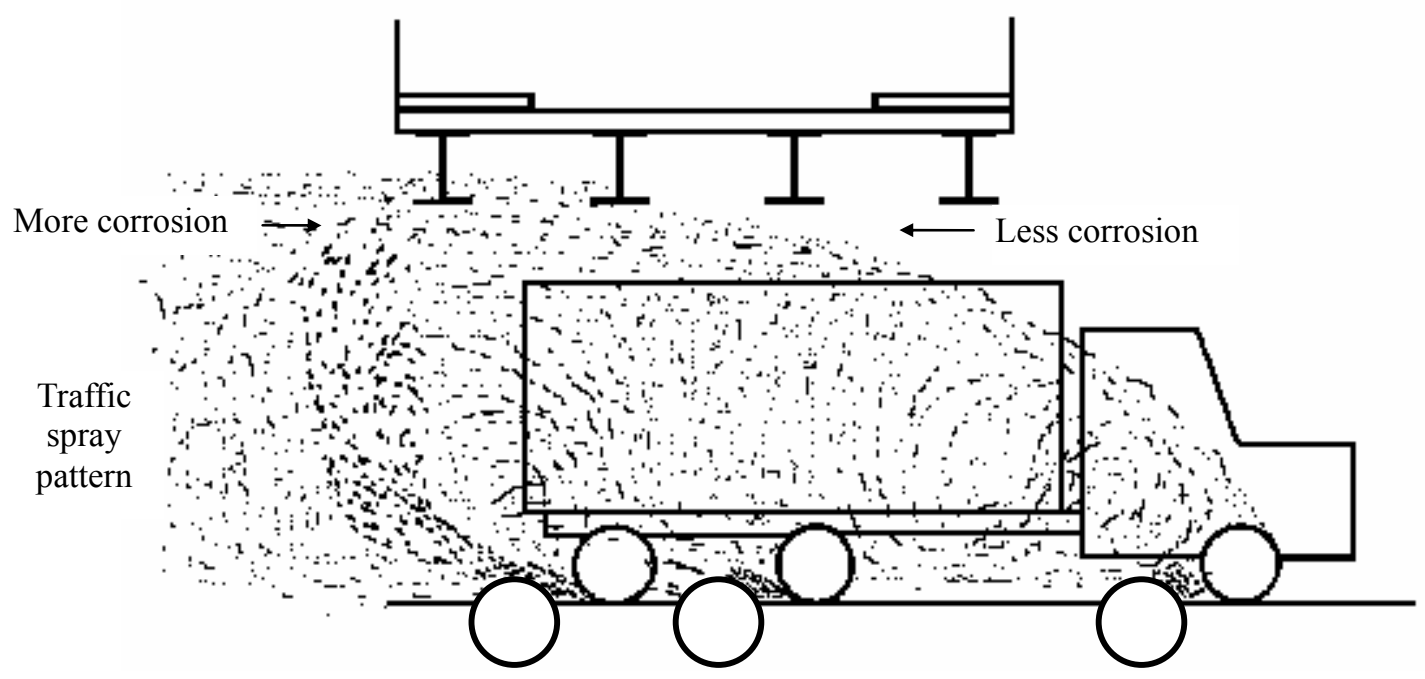

Figure 2(a) The Traffic Spray Accumulation on Girder Flanges and Webs 


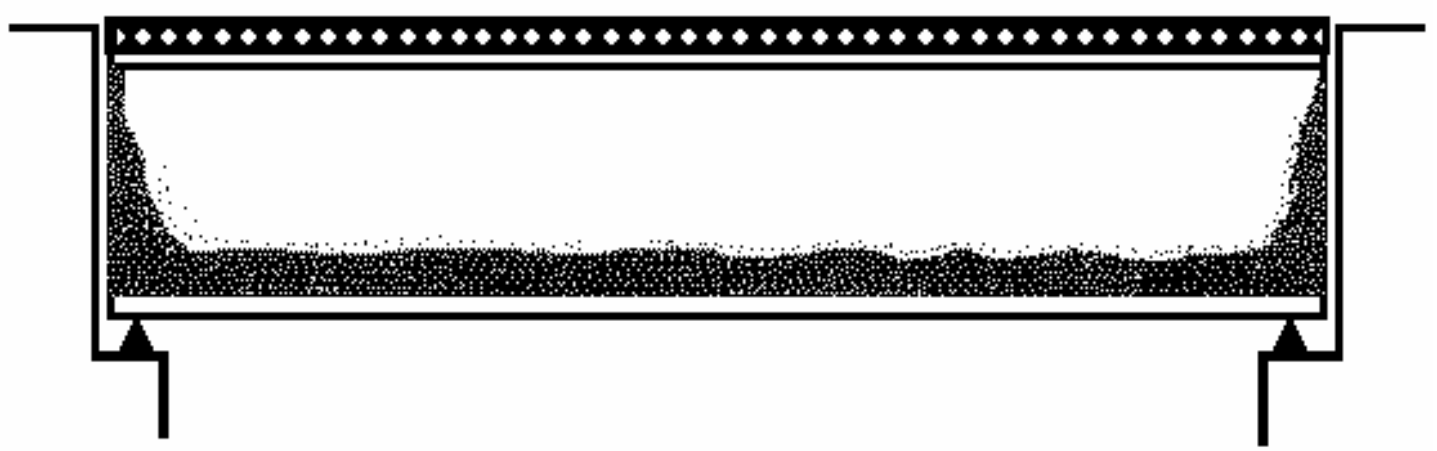

Figure 2(b). Typical Locations where Corrosion can Occur on a Steel Girder Bridge

The development of corrosion model mainly requires the information on the locations where corrosion normally occurs and the types of corrosion damage of steel members. The locations where corrosion occurs were discussed earlier. Using this information, corrosion model were considered by reducing the thickness of the sections. The model which is shown in Figure 3 is as follow:

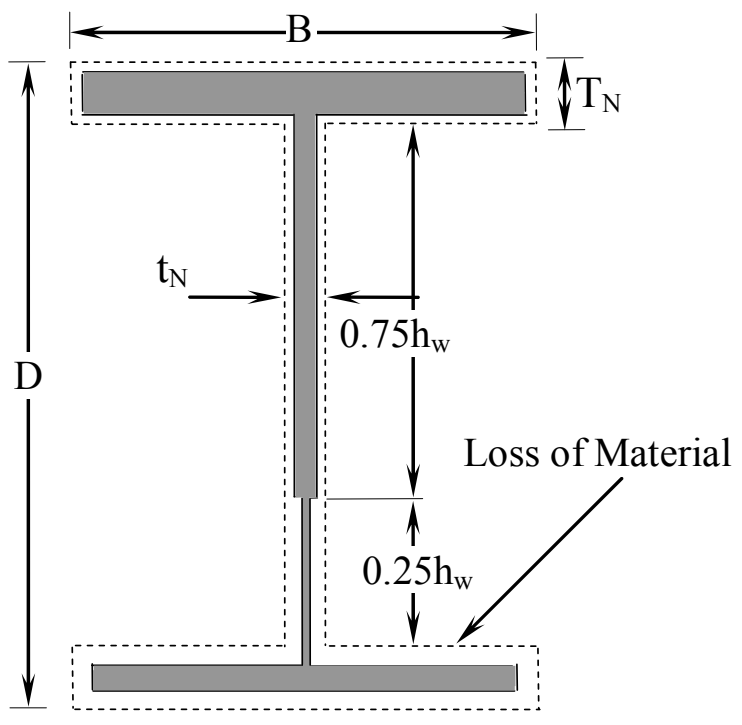

\section{Loss of Material}

Top flange

$0.7 \eta T_{N}$

Upper part of the web

$\left(0.75 h_{w}\right)$

$0.25 \eta t_{N}$

Lower part of the web

$\left(0.25 h_{w}\right)$

$1.25 \eta t_{N}$

Bottom flange

$1.3 \eta T_{N}$

where $\eta=\% L F T / 100$

Figure 3. Corrosion Model Simulated By Reducing the Thickness of Elements

Thickness of the top flange $=T_{N}(1-0.7 \eta)$

Thickness of the bottom flange $=T_{N}(1-1.3 \eta)$

Average thickness of the flanges $T_{c}=T_{N}(1-\eta)$

Thickness of the upper part of the web $\left(0.75 h_{w}\right)=t_{N}(1-0.25 \eta)$

Thickness of the lower part of the web $\left(0.25 h_{w}\right)=t_{N}(1-1.25 \eta)$

Average thickness of the web, $t_{c}=t_{N}(1-0.5 \eta)$

where $\eta=\eta_{F}=2 \eta_{W}$.

The thickness loss of flanges and web were in similar proportion to the thickness loss of the samples of corrosion damaged beams obtained from a chemical plant (Table 1). The measured thicknesses of these beams are given in Table 1. It can be established from Table 1 that the thickness loss of the bottom flange of sample beams is approximately twice as that of the loss of the 
top flange. The thickness loss of the lower part of the web $\left(0.25 h_{w}\right)$ is nearly five times as that of the upper part of the web $\left(0.75 h_{w}\right)$. For two sample beams the average thickness loss of the web is approximately half of that of the average loss of the flanges.

\section{REVIEW OF EXISTING FORMULAE FOR DIFFERENT FAILURES OF A STEEL BEAM}

As already noted when beam strength is considered, (1) collapse strength (no buckling), (2) local buckling strength, (3) shear strength of web plates, (4) lateral-distortional buckling strength, and (5) web crippling strength under concentrated loading are important factors (Nethercot [13]). Therefore, here the abovementioned failures will be investigated as following:

\subsection{Moment Strength (No Buckling)}

The effect of shear force $\left(F_{v}\right)$ is to reduce the plastic moment capacity but the reduction for an I-section is small for $F_{v}<0.6 P_{v}$, where $p_{v}$ is the shear capacity. For low shear load $\left(F_{v}<0.6 P_{v}\right)$ the moment capacity, $M_{c}$, is as follows:

For plastic and compact sections:

$M_{c}=p_{y} S \quad$ but $<1.2 P_{y} Z_{C}$

For semi-compact sections

$M_{c}=p_{y} Z$

For slender sections

$M_{c}=p_{y} Z$

where

$p_{y}$ is the design strength (reduced for slender sections-BS 5950 [16]), $S$ and $Z$ are the plastic and the elastic modulus of the section about the relevant axis, respectively.

\subsection{Local Buckling Strength}

Structural steel members such as I-beams, columns, channels, are composed of connected elements (web to flanges) which, for the purpose of analysis and design, can be treated as flat plates. When compression forces are applied to opposite edges of a flange as shown in Figure 4, a theoretical critical stress can be evaluated indicating that the flange may buckle locally before the member as a whole becomes unstable or before the yield stress of the material is reached. Such a critical stress may be in either the elastic or inelastic range.

The resistance of an element to plate buckling depends on its geometry, its material properties and its external restraint conditions along the boundaries. For the case of flange buckling, the critical factor is found to be the ratio of the width of the outstand element of compression flange, $b=B / 2$, to the flange thickness, $T$ (Trahair et al. [17]).

The thin plate shown in Figure 4 is simply supported along both transverse edges and one longitudinal edge and is free along the other, which is subjected to compression forces as shown. When the applied forces are equal to the critical value, the plate can buckle by deflecting laterally out of its original plane as shown in Figure 4. The magnitude of this elastic critical compressive stress, $P_{c r}$, at which the plate buckles, is given by Timoshenko and Gere [18] as: 


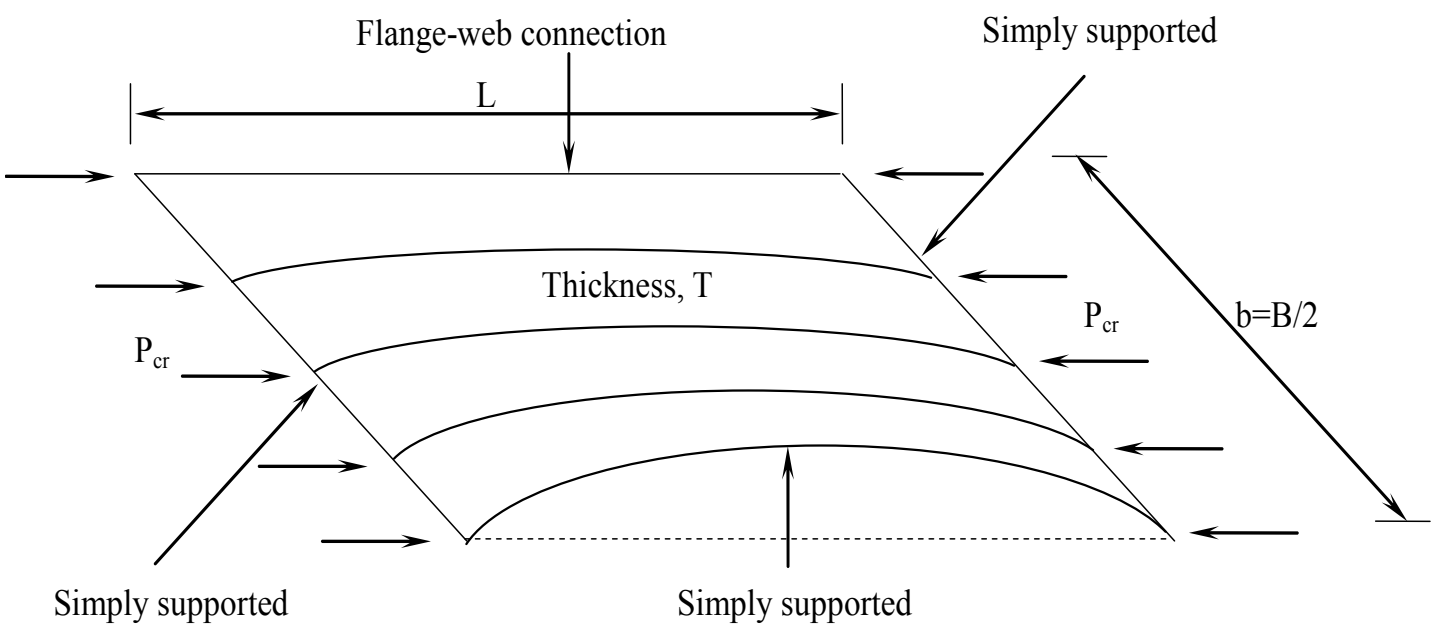

Figure 4. Buckled Shape of a Plate Free Along One Side

$P_{c r}=k \frac{\pi^{2} E}{12\left(1-v^{2}\right)(b / T)^{2}}$

where, $k$ is a buckling coefficient determined by a theoretical critical load analysis (Timoshenko and Gere [18]). It is a function of plate geometry and restraint conditions.

This elastic critical compressive stress was obtained by assuming that the buckled shape of the plate is in the form of a sinusoidal half-wave over the full length of the flange as shown in the Figure 5. When a member cross section is composed of various connected elements, lower bound of the critical stress can be determined by assuming, for each plate element, a simple support condition for each edge attached to another plate element or a free condition for any edge not so attached (Johnston [19]). In the case of a flange (by treating it as a plate), the restraint condition can be taken as simple support along the connection with the web and free at the other. In this case, the buckling coefficient, $k$, is approximated by Trahair et al. [17] as:

$k=0.425+\left(\frac{b}{L}\right)^{2}$

For long plate elements, which are used in most structural steel members, the length of the plate, $L$, can be taken as large or infinity and the buckling coefficient, $k$, can be taken as the minimum value of 0.425 . In this case, the elastic critical stress is equal to the yield stress, $p_{y}$, of steel for which $E=$ $205000 \mathrm{~N} / \mathrm{mm}^{2}$ and $v=0.3$ when the limiting $b / T$ ratio is as follows:

$b / T=16.9 \varepsilon$

where $\quad \varepsilon=\sqrt{\frac{275}{p_{y}}}$

If this $b / T$ ratio is exceeded, elastic buckling of the outstanding elements is predicted. However this $b / T$ ratio is not necessarily a conservative basis for design, since residual stresses and initial imperfections will have their greatest strength reducing influence precisely at the $b / T$ ratio found in 
this manner (Johnston [19]). BS 5950 [16] predicts elastic buckling of outstanding elements of rolled sections when the ratio, $b / T>9.5 \varepsilon$. BS 5950 [16] recommends a reduced design strength, $p_{y}$, when the ratio, $b / T>15 \varepsilon$ for slender cross sections.

\subsection{Shear Strength of Web Plates}

The web panel shown in Figure 5(a) is loaded in shear and the web is stiffened using stiffeners of length $a_{s}$. The thin flat plate of length, $a_{s}$, depth $d$, and thickness $t$ shown in Figure 5(b) is simply supported along all four edges. The plate is loaded in shear, distributed uniformly along its edges. When these stresses are equal to the elastic buckling value, $\tau_{c r}$, then the plate will buckle laterally out of its original plane into an adjacent position (Trahair et al. [17]).

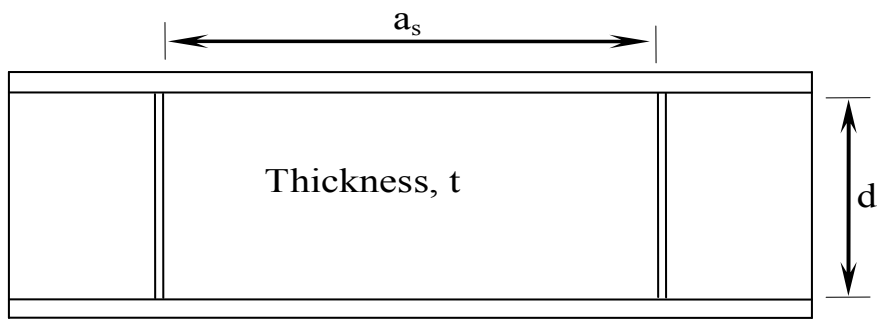

(a) Geometry of Web Panel

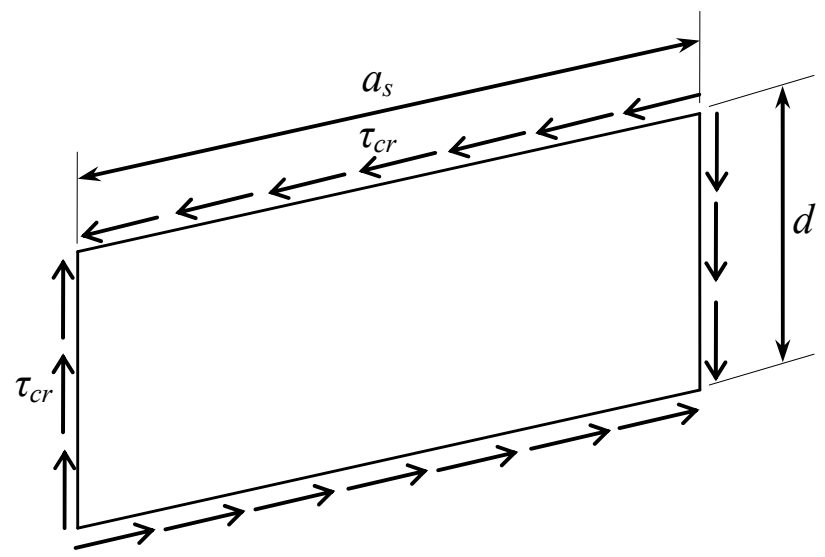

(B) Buckled Pattern of a Simply Supported Plate in Shear

Figure 5. Web Buckling Due to Pure Shear

The elastic critical shear stress $\tau_{c r}$, at which the web buckles can be predicated from plate buckling theory and is given by Timoshenko and Gere [18] as:

$\tau_{c r}=k \frac{\pi^{2} E}{12\left(1-v^{2}\right)(d / t)^{2}}$

In which the buckling coefficient, $k$ is determined by a theoretical critical load analysis (Timoshenko and Gere [18]). It is a function of plate geometry and boundary conditions and is given by Johnston [19] as: 


$$
\begin{array}{ll}
k=4.00+\frac{5.34}{\left(a_{s} / d\right)^{2}} & \text { for } a_{s} / d \leq 1 \\
k=5.34+\frac{4.00}{\left(a_{s} / d\right)^{2}} & \text { for } a_{s} / d \geq 1
\end{array}
$$

If the numerical values for $v=0.3$ and $E=205000 \mathrm{~N} / \mathrm{mm}^{2}$ are substituted in to Equation (7), and further combined with Equation (8a) and (8b), then,

$$
\begin{array}{ll}
\tau_{c r}=\left(0.75+\frac{1.00}{\left(a_{s} / d\right)^{2}}\right)\left(\frac{995}{d / t}\right)^{2} \quad \text { for } a_{s} / d \leq 1 \\
\tau_{c r}=\left(1.00+\frac{0.75}{\left(a_{s} / d\right)^{2}}\right)\left(\frac{995}{d / t}\right)^{2} \quad \text { for } a_{s} / d \geq 1
\end{array}
$$

The shear stresses in many structural members are transmitted by unstiffened webs, for which the aspect ratio, $a / d$, is large and assumed infinity. Therefore, for unstiffened webs, using Equation (9b), $\tau_{c r}$ can be given as:

$$
\tau_{c r}=\left(\frac{995}{d / t}\right)^{2}
$$

Using maximum distortion strain energy theory (Von-Mises yield criterion); it can be shown that the yield stress in shear, $\tau_{y}$, is equal to $p_{y} / \sqrt{3}\left(\approx 0.6 p_{y}\right)$, where $p_{y}$ is the design strength of the web (Trahair et al. [17]). Stocky unstiffened webs in steel beam yield in shear before they buckle elastically. When a web panel yields, the critical shear stress is equal to the yield stress in shear.

i.e. $\tau_{c r}=\frac{p_{y}}{\sqrt{3}}$

Using Equations (10) and (11), the limiting ratio of $d / t$ for web yielding in shear can be given as:

$d / t=79 \varepsilon$

where

$\varepsilon=\sqrt{275 / p_{y}}$

A stocky unstiffened web in an I-section beam subjected to pure shear loading is shown in Figure 6(a). The web behaves elastically in shear until yielding starts at $\tau_{y}=p_{y} / \sqrt{3}$, yielding continues as the section undergoes increasing plastification until the web has yielded fully in shear. Because the shear stress distribution at first yield is nearly uniform, the nominal first yield and fully plastic loads are nearly equal, and the shear shape factor is usually very close to 1.0. Stocky unstiffened webs in steel beams reach first yield before they buckle elastically, hence their strengths are determined by the shear stress $\tau_{y}$, as indicated in Figure 6. 
Thus the resistance of a stocky web in a flanged section for which the shear shape factor is near unity is closely approximated by the web plastic shear resistance:

$V_{w}=d t \tau_{y}$

When the depth to thickness ratio $d / t$ of a long unstiffened steel web exceeds $79 \sqrt{275 / p_{y}}$, its elastic buckling shear stress $\tau_{c r}$, is less than the shear yield stress.

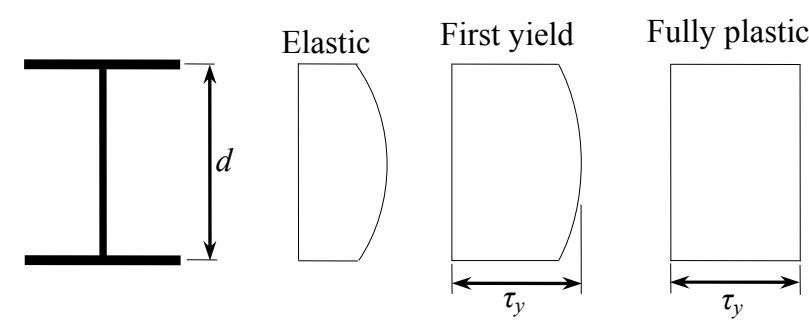

$\begin{array}{ll}\text { (a) I-section } & \text { (b) Shear stress distributions }\end{array}$

Figure 6. Plastification of an I-Section Web in Shear

The design shear force $F_{v}$ on a web for which the shear stress is approximately uniform must satisfy $F_{v} \leq P_{v}$, in which $P_{v}$ is the uniform shear capacity. The uniform shear capacity of a stocky web of area $A_{v}$ is given by:

$P_{v}=0.6 p_{y} A_{v}$

Which is very close to $d t \tau_{y}\left(\approx 0.58 A_{v} p_{y}\right)$ given for the fully plastic shear capacity, where $d$ is the depth of the web and $t$ the web thickness. An I-section web is classified by BS 5950 as stocky when its depth to thickness ratio satisfies $d /(t \varepsilon) \leq 70$ for a hot-rolled beam (the web of all British universal sections of S275 or S355 steel are stocky), and when $d /(t \varepsilon) \leq 62$ for a welded plate girder, otherwise it is classified as slender. Not that the value 62 is less than the value of 79 which developed earlier (Equation (12)) on limiting slenderness when elastic buckling $\tau_{c r}$ is equal to shear yield stress $\tau_{y}$ (Trahair et al. [17]).

BS 5950 recommends that when $d / t$ exceeds $62 \varepsilon$ the web should be checked for sighs of shear buckling. The code uses notation $q_{e}$ instead of $\tau_{c r}$ for the elastic critical shear stress. It also identifies three modes of behavior for webs.

The first mode is where the web strength is governed by its ultimate yield strength, i.e. $p_{y} / \sqrt{3}$, the third is where the capacity is solely governed by the elastic critical shear stress, $q_{c r}$, and the intermediate stage is where an interaction occurs between the first and third modes. The divisions between the three modes are quantified by equivalent web slenderness factor, $\lambda_{w}$, which is given by Trahair et al. [17]:

$\lambda_{w}=\left(p_{v} / q_{e}\right)^{0.5}$

where

$p_{v}=0.6 p_{y}$ 
Code (BS 5950) gives the critical shear strength, $q_{w}$, of a web panel as follows:

For $\lambda_{w} \leq 0.8, q_{w}=p_{v}$

For $0.8<\lambda_{w}<1.25, q_{w}=\left[\left(13.48-5.6 \lambda_{w}\right) / 9\right] p_{v}$

For $\quad \lambda_{w} \geq 1.25, q_{w}=\left(0.9 / \lambda_{\mathrm{w}}\right) p_{v}$

when no stiffener is provided, using Equations (10) and (16) it can be shown that,

For $\quad \lambda_{w}=0.8$, then $d / t=62 \varepsilon$

For $\lambda_{w}=1.25$, then $d / t=97 \varepsilon$

When an I-beam is subjected to bending, most of the applied shear force is resisted by the web. Web thickness of a corroded beam can remain uniform at initial stages of corrosion. In sections, where web thickness does not vary significantly due to corrosion, average web thickness may be used for evaluating the shear capacity. When depth to thickness ratio, $d / t$, exceeds $62 \varepsilon$ the web should be checked for shear buckling in accordance with BS 5950 [16].

\subsection{Lateral Distorsional Buckling Strength}

The compression flange of an I-beam acts like a column and will buckle sideways if the beam is not sufficiently stiff or the flange is not restrained laterally. The load at which the beam buckles can be much less than that causing the full moment capacity to develop. For an idealized perfectly straight beam, there are no deformations normal to the loading plane until the applied moment reaches a critical value $M_{E}$, less than the moment capacity. At this point the beam buckles by deflecting laterally and twists as shown in Figure 7. These two deformations are interdependent, when the beam deflects laterally; the applied moment exerts a component torque about the deflected longitudinal axis which causes the beam to twist. This behavior, which is important for long unrestrained I-beams, is called lateral torsional buckling.

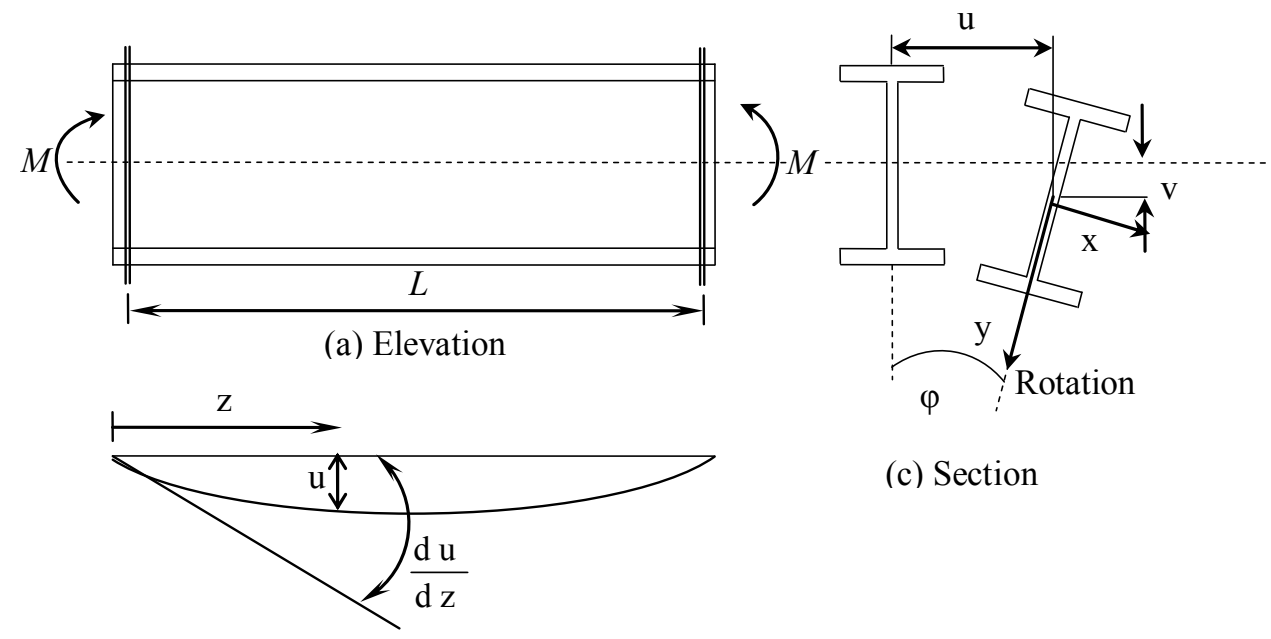

(b) Plan on the longitudinal axis

Figure 7. Lateral Torsional Buckling of a Simply Supported I-Beam 
A perfectly straight beam which is loaded by equal and opposite end moments is shown in Figure 7. The beam is simply supported at its ends so that lateral deflection and twist rotation are prevented, while the flange ends are free to rotate in horizontal planes. Elastic theory is used to set up equilibrium equations that equate external disturbances to the lateral bending and torsional resistance of the beam. The solution of these equations for the elastic critical moment was given by Timoshenko and Gere [18] as:

$M_{E}=\frac{\pi}{L}\left(E I_{y} G J\right)^{1 / 2}\left(1+\frac{\pi^{2} E I_{w}}{L^{2} G J}\right)^{1 / 2}$

where, $M_{E}$ is elastic critical buckling moment, $E I_{y}$ is the minor axis flexural rigidity, $G J$ is the torsional rigidity, $E I_{w}$ is the warping rigidity of the beam, and $L$ is the beam length, Equation (20) shows that the resistance to buckling depends on the geometric mean of the flexural resistance $\left(\pi^{2} E I_{y} / L^{2}\right)$ and the torsional resistance $\left(G J+\pi^{2} E I_{w} / L^{2}\right)$.

The magnitude of the critical moment given by Equation (20) does not depend on the major axis flexural rigidity $E I_{x}$ of the beam in the vertical plane. This conclusion is obtained as a result of the assumption that the deflections in the vertical plane are small as shown in Figure 7, which is justifiable since the flexural rigidity $E I_{x}$ is much greater than the rigidities $E I_{w}$ and $E I_{y}$. If the rigidities are of the same order of magnitude, the effects of bending in the vertical plane should be considered (Timoshenko and Gere [18]). The equation for the elastic critical buckling moment, which includes the effect of major axis bending, is given by Martin et al. [20] as:

$M_{E}=\frac{\pi}{L}\left(\frac{E I_{y} G J}{\gamma}\right)^{1 / 2}\left(1+\frac{\pi^{2} E I_{w}}{L^{2} G J}\right)^{1 / 2}$

Where $\gamma$ is the correction factor, which is just less than unity for most beam sections, and is given by, $\gamma=1-\frac{I_{y}}{I_{x}}$

\subsection{Web Bearing Strength}

Plate elements (e.g. webs) are subjected to bearing stresses by concentrated loads or locally distributed edge loads (reactions from supports or other members) as shown in Figure 8. For example, a concentrated load applied to the top flange of a beam induces local bearing stresses in the web immediately beneath the load. When the load reaches its critical value, the web crushes (cripples) by combined compression and folding directly under the load. 


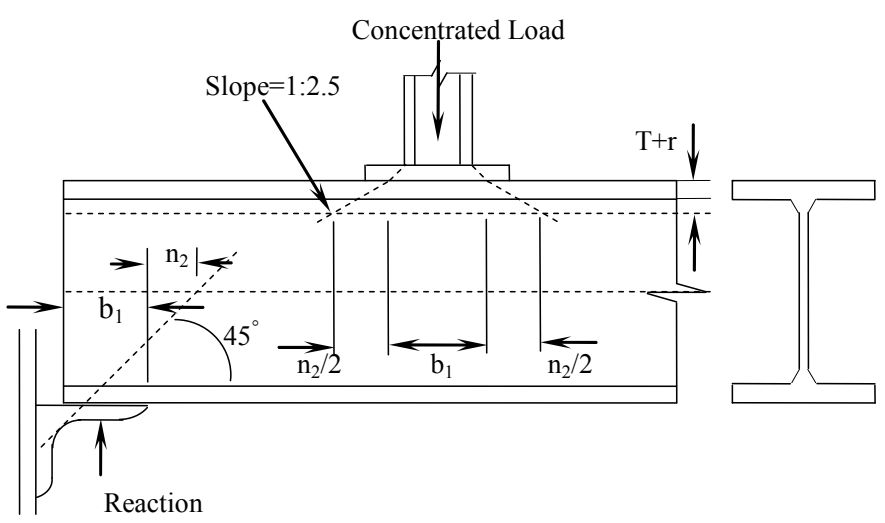

Figure 8. Effective Web Bearing Length to Resist Crushing

The ultimate bearing strength of a thick web depends on its design strength, $p_{y}$. although yielding first occurs under the centre of the bearing plate, general yielding does not takes place until the applied load is large enough to cases yielding of a web area defined by a dispersion of the applied load is large enough the flange. Even at this load the web does not collapse catastrophically, and some further yielding and redistribution is possible (Trahair et al. [17]).

Where point loads or reactions from supports or other members are applied to a beam as shown in Figure 8 then the web should be checked for bearing stresses. The web bearing strength, $P_{w b g}$, is given by

$P_{w b g}=\left(b_{t}+n_{2}\right) t p_{y}$

where

$b_{t}$ is the stiff bearing length,

$n_{2}$ is the length obtained by the slope 1:2.5 dispersion through the flange and can be taken as follows: $n_{2}=2 \times 2.5(T+r)$ for forces applied through a flange by loads or reactions in the length between the ends and

$n_{2}=2.5(T+r)$ for forces applied through a flange by loads or reactions at the ends,

$t$ is the thickness of the web and,

$p_{y}$ is the design strength of the web.

The code recommends that if the force applied through a flange by loads or reactions exceeds the local capacity of the web at its connection to the flange, then bearing stiffeners should be provided.

\section{INVESTIGATION OF CORROSION EFFECTS ON RESIDUAL STRENGTH OF STEEL I-BEAMS}

To demonstrate the effect of corrosion on residual capacity, a steel beam which has been subjected to flexural bending is considered. It is mentioned that a steel beam can fail in different ways depending on its dimension and loading. The principle modes of failure are:

1. Flexural bending

2. Shear failure

3. Lateral distorsional buckling

4. Bearing failure of the web 
As mentioned earlier, loss of material due to corrosion not only reduces the section properties and hence the carrying capacity of a member, but also it can change the mode of failure from one to another depending on the rate and place of corrosion. The loss of thickness in the flanges and web due to corrosion, results in reduction in the capacity. For example, an element may become slender due to corrosion during its service life and local buckling may prevent the development of full plastic moment in such cases. To verify these effects of corrosion, an investigation has been carried out using the corrosion model shown in Figure 3 and the foregoing approaches on the steel structures members. A section of arbitrary dimension was used to illustrate this phenomenon.

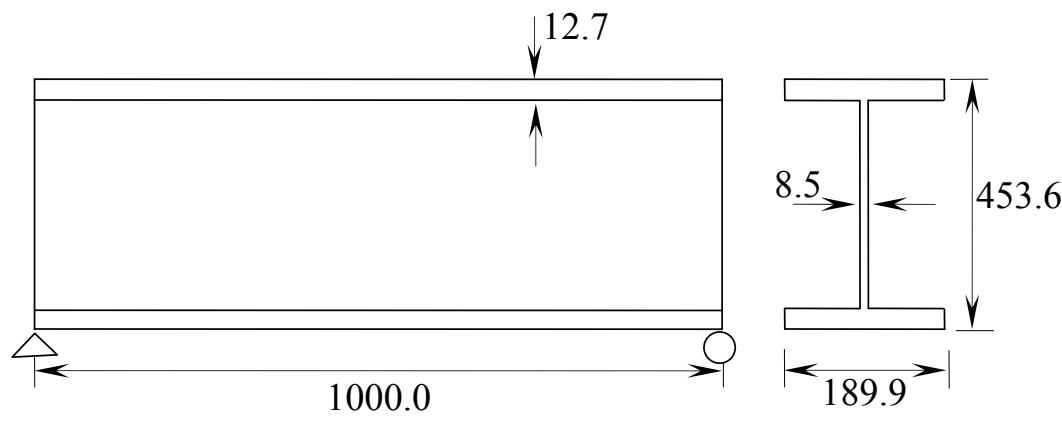

Figure 9. Dimensions of I-Beam (All Measurements are in $\mathrm{mm}$ )

It was assumed that the beam is $1000 \mathrm{~mm}$ long and simply supported at the ends. It was also assumed that the beam carries a central point load. The dimensions of the beam are shown in Figure 9. The theories given in BS 5950 [16] were used for the assessment of the capacities with regard to the failure mechanisms mentioned above. The results, obtained from the above analysis, are plotted in Figure 10.

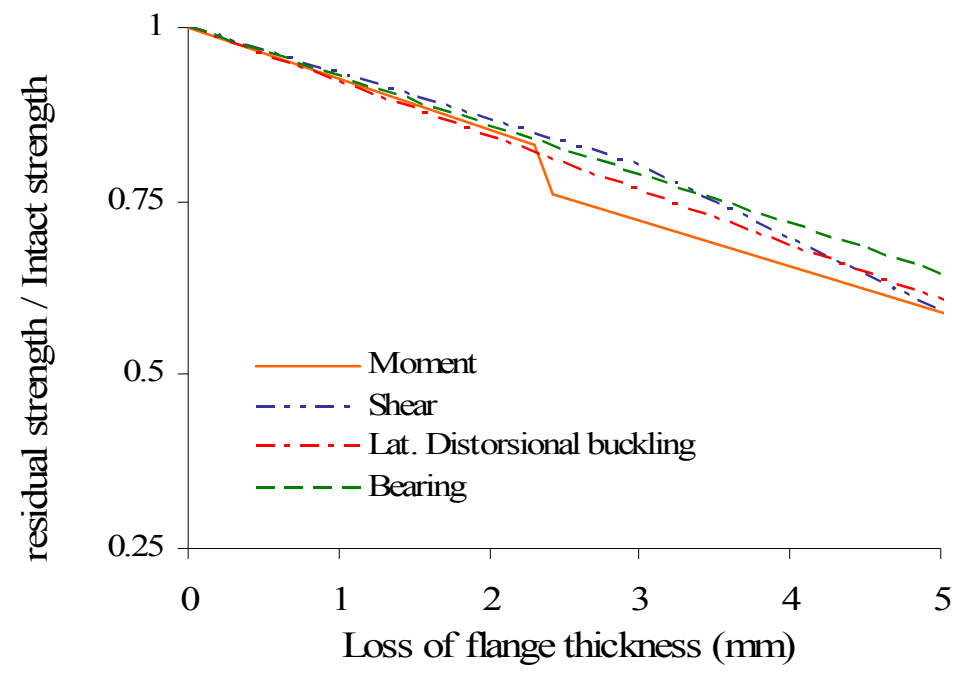

Figure 10. Remaining Capacities of a Corroded I-Beam

As it can be seen from Figure 10 that the reduction in capacities is approximately linear. Moreover, at a certain point there is a sudden drop in the moment and shear capacities. This happens when the class of the compression flange or web is changed from one to another due to loss of thickness. When this happens local buckling of flange or web may prevent the development of full plastic moment and shear. It is observed from these analyses that the rate of reduction of shear capacity is greater than of the bending capacities. The lateral distorsional buckling is the critical failure mode at the early stages of corrosion. 


\section{CONCLUSIONS}

It is clear that the important result of corrosion damage is reduction of the section properties and hence the carrying capacity of a member in during of service life. It can also change the mode of failure from one to another. In other word by increasing the age of steel I-beam, not only all capacities will be decreased but also the mode of failure may change. The analysis of existing structures may differ from the analysis of structures under design, especially if there is damage by corrosion. Some of the assumptions made in design may no longer be true and other failure mechanisms may become significant. It can be found from Figure 10 that the critical failure mode changes from lateral distorsional buckling to local buckling of flanges. The lateral distorsional buckling failure mode governs the flexural member in its early stages. Then, after several years of corrosion, the local buckling of flanges becomes the critical failure mode.

\section{ACKNOWLEDGEMENTS}

The author is pleased to acknowledge the Vali-e-Asr University of Rafsanjan support.

\section{REFERENCES}

[1] Fontana, M.G., "Corrosion Engineering”, McGraw Hill Book Company, New York, Third Edition, 1987.

[2] Kayser, J.R., "The Effects of Corrosion on The Reliability of Steel Girder Bridges", $\mathrm{PhD}$ thesis, Department of Civil Engineering, University of Michigan, 1988.

[3] Sharifi, Y. and Rahgozar, R., "Evaluation of the Remaining Shear Capacity in Corroded Steel I-Beams", International Journal of advanced Steel Construction, 2010, Vol. 6, No. 2, pp. 803-816.

[4] Sharifi, Y. and Rahgozar, R., "Remaining Moment Capacity of Corroded Steel Beams", International Journal of Steel Structures, 2010, Vol. 10, No. 2, pp. 165-176.

[5] Sharifi Y. and Rahgozar R., "Simple Assessment Method to Estimate the Remaining Moment Capacity of Corroded I-Beam Sections", Scientia Iranica Journal, 2010, Vol. 17, No. 2, pp. 161-167.

[6] Sharifi Y. and Rahgozar R., "Evaluation of the Remaining Lateral Torsional Buckling Capacity in Corroded Steel Beams", Journal of Zhejiang University Science A, 2010, Vol. 11, No. 11, pp. 887-897.

[7] Sharifi, Y. and Rahgozar, R., "Fatigue Notch Factor in Steel Bridges Due to Corrosion", Archives of Civil and Mechanical Engineering, 2009, Vol. IX, No. 4, pp. 75-83.

[8] Kulicki, J.M., Prucs, Z., Sorgenfrei, D.F. and Mertz, D.R., "Guidelines for Evaluating Corrosion Effects in Existing Steel Bridges", National Cooperative Highway Research Program, Report 333, Transportation Research Board, National Research Council, Washington, D.C; 1990.

[9] Czarnecki, A.A. and Nowak, A.S., "Time-Variant Reliability Profiles for Steel Girder Bridges", Structural Safety, 2008, Vol. 30, No. 49-64.

[10] Sharifi, Y. and Paik, J.K., "Ultimate Strength Reliability Analysis of Corroded Steel-box Girder Bridges", Thin-Walled Structures, 2011, Vol. 49, No. 1, pp. 157-166.

[11] Sharifi, Y. and Paik, J.K., "Environmental Effects on Ultimate Strength Reliability of Corroded Steel Box Girder Bridges", Structural Longevity, 2009, Vol. 2, No. 2, pp. 81-102.

[12] Sharifi, Y. "Reliability of Deteriorating Steel Box-Girder Bridges under Pitting Corrosion", International Journal of advanced Steel Construction, 2011, Vol. 7, No. 3, pp. 220-238. 
[13] Nethercot, D.A., "Limit States Design of Structural Steelwork", 3rd ed. Spon Press, London, UK, 2001.

[14] Rahgozar, R., "Remaining Capacity Assessment of Corrosion Damaged Beams using Minimum Curves", Journal of Constructional Steel Research, 2009, Vol. 65, pp. 299-307.

[15] Kayser, J.R. and Nowak, A.S., "Capacity Loss Due to Corrosion in Steel-Girder Bridges", Journal of Structural Engineering, ASCE, 1989, 115, pp. 1525-1537.

[16] BS 5950, "Structural use of Steel Work in Building: Part 1, Code of Practice for Design in Simple and Continuous Construction, Hot rolled Sections", British Standard Institution, London, 1985.

[17] Trahair, N.S., Bradford, M.A. and Nethercot D.A, "The Behavior and Design of Steel Structures to BS5950", Third Edition-British, London, Spon Press, Taylor \& Francis Group, 2001.

[18] Timoshenko, S.P. and Gere, J.M. “Theory of Elastic Stability", McGraw-Hill Book Company, 1961.

[19] Johnston, B.G. "Guide to Stability Design Criteria for Metal Structures", Third Edition, John Wiley \& Sons, 1976.

[20] Martin L.H. and Purkiss, J.A. "Structural Design of Steelwork to BS 5950", First Edition, Edward Arnold, London, 1992. 


\title{
HIGHER-ORDER NON-LINEAR ANALYSIS OF STEEL STRUCTURES PART I : ELASTIC SECOND-ORDER FORMULATION
}

\author{
C.K. Iu ${ }^{*}$ and M.A. Bradford \\ Centre for Infrastructure Engineering and Safety \\ School of Civil and Environmental Engineering \\ The University of New South Wales, UNSW Sydney, NSW 2052, Australia \\ *(Corresponding author: E-mail: iu.jerryu@gmail.com)
}

Received: 31 May 2011; Revised: 10 October 2011; Accepted: 14 November 2011

\begin{abstract}
This paper presents a higher-order beam-column formulation that can capture the geometrically non-linear behaviour of steel framed structures which contain a multiplicity of slender members. Despite advances in computational structural frame software, analyses of large frames can still be problematic from a numerical standpoint, with efficacious and reliable convergence not always being ensured. To this end, the intent of this paper is to fulfil a need for versatile, reliable and efficient non-linear analysis of general steel framed structures with a large number of members suitable for engineering practice. Following a comprehensive review of numerical frame analysis techniques, a fourth-order element is derived, in which the crucial member bowing effect involved in the equilibrium equation is captured, and implemented in an updated Lagrangian formulation. Because of this, it is able to predict flexural buckling, snap-through buckling and the large displacement post-buckling behaviour of typical structures whose responses have been reported by independent researchers. The present approach with its efficacious and reliable convergence is shown in comparison studies to be applicable to selected applications which are prone to several forms of geometric non-linearity.
\end{abstract}

Keywords: Beam-column, Frames, Geometric non-linearity, Higher-order element, Steel, Updated lagrangian

\section{INTRODUCTION}

Displacement-based finite element techniques have been the most favoured for frame structures, mainly because of their accuracy, versatility, fully-established mathematical (variational) basis, and their suitability for computer implementation. The finite element method is based on the general principle that equilibrium of the structure under applied loading is achieved at displacements which correspond to the potential energy of the structure being stationary. In the description of the kinematic deformations of framed structures is favourably based on an updated Lagrangian system. Wen and Rahimzadeh [1] and Meek and Tan [2] employed a cubic displacement function to develop their displacement-based finite element method, while So and Chan [3] developed a quartic finite element, whose additional freedom in the displacement function was evaluated using the mid-span deflection of an element; a quintic element (PEP) was presented by Chan and Zhou [4] on the basis of force equilibrium at mid-span to quantify the large displacement behaviour of framed structures. Based on this, Chan and Zhou [5] incorporated initial imperfections into the element formulation, for which a single element can capture buckling of a member under axial compression alone. More recently, Gu and Chan [6] presented refined element including flexural and torsional buckling with finite rotations. Liew et al. [7] proposed a second-order analysis which allows for the geometric non-linear behaviour using one element. Their formulation makes use of stability functions for the transverse displacements, and it also considers the elastic coupling of axial, flexural and torsional deformations. Later, Liew et al. [8, 9] developed their numerical non-linear analysis of a structure subjected to fire and explosion. Similarly, Iu et al. [10,11] presented the non-linear fire analysis of steel structure including heating and cooling behaviour. 
Contemporary steel framed structures invariably contain a multiplicity of slender members, which makes them prone to instability effects so that large displacements and various kinds of buckling can occur because of geometrical non-linearities. For large framed structures containing many members, accurate solutions with computational expediency for the member forces and the structural deformations are needed for engineering practice. Despite significant advances in computational treatments of geometric and material non-linearities in structural frames, the non-linear analysis of slender framed structures with many members is still problematic, with accurate and efficient solutions not always being achievable for large-scale structures. In order to facilitate such a solution, a higher-order displacement-based finite element procedure is proposed in the present paper, based on a fourth-order element. Modern performance-based design paradigms for extreme loading events such as fire, blast and earthquake loads require accurate and efficient techniques, such as that developed in this paper. It is shown that this higher-order element, derived with reference to an incremental updated Lagrangian formulation, is able to provide efficient solutions for structures experiencing significant geometric non-linearity. It also provides the basis for including material non-linearity, which is introduced in the companion paper.

\section{FINITE ELEMENT FORMULATION}

The deformations along the member are taken as $\mathbf{u}=\{u, v, w, \phi\}^{\mathrm{T}}$, which comprise of the deformations $u$ in the $x$ direction, $v$ in the $y$ direction, $w$ in the $z$ direction and the twist $\phi$ about the $x$-axis. The member is idealised in a finite element formulation from the standpoint of having only one element, with the displacement functions chosen being required to satisfy the kinematic condition containing the $\mathrm{P}-\delta$ induced second-order moment as depicted in Figure 1 . The nodal displacement functions of the element are based on nodal displacements in a co-rotational coordinate, so that the dependent variables for the transverse displacements $v$ and $w$ are replaced by the nodal rotations $\theta_{z}$ and $\theta_{y}$ about the $z$ and $y$ axes respectively. These rotations are the dependent variables which define the transverse displacements in the element stiffness formulation which follows.

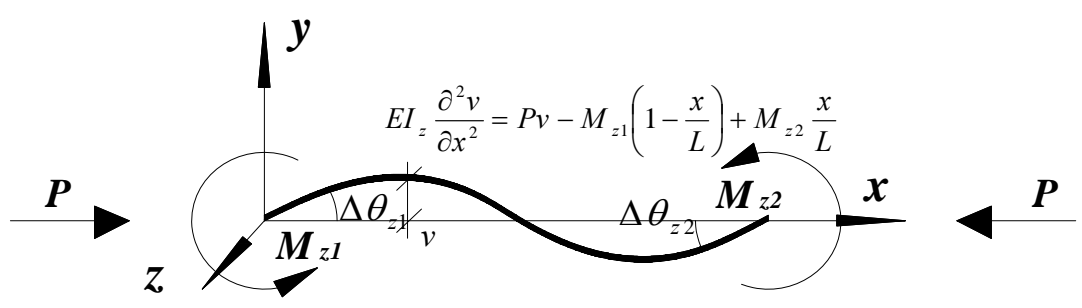

a) Equilibrium of a beam-column element about z-axis

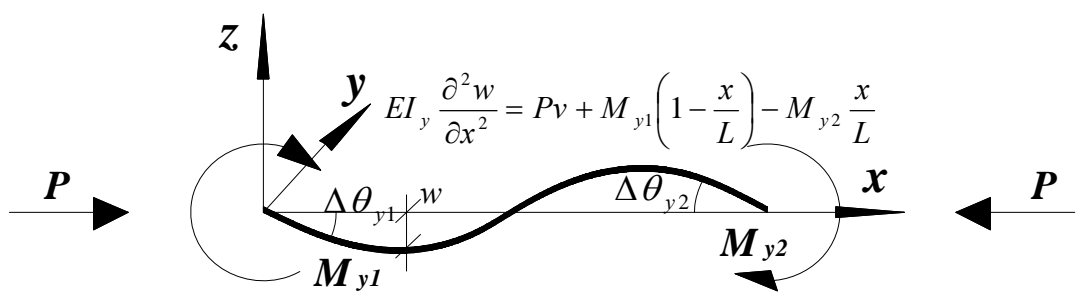

b) Equilibrium of a beam-column element about $y$-axis

Figure 1. Equilibrium Conditions for Deflected Beam-column Element 
Linear functions are assumed for the axial deformation and twist, so that

$u=(1-\xi) u_{1}+\xi u_{2}$

$\phi=(1-\xi) \theta_{x 1}+\xi \theta_{x 2}$

in which $u=u_{1}$ at $x=0, u=u_{2}$ at $x=L$ are the axial nodal deformations, $\phi=\theta_{x 1}$ at $x=0, \phi=\theta_{x 2}$ at $x=L$ are the twist nodal deformations, and where

$\xi=\frac{x}{L}$.

This paper uses fourth-order displacement functions to simulate member bowing behaviour; this necessitates the use of an additional equilibrium condition to tackle an additional unknown coefficient in the fourth-order term which constitutes a secondary or statical boundary condition. This moment equilibrium equation includes the second-order moment due to the member bowing effect and is introduced in the proposed displacement function, and subsequently its stiffness formulation. For the transverse displacement $v$ in the $y$ direction, the primary boundary conditions are

$v=0 \quad$ and $\quad \frac{\partial v}{\partial x}=\theta_{z 1} \quad$ at $x=0$

and

$v=0 \quad$ and $\quad \frac{\partial v}{\partial x}=\theta_{z 2} \quad$ at $x=L$,

while the equation of bending given by

$E I_{z} \frac{\partial^{2} v}{\partial x^{2}}=P v-M_{z 1}(1-\xi)+M_{z 2} \xi$

produces

$E I_{z} \frac{\partial^{2} v}{\partial x^{2}}=P v+\frac{M_{z 2}-M_{z 1}}{2} \quad$ at $\xi=1 / 2$

and which leads to the deformation

$$
\begin{aligned}
v= & {\left[\xi-\frac{4(24+q) \xi^{2}}{48+q}+\frac{(48+5 q) \xi^{3}}{48+q}-\frac{2 q \xi^{4}}{48+q}\right] L \theta_{z 1} } \\
& +\left[\frac{-(48-q) \xi^{2}}{48+q}+\frac{3(16-q) \xi^{3}}{48+q}+\frac{2 q \xi^{4}}{48+q}\right] L \theta_{z 2}
\end{aligned}
$$

in which

$$
q=\frac{P L^{2}}{E I} .
$$


The transverse displacement $w$ in the $z$ direction is derived in a similar fashion. It should be noted that when the stability parameter $q=0$, the transverse displacements reduce to the conventional cubic deformations.

In order to verify the use of the displacement functions given in Eqs. 8, the displacements of the propped cantilever shown in Figure 2 with a tip rotation of 1 radian have been determined based on stability functions, as well as using a third-order polynomial, the present quartic representation, and using a fifth-order polynomial. In the range $0 \leq q \leq \pi^{2}$ (the limit $q=\pi^{2}$ representing the Euler load), the present representation is in good agreement with the exact solution. However, it can be seen that the quartic does produce underestimates of the deformations at very high axial compressive forces $\left(q=2 \pi^{2}\right)$, but this level of axial force is argued to be within the range of inelastic buckling for which elastic stability considerations are not significant.

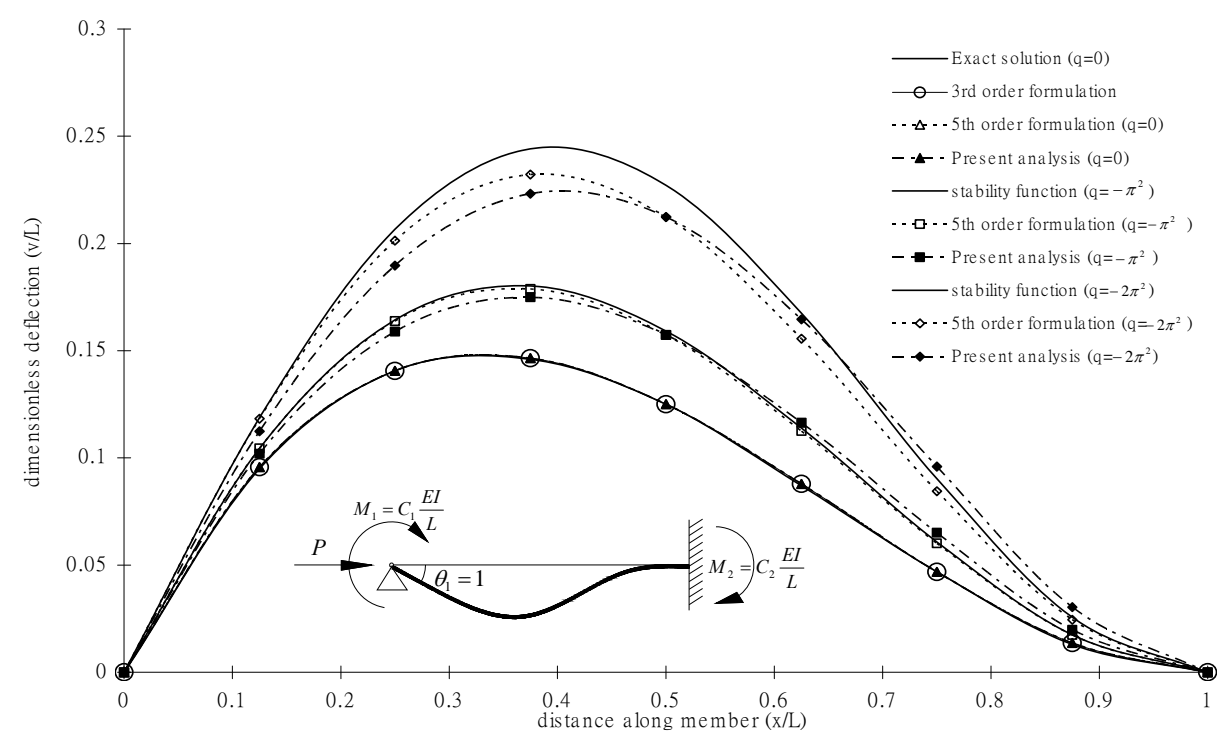

(a) Unit Rotation at Left Hand Support

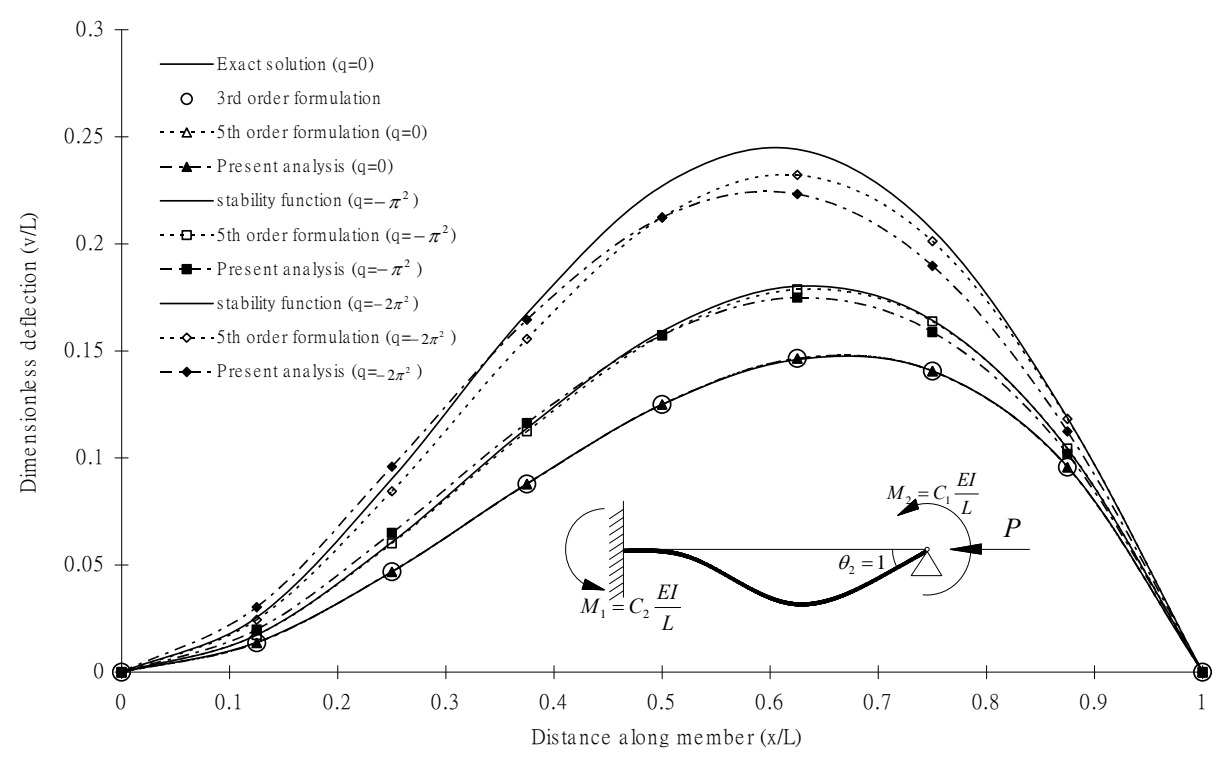

(b) Unit Rotation at Right Hand Support

Figure 2. Deflections of a Propped Cantilever 


\section{STIFFNESS FORMULATION FOR $4^{\mathrm{TH}}$ ORDER BEAM-COLUMN ELEMENT}

The internal strain energy $U$ caused by the axial strain $\varepsilon_{x}$ and twist strain $\gamma_{x}$ along the beam-column continuum can be accumulated by integration of $\delta U_{A}=E \varepsilon_{x} \delta \varepsilon_{x}$ and of $\delta U_{T}=G \gamma_{x} \delta \gamma_{x}$ over the domain of length, which can be expressed in terms of $u, v, w$ and $\phi$ from an appropriate expansion of Green's strain tensor as

$$
U=\int_{V o l}\left(\int_{\varepsilon_{x}} E \varepsilon_{x} \mathrm{~d} \varepsilon_{x}+\int_{\gamma_{x}} G \gamma_{x} \mathrm{~d} \gamma_{x}\right) \mathrm{d} V o l=\frac{1}{2} \int_{V o l}\left(E \varepsilon_{x}^{2}+G \gamma_{x}^{2}\right) \mathrm{d} V o l
$$

in which $E$ is the elastic modulus and $G$ is the shear modulus. For the beam-column representation, Eq. 10 becomes

$$
\begin{aligned}
U= & \frac{E A}{2} \int_{L}\left(\frac{\mathrm{d} u}{\mathrm{~d} x}\right)^{2} \mathrm{~d} x+\frac{P}{2} \int_{L}\left(\frac{\mathrm{d} v}{\mathrm{~d} x}\right)^{2} \mathrm{~d} x+\frac{P}{2} \int_{L}\left(\frac{\mathrm{d} w}{\mathrm{~d} x}\right)^{2} \mathrm{~d} x+\frac{E I_{z}}{2} \int_{L}\left(\frac{\mathrm{d}^{2} v}{\mathrm{~d} x^{2}}\right)^{2} \mathrm{~d} x \\
& +\frac{E I_{y}}{2} \int_{L}\left(\frac{\mathrm{d}^{2} w}{\mathrm{~d} x^{2}}\right)^{2} \mathrm{~d} x+\frac{G J}{2} \int_{L}\left(\frac{\mathrm{d} \phi}{\mathrm{d} x}\right)^{2} \mathrm{~d} x
\end{aligned}
$$

in which $E A$ is the axial rigidity, $E I_{y}$ and $E I_{z}$ are the flexural rigidities and $G J$ is the torsional rigidity.

The elastic stiffness relationship for a general fourth-order element is derived from the total potential energy $\Pi$ in terms of displacements; the total potential energy for nonlinear analysis being the sum of the internal strain energy $U$ in Eq. 11 and of the external work done $V$, which can be written as

$$
\begin{aligned}
\Pi= & \frac{E A}{2} \int_{L}\left(\frac{\mathrm{d} u}{\mathrm{~d} x}\right)^{2} \mathrm{~d} x+\frac{P}{2} \int_{L}\left(\frac{\mathrm{d} v}{\mathrm{~d} x}\right)^{2} \mathrm{~d} x+\frac{P}{2} \int_{L}\left(\frac{\mathrm{d} w}{\mathrm{~d} x}\right)^{2} \mathrm{~d} x+\frac{E I_{z}}{2} \int_{L}\left(\frac{\mathrm{d}^{2} v}{\mathrm{~d} x^{2}}\right)^{2} \mathrm{~d} x \\
& +\frac{E I_{y}}{2} \int_{L}\left(\frac{\mathrm{d}^{2} w}{\mathrm{~d} x^{2}}\right)^{2} \mathrm{~d} x+\frac{G J}{2} \int_{L}\left(\frac{\mathrm{d} \phi}{\mathrm{d} x}\right)^{2} \mathrm{~d} x-\mathbf{u}_{k}^{\mathrm{T}} \mathbf{f}_{k}
\end{aligned}
$$

where $\mathbf{u}_{k}$ and $\mathbf{f}_{k}$ are the column vectors of the incremental displacements and external applied forces with respect to the corresponding freedom, with $\mathbf{u}_{k}=\left\{\Delta u, \Delta \theta_{z 1}, \Delta \theta_{z 2}, \Delta \theta_{x}, \Delta \theta_{y 1}, \Delta \theta_{y 2}\right\}^{\mathrm{T}}$ in which $\Delta u$ $=u_{1}-u_{2}$ and $\Delta \theta_{x}=\phi_{1}-\phi_{2}$. Since the kinematic deformations in the present non-linear analysis rely on an updated Lagrangian description, the total potential energy equation which governs the problem can be linearised in each load increment, so that incremental displacements are utilised in each load increment of the total potential energy equation from which the incremental stiffness formulation for the proposed second-order analysis is derived.

The principle of virtual displacements is used in the present paper to derive the incremental secant $\left(\mathbf{K}_{s}\right)$ stiffness in the form of member resistance and tangent $\left(\mathbf{K}_{t}\right)$ stiffness matrices. Since the strain energy functional in Eq. 11 depends not only on the dependent variables $\mathbf{u}_{k}$, but also on the axial load parameter $q$, invoking Castigliano's first theorem of strain energy, as also given by Oran $[12,13]$ produces 
$\mathbf{K}_{s}=\frac{\partial U}{\partial \mathbf{u}_{k}}+\frac{\partial U}{\partial q} \cdot \frac{\partial q}{\partial \mathbf{u}_{k}}$

Using this, the secant stiffness formulation can be obtained from

$$
\begin{gathered}
M_{\alpha 1}=\frac{\partial U}{\partial \theta_{\alpha 1}}=\frac{E I_{\alpha}}{L}\left[\frac{9216+3456 q / 5+68 q^{2} / 5+8 q^{3} / 105}{(48+q)^{2}}\right] \Delta \theta_{\alpha 1} \\
+\frac{E I_{\alpha}}{L}\left[\frac{4608+576 q / 5+2 q^{2}+q^{3} / 42}{(48+q)^{2}}\right] \Delta \theta_{\alpha 2}
\end{gathered}
$$

or

$$
\begin{aligned}
M_{\alpha 1}= & \frac{E I_{\alpha}}{L}\left(C_{1} \Delta \theta_{\alpha 1}+C_{2} \Delta \theta_{\alpha 2}\right), \\
M_{\alpha 2}= & \frac{\partial U}{\partial \theta_{\alpha 2}}=\frac{E I_{\alpha}}{L}\left[\frac{9216+3456 q / 5+68 q^{2} / 5+q^{3} / 105}{(48+q)^{2}}\right] \Delta \theta_{\alpha 2} \\
+ & \frac{E I_{\alpha}}{L}\left[\frac{4608+576 q / 5+2 q^{2}+q^{3} / 42}{(48+q)^{2}}\right] \Delta \theta_{\alpha 1}
\end{aligned}
$$

or

$M_{\alpha 2}=\frac{E I_{\alpha}}{L}\left(C_{1} \Delta \theta_{\alpha 2}+C_{2} \Delta \theta_{\alpha 1}\right)$

in which the subscript $\alpha$ denotes $y$ or $z$, and

$$
\begin{aligned}
\Delta P= & P_{1}-P_{2}=\frac{\partial U}{\partial e}+\frac{\partial U}{\partial q} \cdot \frac{\partial q}{\partial e}=\frac{E A e}{L}+E A \sum_{\alpha=y, z}\left[\frac{16 q^{2} / 35}{(48+q)^{3}}\right]\left(\Delta \theta_{\alpha 1}-\Delta \theta_{\alpha 2}\right)^{2} \\
& =E A\left[\frac{e}{L}+\sum_{\alpha=y, z} C_{b}\right]
\end{aligned}
$$

where $e=\Delta u=u_{1}-u_{2}$ is the axial shortening with respect to the incremental axial member load $\Delta P$ as a dependent variable.

The tangent stiffness matrix can be obtained from the second derivative of the total potential functional in Eq. 12 with respect to the dependent variables $\mathbf{u}_{k}$ and the load parameter $q$, which includes the second order $\mathrm{P}-\delta$ effect. When the external work done $V$ is linear, the tangent stiffness can be written as the second derivative of $U$ with respect to $\mathbf{u}_{k}$ as

$$
\mathbf{K}_{t}=\frac{\partial^{2} \Pi}{\partial \mathbf{u}_{j} \partial \mathbf{u}_{k}}=\frac{\partial}{\partial \mathbf{u}_{j}}\left(\frac{\partial U}{\partial \mathbf{u}_{k}}\right)+\frac{\partial}{\partial \mathbf{u}_{k}}\left(\frac{\partial U}{\partial q} \cdot \frac{\partial q}{\mathbf{u}_{j}}\right) .
$$

The tangent stiffness for the fourth-order element, which relates the incremental deformation to the corresponding external loads imposed on the element in the member coordinate system, is then given as 


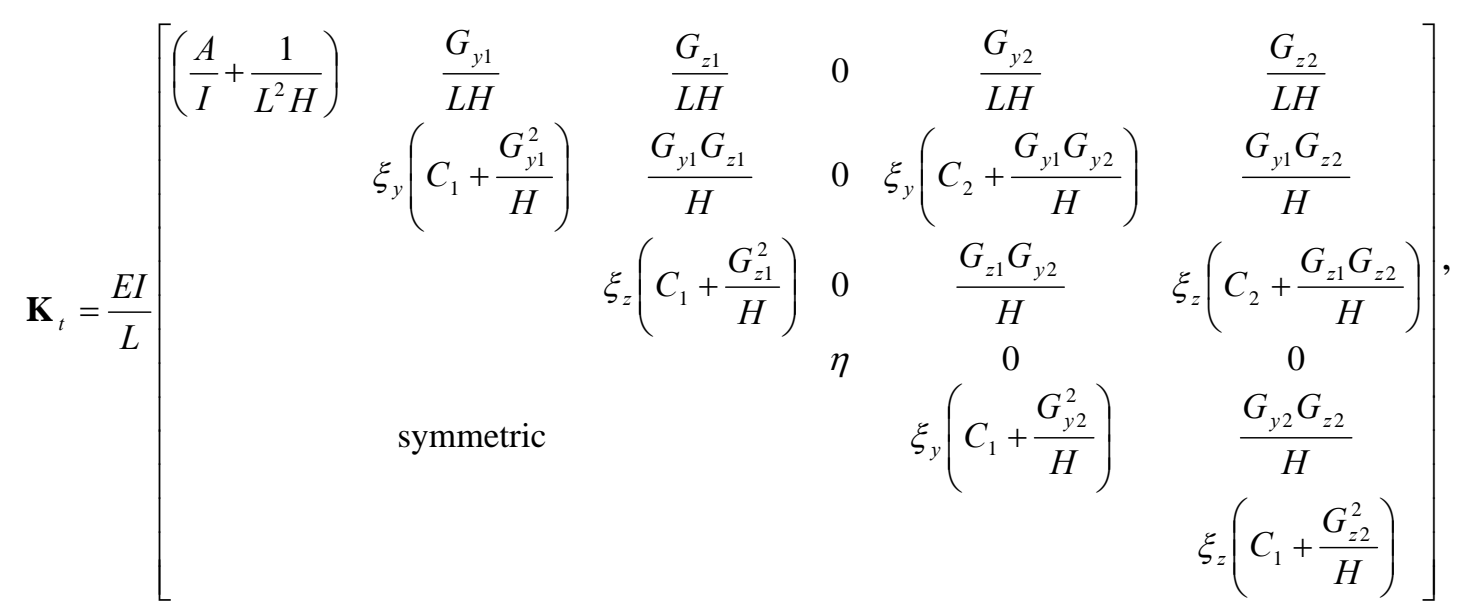

in which $I$ is the second moment of area about the relevant axis for which buckling is to be considered, $\xi_{y}=I_{y} / I, \xi_{z}=I_{z} / I$ and the coefficients $G_{\alpha i}$ and $H$ are given in the Appendix. When the axial force parameter $q$ is taken as zero, the stiffness terms $G_{\alpha i}$ vanish and the tangent stiffness matrix in Eq. 20 is the same as that for a conventional cubic element.

For the global coordinate system, the tangent stiffness $\mathbf{K}_{T}$ is represented as

$$
\mathbf{K}_{T}=\sum_{\text {elements }} \mathbf{L} \mathbf{K}_{e} \mathbf{L}^{\mathrm{T}}=\sum_{\text {elements }} \mathbf{L}\left(\mathbf{T}^{\mathrm{T}} \mathbf{K}_{t} \mathbf{T}+\mathbf{N}\right) \mathbf{L}^{\mathrm{T}},
$$

where $\mathbf{T}$ is a transformation matrix which relates the member forces to the element forces in the local coordinate system, $\mathbf{L}$ is a transformation of the local coordinates to global coordinates, and $\mathbf{N}$ is a stability matrix to allow for the work done by rigid body motions or changes of the geometry of the structure. Consequently, the geometry of the structure is then updated by accumulating both the 'neutral' member deformations and rigid body movements in an updated Lagrangian approach. Because the governing equation for total potential energy in Eq. 12 on which the stiffness matrices have been obtained is non-linear, an incremental-iterative procedure is needed to trace the non-linear equilibrium path.

\section{NUMERICAL VERIFICATIONS}

The proposed non-linear analysis formulation of this paper which handles geometric non-linearity is investigated in this section for a cantilever undergoing a large tip deflection, as well as for three frame structures. A two-member right angled frame is investigated, as well as a two-bar toggle frame and a two-bar truss, and finally a 24-member reticulated shallow dome structure is investigated, in which snap-through buckling, post-buckling and large displacement can occur.

\subsection{Large Displacement of a Cantilever}

The large displacement analysis of an elastic cantilever beam was first presented by Bisshopp and Drucker [14], in which an exact theoretical solution was developed. Their analysis allows for expressions of the exact curvature and the effect of shortening due to the deflection of the tip load on the cantilever. This problem was also investigated by Saleeb and Chen [15], and others. For the modelling of this paper, four elements were used for the cantilever. 


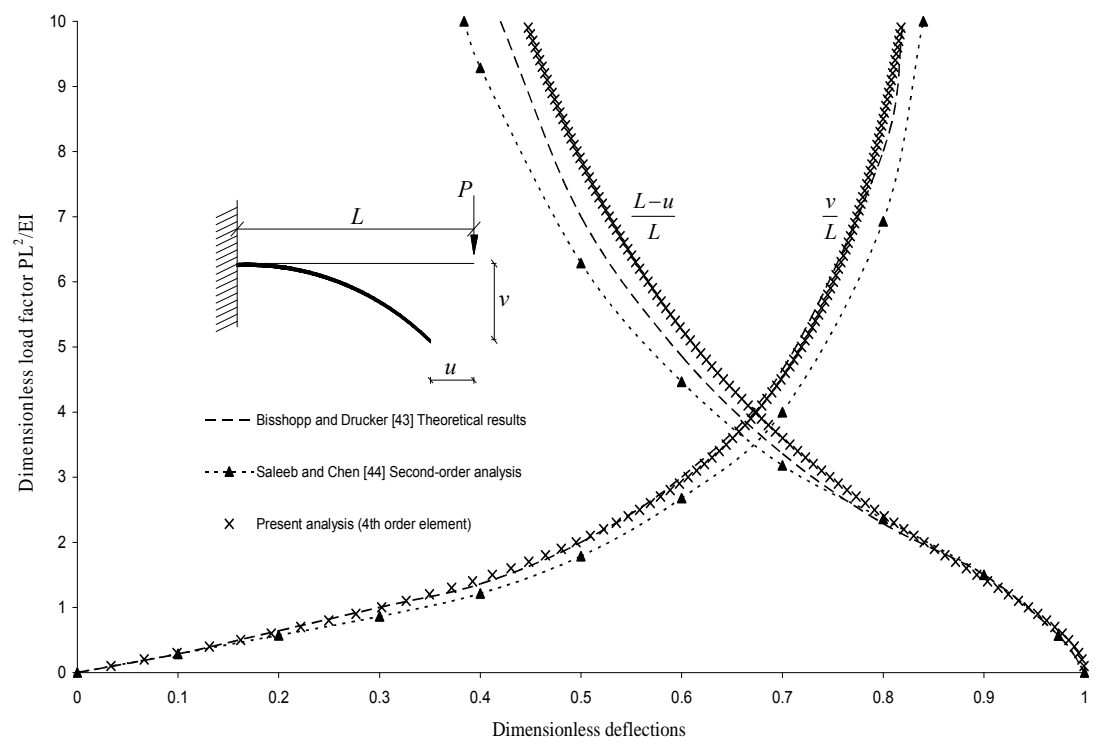

Figure 3. Large Displacement Analysis of Tip-loaded Cantilever

Figure 3 shows the normalised horizontal and vertical deflections of the free end, plotted against the dimensionless applied load $P L^{2} / E I$. It can be seen that the axial deformations $u$ from the present analysis are in good agreement with the theoretical solution [14], with the transverse deformations $v$ coinciding with the theoretical solution throughout the entire range. The proposed non-linear modelling therefore allows large displacement behaviour due to bending and shortening to be simulated.

\subsection{Load-deflection Response of Right Angled Frame}

Koiter [16] provided the first analytical solution of a right angled frame, presenting a formulation for studying its buckling and post-buckling response. Chan and Zhou [4] have also studied this frame in order to verify their higher-order element formulation. A right-angled frame with pin supports and equal column and beam lengths, subjected to a point load $P$ with an eccentricity $e$ $(0.254 \mathrm{~m})$ to the beam-to-column joint, was modelled in the present analysis with two elements for each member. The section, geometry and material properties are shown in Figure 4, which also shows the joint rotation plotted against the dimensionless load $P / P_{E}$, where $P_{E}$ is the Euler load. The proposed non-linear modelling produces results consistent with those of Chan and Zhou [4], and moreover predicts the post-buckling response of a perfect frame given by Koiter [16].

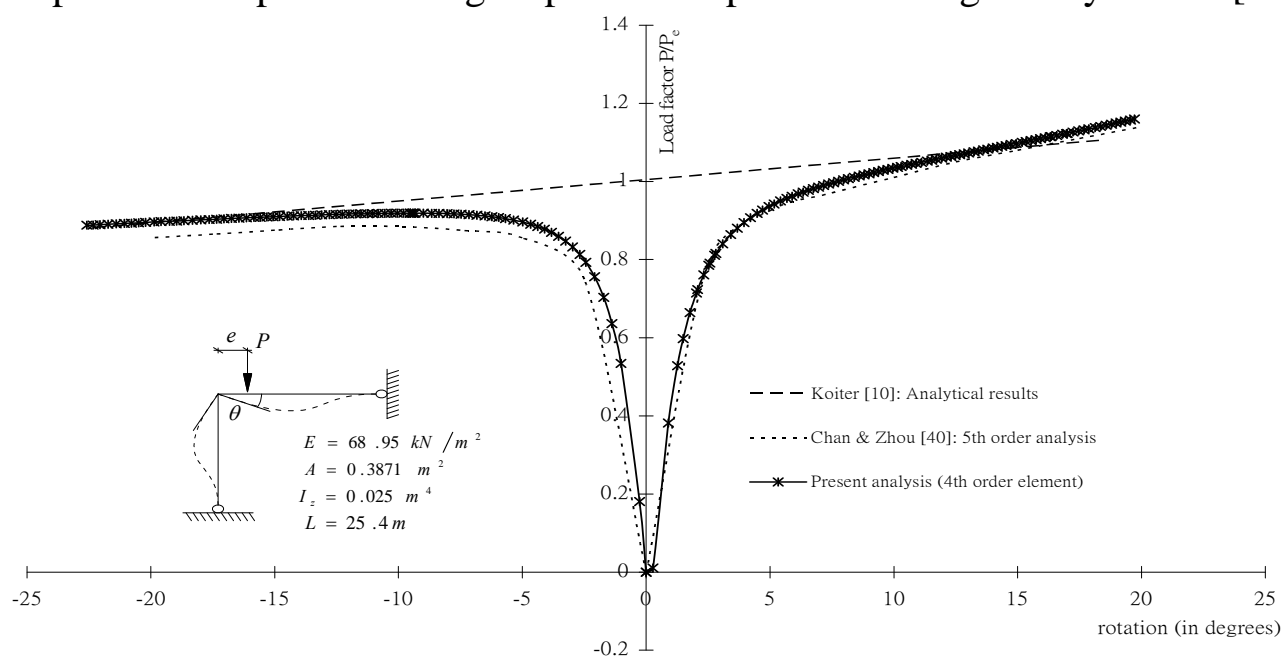

Figure 4. Large Displacement of Right-angle Frame 


\subsection{Snap-through Buckling and Post-buckling of Toggle Frame}

A shallow two-bar frame (toggle frame) was proposed by Williams [17] for demonstrating the snap-through buckling behaviour of a structure, and he presented experimental and analytical solutions for a toggle frame with fixed end supports under a vertical load $P$ at its apex. The elastic modulus of the bars is $71.02 \mathrm{kN} / \mathrm{mm}^{2}$ and they are of rectangular section with a width of 19.126 $\mathrm{mm}$ and depth of $6.1722 \mathrm{~mm}$. For the modelling of this paper, four elements were used for each bar.

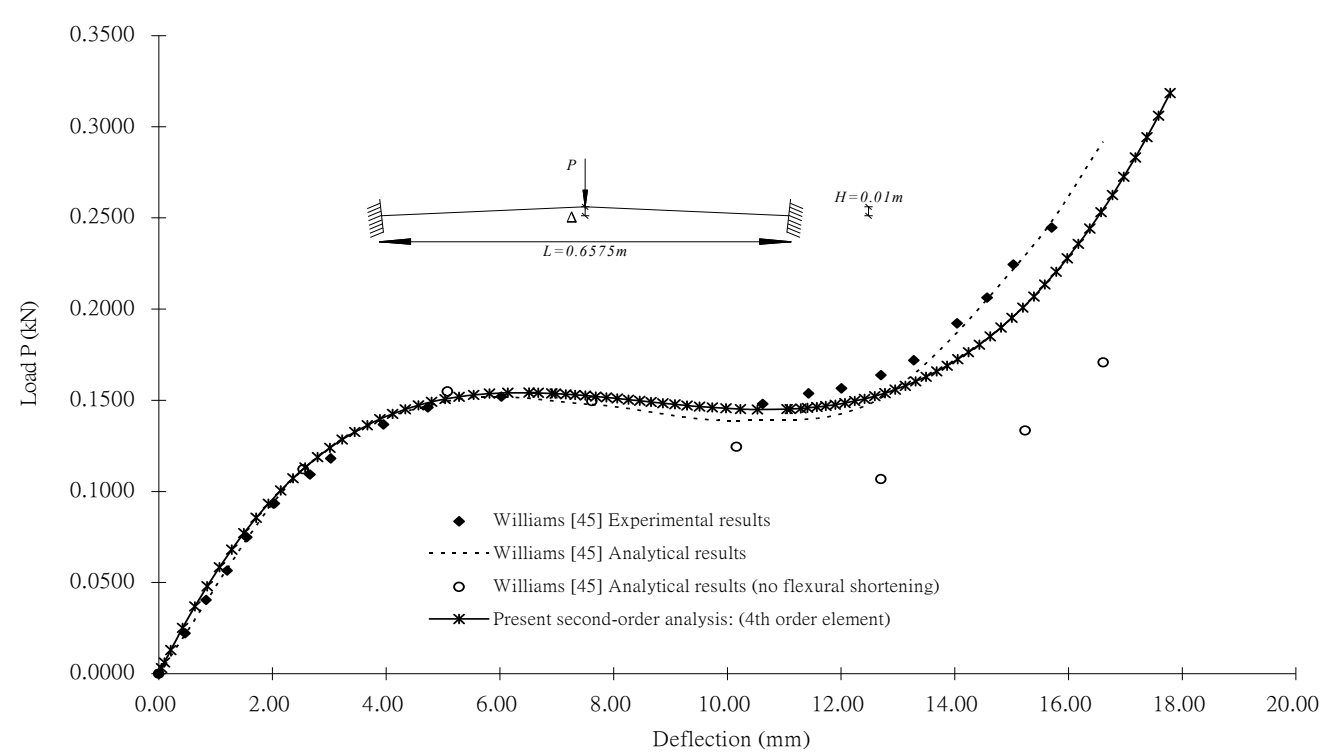

Figure 5. Load-deflection curve and snap-through buckling of toggle frame

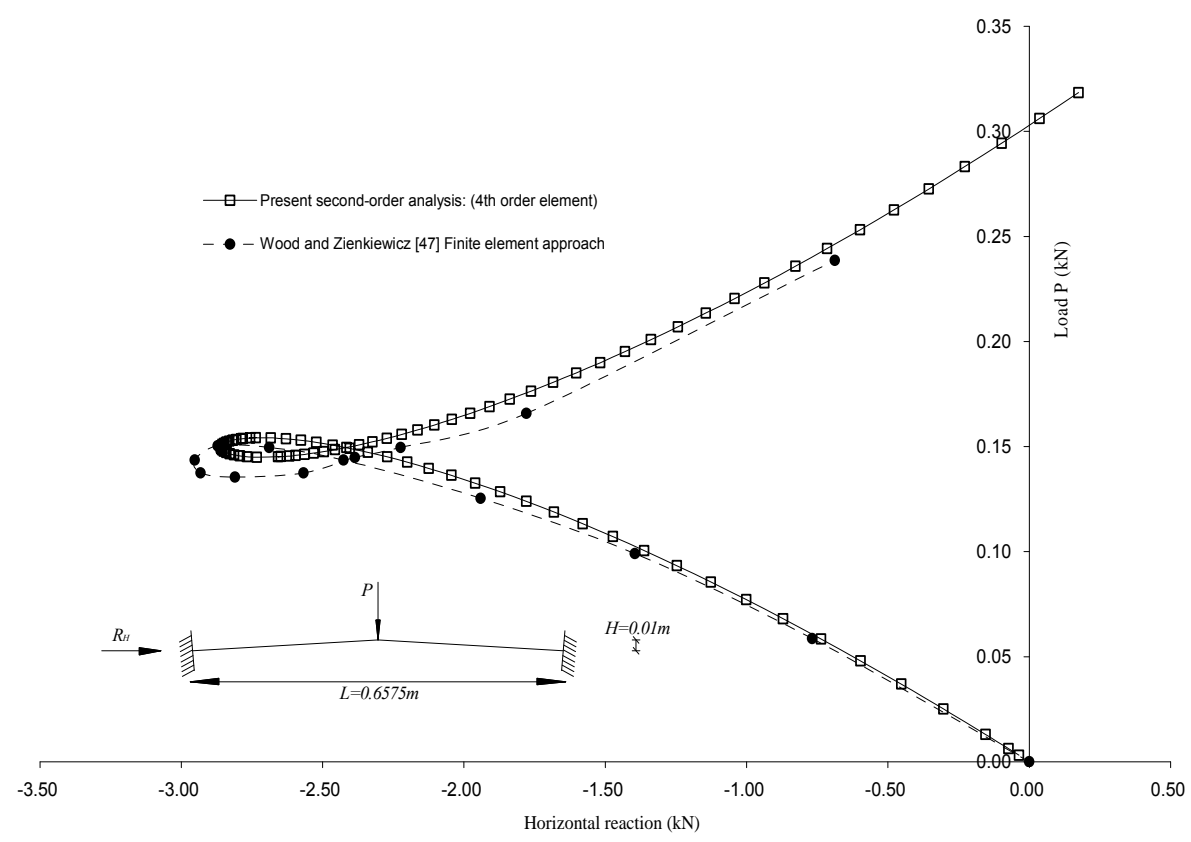

Figure 6. Horizontal reaction and snap-through buckling of toggle frame

Figure 5 shows the toggle frame with a rise of $100 \mathrm{~mm}$ and a horizontal span of $657.5 \mathrm{~mm}$ between supports, for which the vertical deflection at the apex is shown as a function of the load. After attaining the critical load for the frame, the structure softens slightly with increasing deformations as the load decreases, and then hardens as the frame is subjected to tension; similar responses occur with very shallow arches with fixed supports [18]. It can be seen from the figure that the experimental results are disparate from the analytical ones when they do not include flexural shortening, but the experiments agree well with the results of the present paper which include 
flexural shortening, as well as those of Williams [17] when flexural shortening is included. Wood and Zienkiewicz [19] analysed Williams' toggle frame using the finite element method with a modified Newton-Raphson technique, and presented results for the horizontal reaction $R_{H}$ shown in Figure 6; their result for the load-deflection curve was consistent with that of Williams [17]. Because of the flatness of the toggle frame, these reactions are very similar to the forces in the two members. The results from the present formulation are also shown in Figure 6, and are in good agreement with those of Wood and Zienkiewicz [19]. During the snap-through bucking of the toggle frame, which is much beyond Euler load of $2.4 \mathrm{kN}$, the member force decreases slightly, and the compression gradually reduces with an increase of the applied load until $R_{H}$ becomes positive and the members are in tension, as shown in the Figure 6.

\subsection{Snap-through Buckling and Post-buckling of Two-member Plane Truss}

A two-member truss is used as a demonstration of the snap-through buckling and post-buckling of a plane truss which is subjected to a vertical load $P$ at its vertex. This plane truss has a rise of 25.4 $\mathrm{mm}$ and clear span of $1.27 \mathrm{~m}$ between two pinned supports, as shown in Figure 7 . Each member of the truss is assumed to have the same cross-sectional area $A$ and elastic modulus $E$. For the modelling of this paper, four elements were used for each member of this truss.

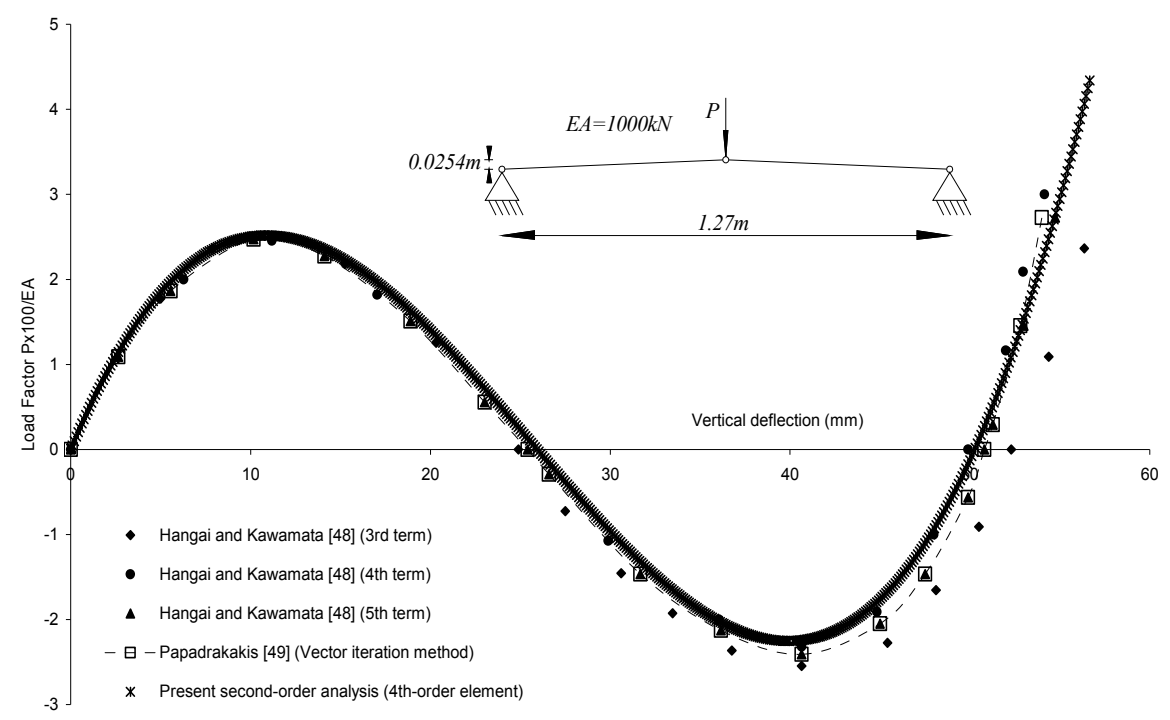

Figure 7. Load-deflection Curves of the Plane Truss

Hangai and Kawamata [20] previously analysed this truss by the static perturbation technique, using various degrees of approximation in the force-displacement relationship. For the same plane truss, Papadrakakis [21] presented a vector iteration method to trace the non-linear load-deflection relationship, including snap-through and post-bucking responses. Figure 7 plots the vertical deflection at vertex against dimensionless load factor $P /(E A)\left(\times 10^{2}\right)$ from the present analysis as well as the former methods [20, 21]. It was found that the present load-deflection curve is in good agreement with the results $[20,21]$ over the entire loading regime, except that using the third-term approximation from Hanagai and Kawamata [20]. In particular, the post-buckling behaviour from this approximation is disparate from the others. The proposed non-linear analysis therefore adequately accounts for snap-through buckling and post-buckling of the truss structures. 


\subsection{Shallow Reticulated Shell Structure}

A 24-member reticulated shallow shell which was studied by Hangai and Kawamata [20] has been analysed by the proposed method of this paper. All members are identical geometrically and materially, and all joints and supports are pinned (the supports are fixed in direction, being unable to transmit bending moments or torques). For this study, a point load is applied at the top of the reticulated shell at node 1, as shown in Figure 8 which also shows the geometry of the shell structure. This reticulated shell experiences snap-through and post-buckling characteristics, as well as large displacements and rotations at its joints (as reported in [20]), and so is an ideal benchmark problem for large-displacement second-order analysis. The reticulated shell structure was also studied by Jagannathan et al. [22], Holzer et al. [23] and Papadrakais [21].
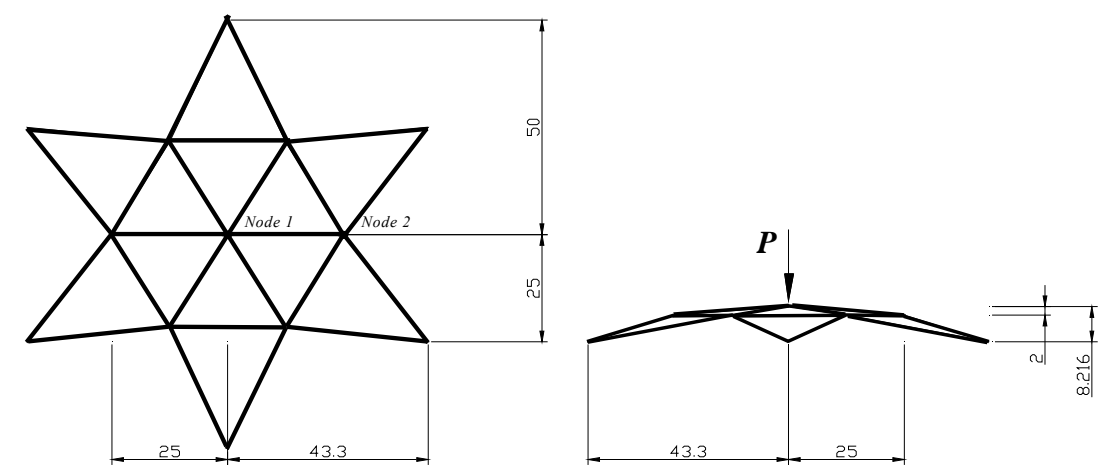

Figure 8. Geometry of 24-member Reticulated Shell Structure

In the analysis of this shell using the proposed formulation, one element was used to model each member of the reticulated structure, and Figure 9 shows the vertical displacement of node 1, plotted against the dimensionless load $P /(E A)\left(\times 10^{4}\right)$, and it can be seen that the results are consistent with those of $[22,23]$ throughout the loading and unloading portions of the curve. Figures 10 and 11 show the vertical and horizontal displacements of node 2 (in Figure 8) respectively, from which it can be seen that the present method agrees very well with the results of Holzer [23], but is disparate with that of Hangai and Kawamata [20] and well as of Jagannathan et al. [22]. It appears from Figs. 9 to 11 that Hangai and Kawamata's solution is not in agreement with those of other investigations, including that proposed in this paper, and this is attributable to the large member rotations at the nodes in which the rigid body rotations also contribute to the strain energy in their formulation. It is interesting to note that there are two zero-load configurations for this shell; at the first the vertical deformations of nodes 1 and 2 are approximately $19 \mathrm{~mm}$ and $-1.16 \mathrm{~mm}$ respectively, at the second they are $40 \mathrm{~mm}$ and $0 \mathrm{~mm}$. Because node 1 is located $20 \mathrm{~mm}$ above the horizontal plane containing the internal ring nodes before loading and $20 \mathrm{~mm}$ below it in the second zero-load configuration, the latter state is symmetrical to the initial unloaded state with respect to this plane and the horizontal deflections are zero, as can be seen from Figs. 10 and 11. The present study therefore allows for large strains, with the large rotations of the shell being captured accurately. 


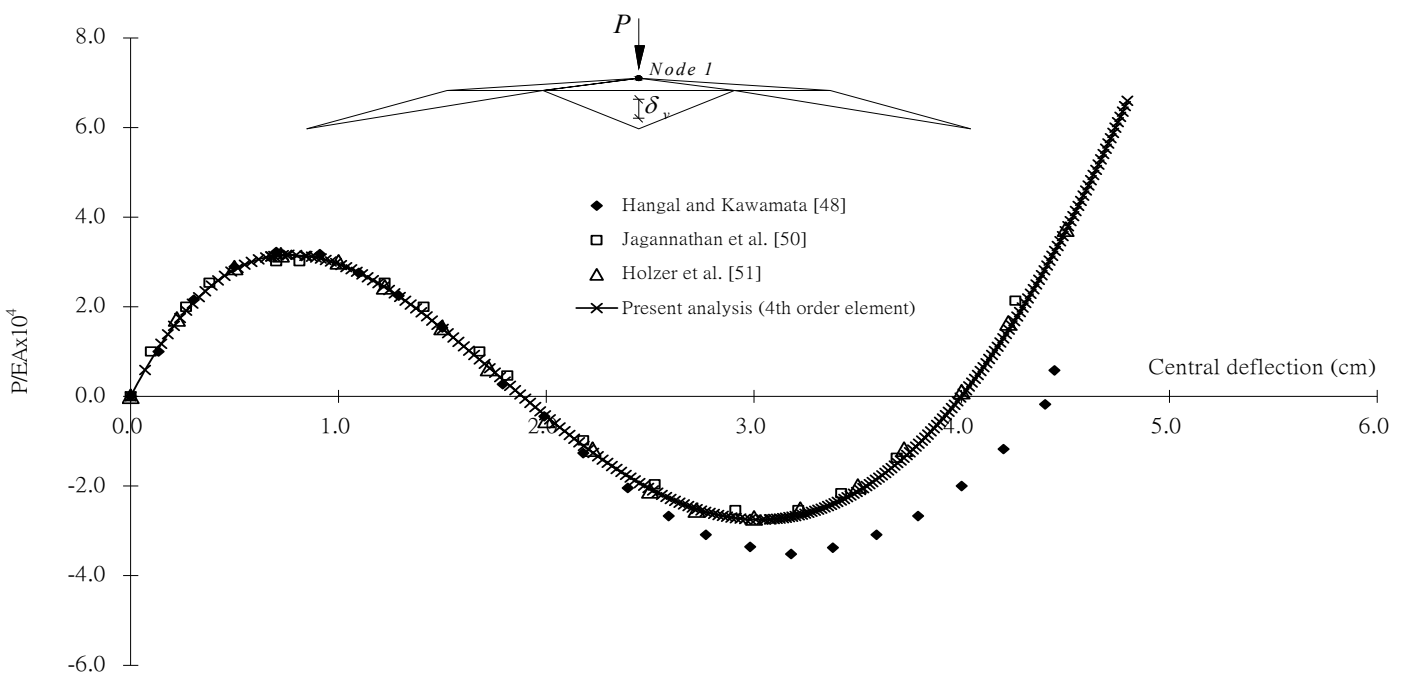

Figure 8. Load vs central deflection displacement for node 1 of reticulated shell

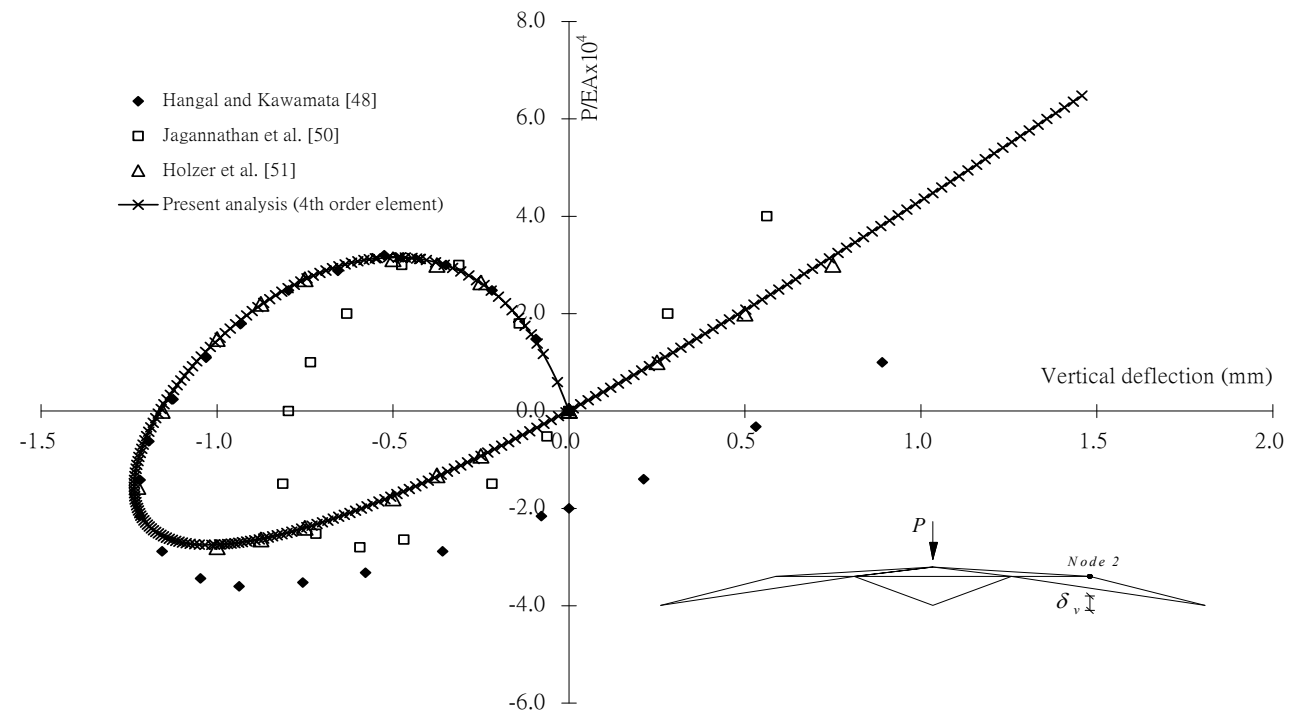

Figure 9. Load vs central deflection displacement for node 2 of reticulated shell

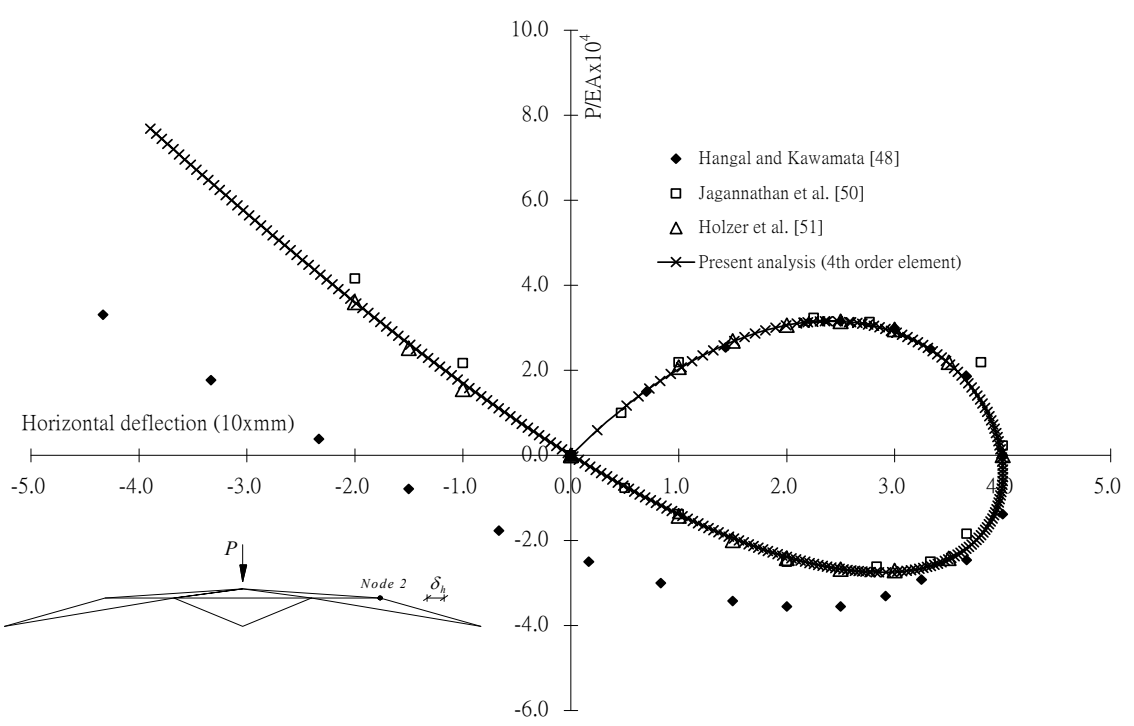

Figure 10. Load vs horizontal deflection displacement for node 2 of reticulated shell 


\section{CONCLUDING REMARKS}

This paper has presented a non-linear finite element formulation using a higher-order element to fulfil a need for versatile, reliable and efficient non-linear analysis of general steel framed structures with very many members. A numerical analysis of this type is a useful formulation for evolution of a method for determining structural responses which occur under extreme loading scenarios such as those of fire and blast, and for which a plethora of scenarios must be considered in design and assessment. The fourth-order element, derived by fulfilling the kinematic conditions needed for the finite element technique and implemented in an incremental updated Lagrangian description, has been shown to predict flexural buckling, snap-through buckling and large displacement post-buckling behaviour of typical structures whose responses have been reported by independent researchers. The technique further forms a basis for the refined plastic hinge approach of the companion paper for handling material non-linearity. In some cases, use of a single element for a member may not be appropriate to capture correctly the geometric non-linearity associated with flexural buckling and snap-through buckling which is attributable to the proposed asymmetric and incomplete bowing function of this paper. Hence at least two elements per member are suggested for these isolated cases. In particular, it was observed from the numerical verifications that four elements per member can, in general, replicate accurate and efficient solutions for structures encountering geometric non-linearities.

\section{ACKNOWLEDGEMENT}

The work in this paper was supported by the Australian Research Council through a Federation Fellowship awarded to the second author.

\section{REFERENCES}

[1] Wen, R.K. and Rahimzadeh, J., "Nonlinear Elastic Frame Analysis by Finite Elements”, Journal of Structural Engineering, ASCE, 1983, Vol. 109, No. 8, pp. 1952-1971.

[2] Meek, J.L. and Tan, H.S., "Geometrically Nonlinear Analysis of Space Frames by An Incremental Iterative Technique", Computer Methods in Applied Mechanics and Engineering; 1984, Vol. 47, pp. 261-281.

[3] So, A.K.W. and Chan, S.L., "Buckling and Geometrically Nonlinear Analysis of Frames Using One Element/Member”, Journal of Constructional Steel Research, 1991, Vol. 20, pp. 271-289.

[4] Chan, S.L. and Zhou, Z.H., "Pointwise Equilibrating Polynomial Element for Nonlinear Analysis of Frames”, Journal of Structural Engineering, ASCE, 1994, Vol. 120, No. 6, pp. 1703-1717.

[5] Chan, S.L. and Zhou, Z.H., "Second-order Elastic Analysis of Frames Using Single Imperfect Element Per Member”, Journal of Structural Engineering, ASCE, 1995, Vol. 121, No. 6, pp. 939-945.

[6] Gu, J.X. and Chan, S.L., "A Refined Finite Element Formulation for Flexural and Torsional Buckling of Beam-column with Finite Rotations”, Engineering Structures, 2005, Vol. 27, pp. 749-759.

[7] Liew, J.Y.R., Chen, H., Shanmugam, N.E. and Chen, W.F., "Improved Nonlinear Plastic Analysis of Space Frame Structures”, Engineering Structures, 2000, Vol. 22, pp. 1324-1338.

[8] Liew, J.Y.R., Tang, L.K. and Choo, Y.S., “Advanced Analysis for Performance-based Design of Steel Structures Exposed to Fires”, Journal of Structural Engineering, ASCE, 2002, Vol. 128, No. 12, pp. 1584-1593. 
[9] Liew, J.Y.R. and Chen, H., "Exposion and Fire Analysis of Steel Frames Using Fiber Element Approach”, 2004, Journal of Structural Engineering, ASCE, Vol. 130, No. 7, pp. 991-1000.

[10] Iu, C.K. and Chan, S.L., "A Simulation-based Large Deflection and Inelastic Analysis of Steel Frames Under Fire”, Journal of Constructional Steel Research, 2004, Vol. 60, pp. 1495-1524.

[11] Iu, C.K., Chan, S.L. and Zha, X.X., "Nonlinear Pre-fire and Post-fire Analysis of Steel Frames”, Engineering Structures, 2005, Vol. 27, pp. 1689-1702.

[12] Oran, C., "Tangent Stiffness in Plane Frames”, Journal of the Structural Division, ASCE, 1973, Vol. 99, No. ST6, pp. 973-985.

[13] Oran, C., "Tangent Stiffness in Space Frames”, Journal of the Structural Division, ASCE, 1973, Vol. 99, No. ST6, pp. 987-1001.

[14] Bisshopp, K.E. and Drucker, D.C., "Large Deflection of Cantilever Beams”, Quarterly Journal of Applied Mathematics, 1945, Vol. 3, No. 3, pp. 272-275.

[15] Saleeb, A.F. and Chen, W.F., "Elastic-plastic Large Displacement Analysis of Pipes", Journal of Structural Engineering, ASCE, 1981, Vol. 107, No. 4, pp. 605-626.

[16] Koiter, W.T., "Post-buckling Analysis of a Simple Two-bar Frame”, Recent Progress in Applied Mechanics (Broberg et al. eds), New York: John Wiley and Sons, 1967, pp. 337-354.

[17] Williams, F.W., "An Approach to the Non-linear Behaviour of Members of a Rigid Jointed Plane Framework with Finite Deflections”, Quarterly Journal of Mechanics and Applied Mathematics, 1964, Vol. 17, No. 4, pp. 451-469.

[18] Bradford, M.A. and Uy, B. and Pi, Y-L., "In-plane Elastic Stability of Arches under a Central Concentrated Load”, Journal of Engineering Mechanics, ASCE, 2002, Vol. 128, No. 7, pp. 710-719.

[19] Wood, R.D. and Zienkiewicz, O.C., "Geometrically Nonlinear Finite Element Analysis of Beams, Frames, Arches and Axisymmetric Shells”, Computers and Structures, 1977, Vol. 4, pp. 725-735.

[20] Hangai, Y. and Kawamata, S., "Nonlinear Analysis of Space Frames and Snap-through Buckling of Reticulated Shell Structures”, Proceedings International Association for Shell and Spatial Structures (IASS) Pacific Symposium, Tokyo, 1971, pp. 803-816.

[21] Papadrakais, M., "Post-buckling Analysis of Spatial Structures by Vector Iteration Methods”, Computers and Structures, 1981, Vol. 14, No. 5-6, pp. 393-402.

[22] Jagannathan, D.S., Epstein, H.I. and Christiano, P.P., "Snap-through Buckling of Reticulated Shells”, Proceedings of the Institution of Civil Engineers London, 1975, Part 2, Vol. 59, pp. 727-742.

[23] Holzer, S.M., Plaut, R.H. and Somer, A.E., "Stability of Lattice Structures under Combined Loads”, Journal of the Engineering Mechanics Division, ASCE, 1980, Vol. 106(EM2), pp. 289-305. 


\section{APPENDIX}

The terms $G_{\alpha i}(\alpha=y$ or $z, i=1$ or 2$)$ in Eq. 25 are:

$$
\begin{gathered}
\frac{\partial M_{\alpha 1}}{\partial q}=\frac{\partial}{\partial \theta_{\alpha 1}}\left(\frac{\partial U}{\partial q}\right)=\frac{E I}{L}\left[\frac{32 q^{2} / 35}{(48+q)^{3}}\right]\left(\Delta \theta_{\alpha 1}-\Delta \theta_{\alpha 2}\right)=\left(\frac{E I}{L}\right) G_{\alpha 1} \\
\frac{\partial M_{\alpha 2}}{\partial q}=\frac{\partial}{\partial \theta_{\alpha 2}}\left(\frac{\partial U}{\partial q}\right)=\frac{E I}{L}\left[\frac{-32 q^{2} / 35}{(48+q)^{3}}\right]\left(\Delta \theta_{\alpha 1}-\Delta \theta_{\alpha 2}\right)=\left(\frac{E I}{L}\right) G_{\alpha 2} \\
\frac{\partial q}{\partial \theta_{\alpha 1}}=\frac{\frac{I}{A L^{2}}-\sum_{\alpha=y, z}\left[\frac{1536 q / 35-16 q^{2} / 35}{(48+q)^{4}}\right]\left(\Delta \theta_{\alpha 1}-\Delta \theta_{\alpha 2}\right)^{2}}{H}=\frac{G_{\alpha 1}}{H} \\
\frac{\partial q}{\partial \theta_{\alpha 2}}=\frac{\left[\frac{-32 q^{2} / 35}{(48+q)^{3}}\right]\left(\Delta \theta_{\alpha 1}-\Delta \theta_{\alpha 2}\right)}{\frac{I}{A L^{2}}-\sum_{\alpha=y, z}\left[\frac{1536 q / 35-16 q^{2} / 35}{(48+q)^{4}}\right]\left(\Delta \theta_{\alpha 1}-\Delta \theta_{\alpha 2}\right)^{2}}=\frac{G_{\alpha 2}}{H} \\
\frac{\partial q}{\partial e}=\frac{1 / L}{\frac{I}{A L^{2}}-\sum_{\alpha=y, z}\left[\frac{1536 q / 35-16 q^{2} / 35}{(48+q)^{4}}\right]\left(\Delta \theta_{\alpha 1}-\Delta \theta_{\alpha 2}\right)^{2}}=\frac{1}{H L}
\end{gathered}
$$




\title{
HIGHER-ORDER NON-LINEAR ANALYSIS OF STEEL STRUCTURES PART II : REFINED PLASTIC HINGE FORMULATION
}

\author{
C.K. Iu ${ }^{*}$ and M.A. Bradford \\ Centre for Infrastructure Engineering and Safety \\ School of Civil and Environmental Engineering \\ The University of New South Wales, UNSW Sydney, NSW 2052, Australia \\ *(Corresponding author: E-mail: iu.jerryu@gmail.com)
}

Received: 31 May 2011; Revised: 10 October 2011; Accepted: 14 November 2011

\begin{abstract}
In the companion paper, a fourth-order element formulation in an updated Lagrangian formulation was presented to handle geometric non-linearities. The formulation of the present paper extends this to include material non-linearity by proposing a refined plastic hinge approach to analyse large steel framed structures with many members, for which contemporary algorithms based on the plastic zone approach can be problematic computationally. This concept is an advancement of conventional plastic hinge approaches, as the refined plastic hinge technique allows for gradual yielding, being recognized as distributed plasticity across the element section, a condition of full plasticity, as well as including strain hardening. It is founded on interaction yield surfaces specified analytically in terms of force resultants, and achieves accurate and rapid convergence for large frames for which geometric and material non-linearity are significant. The solutions are shown to be efficacious in terms of a balance of accuracy and computational expediency. In addition to the numerical efficiency, the present versatile approach is able to capture different kinds of material and geometric non-linearities on general applications of steel structures, and thereby it offers an efficacious and accurate means of assessing non-linear behaviour of the structures for engineering practice.
\end{abstract}

Keywords: Beam-column, Frames, Interaction surface, Material non-linearity, Refined plastic hinge method, Strain hardening

\section{INTRODUCTION}

This paper is concerned with an innovative extension of the geometrically non-linear elastic finite element formulation with a higher-order element, described in the companion paper [1], to include steel yielding so as to produce a robust and highly efficient technique for analysing frames with a multiplicity of component structural members. The material yielding of an infinitesimal steel element or particle across the element section has been investigated numerically through the plastic hinge approach in the efficacious manner.

King et al. [2] presented a plastic hinge method which accounts for the degradation of the member stiffness. The plastic hinge stiffness is formulated in this method by inserting a hinge in the incremental element stiffness equation if a linear initial yield and fixed full yield condition [3] with residual stresses are satisfied. In later work, Liew et al. [4, 5] proposed a second-order refined plastic hinge analysis for steel frame design which included inelastic stiffness degradation, with reference to a bilinear interaction equation AISC [6]. A tangent modulus technique was applied which reduced the modulus of elasticity from its elastic value continuously as it entered the plastic range.

Yau and Chan [7] established a plastic hinge analysis of steel frames in which the hinge stiffness is formulated into the element stiffness matrix based on the incremental moment equation of equilibrium at a node, with the full yield criterion of Duan and Chen [3] being adopted in the formulation. Further, Chan and Chui [8] proposed a method for considering the gradual yielding 
across a cross-section subjected to bending action, for which the axial force was included by reducing the bending moment capacity. More recently, Iu and Chan [9] developed a refined plastic hinge method which included strain-hardening for steel structures subjected to elevated temperatures, while Iu et al. [10] modified a plastic hinge approach in which the interaction of bending and axial actions on the yield surface at elevated temperature was formulated. Using a higher-order element representation, Chan and Zhou [11, 12] presented a large displacement analysis using a plastic hinge approach in which large deflections in the presence of a hinge along the member can be included.

In the companion paper [1], the geometric non-linearities associated with a second-order analysis of an elastic framed structure were discussed. Commonly, material yielding is an important consideration for steel structures at their strength or ultimate limit state, and so generalised numerical non-linear analysis of steel framed structures at their strength limit state necessitates the accurate modelling of both geometric and material non-linearities. Many contemporary steel structures are very large, comprising of a great number members of which many are slender, and despite advances in computational algorithms and computer hardware capabilities, efficient and accurate analyses of these structures is still problematic when material non-linearities have to be considered. In order to provide a solution technique which overcomes these difficulties, the plastic hinge approach is engaged in this paper to provide a balance between efficiency and accuracy. Elasto-plastic hinge methods have been developed and reported by many researchers (e.g. in $[2,7,13])$, but contrary to these, the present paper develops a refined plastic hinge approach to allow for the gradual development of yielding as distributed plasticity across the section to a fully plastic hinge, which admits strain hardening and accounts for the interaction of axial and bending actions. This is an advance on elasto-plastic hinge methods because it allows for a more general description of the materially non-linear behaviour of the steel in terms of force resultants (rather than of stresses in a much less-efficient plastic zone approach). This paper therefore offers a non-linear analysis with accuracy in solution, versatile for vast forms of structures and reliability in convergence for engineering practice.

\section{INTERACTION EQUATIONS FOR YIELDING CRITERION}

In accordance with the so-called "plastic zone method", the yield condition of the steel is examined with respect to each point in the member, and so it is convenient to express the behaviour of the steel in terms of its stress-strain relationship. This technique is valid for all cross-sections along the member once the domain of the numerical integration has been defined. On the other hand, the "plastic hinge method" bases its material modelling on the load-displacement relationship for a beam-column cross-section [3, 6]. This modelling requires interaction equations between bending and axial actions which defined the capacity its cross-sections.

In general, initial yielding within a member occurs well before the fully plastic cross-sectional strength is reached. It depends on both the shape factor for the cross-section $\eta$ and the residual stresses on the cross-section. The initial yield surface $\phi_{y}$, or initial yield interaction equation, may be defined from the bending actions about the major principal axis $M_{x}$, minor principal axis $M_{y}$ and axial force $P$ collected in the vector $\mathbf{f}=\left\{P, M_{x}, M_{y}\right\}^{\mathrm{T}}$ and related by

$\phi_{y}(\mathbf{f})=\frac{P}{0.8 P_{y}}+\frac{\eta_{x} M_{x}}{0.9 M_{p x}}+\frac{\eta_{y} M_{y}}{0.9 M_{p y}}=1$ 
in which the numbers 0.8 and 0.9 in the denominator account for residual stresses, $P_{y}$ is the axial force capacity of the cross-section, and $M_{p x}$ and $M_{p y}$ are its full plastic moments about the major and minor principal axes respectively which have respective shape factors of $\eta_{x}$ and $\eta_{y}$. When $\phi_{y}(\mathbf{f})<1$, the cross-section is taken as elastic. For a doubly-symmetric I-section, a convenient formulation used for the first yield surface is

$\phi_{y}(\mathbf{f})=\frac{P}{0.8 P_{y}}+\frac{1.25 M_{x}}{M_{p x}}+\frac{1.25 M_{y}}{M_{p y}}=1$.

The AISC-LRFD standard [6 provides bilinear interactions for the criterion of full yield in terms of a function $\phi_{p}(\mathbf{f})=1$, but it is known that this is generally conservative for both short beam-columns for which material non-linearities are dominant and for biaxial loading cases. The present formulation therefore adopts the full yield interaction function $\phi_{p}(\mathbf{f})$ proposed by Duan and Chen [3], which defines a continuous convex full yield surface as shown in Fig. 1, with vertices as its intersection with the $P$ axis.

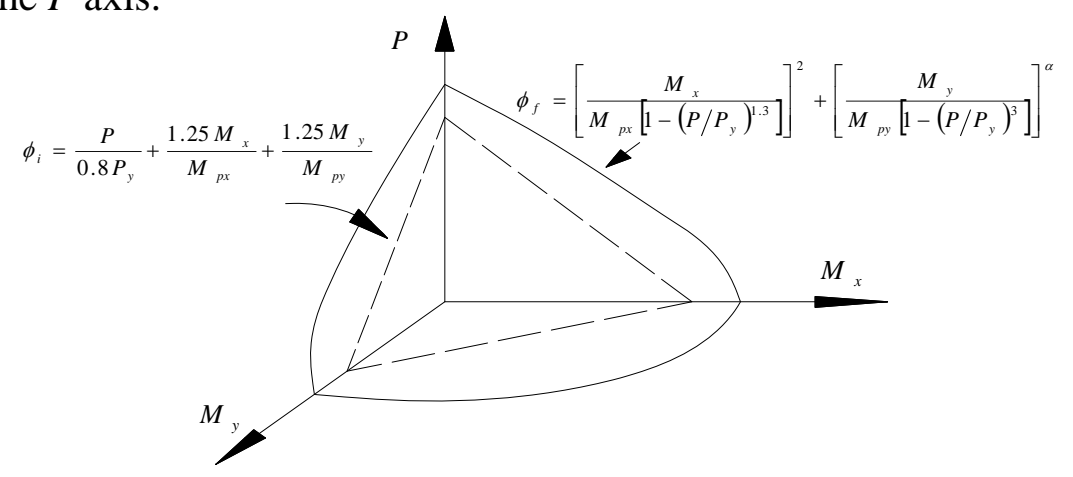

Figure 1. Initial and Full Yield Surface under Interaction of Force Resultants

For the case of uniaxial bending about the major axis, full yield is taken as

$\phi_{p}\left(\left\{P, M_{x}, 0\right\}\right)=\frac{M_{x}}{\bar{M}_{p x}}=\frac{M_{x}}{M_{p x}\left[1-\left(P / P_{y}\right)^{1.3}\right]}=1$,

while for uniaxial bending about the minor axis, it is taken as

$\phi_{p}\left(\left\{P, 0, M_{y}\right\}\right)=\frac{M_{y}}{\bar{M}_{p y}}=\frac{M_{y}}{M_{p y}\left[1-\left(P / P_{y}\right)^{3}\right]}=1$

in which $P_{y}=f_{y} A, A$ is the area of the cross-section, $f_{y}$ is the uniaxial yield stress and the moments $\bar{M}_{p x}$ and $\bar{M}_{p y}$ are the major and minor axis bending capacities reduced in the presence of axial force. A modified interaction surface from Tebege and Chen [14] is

$\phi_{p}(\mathbf{f})=\left(\frac{M_{x}}{\bar{M}_{p x}}\right)^{2}+\left(\frac{M_{y}}{\bar{M}_{p y}}\right)^{\alpha}=1$

so that using Eqs. 3 and 4, 
$\phi_{p}(\mathbf{f})=\left\{\frac{M_{x}}{M_{p x}\left[1-\left(P / P_{y}\right)^{1.3}\right]}\right\}^{2}+\left\{\frac{M_{y}}{M_{p y}\left[1-\left(P / P_{y}\right)^{3}\right]}\right\}^{\alpha}=1$

in which

$\alpha=1.2+2\left(\frac{P}{P_{y}}\right)$

In the refined plastic hinge approach, gradual yielding is defined when the vector of actions on the cross-section $\mathbf{f}$ is such that $\phi_{y}(\mathbf{f})>1$ and $\phi_{p}(\mathbf{f})<1$; this situation is common for beam-columns at their strength limit state. The initial and full yield surfaces shown in Fig. 1 have been shown [3] to be valid for a large range of steel cross-sections under biaxial bending and compression, and provide an empirical basis for the refined plastic hinge approach of this paper.

\section{REFINED PLASTIC HINGE STIFFNESS FORMULATION}

\subsection{Plastic Hinge Spring Stiffness}

The present non-linear analysis for beam-columns relies on plastic hinge springs, as shown in Fig. 2 , to be activated when the vector of actions at a node $\mathbf{f}$ are such that $\phi_{y}(\mathbf{f})$ exceeds unity. When this vector is such that $\phi_{p}(\mathbf{f})$ exceeds unity, the cross-section experiences strain hardening. The stiffnesses of the axial and bending springs are then taken as

$S_{a}=\frac{E A}{L}\left[\frac{1-\phi_{p}(\mathbf{f})}{\phi_{y}(\mathbf{f})-1}+\mu_{a}\right]$

and

$S_{b}=\frac{E I}{L}\left[\frac{1-\phi_{p}(\mathbf{f})}{\phi_{y}(\mathbf{f})-1}+\mu_{b}\right]$

in which the stiffnesses are such that $\infty>S_{a}>0$ and $\infty>S_{b}>0, \mu_{a}$ and $\mu_{b}$ are strain hardening parameters, $E I / L$ is the elastic flexural stiffness of the beam-column and $E A / L$ is its elastic axial stiffness. The spring formulation of Eqs. 8 and 9 was first introduced by Iu et al. [15].

The interaction between the three force resultants in the vector $\mathbf{f}$ has a twofold effect in the refined hinge formulation; it firstly defines the initial yield and fully plastic surfaces by $\phi_{y}(\mathbf{f})=1$ and $\phi_{p}(\mathbf{f})$ $=1$, and it secondly defines the spring stiffness by Eqs. 8 and 9 which are degraded when $\phi_{y}(\mathbf{f})>1$. This kind of gradual yielding by proposed refined plastic hinge approach heralds distributed plasticity across the member section. The spring formulation is therefore able to capture the non-linear material behaviour, including its elastic domain, gradual or partial yielding, full plasticity, strain hardening as well as residual stresses, in the load-deformation relationship for the quartic beam-column finite element. These hinges may be incorporated into the second-order elastic stiffness formulation of the companion paper [1] using the procedures described in [7, 16]. In reference to [15], it is also worth mentioning that the plastic hinges in Eqs. 8 and 9 are versatile 
for different kind materials, once the interaction equations $\phi_{y}(\mathbf{f})$ and $\phi_{p}(\mathbf{f})$ are replaced by the corresponding material failure surfaces.

\subsection{Secant Stiffness in Plastic Hinge Formulation}

In order to combine the plastic hinge spring stiffness formulation with the second-order elastic stiffness formulation for a beam-column element, the incremental equilibrium equation of the element is written as

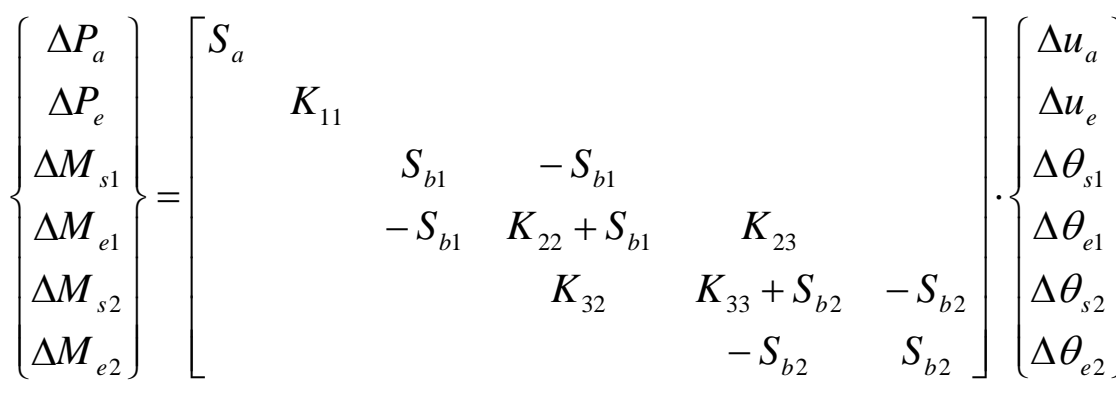

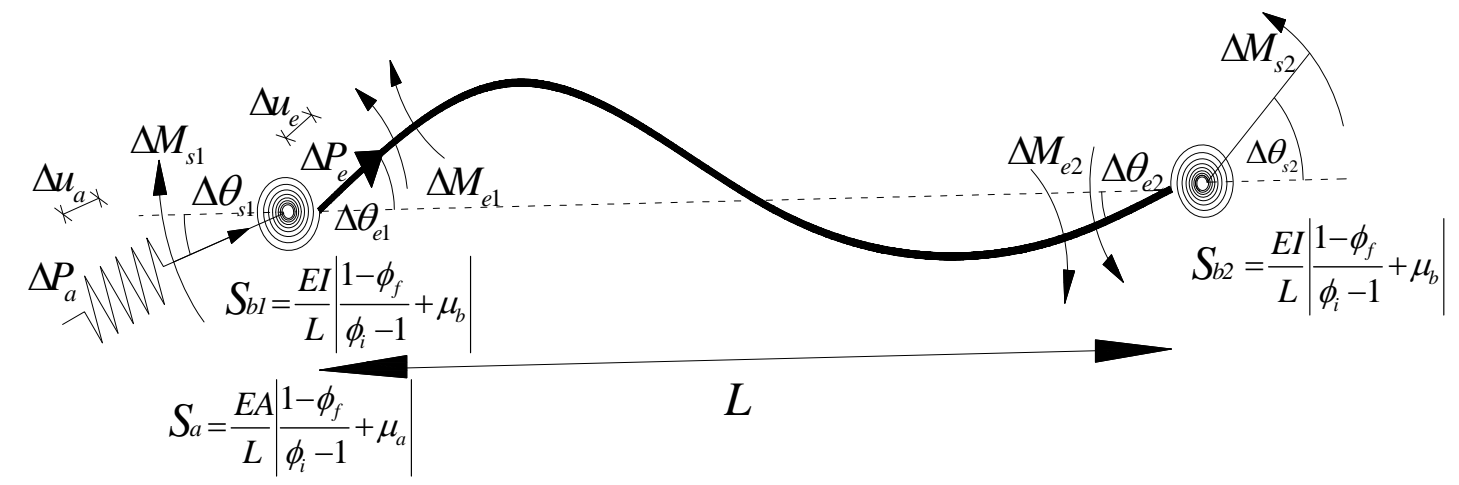

Figure 2. Beam-column element with axial and rotational springs

and for which it can be assumed that moment and axial force equilibrium of the beam-column element can be considered separately in regard to material yielding behaviour. Since a plastic hinge is inserted at the ends of the beam-column element, additional rotational degrees of freedom at the nodes $\Delta \theta_{s 1}$ and $\Delta \theta_{s 2}$ are introduced, as shown in Fig. 2. Using matrix condensation of the internal degree of freedom of the beam-column element $\left(\Delta M_{e 1}=\Delta M_{e 2}=0\right)$, Eq. 10 can be decomposed into

$\left\{\begin{array}{l}\Delta M_{s 1} \\ \Delta M_{s 2}\end{array}\right\}=\left[\begin{array}{ll}S_{b 1} & \\ & S_{b 2}\end{array}\right]\left\{\begin{array}{l}\Delta \theta_{s 1} \\ \Delta \theta_{s 2}\end{array}\right\}+\left[\begin{array}{ll}-S_{b 1} & \\ & -S_{b 2}\end{array}\right]\left\{\begin{array}{l}\Delta \theta_{e 1} \\ \Delta \theta_{e 2}\end{array}\right\}$

and

$\left\{\begin{array}{l}0 \\ 0\end{array}\right\}=\left[\begin{array}{cc}-S_{b 1} & \\ & -S_{b 2}\end{array}\right]\left\{\begin{array}{l}\Delta \theta_{s 1} \\ \Delta \theta_{s 2}\end{array}\right\}+\left[\begin{array}{cc}K_{11}+S_{b 1} & K_{12} \\ K_{21} & K_{22}+S_{b 2}\end{array}\right]\left\{\begin{array}{l}\Delta \theta_{e 1} \\ \Delta \theta_{e 2}\end{array}\right\}$.

After matrix condensation as in Eqs. 12 and 13, the incremental rotational deformations of the beam-column element $\Delta \theta_{\mathrm{e} 1}$ and $\Delta \theta_{\mathrm{e} 2}$ can be evaluated from the incremental joint rotations $\Delta \theta_{\mathrm{s} 1}$ and $\Delta \theta_{\mathrm{s} 2}$ from the equation 
$\left\{\begin{array}{l}\Delta \theta_{e 1} \\ \Delta \theta_{e 2}\end{array}\right\}=\left[\begin{array}{cc}K_{11}+S_{b 1} & K_{12} \\ K_{21} & K_{22}+S_{b 2}\end{array}\right]^{-1}\left[\begin{array}{cc}S_{b 1} & \\ & S_{b 2}\end{array}\right]\left\{\begin{array}{l}\Delta \theta_{s 1} \\ \Delta \theta_{s 2}\end{array}\right\}$,

or

$\left\{\begin{array}{l}\Delta \theta_{e 1} \\ \Delta \theta_{e 2}\end{array}\right\}=\frac{1}{|\mathrm{~K}|}\left[\begin{array}{cc}S_{b 1}\left(K_{22}+S_{b 2}\right) & -S_{b 2} K_{12} \\ -S_{b 1} K_{21} & S_{b 2}\left(K_{11}+S_{b 1}\right)\end{array}\right]\left(\begin{array}{c}\Delta \theta_{s 1} \\ \Delta \theta_{s 2}\end{array}\right)$

where $|\mathbf{K}|=\left(K_{11}+S_{s 1}\right) \cdot\left(K_{22}+S_{s 2}\right)-K_{12} K_{21}$. Once the element incremental rotations $\Delta \theta_{e 1}$ and $\Delta \theta_{e 2}$ are known from Eq. 14 which includes material non-linearity, the incremental bending resistance can be evaluated from

$\left\{\begin{array}{l}\Delta M_{e 1} \\ \Delta M_{e 2}\end{array}\right\}=\left[\begin{array}{ll}K_{11} & K_{12} \\ K_{21} & K_{22}\end{array}\right]\left\{\begin{array}{c}\Delta \theta_{e 1} \\ \Delta \theta_{e 2}\end{array}\right\}$

which is based on the elastic stiffness formulation based on elastic stiffnesses $K_{i j}$ because it is assumed that the element is elastic. Hence the equation

$\left\{\begin{array}{l}\Delta M_{e 1} \\ \Delta M_{e 2}\end{array}\right\}=\frac{1}{|\mathbf{K}|}\left[\begin{array}{ll}K_{11} & K_{12} \\ K_{21} & K_{22}\end{array}\right]\left[\begin{array}{cc}S_{b 1}\left(K_{22}+S_{b 2}\right) & -S_{b 2} K_{12} \\ -S_{b 1} K_{21} & S_{b 2}\left(K_{11}+S_{b 1}\right)\end{array}\right]\left(\begin{array}{l}\Delta \theta_{s 1} \\ \Delta \theta_{s 2}\end{array}\right)$

is equivalent to the incremental secant stiffness in the second-order elastic stiffness formulation in the companion paper [1]. For axial actions, the incremental force equilibrium equation is written separately as

$\left\{\begin{array}{l}\Delta P_{a} \\ \Delta P_{e}\end{array}\right\}=\left[\begin{array}{cc}S_{a} & 0 \\ 0 & K_{11}\end{array}\right]\left\{\begin{array}{l}\Delta u_{a} \\ \Delta u_{e}\end{array}\right\}=\left[\begin{array}{cc}S_{a} & 0 \\ 0 & E A / L\end{array}\right]\left\{\begin{array}{l}\Delta u_{a} \\ \Delta u_{e}\end{array}\right\}$,

where the incremental axial force in the linear spring $\Delta P_{a}$ is equal to the axial force in the beam-column element $\Delta P_{e}$. The total incremental axial deformation $\Delta u$ is the sum of the incremental axial deformation in the axial spring $\Delta u_{a}$ and in the element $\Delta u_{e}$, and consequently the axial resistance of an element can be expressed as

$\Delta P=\left(\frac{1}{S_{a}+E A / L}\right) \Delta u$,

which describes the axial resistance of the element in terms of the axial displacement and so is equivalent to the secant stiffness for a plastic axial spring.

\subsection{Tangent Stiffness for Plastic Hinge Formulation}

For bending actions, the incremental moment-rotation relationship needs to be reformulated with respect to the nodal or local coordinate system, and the axial spring stiffness superimposed into the stiffness formulation in a similar way; it being assumed that the moment and axial force equilibrium conditions can be formulated separately. This produces 
$\left\{\begin{array}{c}\Delta P \\ \Delta M_{s 1} \\ \Delta M_{s 2}\end{array}\right\}=\left[\begin{array}{lll}K_{11}^{\prime} & & \\ & K_{22}^{\prime} & K_{23}^{\prime} \\ & K_{32}^{\prime} & K_{33}^{\prime}\end{array}\right]\left\{\begin{array}{c}\Delta u \\ \Delta \theta_{s 1} \\ \Delta \theta_{s 2}\end{array}\right\}$

where

$$
\begin{aligned}
& K_{11}^{\prime}=\frac{S_{a} K_{11}}{K_{11}+S_{a}}, \\
& K_{22}^{\prime}=\frac{1}{|\mathbf{K}|}\left[S_{b 1} K_{22}\left(K_{33}+S_{b 2}\right)-S_{b 2} K_{23}^{2}\right], \\
& K_{23}^{\prime}=K_{32}^{\prime}=\frac{1}{|\mathbf{K}|}\left[S_{b 2} K_{23}\left(K_{22}+S_{b 1}\right)-S_{b 2} K_{22} K_{32}\right], \\
& K_{33}^{\prime}=\frac{1}{|\mathbf{K}|}\left[S_{b 2} K_{33}\left(K_{22}+S_{b 1}\right)-S_{b 1} K_{32}^{2}\right] .
\end{aligned}
$$

Eq. 19 is equivalent to the tangent stiffness in the second-order elastic stiffness formulation in the companion paper [1]. This non-linear equilibrium path due to material non-linearities can be traced using the non-linear solution procedures described in the companion paper [1].

\section{NUMERICAL VERIFICATIONS}

In order to verify the accuracy and efficiency of the present non-linear second-order inelastic analysis, material non-linearities for an encastré beam with a concentrated load are compared with other inelastic analyses. Two benchmark solutions for frame structures are also investigated, including both material and geometric non-linearities, while a calibration frame is studied for investigating the effect of spreading of plasticity. Finally, a large-scale space framed structure is analysed using the proposed method.

\subsection{Encastré Beam with An Asymmetric Point Load}

A beam with fixed or encastré ends has been investigated to isolate a case which is governed by material yielding. The inelastic behaviour of this fixed beam with a residual stress of $60 \%$ of the yield stress was studied by Liew et al. [17], in which a point load was applied at one-third of the beam, as shown in Fig. 3. Plastic hinges then form in sequence, until a plastic mechanism is achieved (the load factor $\lambda_{p}=P L / M_{p}$ quoted in Trahair et al. [18] is 9.0 for a full plastic mechanism). Liew et al. [17] analysed this problem by both a refined plastic hinge method and a hinge-by-hinge method. The load factor $\lambda_{p}=P L / M_{p}$ is plotted against the dimensionless deflection $\delta \cdot E I / M_{P} L^{2}$ at the point of application of the load in Fig. 3. For the proposed non-linear analysis, two elements were used for the beam with the load being applied at span. It can be seen that the results of the present method are in accord with those of Liew et al. [17]. In the present non-linear analysis, initial yielding initiates at location 1 with a load factor $\lambda_{p 1}=5.41$; this hinge becomes fully plastic when $\lambda_{p 1}=8.81$. Fully-yielded plastic hinges form at locations 2 and 3 at values of $\lambda_{p 2}=8.91$ and $\lambda_{p 3}=9.01$. 


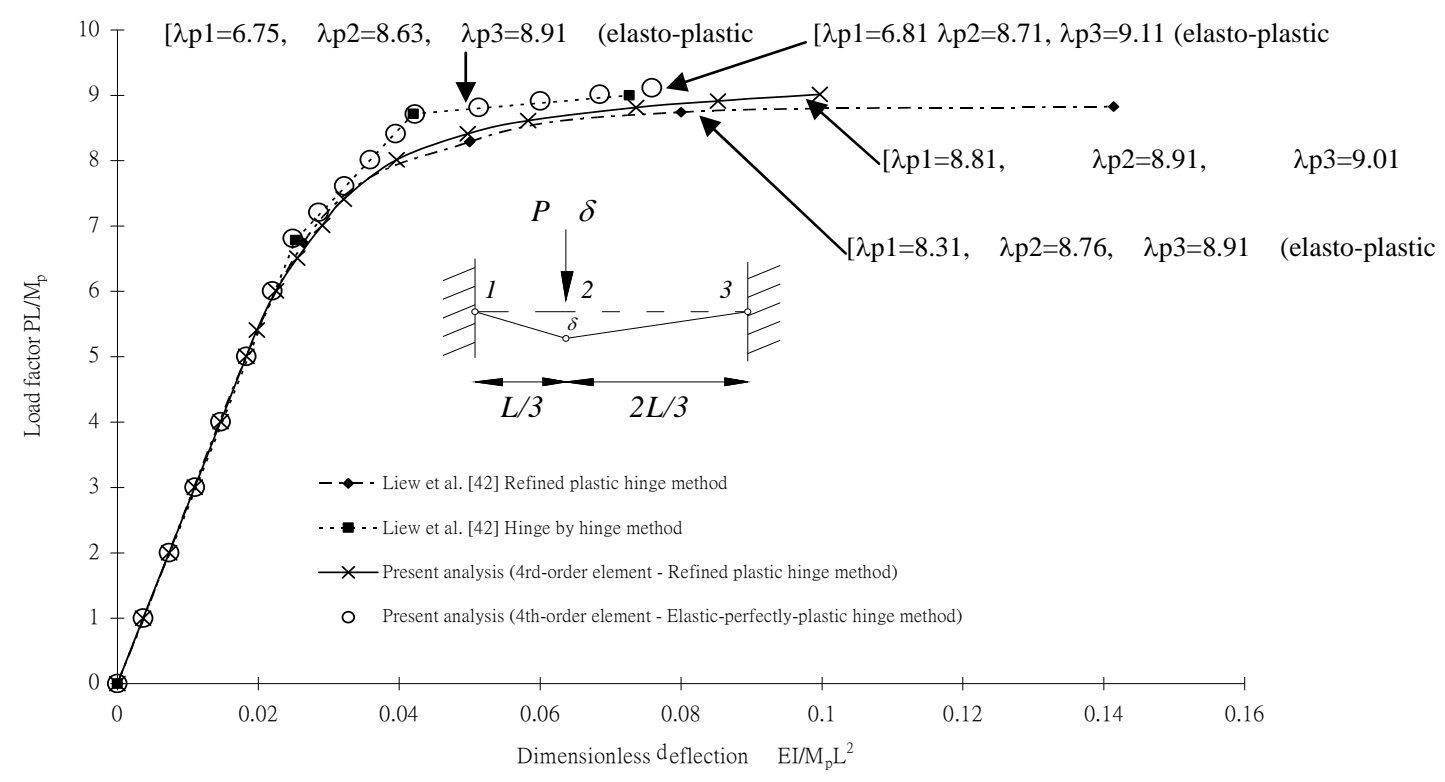

Figure 3. Normalized Load-displacement Curve of a Fixed-end Beam

Figure 3 also summarises the plastic load factors from various approaches. This numerical verification illustrates that the proposed plastic hinge method is able to model residual stresses, gradual yielding and fully-yielded material behaviour.

\subsection{Single-bay Frame of Vogel}

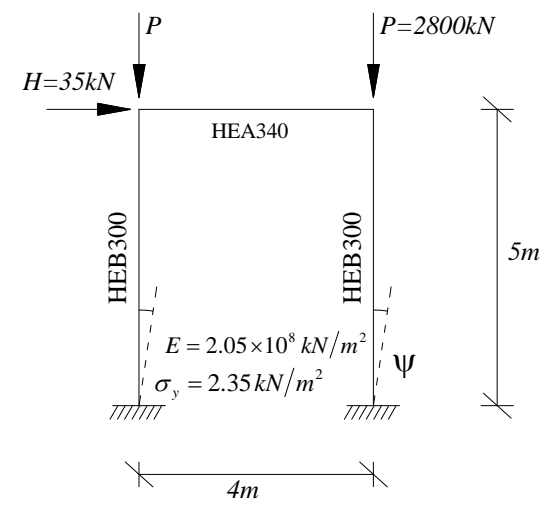

Figure 4. Geometric Configurations and Loading Pattern of Vogel’s Frame

The portal frame shown in Fig. 4 was analysed numerically in 1985 by Vogel [19], and this frame has been used by several researchers (e.g. Chan and Zhou [12] and Toma and Chen [20]) as a benchmark solution for including material non-linearities including residual stresses, gradual yielding and full-plasticity, as well as geometric non-linearities. Figure 4 shows the applied loading, material properties, member cross-section and geometry of the simple portal frame. The initial out-of-straightness $\psi=1 / 400$ of the column height was engaged in the plastic zone method [19]. The horizontal load on the top of the frame produces sway in the frame, and the vertical loads generate second-order effects in the columns. 


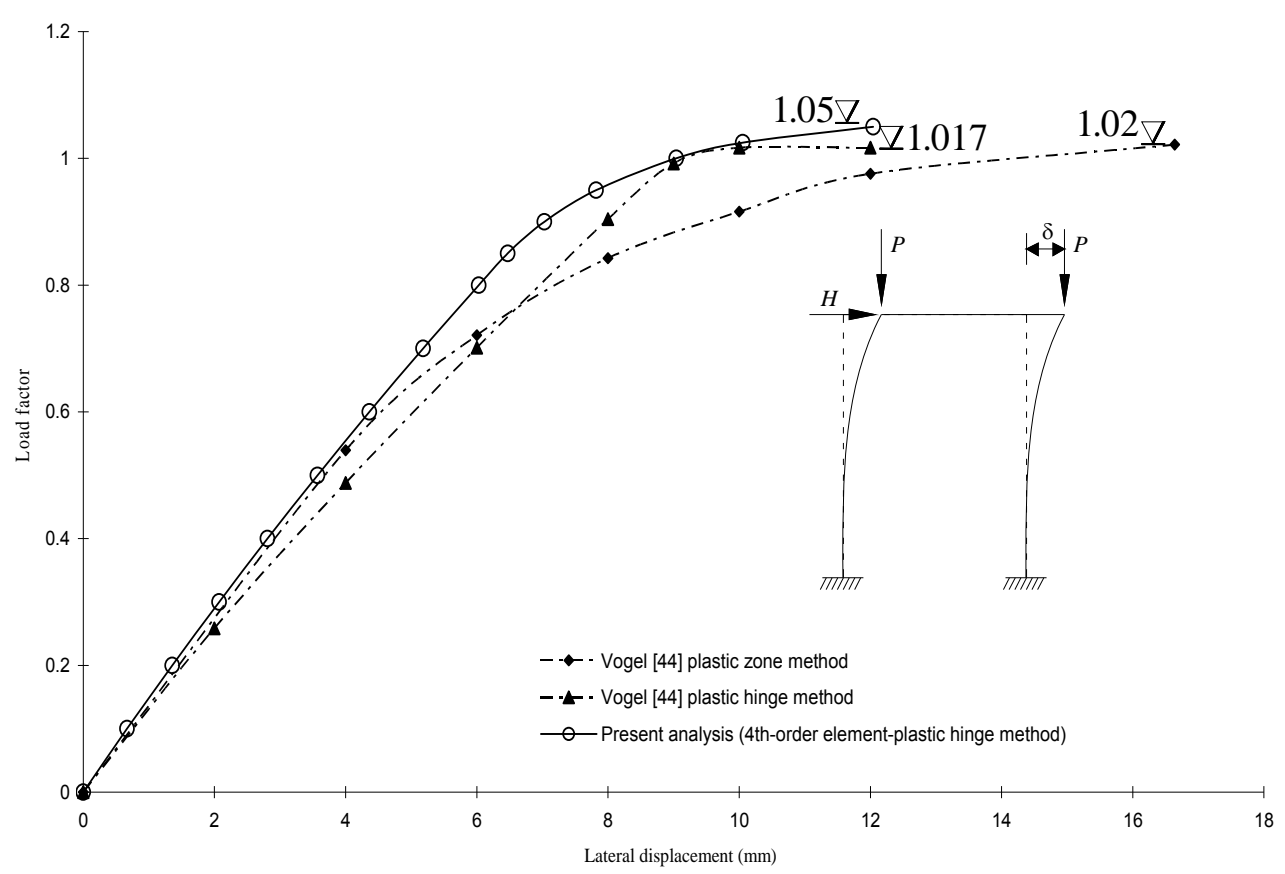

Figure 5. Load-displacement Curve at the Top of Vogel's Portal Frame

In the model herein, only one element was used to model each of the members, whereas Clarke [21] used a refined mesh with 50 elements for each column and 20 elements for the beam in his numerical modelling. More recently, Teh and Clarke [22] produced a more computationally efficient approach in their plastic zone method for which 4 elements were used in each column to model geometric non-linearity and stability effects, and one element for the beam. The present technique is still more computationally efficient than the latter modelling of Teh and Clarke [22].

The load versus displacement curves for the top of the column from both the approach of this paper and that of Vogel [19] are shown in Fig. 5. Generally, the load-displacement behaviour from the present method is reasonably consistent with that of Vogel, the deviation between the present analysis and Vogel's plastic zone method being attributed mainly to the different onsets of initial yielding at load factors of 0.8 and 0.6 respectively. The plastic hinge formulation of Vogel does not include gradual yielding. The ultimate load factor from the analysis of this paper is 1.05, whereas that from Vogel's plastic zone analysis is 1.02 and Vogel's plastic hinge analysis is 1.07. All of these three methods produce a consistent ultimate load factor.

Initial yielding occurs firstly in the right column at its bottom at a load factor of 0.825 , and all four joints of the frame have reached initial yield at a load factor of 0.875 . When the frame is loaded to a load factor of 1.05, a fully yielded plastic hinge forms in the right column at its bottom, and with an infinitesimal increase of this load factor, a failure mechanism develops in the frame. The portal frame exhibits no strength reserve from its threefold redundancy because of the symmetric loading distribution in this frame; when the fully yielded plastic hinge is formed, the other three hinges for which full yielding is imminent form fully plastic hinges in the next iteration with numerical divergence being detected at a load factor of 1.05. This represents the ultimate capacity of the frame. The lateral behaviour of the frame from the present approach is stiffer than the results of Vogel [19], probably because of the different initial yielding conditions which are engaged in both analyses. This benchmark numerical example is used commonly as a countercheck of gradual yielding behaviour. 


\subsection{Six Storey Rigid-jointed Frame of Vogel}

The two-bay six-storey European calibration frame shown in Fig. 6 was subjected to proportionally applied distributed gravity loads and to concentrated loads, and its behaviour was reported by Vogel [19]. The member sections and frame geometry are depicted in Fig. 6, and the elastic modulus and yield stress of the steel were taken as $2.05 \times 10^{8} \mathrm{kN} / \mathrm{m}^{2}$ and $2.35 \times 10^{5} \mathrm{kN} / \mathrm{m}^{2}$ throughout. The initial out-of-straightness of the frame was assumed to be $\psi=1 / 450$, with all members being rigidly connected at their joints. In the modelling of this frame, each column was discretised as one element whilst the beams were subdivided into four elements because only nodal loads are admitted, although the present formulation does allow for a quadratic bending moment distribution to be simulated in by the fourth-order finite element. It is worth noting that using the plastic zone approach [21], each column was subdivided into 20 elements and each beam into either 20 or 40 elements, depending on the degree of non-linearity.

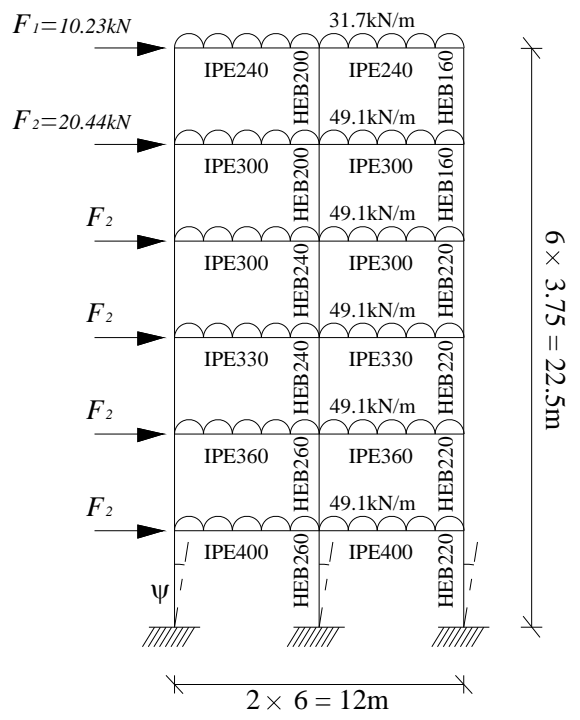

Figure 6. Geometric Configuration and Loading Pattern of Vogel’s six-storey Frame

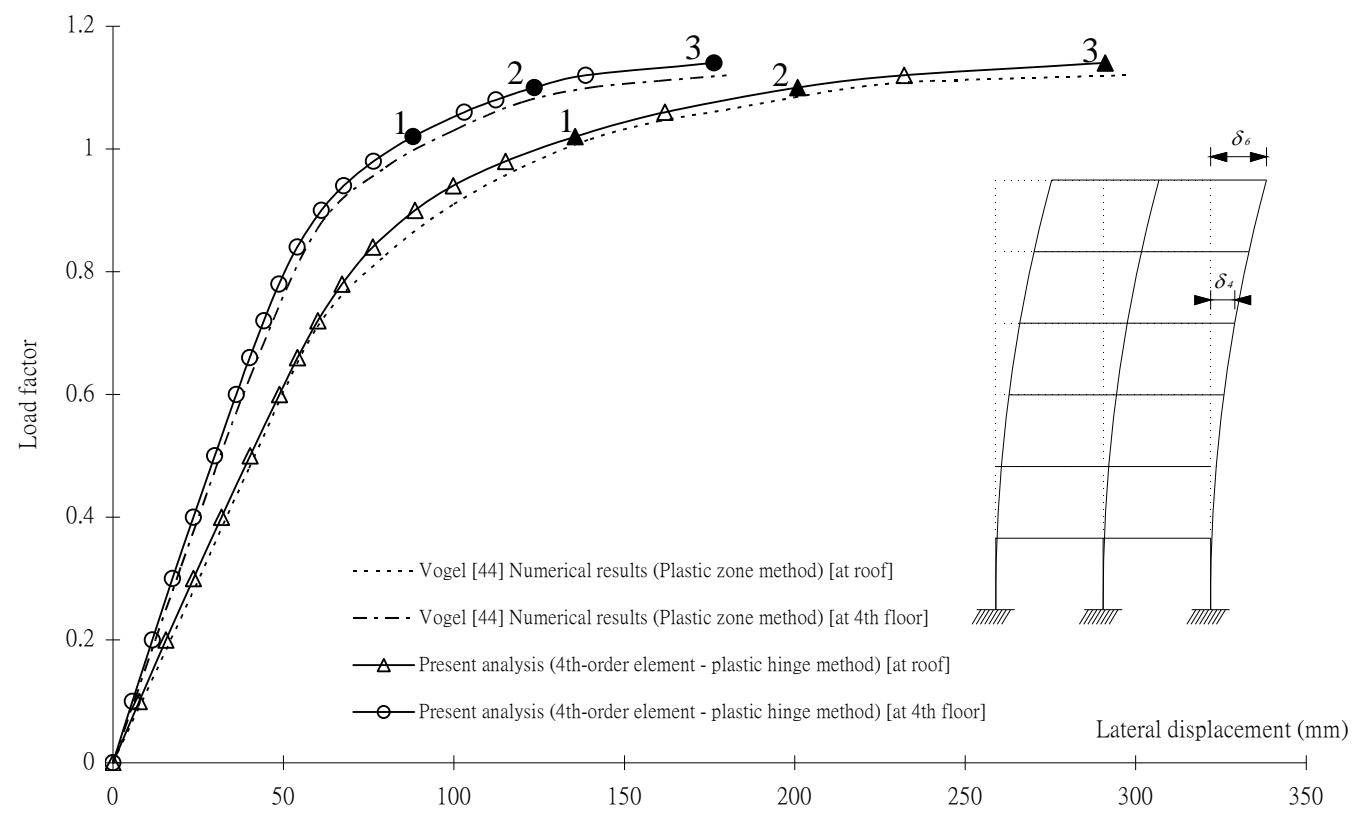

Figure 7. Lateral Drifts of the Vogel’s six-storey Frame 
Figure 7 shows the lateral drifts of the $4^{\text {th }}$ and $6^{\text {th }}$ floors of the frame determined from the analysis of this paper, and those reported by Vogel [19], and it can be seen that they are in excellent agreement. The ultimate load factor predicted by the current method is 1.14 , which is slightly higher than the value of 1.12 given by Vogel [19].

In the approach of this paper, initial yielding occurs at a load factor of 0.62 at the beams adjacent to the interior column joints at the $4^{\text {th }}$ and $6^{\text {th }}$ floor levels. Both of these hinges have fully yielded when a load factor of 0.94 is reached, which heralds the onset of non-linearity which can be seen in Fig. 7. At a load factor of 1.02 in Fig. 7, the number of fully-yielded plastic hinges increases to four, and these are denoted by the numeric index 1 in Fig. 8a and in Fig. 7. When the frame is loaded further to a load factor of 1.10, a total of 10 fully-yielded plastic hinges have formed and the additional ones are denoted by the index 2 in Fig. 8a and in Fig. 7. When the ultimate load of the frame has been reached, there are a total of 23 fully-yielded plastic hinges, those formed at the beams' mid-spans are due mainly to gravity loading, whereas those formed at the beams' ends are a result of the effect of sway in accordance with the distribution of bending moment at ultimate loading which is shown in Fig. 8b. This verification example indicates that the present inelastic approach can accurately replicate the effects of gradual yielding and full plasticity in a large-scale multi-storey steel frame. Ziemian [23] also carried out a calibration study of this frame in his numerical analysis in 1992. It is worth noting that the following comparison is for information only because of different computational technologies being used. While Ziemian's plastic zone approach took 8 minutes to perform the analysis, the present analysis took 4 seconds on a desktop personal computer. The present plastic hinge analysis is more efficient by comparison and can capture the real inelastic and stability behaviour of large-scale frames accurately, including initial yield, gradual or partial yield and full plasticity, as well as frame sway and member bowing.

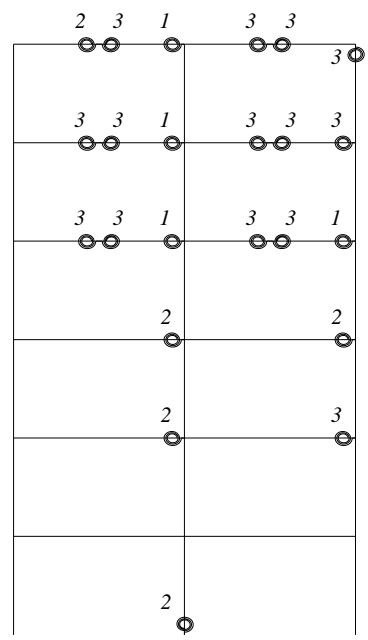

a) Locations of the fully plastic

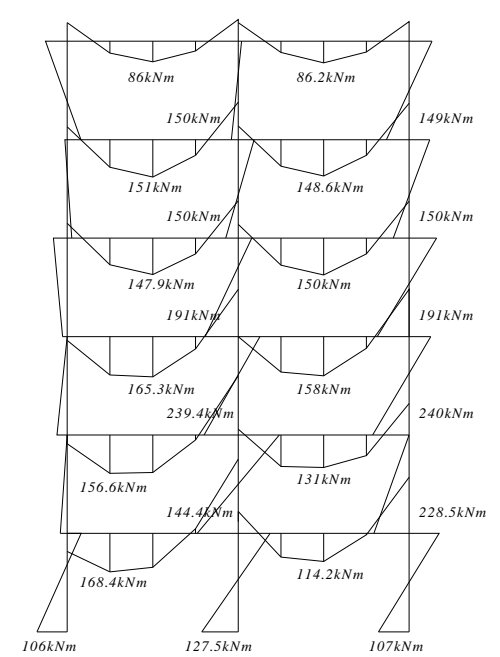

b) Moment distribution on the

Figure 8. Plastic Hinge Pattern and Moment Distribution on the Frame

\subsection{Two-storey Asymmetric Calibration Frame}

The two-storey two-bay asymmetrical frame subjected to vertical loading only shown in Fig. 9 was studied in 1982 by Iffland and Birnstiel [24] as part of the American Institute of Steel Construction report on frame stability with plasticity. This calibration frame was chosen as a benchmark for validating the loading redistribution due to plasticity. The material modelling used was elastic-perfectly-plastic (without strain hardening), and the geometry, material properties, loading and section configurations are shown in Fig. 18. Ziemian [23] and Clarke [21] also analysed this frame in the verification of their numerical analyses. Ziemian [23] presented both plastic zone 
and hinge methods, in which he used 60 elements per beam and 50 elements per column in his modelling, while Clarke [21] undertook a plastic zone method analysis of the frame with each column being subdivided into 20 elements, beams B1 and B3 into 20 elements and beams B2 and B4 into 40 elements. However, modelling the frame using the approach of this paper necessitated subdividing the columns into one element beams into 4 elements to include the distributed loading, as discussed previously. Both arc-length [25] and residual load [26] strategies are proposed to trace the non-linear equilibrium solution of this two-storey asymmetrical frame.

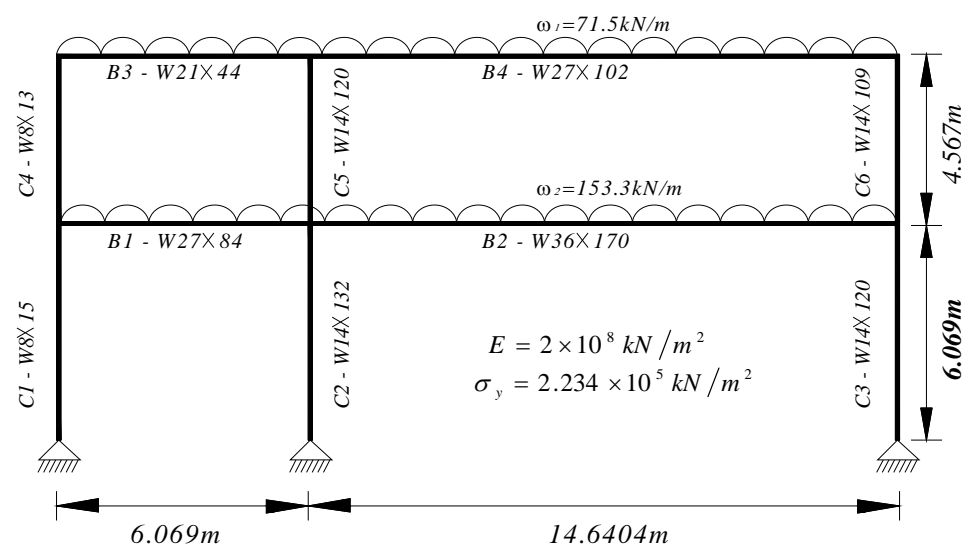

Figure 9. Configurations of the American Calibration Frame

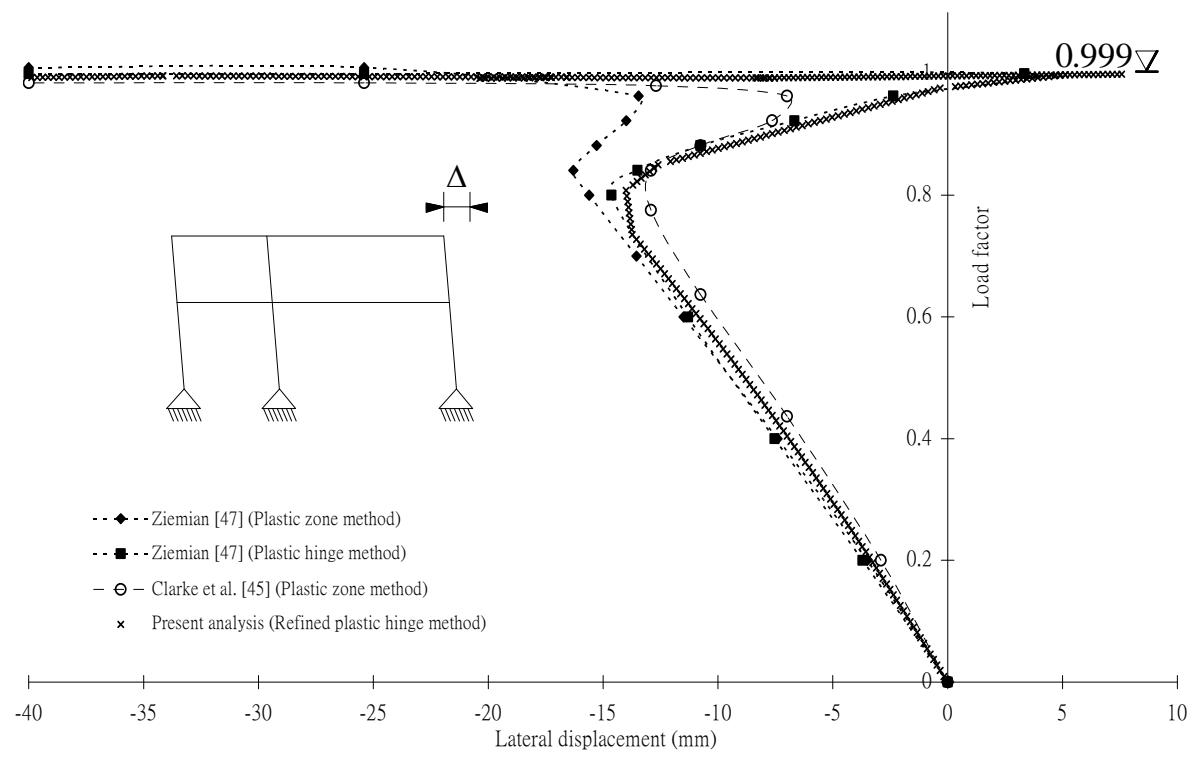

Figure 10. Lateral Displacement at Top of the Two-storey Frame Against Load Factor

The lateral displacement of the frame at the roof level $\Delta$ is plotted in Fig. 10 against the load factor. The lateral displacement from the method of this paper agrees almost completely with the plastic hinge method [23] throughout the entire loading range. Columns C1 and C4 are much more flexible than the other columns of the frame, and so initially the frame sways towards its weaker bay as shown in Fig. 10. At a load factor of about 0.808, three plastic hinges are formed as shown in Fig. 11, with the differential yielding between the stronger and weaker bays causing their relative stiffnesses to change, with a consequent change in the direction of the sway $\Delta$, as shown in Fig. 10. Using the present non-linear analysis, the plastic hinges form subsequently with an increase in load until the ultimate load factor $\left(\lambda_{u}=0.999\right)$ is reached, with the hinges shown in Fig. 11, but before doing so the sway reverses its direction again due to the significant yielding of the stronger bay, in which plastic hinges form at the mid-span of beams B2 and B4. The ultimate load factor of $\lambda_{u}=$ 0.999 compares very well with that of Ziemian [23] $\left(\lambda_{u}=1.01\right)$ and Clarke [21] $\left(\lambda_{u}=0.985\right)$. The numerical analysis proposed herein was completed in 6 seconds for 300 load cycles. 


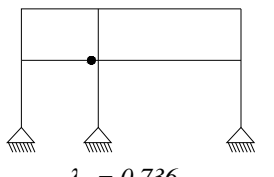

$\lambda_{p}=0.736$

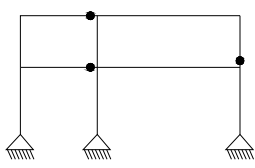

$\lambda_{p}=0.808$

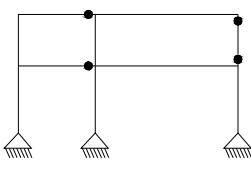

$\lambda_{p}=0.85$

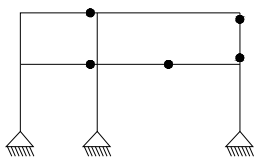

$\lambda_{p}=0.976$

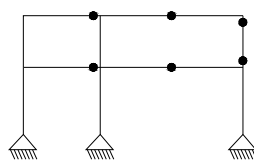

$\lambda_{p}=0.998$

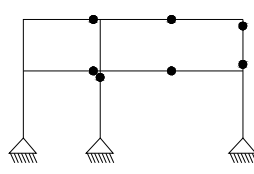

$\lambda_{p}=0.999$

Figure 11. Sequence of Plastic Hinges Formed at Corresponding Plastic Load Factors

\subsection{6-storey Large Space Frame Structure}

The rigid-jointed 6-storey asymmetrical space frame shown in Fig. 12 was proposed and analysed by Orbison et al. [27], and later by Liew et al. [28] and Jiang et al. [29]. The yield strength and elastic modulus were taken as $250 \times 10^{5} \mathrm{kN} / \mathrm{m}^{2}$ and $2.07 \times 10^{8} \mathrm{kN} / \mathrm{m}^{2}$ respectively, and the frame was subjected to both uniform gravity loads of $9.6 \mathrm{kN} / \mathrm{m}^{2}$ on each floor and lateral loads of $53.376 \mathrm{kN}$ which were applied at every beam-column joint in the transverse z-direction, as shown in Fig. 12. The member sections and plan configuration of the floors are also shown in Fig. 12. In the present numerical modelling, one element was used for each member to replicate the overall load-displacement behaviour of the space frame, which is the same as used in [28, 29]. The main differences in these analyses is in the treatment of inelasticity; a plastic hinge model using a plastic interaction function was employed by Orbison et al. [27] and by Liew et al. [28], whereas a plastic zone approach with gradual member yielding was used by Jiang et al. [29]. The refined plastic hinge approach in the present method allows for gradual yielding at the hinge under both axial and bending actions.
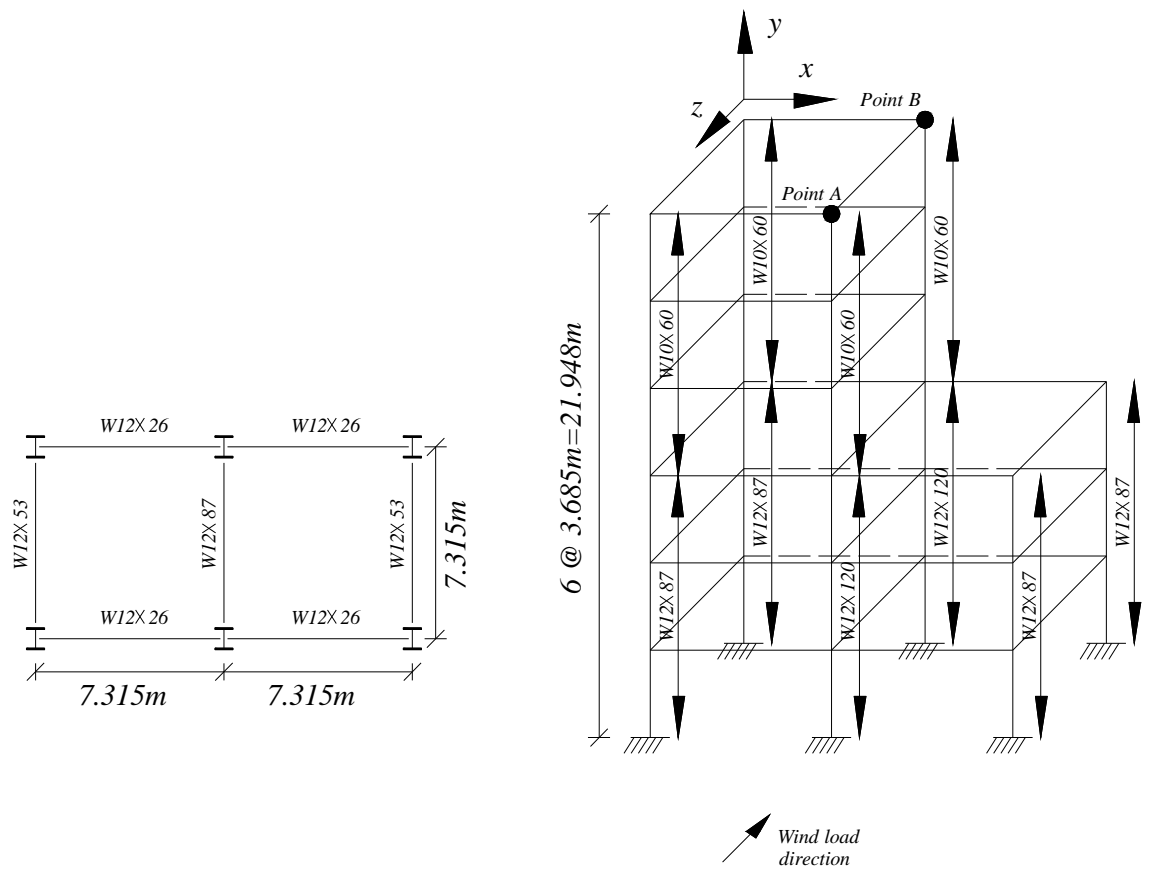

Figure 12. Section and geometric configuration of 6-storey space framed structure 


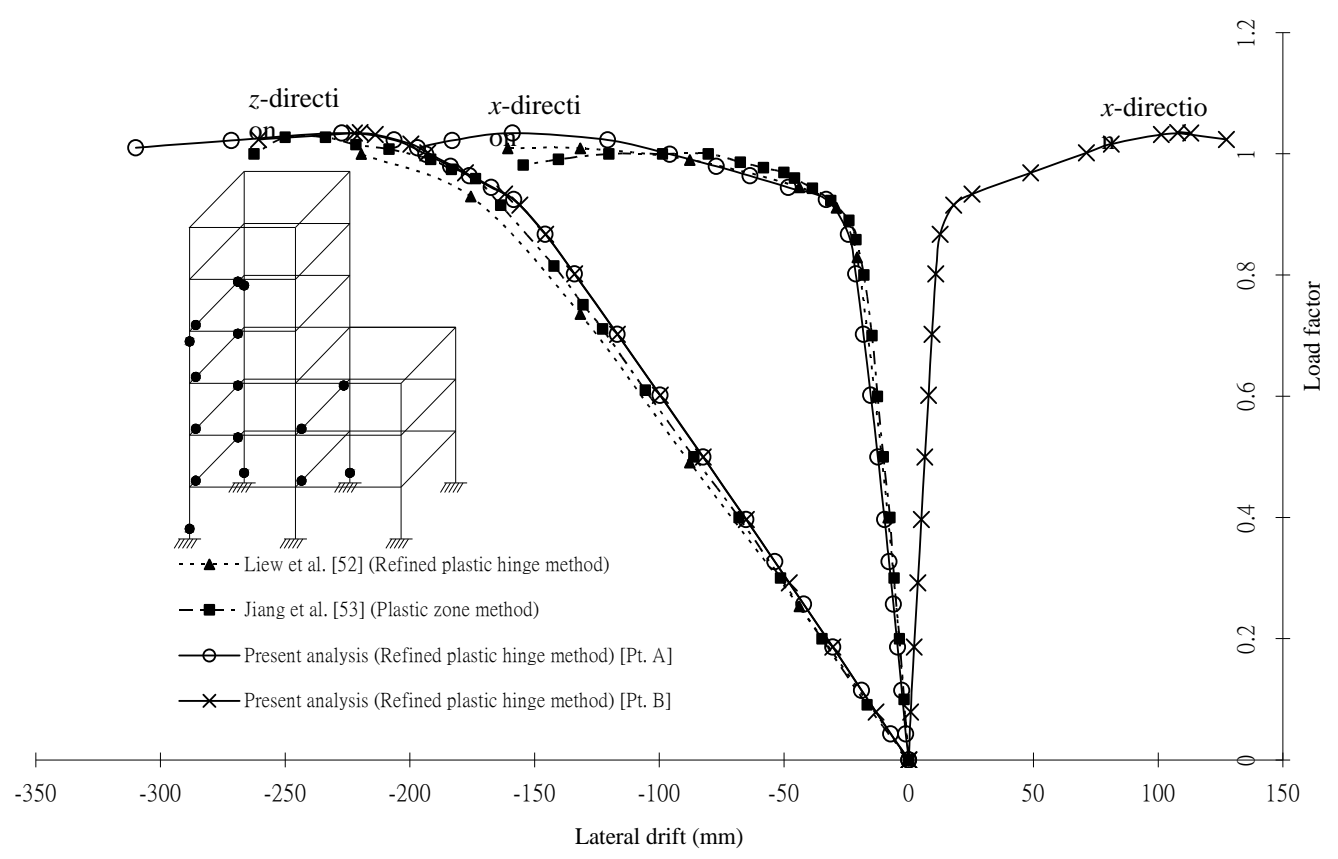

Figure 13. Lateral drifts of points A and B in $x$ - and $z$-directions vs load factor

Figure 13 plots the lateral drifts at points $\mathrm{A}$ and $\mathrm{B}$, which are shown as black dots in Fig. 12, in the $x$ and $z$-directions against the load factor. In [28, 29], the lateral displacements of point A are completely consistent in all ranges with the results of the present non-linear analysis. The present analysis predicts initial frame yielding at a load factor of 0.835 ; the ultimate load factor of the space frame from [28] is 1.005 whereas a value of 1.0344 is predicted from the present approach. In Fig. 13 , it can be seen that the lateral displacement of point B in the $x$-direction is antisymmetric to that of point A, whilst the lateral displacements for points A and B are the same in the $z$-direction. This implies that the structure twists as the applied loads and structural form are asymmetrical because of the change of the structural plan at the fourth floor level. In addition, after sufficient plastic hinges have formed at a load factor of about 0.92, the space frame undergoes large lateral displacements in both transverse directions and the present non-linear analysis predicts the formation of 16 plastic hinges at the ultimate load factor of 1.0344. The locations of the plastic hinges are shown by the dots in Fig. 13, indicating the yielding which occurs at the ends of the beams in the 6-sotrey space frame due to the torsional effect on the whole structure. In [28], a total of 20 plastic hinges developed and most of them were located at the fourth floor owing to the twisting of this space structure. In summary, the general material and geometric non-linear behaviour of the large-scale space structure is adequately captured using the present non-linear analysis.

\section{CONCLUDING REMARKS}

In this paper, a refined plastic hinge method has been proposed to account for material non-linearities in steel framed structures. The formulation makes recourse to a gradual yielding from prescribed initial and fully-yielded interaction criteria in terms of force resultants (axial and bending actions), so that distributed plasticity across the element section is adequately modelled. This proposed refined plastic hinge formulation is incorporated into the non-linear elastic stiffness analysis described in the companion paper. The technique has been applied to a number of independent sample problems, with good agreement being obtained, and moreover the solutions were obtained very rapidly. 
Both this and the companion paper demonstrate that the present fourth-order stiffness formulation with a refined plastic hinge methodology can accurately tackle material yielding and structural instability, using a minimum of element discretisations by comparing with the conventional finite element in deference to the plastic zone method. The technique provides an efficacious and reliable means for the analysis of general steel structures numerically, when they have many members, accounting adequately for geometric and material non-linear effects. Further, the present plastic hinge stiffness formulation is able to evolve itself accounting for the various kinds of materials versatilely, such as concrete or composite, once the failure surfaces in the hinge stiffness are replaced correspondingly. This paper therefore offers a non-linear analysis with accuracy in solution, versatile for vast forms of structures and efficiency in convergence for engineering practice.

\section{ACKNOWLEDGEMENT}

The work in this paper was supported by the Australian Research Council through a Federation Fellowship awarded to the second author.

\section{REFERENCES}

[1] Iu, C.K. and Bradford, M.A., "Higher-order Non-linear Analysis of Steel Structures”, Part 1: Elastic second-order formulation, (???? Year).

[2] King, W.S., White, D.W. and Chen, W.F., "On Second-order Inelastic Analysis Methods for Steel Frame Design”, Journal of Structural Engineering, ASCE, 1992, Vol. 118, No. 2, pp. 408-428.

[3] Duan, L. and Chen, W.F., "Design Interaction Equation for Steel Beam-columns”, Journal of Structural Engineering, ASCE, 1989, Vol. 115, No. 5, pp. 1225-1243.

[4] Liew, J.Y.R., White, D.W. and Chen, W.F., "Second-order Refined Plastic-hinge Analysis for Frame Design”, Part I, Journal of Structural Engineering, ASCE, 1993, Vol. 119, No. 11, pp. 3196-3216.

[5] Liew, J.Y.R., White, D.W. and Chen, W.F., "Second-order Refined Plastic-hinge Analysis for Frame Design”, Part II, Journal of Structural Engineering, ASCE, 1993, Vol. 119, No. 11, pp. 3217-3237.

[6] American Institute of Steel Construction, Load and Resistance Factor Design Specification for Structural Steel Buildings, AISC, Chicago, 1986.

[7] Yau, C.Y. and Chan, S.L., "Inelastic and Stability Analysis of Flexibly Connected Steel Frames by Springs-in-series Model”, Journal of Structural Engineering, ASCE, 1994, Vol. 120, No. 10, pp. 2803-2819.

[8] Chan, S.L. and Chui, P.P.T., “A Generalized Design-based Elastoplastic Analysis of Steel Frames by Section Assemblage Concept”, Engineering Structures, 1997, Vol. 19, No. 8, pp. 628-636.

[9] Iu, C.K. and Chan, S.L., "A Simulation-based Large Deflection and Inelastic Analysis of Steel Frames under Fire”, Journal of Constructional Steel Research, 2004, Vol. 60, pp. 1495-1524.

[10] Iu, C.K., Chan, S.L. and Zha, X.X., "Material Yielding by Both Axial and Bending Spring Stiffness at Elevated Temperature”, Journal of Constructional Steel Research, 2007, Vol. 63, pp. 677-685.

[11] Zhou, Z.H. and Chan, S.L., "Elastoplastic and Large Deflection Analysis of Steel Frames by One Element per Member I: One Hinge along Member,” Journal of Structural Engineering, ASCE, 2004, Vol. 130, No. 4, pp. 538-544. 
[12] Chan, S.L. and Zhou, Z.H., "Elastoplastic and Large Deflection Analysis of Steel Frames by One Element per Member II: Three Hinges along Member", Journal of Structural Engineering, ASCE, 2004, Vol. 130, No. 4, pp. 545-553.

[13] Kassimali, A., "Large Deformation Analysis of Elastic-plastic Frames," Journal of Structural Engineering, ASCE, 1983, Vol. 109, No. 8, pp. 1869-1886.

[14] Tebedge, N. and Chen, W.F., "Design Criteria for H-columns under Biaxial Loading", Journal of the Structural Division, ASCE, 1974, Vol. 100(ST3), pp. 579-598.

[15] Iu, C.K., Bradford, M.A. and Chen, W.F., "Second-order Inelastic Analysis of Composite Framed Structures based on the Refined Plastic Hinge Method”, Engineering Structures, 2009, Vol. 31, No. 3, pp. 799-813.

[16] Iu, C.K., "Inelastic Finite Element Analysis of Composite Beams on the Basis of the Plastic Hinge Approach”, Engineering Structures, 2008, Vol. 30, pp. 2912-2922.

[17] Liew, J.Y.R., White, D.W. and Chen, W.F., "Second-order Refined Plastic Hinge Analysis of Frames”, Structural Engineering Report CE-STR-92-12, Purdue University, West Lafayette, Indiana, 1992.

[18] Trahair, N.S., Bradford, M.A., Nethercot, D.A. and Gardner, L., "The Analysis and Behaviour of Steel Structures to EC4”, 4 ${ }^{\text {th }}$ edn., Taylor and Francis, London, 2008.

[19] Vogel, U., “Calibrating Frames”, Der Stahlbau 1985, Vol. 10, pp. 296-301.

[20] Toma, S. and Chen, W.F., "European Calibration Frames for Second-order Inelastic Analysis”, Engineering Structures 1992, Vol. 14, No. 1, pp. 7-14.

[21] Clarke, M.J., "Plastic Zone Analysis of Frames", In: Advanced Analysis of Steel Frames, Chen, W.F. and Toma, S., eds., CRC Press, Boca Raton, Florida, 1994, pp. 259-320.

[22] Teh, L.H. and Clarke, M.J., "Plastic-zone Analysis of 3D Steel Frames using Beam Elements”, Journal of Structural Engineering, ASCE, 1999, Vol. 125, No. 11, pp. 1328-1337.

[23] Ziemian, R.D., “A Verification Study for Methods of Second-order Inelastic Analysis”, Proceedings of Annual Technical Session, Structural Stability Research Council, Pittsburgh, Pennsylvania, 1992, pp. 315-326.

[24] Iffland, J.S.B. and Birnstiel, C., "Stability Design Procedures for Building Frameworks", Research Report, AISC Project No. 21.62, American Institute of Steel Construction, Chicago, Illinois, 1982.

[25] Crisfield, M.A., "An Arc-length Method including Line Searches and Accelerations”, International Journal for Numerical Methods in Engineering, 1983, Vol. 19, pp. 1269-1289.

[26] Chan, S.L., "Geometric and Material Nonlinear Analysis of Beam-columns and Frames using the Minimum Residual Displacement Method”, International Journal for Numerical Methods in Engineering 1988, Vol. 26, pp. 2657-2669.

[27] Orbison, J.G., McGuire, W. and Abel, J.F., "Yield Surface Applications in Nonlinear Steel Frame Analysis”, Computer Methods in Applied Mechanics and Engineering 1982, Vol. 33, No. 1, pp. 557-573.

[28] Liew, J.Y.R., Chen, H., Shanmugam, N.E. and Chen, W.F., "Improved Nonlinear Plastic Hinge Analysis of Space Frame Structures”, Engineering Structures, 2000, Vol. 22, No. 2, pp. 1324-1338.

[29] Jiang, X.M., Chen, H. and Liew, J.Y.R., "Spread of Plasticity Analysis of Three-dimensional Steel Frames”, Journal of Constructional Steel Research, 2002, Vol. 58, pp. 193-212. 


\title{
TEST STUDY ON BASIC STATIC CHARACTERISTICS OF CABLE SUPPORTED BARREL VAULT STRUCTURE
}

\author{
Wentao Qiao ${ }^{1, *}$, Zhihua Chen ${ }^{2}$ and Mingshan Zhao ${ }^{3}$ \\ ${ }^{1}$ Lecturer, School of Civil Engineering, Shi Jiazhuang Tiedao University, China \\ ${ }^{2}$ Professor, School of Civil Engineering, TianJin University, China \\ ${ }^{3} \mathrm{PhD}$. Student, School of Civil and environmental Engineering, Nanyang Technological University, Singapore \\ "(Corresponding author: E-mail: tottyer@126.com)
}

Received: 21 November 2011; Revised: 12 March 2012; Accepted: 20 March 2012

\begin{abstract}
By combining single layer cylindrical latticed shell (SLCLS) and beam string structure, a new-style prestressed spatial structure cable supported barrel vault structure (CSBV) is formed. Taking a practical CSBV project as prototype, a scaled model with a scale of 1:15 is designed and fabricated, the static loading test is carried out. Research results indicate that the characteristics of the prototype structure can be reflected by this model test. As the load increases, the change rule of the test values of the cables' forces agree with that of theoretical values. The two outmost cables' forces are generally smaller than the other interior cables' forces. The cables' forces in the symmetrical places keep closer. For rods' forces and nodal displacements of CSBV, the test values and theoretical values both keep closer. The differences between test values and theoretical values increases with the load. The test values are larger than the theoretical values, but the change rule still matches. Compared with SLCLS in the same condition, the rods' forces and nodal displacements of the CSBV are both smaller, and the mechanic characteristics of CSBV are more efficient.
\end{abstract}

Keywords: Cable supported barrel vault, Beam string structure, Cylindrical latticed shell, Rise-span ratio, Sag-span ratio, Strut number

\section{INTRODUCTION}

Spatial structures with longer span have gained more popularity in recent years. New types of spatial structures appear from time to time nowadays, such as cable dome structure, beam string structure, suspend-dome structure and cable supported barrel vault structure (CSBV). CSBV is a new-style highly efficient pre-stressed spatial structure. Inspired by beam string structure [1-7], and based on the single layer cylindrical latticed shell (SLCLS) [8], CSBV was first proposed. It consists of struts and cables distributed at suitable positions in the single layer cylindrical latticed shell. On one hand, stiffness of the whole structure is enhanced due to the introduction of pre-stressed cables and struts, which can effectively solve the problem SLCLS out-plane stability [9]. On the other hand, both steel usage and construction difficulty are significantly reduced. Moreover, horizontal forces that the supports bear and the burden on the lower structure are significantly reduced, due to the setting of cables which could be pre-stressed. This new-style structure was first proposed and its basic mechanical properties were theoretically studied in paper [10]. Theoretical research on mechanic feature of CSBV was carried out in paper [11], the initial prestress design method was proposed. The dynamic feature of CSBV was studied in papers [12] and [13], the wind resistant design method and seismic design method were respectively proposed.

Model test is one of the best methods to study mechanic feature of a new-style structure system. Directed by theoretical research results, the static loading test on a CSBV is carried out in this paper, and test details are listed below. 
First, SLCLS is tested under the whole span loading. Important variables including crucial members' strain values, horizontal displacements at supports and vertical displacements of crucial nodes at mid-span are monitored.

Second, CSBV with prestressed cables is tested under the whole span loading and important variables checked in the first step are monitored again.

By combing and comparing the results from the monitored two steps above, basic mechanical properties of CSBV are therefore concluded.

\section{EXPERIMENTAL MODEL AND LOADING SCHEME}

\subsection{Scaled Model}

Taking a practical CSBV project of a spinning mill as prototype, a scaled model with a scale of $1: 15$ is designed and fabricated. The span, length, rise and sag of the prototype are $50 \mathrm{~m}, 53.8 \mathrm{~m}$, $4.3 \mathrm{~m}$ and $0.7 \mathrm{~m}$ respectively. 7 cables are evenly spaced in the longitudinal direction, with 3 rods uniformly spaced in the span direction between each cable and the upper shell. The roof model is shown in Figure 1.

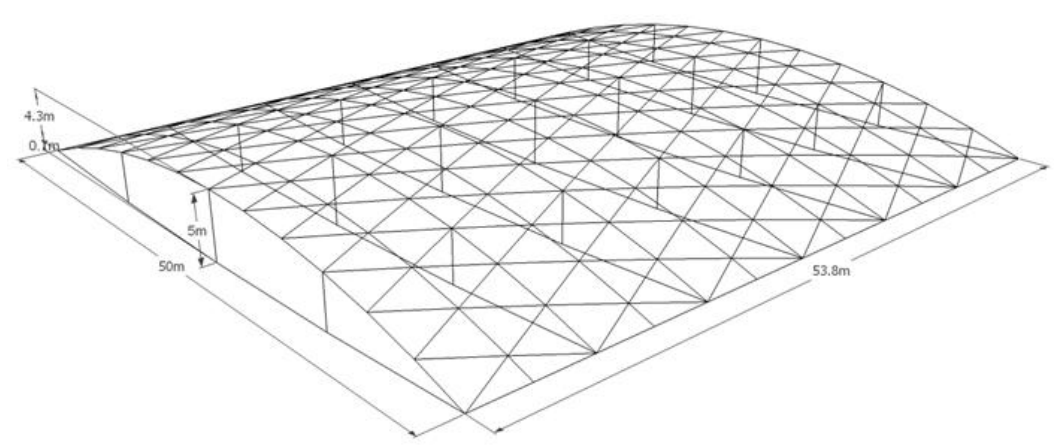

Figure 1. Cable Supported Barrel Vault Roof

The experimental model applies a 1:15 scale to the prototype, and the geometrical dimensions are calculated from the prototype according to the similarity constant and similarity ratio relationship in static loading experiment of engineering structure [14]. This scaled model has a $3.333 \mathrm{~m}$ span, $3.587 \mathrm{~m}$ length, $0.287 \mathrm{~m}$ rise and $0.047 \mathrm{~m}$ sag. Cross-sections of structural members are supposed to be chosen according to similarity ratio as well. Considering market supply and the requirement from welding, Q235B steel circular hollow sections with dimensions of $8 \mathrm{~mm} \times 1 \mathrm{~mm}, 10 \mathrm{~mm} \times$ $1 \mathrm{~mm}$ and $12 \mathrm{~mm} \times 1 \mathrm{~mm}$ are chosen. High strength steel wires with diameter of $6 \mathrm{~mm}$ and tensile strength of 600MPa are chosen as cables. The scaled model for test is shown in Figure 2. 


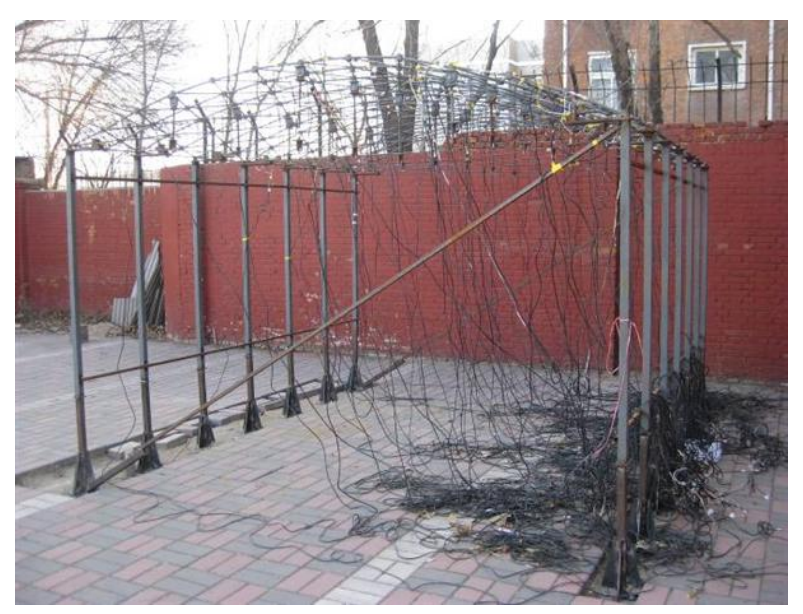

Figure 2. Scaled Model for Test

\section{$2.2 \quad$ Loading Scheme}

Considering the practical condition of the experimental model, hanging sand bags is chosen as loads, while the pre-stress in the cable is put by tightening the screw at the end of the cable, and the pre-stress value is measured by the strain of the steel bar at the end of the cable.

(1) Equivalent nodal loads

According to the actual load of the prototype and similarity ratio (ratio of surface load is $1: 1$ ), experimental loads are converted from the actual loads of prototype, which is calculated with the load condition as $1.2 \times$ dead load $+1.4 \times$ live load. Therefore the experimental load on the whole roof is designed to be $1.2 \times 0.8 \mathrm{kN} / \mathrm{m}^{2}+1.4 \times 0.5 \mathrm{kN} / \mathrm{m}^{2}=1.66 \mathrm{kN} / \mathrm{m}^{2}$. Since this barrel vault is relatively flat and the grids were uniformly distributed, the equivalent nodal loads are calculated according to the ratio of the horizontal projection area of each grid to that of the whole roof. Moreover, because the nodes sustained the roof surface load uniformly, the load each node bears is $15 \mathrm{Kg}$.

(2) Pre-stresses in cables

Pre-stresses in cables are considered to be concentrated loads which are 1/255 of the loads in cables of the prototype (similarity ratio is square of length similarity ratio). Therefore, the pre-stresses in cables are designed to be $75 \mathrm{~N}$ in the two outmost cables, and $85 \mathrm{~N}$ in the five middle cables. In this test, the tension prestress is put by tightening screws at the ends of cables, and the values are controlled by monitoring the strain of the steel bars at the end of the cables, i.e. Pre $=E \cdot \varepsilon \cdot A$ (Pre is the cable pre-stress, $E$ is the Young' s modulus of the steel bar, $\varepsilon$ is the strain, while $A$ is the area of the cross section of the steel bar.)

(3) Loading positions

Hanging method is employed to put the equivalent nodal forces, and there are 149 nodes in total responsible for equivalent node forces. However, only 30 nodes are chosen as the loading positions by taking the advantage of structural symmetry, and the goals of the test is not affected in this case. The loading positions are shown in Figure 3, in which the points covered by dash lines are not loaded during half span test. 


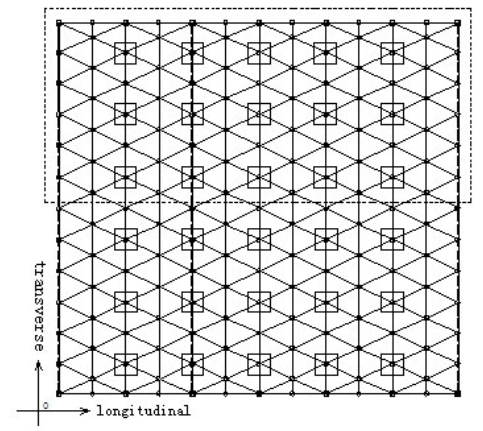

Figure 3. Locations for Loading

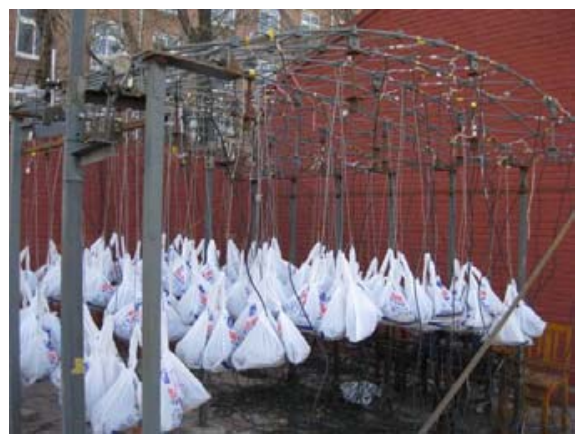

Figure 4. Full-span Load

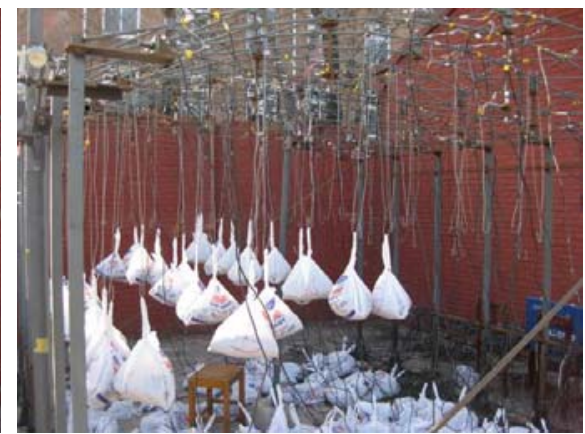

Figure 5. Half-span Load

\section{$2.3 \quad$ Loading Steps}

Considering that the bearing capacity of the SLCLS experimental model is low, the load each node has to carry in SLCLS test is set as only 3Kg, i.e. $20 \%$ of that in CSBV test, and both loading and unloading procedures are divided into 2 steps (50\% load for each step). For CSBV test, the load for each node to carry at full loading is $15 \mathrm{Kg}$, and it is divided into 6 steps. The detailed loading scheme is shown in Table 1.

Table 1. Load Step Increments

\begin{tabular}{|c|c|c|c|}
\hline No. & $\begin{array}{c}\text { Ratio } \\
(\%)\end{array}$ & $\begin{array}{c}\text { Load } \\
(\mathrm{kg})\end{array}$ & $\begin{array}{c}\text { Increment } \\
(\mathrm{kg})\end{array}$ \\
\hline 1 & 20 & 3 & 0 \\
\hline 2 & 50 & 7.5 & 4.5 \\
\hline 3 & 70 & 10.5 & 3 \\
\hline 4 & 80 & 12 & 1.5 \\
\hline 5 & 90 & 13.5 & 1.5 \\
\hline 6 & 100 & 15 & 1.5 \\
\hline
\end{tabular}

\section{DATA MEASUREMENT AND RECORD}

\subsection{Equipments For Measurement}

Two sets of 60 points YE2539 high speed static strain indicator, and one computer are employed as the strain measurement system, while the structure displacements are measured by dial indicators, as shown in Figure 6 and Figure 7.

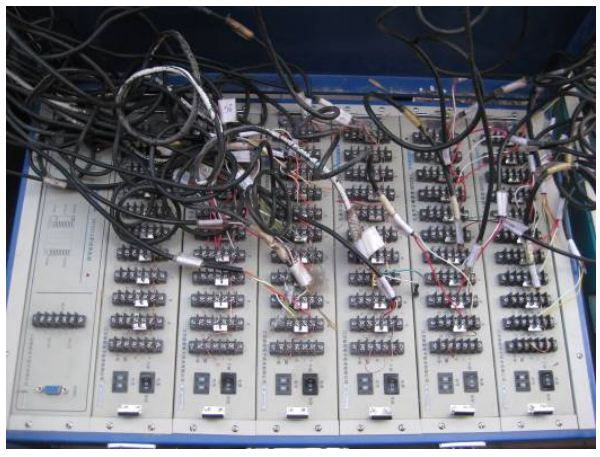

Figure 6. High-speed Static Strain Indicator

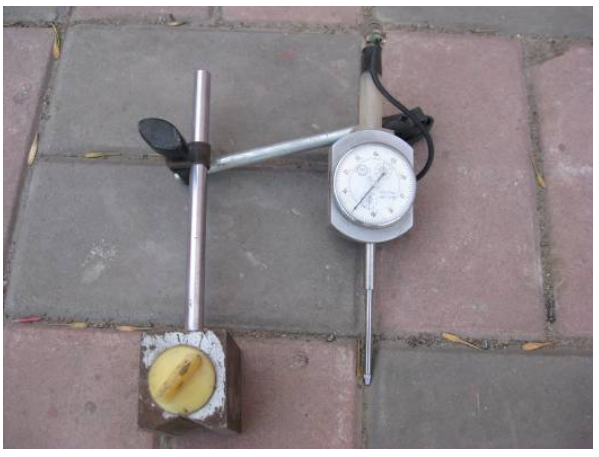

Figure 7. Dial Indicator 


\subsection{Measured points}

Before the experiment, the structural members with large stress (stress ratio exceeds 0.6) and nodes with largest displacements are found and marked by theoretical analysis in Midas/gen. Strain of those structural members and displacements of those nodes are monitored during the test as the crucial indicators for evaluating the whole structure system. The single cylindrical latticed shell part of CSBV consists of rod pieces with 3 different cross section areas. Different marks were employed to differentiate each type of rod piece.

As shown in Figure 8, the measured strain points are numbered from up to down in the transverse direction and then from left to right in the longitudinal direction. The points on rods are marked from No. 1 to 73, and the points on struts are marked from No. 74 to 82, while the points on steel bar at the end of the cables are marked from No. 83 to 96.

Besides, vertical displacements at mid-span are monitored at the position marked No. 1 and 2, while horizontal displacements at supports are measured by dial indicator at positions marked from No. 3 to 6.

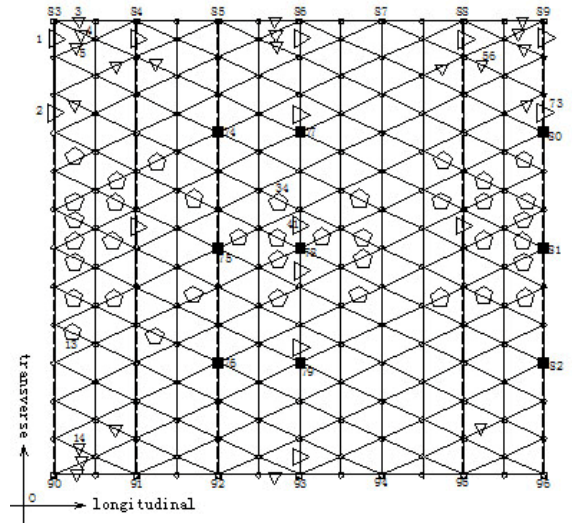

Figure 8. Nodes and No. for Strain Survey

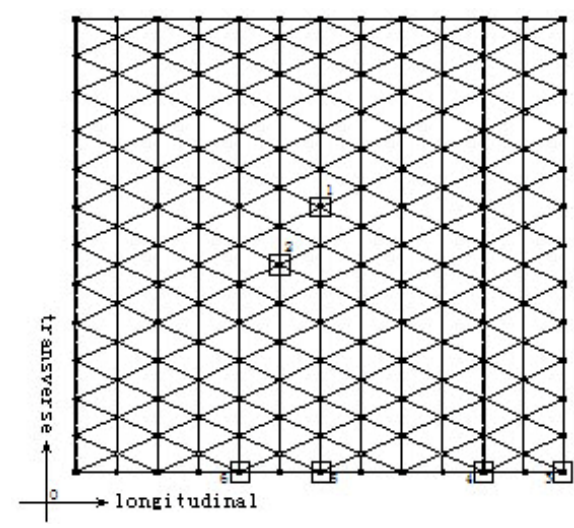

Figure 9. Nodes and No. for Displacement Survey

\subsection{Data Recording}

Data recording starts 5 minutes later after each loading step each data is recorded 6 times, with 2minute interval each time. Then, next loading increment is put 1 minute later after 6 times data collection. The unloading step and data recording procedure keep the same with the loading.

The time is set as 0 when the first loading step is finished, then the first data collection time is 5 , and the second is $7, \cdots$, the second loading step happens at time 16 , and so on. For measurement of displacements, data is recorded after all the strain data are recorded but before next loading step. The detailed schedule for loading and recording is shown in Table 2.

Considering that the whole structure needs some time to finish internal force re-distribution, data recoded at time closer to ideal equilibrium status takes up more weight in calculating the final strain by weighted average method. Supposing the whole weight being $P=1+2+3+\cdots+n$, then the first data weight is $1 / P$, and the $n^{\text {th }}$ data weight is $n / P$. As a result, the formula calculating the final strain and stress can be written as below. 
Table 2. Time for Loading and Recording Data (min)

\begin{tabular}{|c|c|c|c|c|c|c|c|}
\hline $\begin{array}{c}\text { No. of } \\
\text { load step }\end{array}$ & $\begin{array}{c}\text { Loading } \\
\text { time }\end{array}$ & $\begin{array}{c}1^{\text {st }} \\
\text { recording } \\
\text { time }\end{array}$ & $\begin{array}{c}2^{\text {nd }} \\
\text { recording } \\
\text { time }\end{array}$ & $\begin{array}{c}3^{\text {rd }} \\
\text { recording } \\
\text { time }\end{array}$ & $\begin{array}{c}4^{\text {th }} \\
\text { recording } \\
\text { time }\end{array}$ & $\begin{array}{c}5^{\text {th }} \\
\text { recording } \\
\text { time }\end{array}$ & $\begin{array}{c}6^{\text {th }} \\
\text { recording } \\
\text { time }\end{array}$ \\
\hline 1 & 0 & 5 & 7 & 9 & 11 & 13 & 15 \\
\hline 2 & 16 & 21 & 23 & 25 & 27 & 29 & 31 \\
\hline 4 & 32 & 37 & 39 & 41 & 43 & 45 & 47 \\
\hline 5 & 48 & 53 & 55 & 57 & 59 & 61 & 63 \\
\hline 6 & 84 & 69 & 71 & 73 & 75 & 77 & 79 \\
\hline
\end{tabular}

$\varepsilon=\sum_{i=n}^{P} \varepsilon_{i} \cdot(i-n) /(1+2+\ldots+n)$

$\sigma=\varepsilon \cdot E$

$E=2.06 \times 10^{11} \mathrm{~N} / \mathrm{m}^{2}$

Where, $E$ is the Young' $\mathrm{s}$ modulus of the steel, $\varepsilon$ is the strain, $\varepsilon_{i}$ is the strain of $i^{\text {th }}, \sigma$ is the stress.

In this test, data at each loading step is recorded 6 times, among which at last 3 times are considered to be stable enough and effective. Therefore, they are chosen to calculate the final strain and stress, and $n$ equals to 3 in this case.

\section{EXPERIMENTAL RESULTS ANALYSIS}

The numerical analysis of the experimental model has been carried out by Midas/gen. In the numerical model, beam element is employed to simulate the rods, columns and connection beams; truss element is employed to simulate the struts and braces; cable element is employed to simulate the cables. The characteristics of these elements are introduced detailedly in the manual of Midas/gen. Results from the theoretical analysis are compared with the test in the next section.

\subsection{Stresses In Members Of SLCLS}

(1) Strain-time relationship

It can be founded that the strain-time relationship of each load step almost keeps same by analysing all the strain data collected in the test. Take CSBV as an example, under the whole span loading, the strain-time relationship of the measured point No. 2(A1) and No. 41(A2) are shown in Figure 10. 


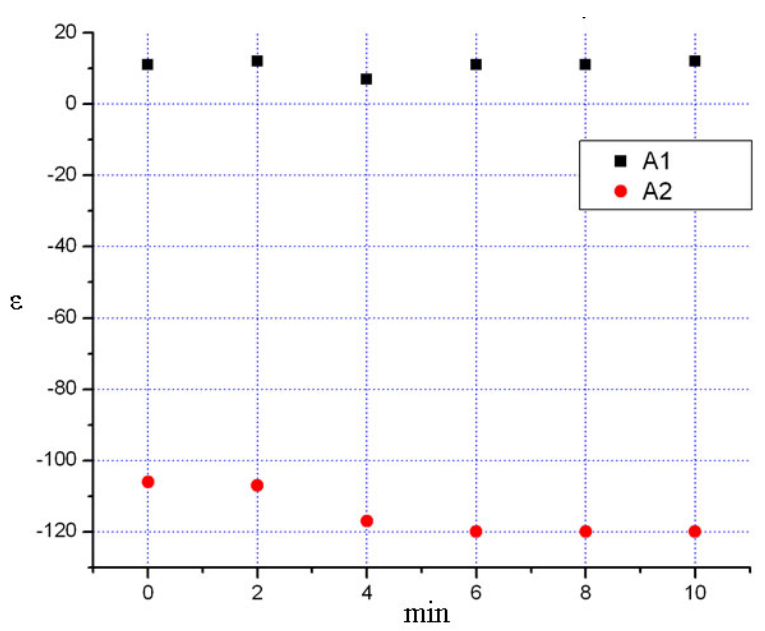

Figure 10. Strain-time Relation Curve

Therefore, the final strain of the measured members can be calculated by filling the data recorded at last 3 times into the formula provided in 3.3. 6 representative rods are analysed in detail in this paper, which are marked as A1, A2, B1, B2, C1, and C2 (corresponding number is 2, 41, 13, 34, 4, and 56 in Figure 8).

(2) Comparison study of stress in members

To study the stress variation rules, stresses of crucial members in CSBV are compared with those in SLCLS, as shown in Figure 11. In addition, stresses of the members from the experimental model are amplified by similarity ratio in order to approximately simulate the stresses in the prototype structure. Then, the results are compared with the theoretical analysis of the prototype structure. The comparison for CSBV is shown in Figure 12.

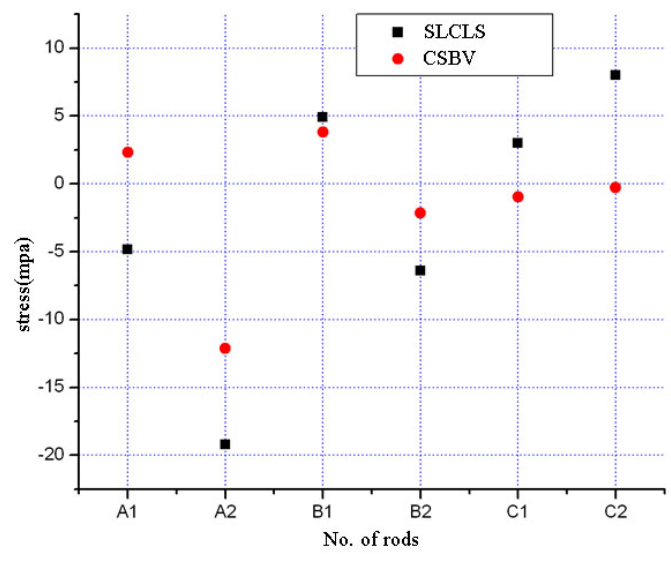

Figure 11. Force Contrast between Different Structures

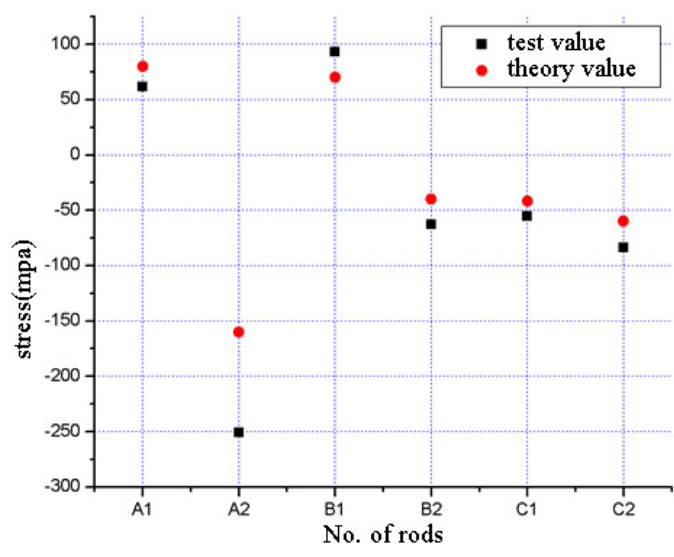

Figure 12. Force Contrast between Scaled Model and Prototype

By comparing the stresses of members of SLCLS and CSBV at the same loading level, it is found from the Figure 11 that the rods stresses of SLCLS are all bigger than that of CSBV, and the biggest member stress of SLCLS reaches 20MPa, while that of CSBV is only 12MPa in the same condition. The stress level of rods in CSBV is about $60 \%$ of SLCLS, CSBV is more efficient in transmission internal force than SLCLS. It can be seen from Figure 12 that the biggest calculated stress in prototype is $250.8 \mathrm{MPa}$, while the numerical modeling counterpart is $180 \mathrm{MPa}$. In this case, the difference between these two values is about $36 \%$. The difference between the two values in other members is smaller, ranging from $20 \%$ to $30 \%$. In a word, the difference level is relatively high, and the experimental values are larger than numerical analysis values. The difference may come 
from the choosing of members by approximate similarity ratio, imperfection of model machining, simplification of boundary conditions in experiment model and data measurement. However, the difference won't influence the goal of the test. The mechanical properties of the prototype structure under practical loading condition can be reflected through this model test.

(3) Member stress in CSBV

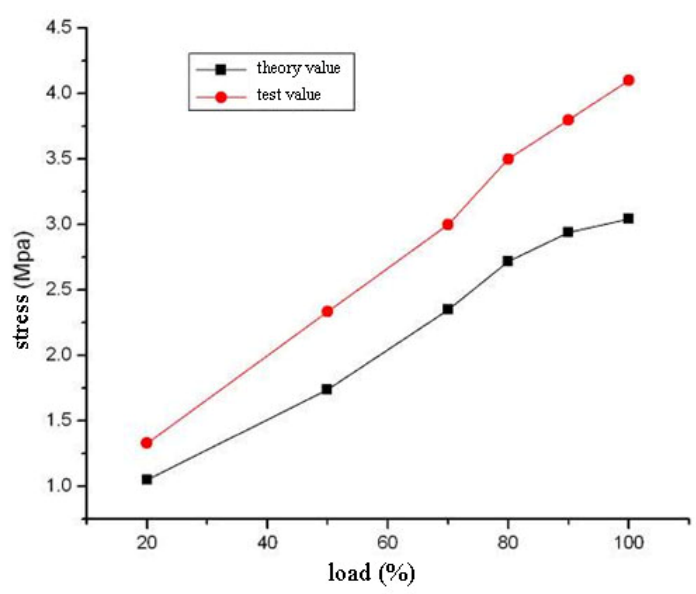

Figure 13. Rod A1 Stress

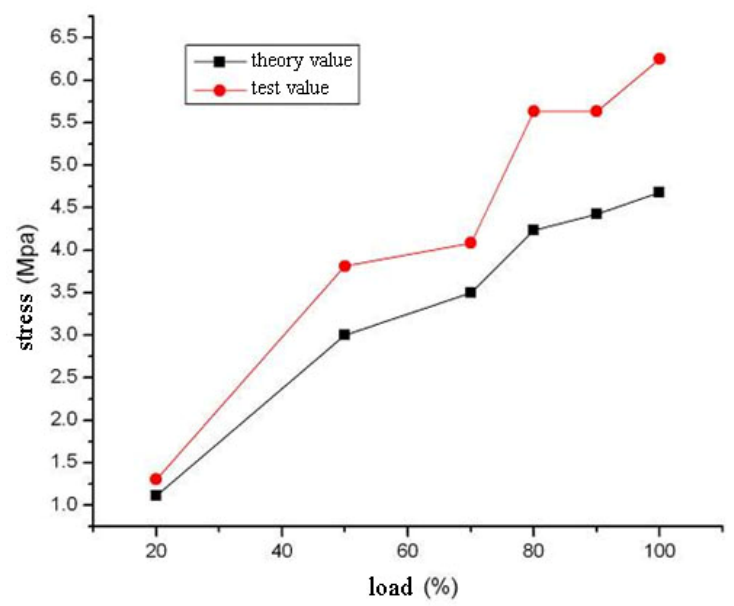

Figure 15. Rod B1 Stress

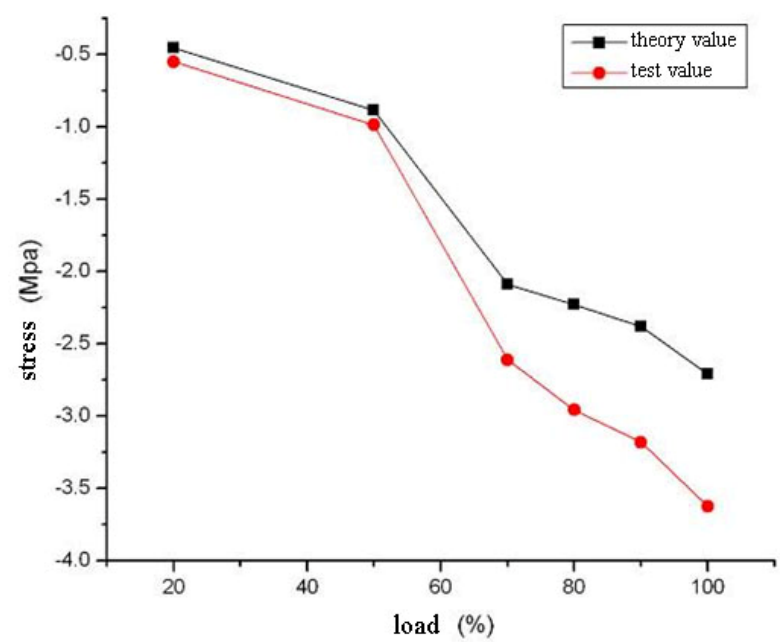

Figure 17. Rod C1 Stress

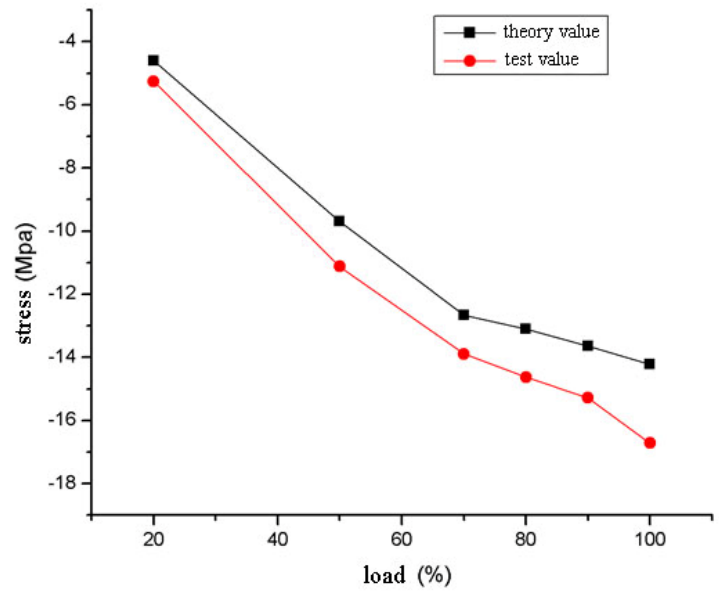

Figure 14. Rod A2 Stress

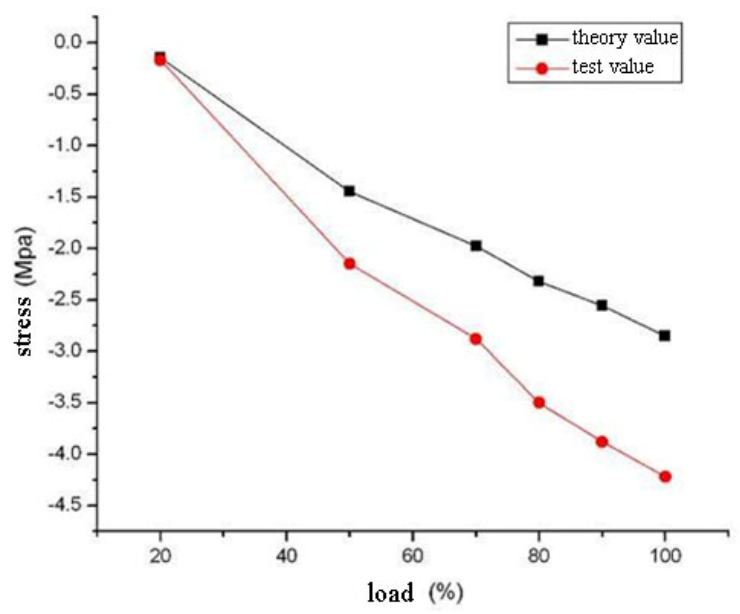

Figure 16. Rod B2 Stress

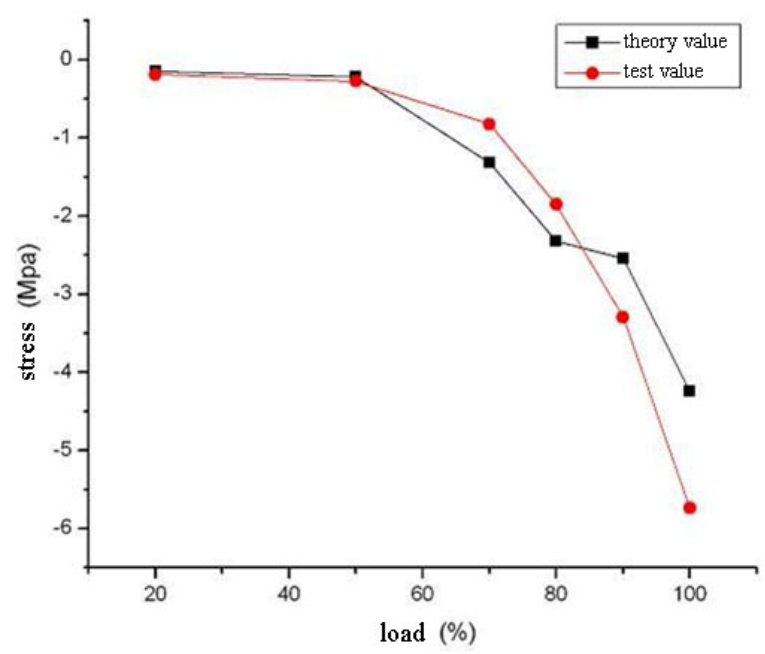

Figure 18. Rod C2 Stress 
The stress-load curves of members are drawn in Figure 13 to Figure 18. It can be obviously seen that the variation of experimental results and numerical analysis results are nearly the same. Essentially, both of them increase with the increase of load, and the experimental values are generally larger than those of the numerical analysis. However, the difference between these two is small at the beginning, and increases with the increase of load. In addition, for both experimental and numerical analysis results, most members' stress-load curves tend to deviate from the straight line in different extents, which reveals that for CSBV, stress-load relationship of rods in the single layer lattice shell tend to be non-linear.

\subsection{Stresses In Cables}

Cables in CSBV, whose inner forces directly affect the mechanical properties of the whole structure, are the kernel of CSBV. In order to precisely control the pre-stress of the cables during the test, the method of tightening the screw at the end of cable and real-time monitoring to the strain of the cable are employed. All the 7 cables are installed on the experimental model, the measured points on the cables and the associated numbers are shown in Figure 8, where points No. 83-89 are chosen as the main study objects, the corresponding number is No. 1 to No. 7 in Figure 19 and Figure 21.

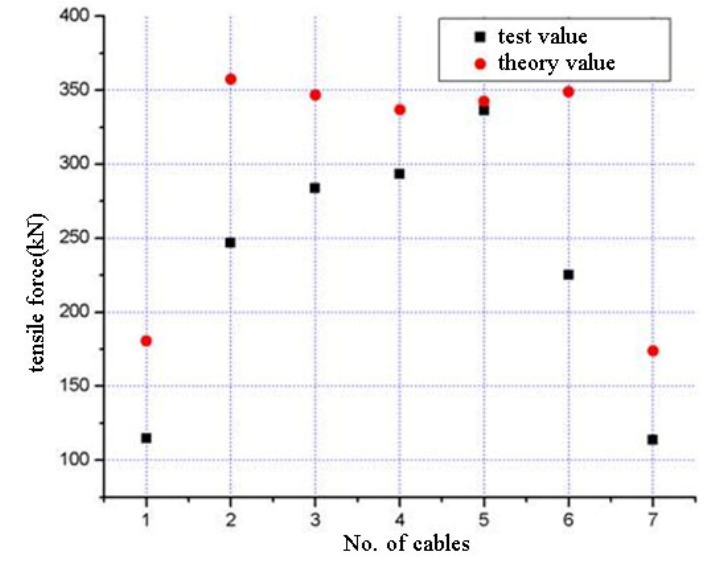

Figure 19. Cable Forces Contrast between Scaled Model and Prototype

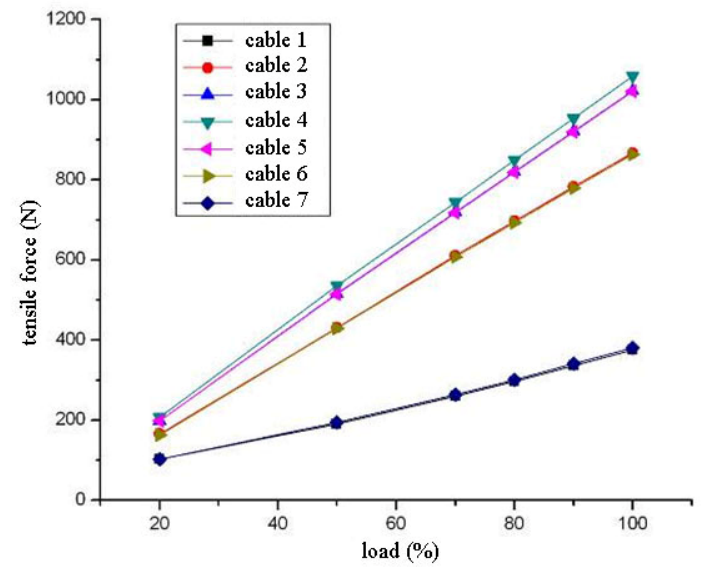

Figure 20. Theoretical Value of Cables' Forces

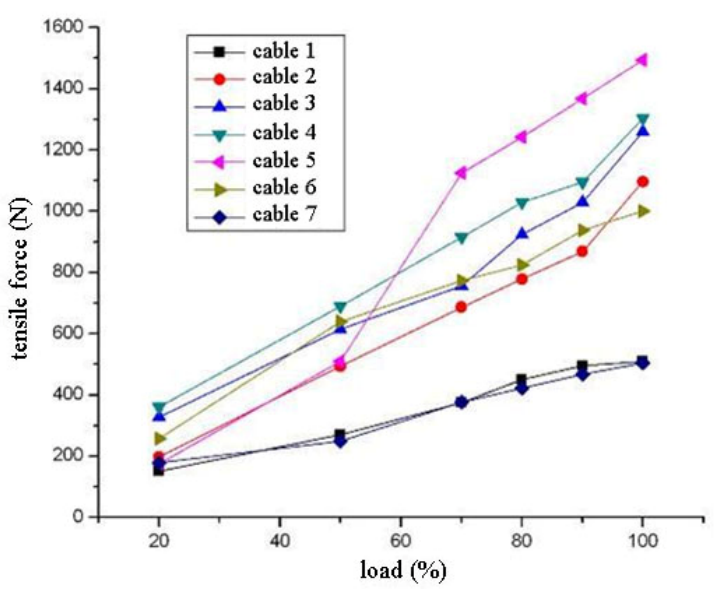

Figure 21. Test Value of Cables' Forces

As shown in Figure 19, the experimental regression value of cable 1 under full loading to the prototype is $114.75 \mathrm{kN}$, while the numerical analysis result of that is $180.5 \mathrm{kN}$, the difference between which is about $60 \%$. Although this difference in other cables is smaller, the general error level is high and experimental values are always smaller than numerical analysis values. 
Moreover, in Figure 20, the numerical analysis results of stresses in each cable vary linearly with loading, and cables in symmetrical positions have the same stress values. In Figure 21, the experimental results variation also shows approximate linearity, but stresses in symmetrical positions do not show strict symmetry. Especially for cable 5 whose stress varies oddly. However, the variation rule of these two types of results is basically the same although the difference does exist to a certain extent.

\subsection{Nodal Displacements}

As it is known that SLCLS has poor out-plane stability and supports suffer from large horizontal force as well. By installing cables and vertical struts, SLCLS can be transformed into CSBV which results in better out-plane stability, while the problem of horizontal force to the supports is also solved. The horizontal displacements at supports and vertical displacements at the mid-span are the indicators of how well the structure can handle these two problems. Therefore, the displacement indicators are assigned and located at mid-span nodes and supports to measure the biggest vertical displacement at mid-span (No. 1 and 2), and the horizontal displacement at supports (No. 3 to 6). Locations and number are shown in Figure 9.

(1) Comparison study of crucial nodal displacements

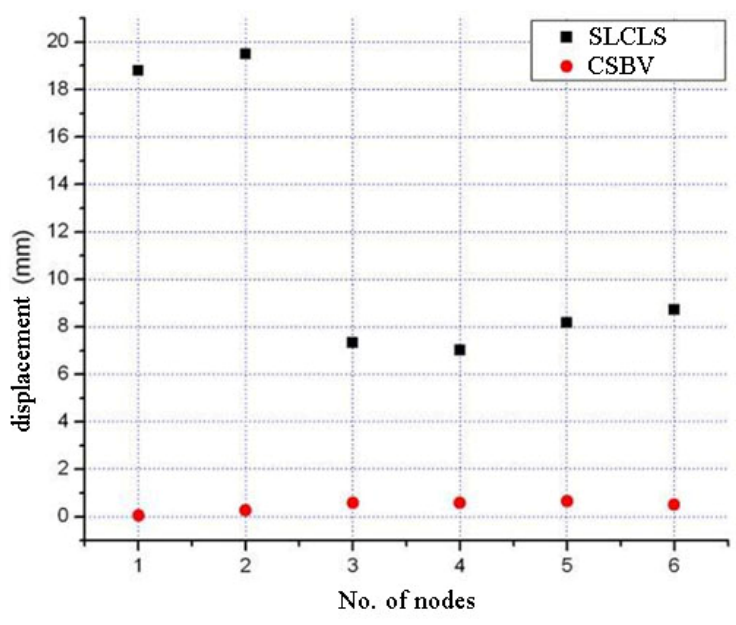

Figure 22. Displacement Contrast between Different Structures

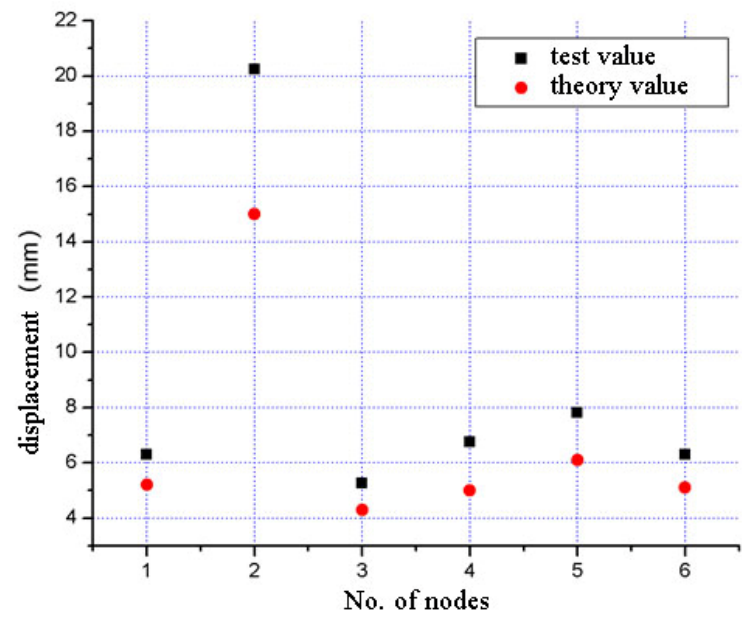

Figure 23. Displacement Contrast between Scaled Model and Prototype

As shown in Figure 22, when the SLCLS is imposed 20\% of the designed load, the biggest vertical nodal displacement reaches $19 \mathrm{~mm}$ and the biggest horizontal displacement at supports is $9 \mathrm{~mm}$, while those in CSBV are only $0.2 \mathrm{~mm}$ and $0.5 \mathrm{~mm}$, respectively, at the same load level. As for the aspect of structure deformation, it also can be revealed that CSBV behaves much better than SLCLS in mechanic characteristics. In Figure 23, the experimental regression value of vertical displacement is $20.25 \mathrm{~mm}$, while the numerical analysis gives $15 \mathrm{~mm}$. That is, experimental values are always larger than those of numerical analysis. The difference between these two values is about 35\%. For the other nodal displacements, most of them are smaller but still above $20 \%$. 
(2) Nodal displacements in CSBV

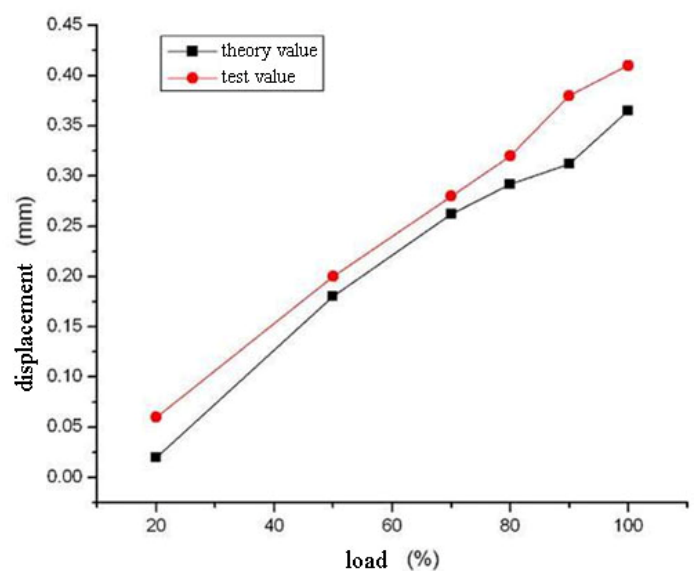

Figure 24. Node 1 Vertical Displacement

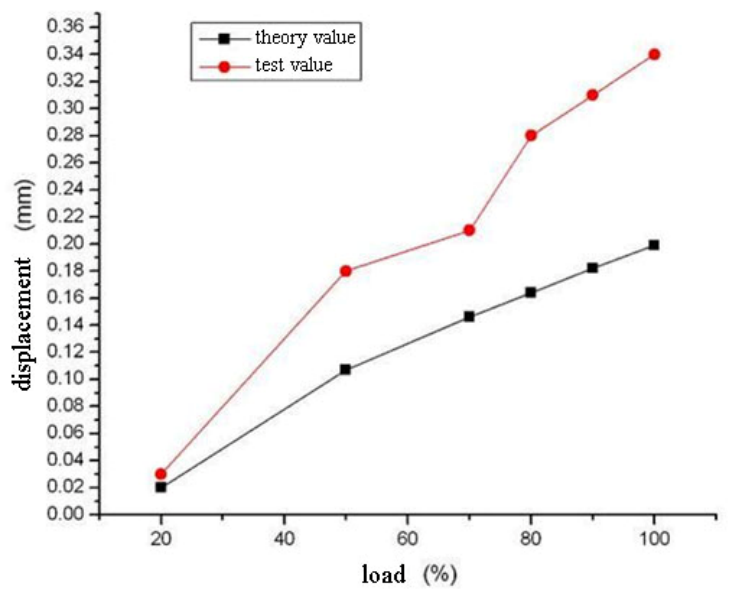

Figure 26. Node 3 Lateral Displacement

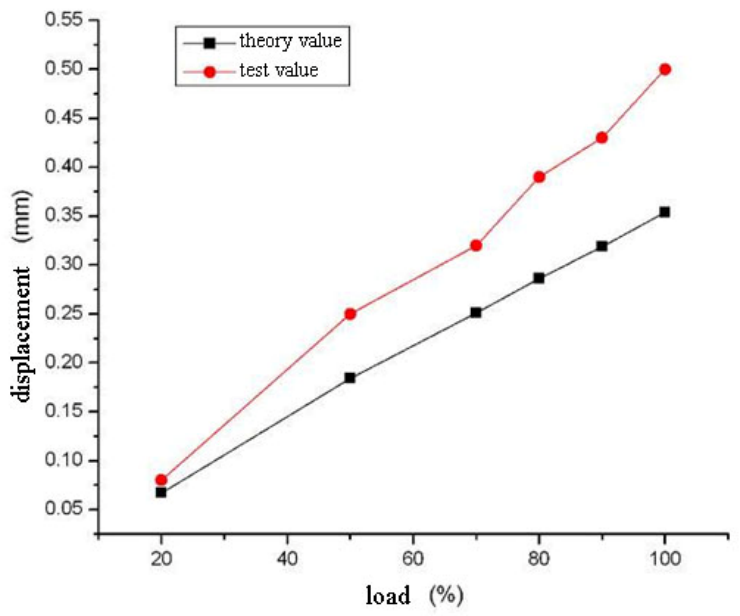

Figure 28. Node 5 Lateral Displacement

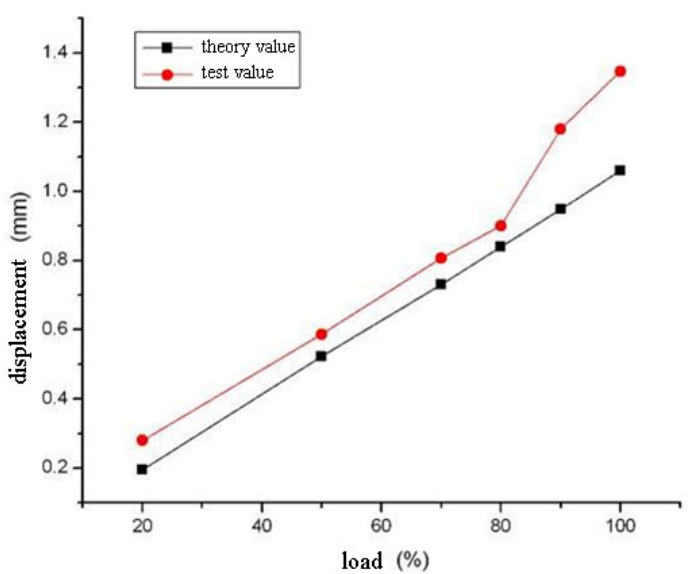

Figure 25. Node 2 Vertical Displacement

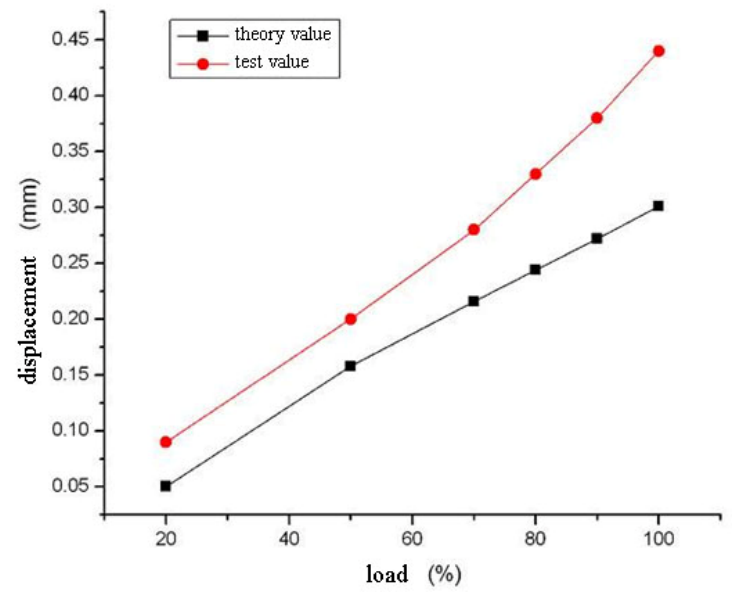

Figure 27. Node 4 Lateral Displacement

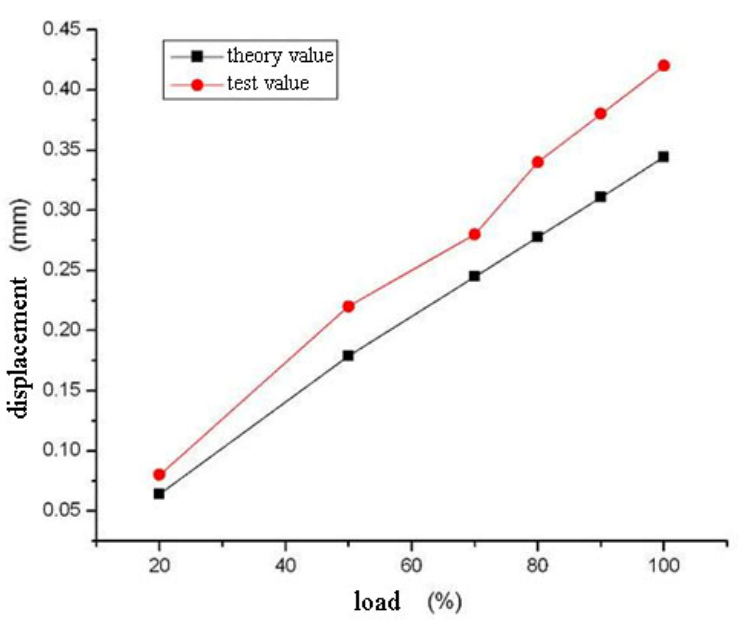

Figure 29. Node 6 Lateral Displacement

From Figure 24 and Figure 25, it can be easily seen that the vertical displacements of node 1 and 2 are generally changing linearly with loading although fluctuation exist in some special conditions. Additionally, experimental results are very close to numerical analysis, and they basically shared the same variation rule. Experimental results are always larger than numerical results and difference is small at the beginning but grows with loading. In Figure 26 to Figure 29, the same displacement-load relationship is demonstrated for horizontal displacements at supports. 


\section{CONCLUSIONS}

Based on the existing theoretical research, we have designed and fabricated a 1:15 (specimen to prototype) scaled model, and have carried out a series of static loading tests on this experimental model. The research results have shown that this experimental model can reflect the basic mechanic properties of the prototype structure, the following conclusions have been drawn.

(1) Rods' stresses in CSBV obtained via experiments and numerical analysis keep close at the beginning but deviate with loading. Although the difference between these two types of results increase with loading, the stress-load relationship still holds.

(2) Stresses in cables obtained in experiments and numerical analysis show approximately the same stress-load relationship. Generally speaking, stresses in cables at the ends are smaller than that at inner positions. Stresses in cables at symmetrical positions are very close due to symmetry.

(3) Nodal displacements in experiments and numerical analysis show similar displacement-load relationship. They are close to each other, but experimental results are larger. Although these two types of results differ more as the loading increases, the displacement-load relationship still holds.

(4) To sum up, by setting struts and cables at suitable positions on SLCLS, the formed CSBV has much better rigidity, out-plane stability and the significantly reduced horizontal forces at supports. CSBV is a new-style and highly efficient spatial structure with larger span and needing less steel.

\section{REFERENCES}

[1] Masao, S. and Kurasiro, T., "A Study on Structural Behaviors of Beam String Structure”, Summaries of Technical Papers of Annual Meeting Architectural Institute of Japan [C], Tokyo, Japan, B 1.1985, pp. 280-284.

[2] Masao, S. and Kurasiro, T., "A Study on Structural Behaviors of Beam String Structure”, Summaries of Technical Papers of Annual Meeting Architectural Institute of Japan [C], Tokyo, Japan, B 1.1985, pp. 280-284.

[3] Masao, S., “A Study on Structural Planning of Radial Type Beam String Structures”, Summaries of Technical Papers of Annual Meeting Architectural Institute of Japan [C], Tokyo, Japan, B 1.1988, pp. 1365-1366.

[4] Masao, S. and Ohtake, T., “A Study on Beam String Structure with Flat Circular Arch”, Summaries of Technical Papers of Annual Meeting Architectural Institute of Japan [C], Tokyo, Japan, B 1.1988, pp. 1369-1374.

[5] Masao, S. and Okasa, A., "The Role of String in Hybrid String Structure”, Engineering Structures, 1999, Vol. 21, No. 8, pp. 756-69.

[6] Wu, M.E., "Analytical Method for the Lateral Buckling of the Struts in Beam String Structures”, Engineering Structures, 2008, Vol. 30, No. 9, pp. 2301-2310.

[7] Xue, W.C. and Liu, S., "Design Optimization and Experimental Study on Beam String Structures”, Journal of Constructional Steel Research, 2008, No. 9, pp. 1-11.

[8] Shen, Z.Y. and Chen, Y.J., "Spatial Truss and Latticed Shell”, Shanghai : Tongji University Press, 1997. [in Chinese]

[9] Shen, S.Z. and Chen, X., "Stability of the Shell Structures", Beijing: Science Press, 1999. [in Chinese]

[10] Chen, Z.H., Qiao, W.T. and Yang, X.Y., “Cable Supported Barrel Vault Structure System and Research on Mechanics Characteristics”, International Journal of Advanced Steel Construction, 2010, Vol. 6, No. 3, pp. 867-878. 
[11] Chen, Z.H. and Qiao, W.T., "Prestress Design and Stability Research of Cable Supported Barrel Vault Structures”, Journal of Building Structures (Supplement), 2010, Vol. 31, pp. 227-233. [in Chinese]

[12] Qiao, W.T. and Chen, Z.H., “Analysis on Wind-induced Vibration Response of Cable Supported Barrel Vault Structures”, Building Structure, 2010, Vol. 40, No. 5, pp. 108-111. [in Chinese]

[13] Qiao, W.T. and Chen, Z.H., "Seismic Response Analysis of Cable Supported Barrel Vault Structures under Multi-support Excitations”, Spatial Structures, 2011, Vol. 1, pp. 15-20. [in Chinese]

[14] Li, Z.X., “Theory and Technique of Engineering Structure Experiments”, TianJin: Tianjin University Press, 2004. [in Chinese] 